\title{
Design, construction and testing of an innovative mechanism for manual wheelchair propulsion
}

Thomas S. Burke Jr.

West Virginia University

Follow this and additional works at: https://researchrepository.wvu.edu/etd

\section{Recommended Citation}

Burke, Thomas S. Jr., "Design, construction and testing of an innovative mechanism for manual wheelchair propulsion" (2002). Graduate Theses, Dissertations, and Problem Reports. 1521.

https://researchrepository.wvu.edu/etd/1521

This Thesis is protected by copyright and/or related rights. It has been brought to you by the The Research Repository @ WVU with permission from the rights-holder(s). You are free to use this Thesis in any way that is permitted by the copyright and related rights legislation that applies to your use. For other uses you must obtain permission from the rights-holder(s) directly, unless additional rights are indicated by a Creative Commons license in the record and/ or on the work itself. This Thesis has been accepted for inclusion in WVU Graduate Theses, Dissertations, and Problem Reports collection by an authorized administrator of The Research Repository @ WVU. For more information, please contact researchrepository@mail.wvu.edu. 
Design, Construction and Testing of an Innovative Mechanism for Manual Wheelchair Propulsion

Thomas S. Burke Jr.

Thesis submitted to the

College of Engineering and Mineral Resources

at West Virginia University in partial fulfillment of the requirements

for the degree of

Master of Science

in

Mechanical Engineering

W. Scott Wayne, Ph.D., Chair

Thomas R. Long, Ed.D.

Alfred H. Stiller, Ph.D.

Kevin D. Swisher, WVUCED

Department of Mechanical Engineering

Morgantown, West Virginia

2002

Keyword: Wheelchair Assistive Technology 


\title{
Abstract \\ Design, Construction and Testing of an Innovative Mechanism for Manual Wheelchair Propulsion
}

\author{
Thomas S. Burke Jr.
}

The concern for people with disabilities who are users of wheelchairs has become a dynamic research area in the past several years. This research is being done to enhance the health and lifestyles of standard manual wheelchair users. As part of this research new and innovative mechanisms that give the manual wheelchair users a mechanical advantage, and allow them to operate a standard wheelchair with less effort and muscle strain are being developed.

In this research, an innovative mechanism was conceived, designed, built, and tested. The path of this innovative mechanism was modeled after the semi-circular (SC) wheelchair stroke pattern. It allows the user to propel a standard wheelchair in both the push and pull strokes of the handle. This new design will allow for a more symmetric muscle development of the shoulder and upper-arm complex, and should reduce muscle (skeletal) injuries. A conceptual model of the new mechanism was formulated using SolidWorks software. Preliminary position and torque analysis were analyzed using Microsoft Excel spreadsheets. A prototype of the innovative mechanism was built and retrofitted onto a standard manual wheelchair. In addition, a portable wheelchair testing station was designed and fabricated to allow for human testing comparative measurements between a standard wheelchair and the innovative mechanism. Comparison of data from the standard wheelchair and the innovative mechanism showed energy, horsepower, and RPM ratio gains of 1.638, 1.631, and 1.64. Therefore, the mechanism shows promise to enhance the quality of life for mobility impaired citizens. 


\section{Table of Contents}

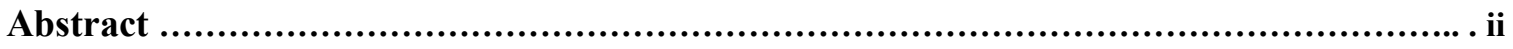

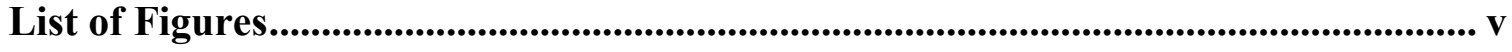

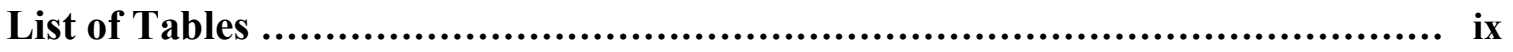

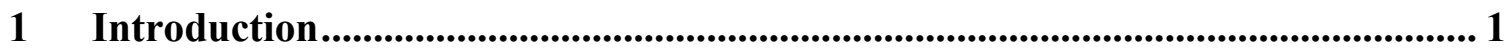

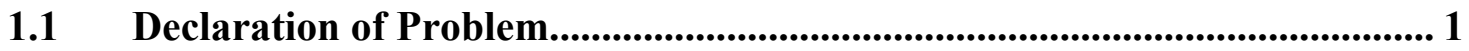

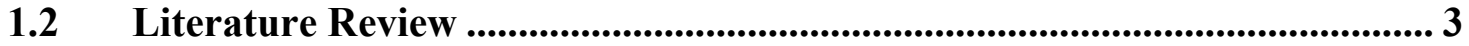

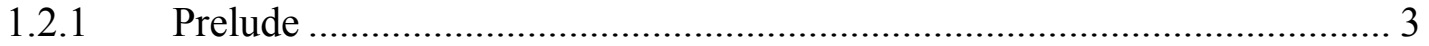

1.2.2 Wheelchair Related Injuries................................................................ 3

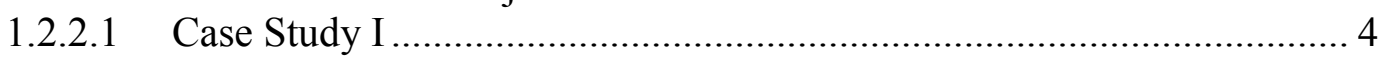

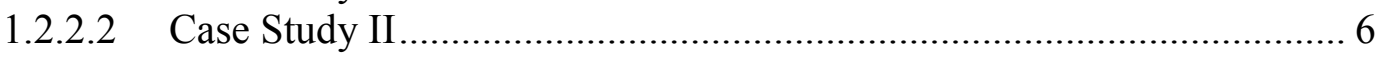

1.2.3 Determining Wheelchair Type - User's Ability .................................... 9

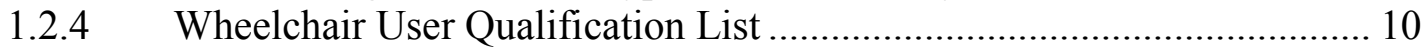

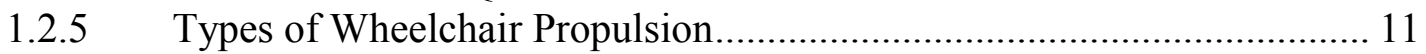

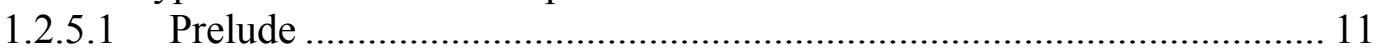

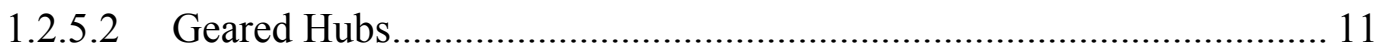

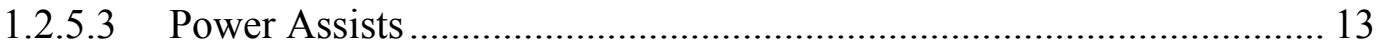

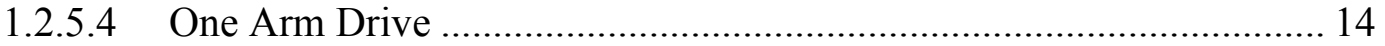

1.2.5.5 Lever Drive ............................................................................ 16

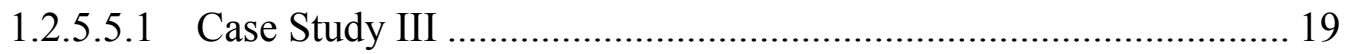

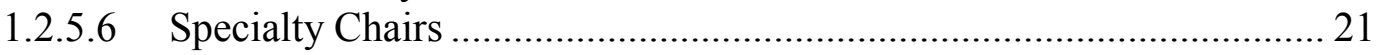

1.3 Problem Statement.............................................................................. 22

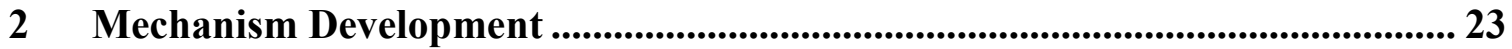

2.1 Proposed Design .............................................................................................. 24

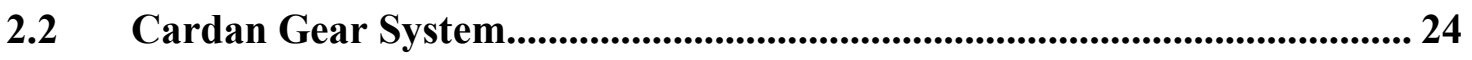

2.3 Adapting the Innovative Mechanism to a Wheelchair Frame.................... 28

2.4 Parametric Design Criteria of the Components of the Innovative

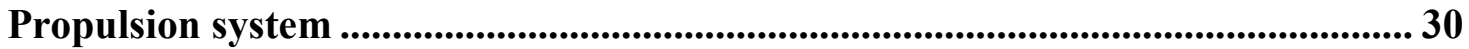

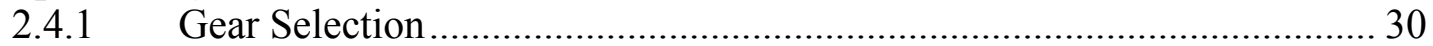

2.4.2 Roller Chair Selection..................................................................... 31

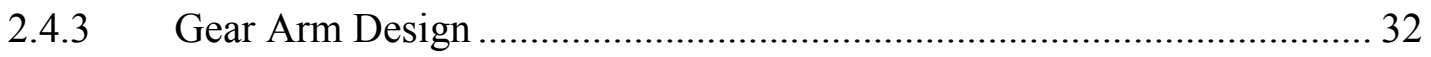

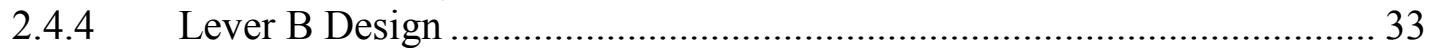

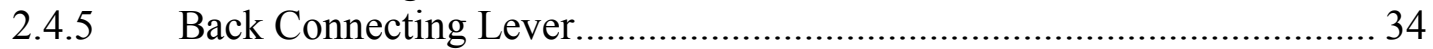

2.5 Innovative Mechanism Parameters................................................................. 34

2.6 Mechanism Assembly ..................................................................... 36

2.7 Visualization of Mechanism Handle Motion ................................................. 37 
2.8 Manufacturing of Prototype ............................................................................ 39

3 Experimental Setup .................................................................................................... 40

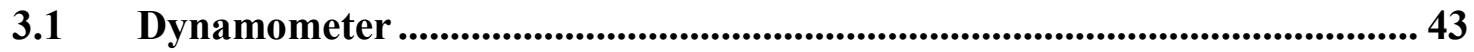

3.2 Dynamometer Controller ................................................................. 45

3.3 Rear Axle ............................................................................................ 45

3.3.1 Singularity Function - Standard Wheels ............................................. 46

3.3.2 Singularity Function - Roller Chain Sprockets .................................. 51

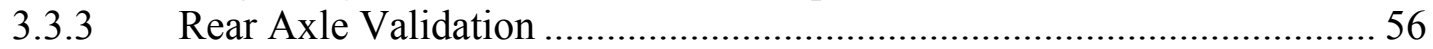

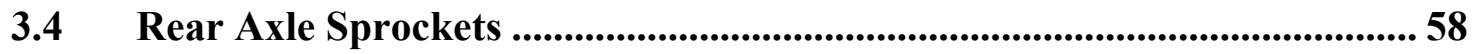

3.5 Dynamometer Sprockets ..................................................................59

3.6 Complete Testing Apparatus .........................................................59

4 Experimental Design and Testing............................................................................... 61

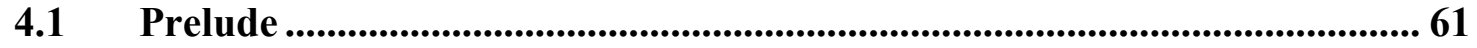

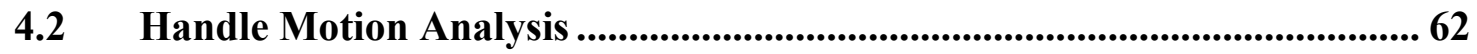

4.3 Torque Analysis ............................................................................................. 64

4.4 Testing Load Calculation ................................................................... 71

4.5 Testing of Human Subjects - Different Mechanism Angles ...................... 72

4.6 Testing of Human Subjects - Mechanism/Wheel Comparison ................... 74

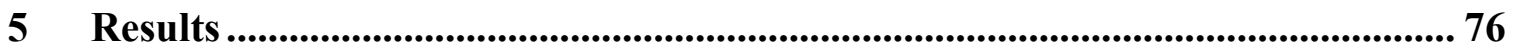

5.1 Results of Testing of Subjects at Different Mechanism Angles ................. 76

5.2 Results of Testing Subjects - Mechanism/Wheel Comparison .................... 84

6 Conclusions .............................................................................................. 94

6.1 Specific Accomplishments of This Research (What's New)...................... 96

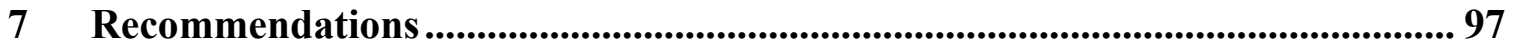

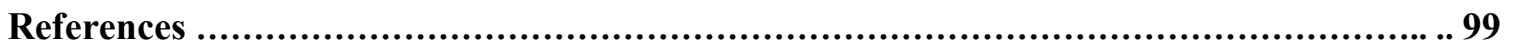

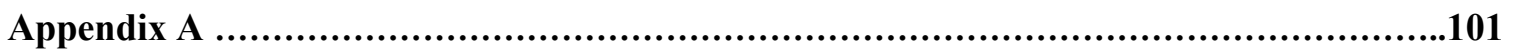

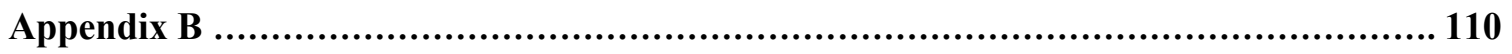

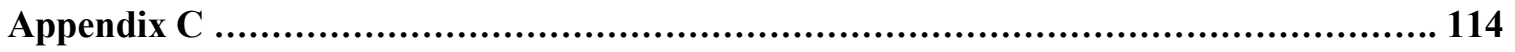




\section{List of Figures}

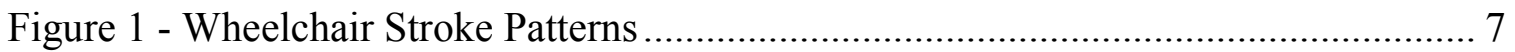

Figure 2 - Example of Power Assist Device ................................................................. 13

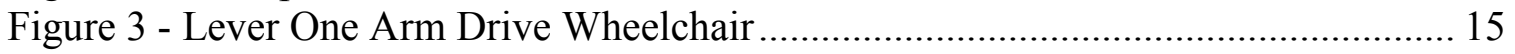

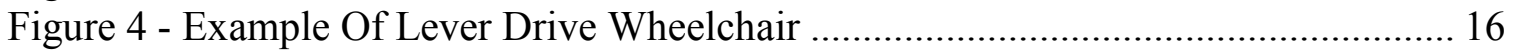

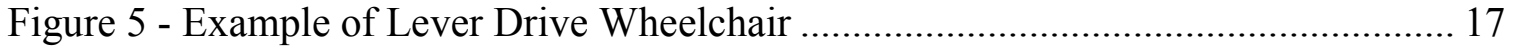

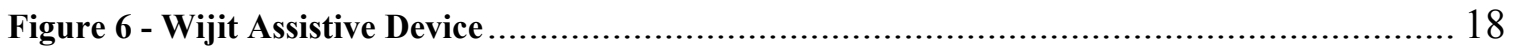

Figure 7- Lever Asynchronous Propelled Wheelchair................................................... 20

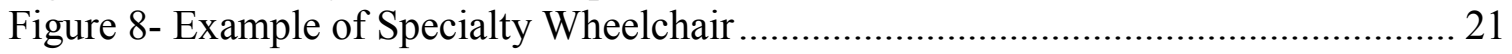

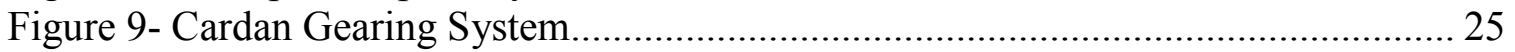

Figure 10 - Cardan Gearing Without Internal Gear .................................................... 25

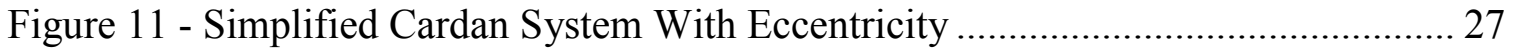

Figure 12 - Wheelchair View With Mechanism and Sprockets ................................... 28

Figure 13 - Example of Elliptical Path of Mechanism Handle ....................................... 29

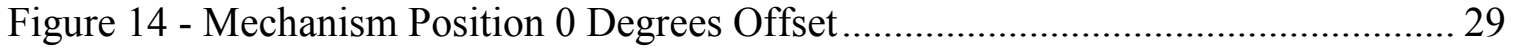

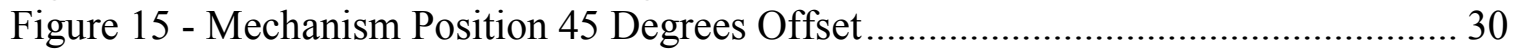

Figure 16- Labeling System for Gear Selection ..................................................... 31

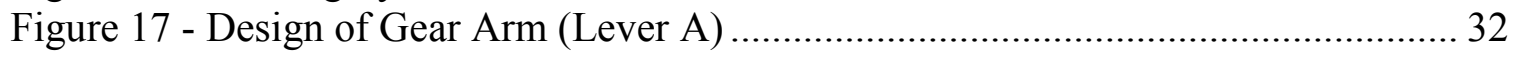

Figure 18 - Lever B, Handle, and Shaft Complex ....................................................... 33

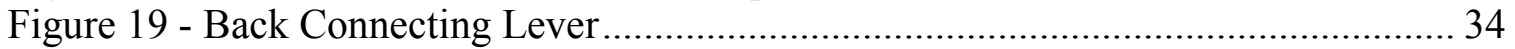

Figure 20 - Elliptical Path Labels ............................................................................... 35

Figure 21 - Exploded View of Innovative Mechanism................................................ 36

Figure 22 - Side View Of Innovative Mechanism ........................................................ 37

Figure 23 - Coordinate System Definition for Mechanism Position Analysis ................ 38

Figure 24 - Isometric View of Dynamometer Setup............................................... 42

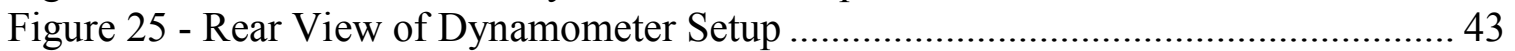

Figure 26 - Picture of Magtrol Dynamometer .............................................................. 44

Figure 27 - Magtrol DSP6000 Controller ..................................................................... 45

Figure 28 - Y - Direction Free Body Diagram (Wheels) ............................................. 46

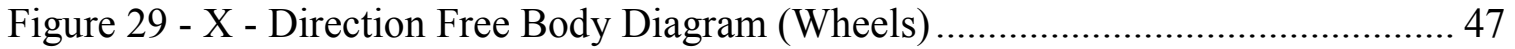

Figure 30 - Y-Direction Shear Diagram For Wheels .................................................. 48

Figure 31 - Y-Direction Moment Diagram For Wheels .............................................. 48

Figure 32 - X-Direction Shear Diagram for Wheels .................................................... 49

Figure 33 - Y-Direction Moment Diagram For Wheels ................................................ 49

Figure 34 - X - Direction Free Body Diagram (Sprocket) ........................................... 52

Figure 35 - Y - Direction Free Body Diagram (Sprocket) ........................................... 52

Figure 36 - X - Direction Shear Diagram (Sprockets) ............................................. 53

Figure $37-X$ - Direction Moment Diagram (Sprockets) ............................................ 54

Figure 38 - Y - Direction Shear Diagram (Sprockets) ................................................ 54

Figure 39 - Y - Direction Moment Diagram (Sprockets) ............................................... 54 


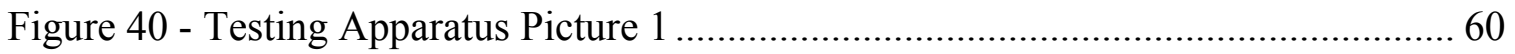

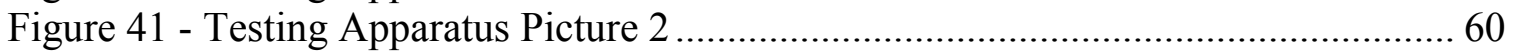

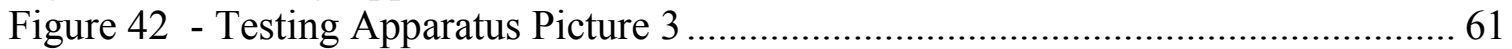

Figure 43 - Example of Handle Path (0-Degrees) ......................................................... 63

Figure 44 - Second Example of Handle Path (45-Degrees)............................................... 64

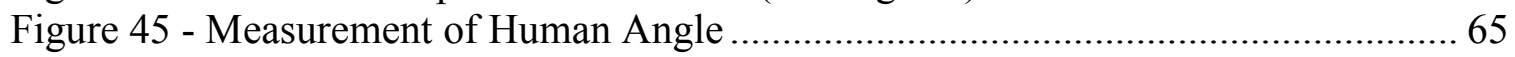

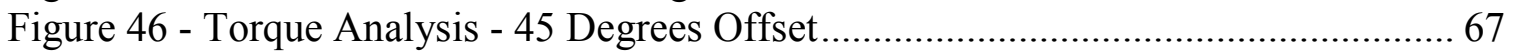

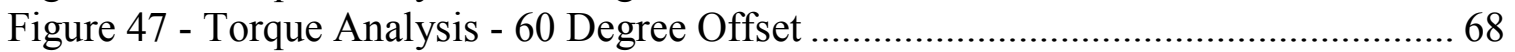

Figure 48 - Torque Analysis - 70 Degrees Offset.......................................................... 69

Figure 49 - Results of Curve Fit Analysis ................................................................... 70

Figure 50 - Diagram of Wheelchair Ramp Requirements ............................................. 72

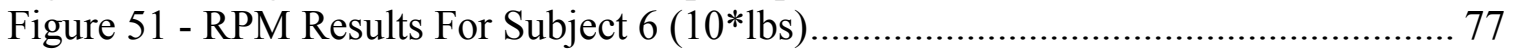

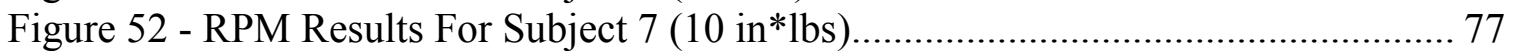

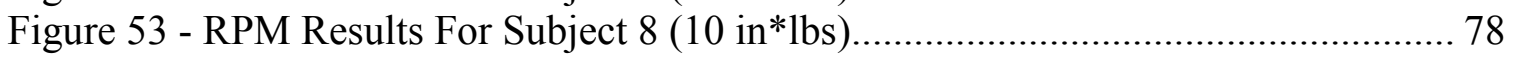

Figure 54 - RPM Results For Subject 1 (10 in*lbs) ................................................... 79

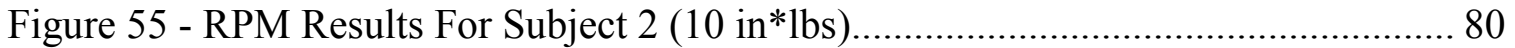

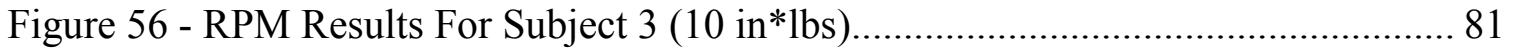

Figure 57 - RPM Results For Subject 4 (10 in*lbs)................................................... 82

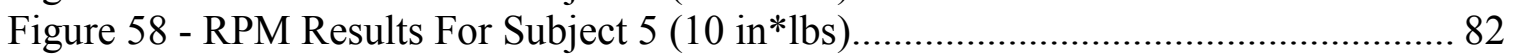

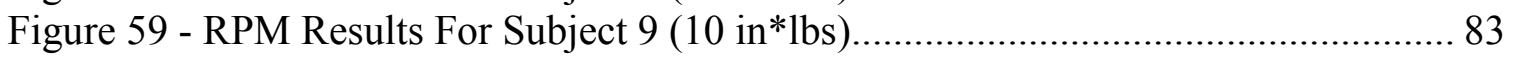

Figure 60 - RPM Results For Subject 10 (10 in*lbs)................................................... 83

Figure 61 - RPM Results For Subject 1 - Wheels (10 in*lbs) .......................................... 86

Figure 62 - RPM Results For Subject 3 - Wheels (10 in*lbs) ......................................... 87

Figure 63 - RPM Results For Subject 4 - Wheels (10 in*lbs) ......................................... 87

Figure 64 - RPM Results For Subject 6 - Wheels (10 in*lbs) .......................................... 88

Figure 65 - RPM Results For Subject 8 - Wheels (10 in*lbs) .......................................... 88

Figure 66 - RPM Results For Subject 10 - Wheels (10 in*lbs) ....................................... 89

Figure 67 - RPM Results For Subject 7 - Wheels (10 in*lbs) ........................................ 90

Figure 68 - RPM Results For Subject 2 - Wheels (10 in*lbs) .......................................... 91

Figure 69 - RPM Results For Subject 9 - Wheels (10 in*lbs) ......................................... 91

Figure 70 - Drawing Of Back Connecting Lever.......................................................... 102

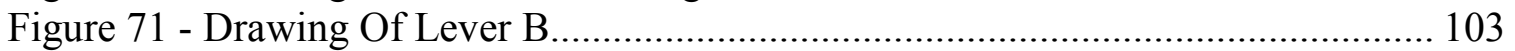

Figure 72 - Drawing Of Lever A (Gear Bar) ............................................................ 104

Figure 73 - Drawing Of Mechanism Shaft \#1 ………............................................ 105

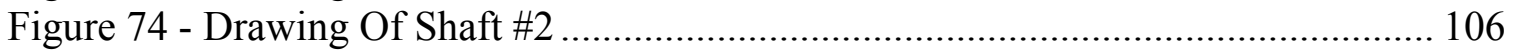

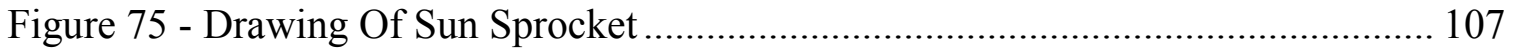

Figure 76 - Drawing Of Planet Sprocket .................................................................... 108

Figure 77 - Drawing Of Connecting Roller Chain Sprocket ............................................ 109

Figure 78 - Results of Torque Analysis For Subject 1............................................ 115

Figure 79 - Results of Torque Analysis For Subject 2.............................................. 115

Figure 80 - Results of Torque Analysis For Subject 3................................................ 116

Figure 81 - Results of Torque Analysis For Subject 4................................................ 116

Figure 82 - Results of Torque Analysis For Subject 5................................................ 117

Figure 83 - Results of Torque Analysis For Subject 6……….................................... 117

Figure 84 - Results of Torque Analysis For Subject 7............................................... 118

Figure 85 - Results of Torque Analysis For Subject 8................................................. 118 
Figure 86 - Results of Torque Analysis For Subject 9.............................................. 119

Figure 87 - Results of Torque Analysis For Subject 10............................................ 119

Figure 88 - Torque Results For Subject 1 (10 in*lbs) .............................................. 121

Figure 89 - RPM Results For Subject 1 (10 in*lbs)................................................... 121

Figure 90 - Horsepower Results for Subject 1 (10 in*lbs) .......................................... 122

Figure 91 - Torque Results For Subject 2 (10 in*lbs) .............................................. 122

Figure 92 - RPM Results For Subject 2 (10 in*lbs)............................................... 123

Figure 93 - Horsepower Results For Subject 2 (10 in*lbs) ......................................... 123

Figure 94 - Torque Results For Subject 3 (10 in*lbs) ............................................... 124

Figure 95 - RPM Results For Subject 3 (10 in*lbs)................................................. 124

Figure 96 - Horsepower Results For Subject 3 (10 in*lbs) ......................................... 125

Figure 97 - Torque Results For Subject 4 (10 in*lbs) ............................................. 125

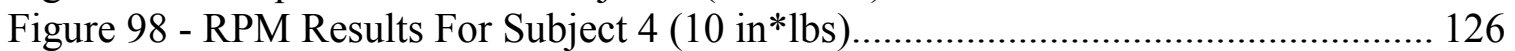

Figure 99 - Horsepower Results For Subject 4 (10 in*lbs) ....................................... 126

Figure 100 - Torque Results For Subject 5 (10 in*lbs) ............................................. 127

Figure 101 - RPM Results For Subject 5 (10 in*lbs)............................................... 127

Figure 102 - Horsepower Results For Subject 5 (10 in*lbs) ........................................ 128

Figure 103 - Torque Results For Subject 6 (10 in*lbs) ............................................. 128

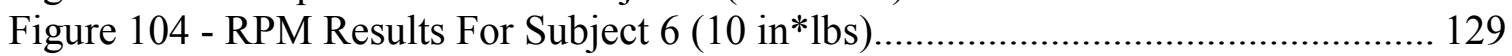

Figure 105 - Horsepower Results For Subject 6 (10 in*lbs) ...................................... 129

Figure 106 - Torque Results For Subject 7 (10 in*lbs) ............................................. 130

Figure 107 - RPM Results For Subject 7 (10 in*lbs)................................................ 130

Figure 108 - Horsepower Results For Subject 7 (10 in*lbs) ........................................ 131

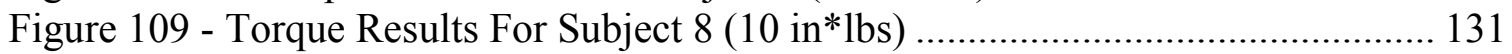

Figure 110 - RPM Results For Subject 8 (10 in*lbs)................................................. 132

Figure 111 - Horsepower Results For Subject 8 (10 in*lbs) ........................................ 132

Figure 112 - Torque Results For Subject $9(10 \mathrm{in} * \mathrm{lbs})$.............................................. 133

Figure 113 - RPM Results For Subject 9 (10 in*lbs)................................................. 133

Figure 114 - Horsepower Results For Subject 9 (10 in*lbs) ......................................... 134

Figure 115 - Torque Results For Subject 10 (10 in*lbs) ............................................ 134

Figure 116 - RPM Results For Subject 10 (10 in*lbs).............................................. 135

Figure 117 - Horsepower Results For Subject 10 (10 in*lbs) ..................................... 135

Figure 118 - Torque Results - Subject 1 - Wheels (10 in*lbs) ..................................... 136

Figure 119 - RPM Results - Subject 1 - Wheels (10 in*lbs) ......................................... 136

Figure 120 - Horsepower Results - Subject 1 - Wheels (10 in*lbs) ............................... 137

Figure 121 - Torque Results - Subject 2 - Wheels (10 in*lbs) ..................................... 137

Figure 122 - RPM Results - Subject 2 - Wheels (10 in*lbs) ......................................... 138

Figure 123 - Horsepower Results - Subject 2 - Wheels (10 in*lbs) ............................. 138

Figure 124 - Torque Results - Subject 3 - Wheels (10 in*lbs) ................................... 139

Figure 125 - RPM Results - Subject 3 - Wheels (10 in*lbs) ........................................ 139

Figure 126 - Horsepower Results - Subject 3 - Wheels (10 in*lbs) .............................. 140

Figure 127 - Torque Results - Subject 4 - Wheels $(10$ in*lbs) .................................... 140

Figure 128 - RPM Results - Subject 4 - Wheels (10 in*lbs) .......................................... 141

Figure 129 - Horsepower Results - Subject 4 - Wheels (10 in*lbs) ............................... 141

Figure 130 - Torque Results - Subject 6 - Wheels $(10$ in*lbs) ..................................... 142

Figure 131 - RPM Results - Subject 6 - Wheels (10 in*lbs) ......................................... 142 
Figure 132 - Horsepower Results - Subject 6 - Wheels (10 in*lbs) ............................. 143

Figure 133 - Torque Results - Subject 7 - Wheels $(10$ in*lbs) ................................... 143

Figure 134 - RPM Results - Subject 7 - Wheels (10 in*lbs) ....................................... 144

Figure 135 - Horsepower Results - Subject 7 - Wheels (10 in*1bs) ............................. 144

Figure 136 - Torque Results - Subject 8 - Wheels (10 in*lbs) ................................... 145

Figure 137 - RPM Results - Subject 8 - Wheels (10 in*lbs) ....................................... 145

Figure 138 - Horsepower Results - Subject 8 - Wheels (10 in*lbs) .............................. 146

Figure 139 - Torque Results - Subject 9 - Wheels (10 in*lbs) ..................................... 146

Figure 140 - RPM Results - Subject 9 - Wheels (10 in*lbs) ....................................... 147

Figure 141 - Horsepower Results - Subject 9 - Wheels (10 in*lbs) .............................. 147

Figure 142 - Torque Results - Subject 10 - Wheels (10 in*1bs) ................................... 148

Figure 143 - RPM Results - Subject 10 - Wheels (10 in*lbs) ...................................... 148

Figure 144 - Horsepower Results - Subject 10 (10 in*1bs).......................................... 149

Figure 145 - Labeled Parts For Dynamometer Setup ............................................... 150 


\section{List of Tables}

Table 1- Wheelchair Use Related Injuries .................................................................. 3

Table 2 - Compilation Table of Various Mechanism Parameters........................................ 35

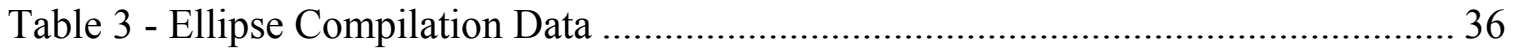

Table 4 - Magtrol Dynamometer Requirements ........................................................... 44

Table 5 - Results Of Boundary Conditions and Integration Constants............................. 51

Table 6 - Results of Boundary Conditions and Integration Constants.............................. 56

Table 7 - Results of Analysis With Wheelchair Wheels.................................................. 57

Table 8 - Results of Analysis With Innovative Mechanisms............................................ 57

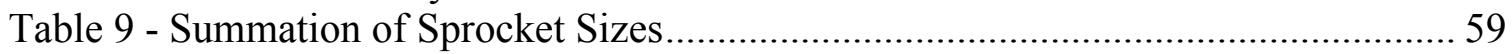

Table 10 - Parameter Inputs for Mechanism Handle Position ........................................... 62

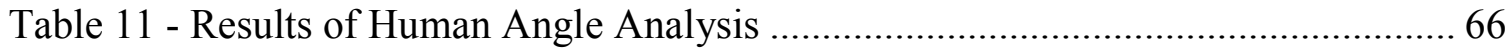

Table 12 - Comparison of Results For Mechanism Position Angle ................................ 71

Table 13 - Comparison of RPM Data For Wheels and Innovative Mechanism ................ 84

Table 14 - Horsepower Comparison of Wheel and Innovative Mechanism Propulsion

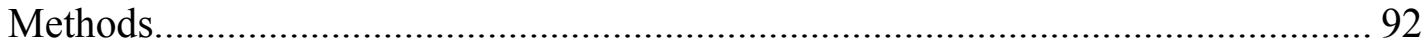

Table 15 - Results of Energy Analysis for Wheels and Innovative Mechanism Propulsion

Table 16 - Results For Deflection and Stress Analysis -Table 1 .................................... 111

Table 17 - Results for Deflection and Stress Analysis -Table 2 …………................... 112

Table 18 - Results of Deflection and Stress Analysis - Table 3 .................................... 113

Table 19 - Testing Torque Calculation Spreadsheet.................................................... 120 


\section{Introduction}

\subsection{Declaration of Problem}

Wheelchair development and use has become a topic of importance. There are approximately 1.4 million users of wheelchairs (in the world) and if those $75 \%$ are using a manual wheelchair. This figure is estimated to be growing at a rate of approximately $10 \%$ per year. Most manual wheelchair users have lower-extremity weakness, amputation, or paralysis that makes walking difficult. These injuries may include spinal cord injuries, hemiplegia, other paralysis, multiple sclerosis, cerebral palsy, spina bifida, arthritis, or lower-limb amputations ${ }^{1}$.

Through increased legislation over the past twenty years, many new opportunities, such as increased access, employment, and mobility, have been granted to wheelchair users. The average of the population with disabilities in West Virginia is 2.9 percent, whereas the national average is only 1.6 percent $^{2}$. Therefore a higher percentage of the citizens of West Virginia benefit more than most other states from this legislation. From these statistics, it is easy to understand how users manual wheelchairs, can greatly benefit from advances in wheelchair mobility and propulsion.

The environment of a wheelchair user is a very complex and difficult place in which to maneuver. Some of the environmental factors that affect a wheelchair user's mobility are functions of the rolling surface; uneven, broken, or missing sidewalks, inclined surfaces, and weather affected areas. Most wheelchairs are not equipped with the necessary options to be able to transverse over such surfaces as sand, dirt, loose gravel, or even thick carpeting. Consider the complexity of negotiating uneven sidewalks 
or sidewalks that do not have ramps to enter from the street. These challenges might discourage even the most physically able person. What if an icy sidewalk or a ramp is added? The situation could become an almost impossibility for the average wheelchair user with today's technologies. There is a great need to find more efficient mechanisms for wheeled-mobility patients.

A person's inability to maneuver a wheelchair through the above-mentioned environments could severely limit his or her independence. Lack of independence can have a great affect on mental and physical health. The use of a manual wheelchair can counteract these ill affects by improving a users cardiovascular and muscular strength. Wheelchair users have less opportunity for aerobic exercise. Normally, the only aerobic exercise that a wheelchair user has will be derived from propelling their wheelchair for daily activities. Many elderly and frail individuals are unable to use a manual wheelchair, but their health, both mental and physical, may be improved by extending the time in which they can use the wheelchair ${ }^{1}$. Assistive technologies are being developed to enable elderly and weaker individuals to gain greater mobility and independence. These devices benefit them and generally lead to a higher quality of life.

It is the goal of this research to create, design, construct, and test a new assist device that can be retrofitted into a standard wheelchair frame that will reduce the potential of injury and produce a higher quality of life for wheelchair users. 


\subsection{Literature Review}

\subsubsection{Prelude}

In this section the literature related to wheelchair injuries, stroke patterns, and other devices will be explored. From this literature review the issues appropriate for the hypothesized mechanism can be delineated.

\subsubsection{Wheelchair Related Injuries}

Users of wheelchairs experience a wide variety of physical injuries. Recent studies have shown that the high degree of reliance of wheelchair users on the upperbody and associated muscular skeleton system, along with the repetitiveness of the wheelchair-stroking pattern, predisposes them to overuse injuries; especially at the shoulder, elbow, and wrist ${ }^{3}$. The following table gives a summary of the various injuries, and percentages of wheelchair users that experience these injuries.

Table 1- Wheelchair Use Related Injuries ${ }^{1}$

\begin{tabular}{|c|c|}
\hline Injury Type & Percentage of Wheelchair Users \\
\hline Shoulder-Related Injuries & 51 \\
\hline Elbow Pain & 16 \\
\hline Wrist Pain & 13 \\
\hline Hand Pain & 11 \\
\hline Rotator Cuff & Greater Than 50 \\
\hline Carpal Tunnel & Greater Than 50 \\
\hline
\end{tabular}

Table 1 only gives a small list of the injuries that wheelchair users develop.

Other injuries and conditions that wheelchair users encounter are: backaches, exhaustion, burning of the hands on the rims, dirty clothes, dirty hands, perspiration, and over heating ${ }^{4}$. Most of these injuries occur from an overuse or misuse of the muscles in the shoulders, arms, and hands. 
Wheelchair users face a higher percentage of certain injuries than the population at large. For example, the incidence of carpal tunnel and rotator cuff tendonitis are greater than 50 percent for wheelchair users as compared to 3 percent for the general population ${ }^{1}$. Many of the injuries are produced by the manner in which an individual must use their body while operating a wheelchair. On a standard wheelchair, the only way to stop the chair comes from the force a person applies to the pushrim with his or her hands. This continuous rubbing on the pushrim causes blisters. In general the inward force generated by a wheelchair user does not help in braking or chair propulsion, but is necessary for the user to gain friction with the pushrim on the wheel

Research in the field of wheelchair related injuries is an ongoing topic. Some general conclusions can be reached from the above review: (1) The basic injuries are to the shoulder and wrist. These are due to the repetitive nature required for wheelchair propulsion. (2) Propulsion of the standard wheelchair requires the individual to use his body in a way that may be responsible for some of these injuries. The following pages contain some case studies that give an illustration of various research that is currently being done in the area of preventing wheelchair related injuries.

\subsubsection{Case Study I}

Kibler studied the results of stretch weakness and inadequately developed opposing muscles. Kibler advocated a preventive exercise program to stretch the muscles most likely to be overdeveloped, and to strengthen the muscles most likely to show stretch weakness. For the basic wheelchair user, this would mean that the anterior upper body musculature is most likely to need stretching and the posterior upper body 
musculature is most likely to need strengthening. This hypothesis was based on earlier work that suggested that therapeutic exercise intervention specifically designed to stretch and strengthen these given muscle groups may possibly reduce the risk of overuse injuries. The procedures used to test the subjects will not be explained, but the results from the testing will be presented. After the proper training and strengthening, wheelchair users gained a significant increase in the peak joint moments at the wrist, elbow, and shoulder. There was a $17.4 \%$ increase in the peak propulsive moment at the handrim. At the wrist joint, there was a $14.4 \%$ increase in the ulnar deviation moment. The extensor moment at the elbow increased by $16.9 \%$, and the flexor moment at the shoulder increased by $13.6 \%$. Peak joint reaction force changes at the wrist included a $14.5 \%$ decrease in the shear force in the radioulnar direction and a $7.6 \%$ increase in the compressive force. The anteroposterior shear forces increased $15.8 \%$ at the elbow, and $14.3 \%$ at the shoulder ${ }^{3}$. These findings suggested that specific training for wheelchair users improved wheelchair propulsion mechanics and decreased the probability of overuse injuries. Further investigation of joint kinetic changes is continuing and it is anticipated that an optimal exercise protocol can be developed.

The general conclusion of this case study is that wheelchair injuries occur from repetitive asymmetric muscle use and an exercise programs that promotes symmetric muscle development can reduce the occurrence of such injuries. 


\subsubsection{Case Study II}

This study characterizes wheelchair propulsion stroke patterns through the investigation of joint accelerations, joint range of motion (ROM), propulsion phases, and stroke efficiency. The second metacarpophalangeal joint plots of seven subjects were used to obtain the data. The kinematic data revealed three distinct stroke patterns. The following descriptions characterize those patterns: semi-circular (SC), single looping over propulsion (SLOP), and double looping over propulsion (DLOP). These patterns are shown in Figure 1 on the next page. The subjects using the SC (Figure 1-A) stroke pattern dropped their hands below the propulsion path during the recovery phase. The subjects using SLOP and DLOP stroke patterns lifted their hands over the propulsion path during the recovery phase. The subjects not sharing a common point on the propulsion and recovery strokes characterized the SLOP (Figure 1-B) stroke pattern. The DLOP (Figure 1-C) stroke pattern had a characteristic shared point on both the propulsion and recovery phases. Figure 1 gives an illustration of the different stroke patterns that were characterized. 

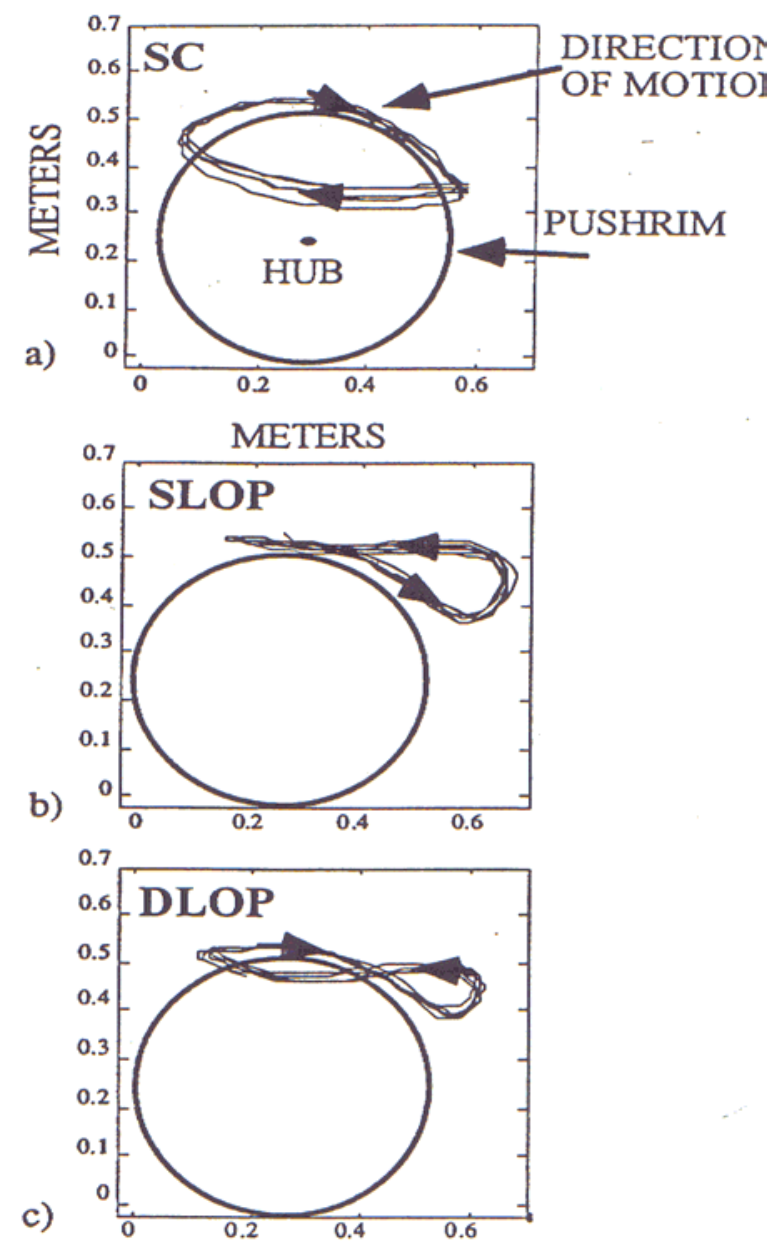

Figure 1 - Wheelchair Stroke Patterns ${ }^{5}$

From Figure 1 it can be seen that none of the given subjects used a pumping stroke pattern. The pumping stroke pattern is considered to be a pattern used by inexperienced wheelchair users.

It has long been known that high joint accelerations are the cause of many wheelchair related injuries of the shoulder, elbow, and hand. The changes in joint angles were quantified through an analysis of joint accelerations. This study revealed that subjects with the SC pattern had smaller flexion/extension and shoulder abduction/adduction acceleration measures during the slower speed, as compared to the 
other stroke patterns. This decrease in acceleration may lessen the risk of accelerationrelated injuries.

The joint excursions data was then used to determine whether the joints were being exposed to abnormal ROM during propulsion. This analysis revealed that subjects with the SC stroke pattern did have a larger ROM during propulsion, but this data was then compared to normal ROM for the given joints and it was concluded that the ROM for the SC stroke pattern was within the satisfactory range. In addition, the study found that individuals with the SC stroke pattern spent a greater percentage of the cycle time (CT) in the propulsion phase of the stroke. By analyzing phases alone, it was concluded that subjects using the SC stroke pattern are more efficient because a larger amount of time is spent in the propulsion phase, which in turn produces a larger impulse at the pushrim. Through the analysis of the data for this study, it was hypothesized that the manual wheelchair users with the SC stroke pattern were more biomechanically efficient when propelling a wheelchair. These subjects had the positive qualities of lower shoulder and elbow joint acceleration measures, along with a greater percentage of time spent in the propulsion phase of the wheelchair stroke. These individuals may also be less prone to injury because they apply less force to the pushrim over a greater amount of time ${ }^{5}$.

In conclusion, this study hyposthesized that the simple elliptical path of the semi-circular stroke produces less injuries to the shoulder and arm complex than the other two patterns that are frequently employed by wheelchair users. Thus, any device that we would like to develop should have an elliptical path in which the force is as close to uniform over the path as possible. 
Wheelchair related injuries come at a price to insurance companies and ultimately the population at large. Over a three-year period from 1995-1997 Medicare expenditures for manual wheelchairs averaged $\$ 98,000,000^{6}$. There is a need for a device that could be affixed to standard wheelchairs so users have the propulsive abilities of a powered chair. This device would then allow for less expensive standard wheelchairs to be used instead of more expensive wheelchairs that are used to accomplish that task. It is one goal of this research to construct and test such a device.

\subsubsection{Determining Wheelchair Type - User's Ability}

There are a wide variety of wheelchairs that are available to each individual. The three main classifications of standard two-armed propelled wheelchairs are standard, standard lightweight, and heavy-duty wheelchairs. Standard wheelchairs are normally heavier than a high-end wheelchair, tending to weigh more than 44 pounds. There are only a few options that are available on the standard chair. The standard lightweight wheelchairs are lighter and often have more manufacturer options than the standard wheelchair. In addition, they have more aftermarket options that are available. The heavy-duty wheelchairs are made to operate at a higher load capacity, often up to 348 pounds. These heavy-duty wheelchairs are also proportionately heavier and cost more than the standard chair ${ }^{7}$.

The cost and weight of a wheelchair are real concerns for the individuals who use them. In many cases Medicare, Veteran's Administration, and other insurances will pay for most if not all of the cost of the wheelchair, but the person still must be able to maneuver the wheelchair in and out of the car and around his or her environment. Where 
independence issues are involved, lighter wheelchairs are seen as advancement because they are easier to maneuver in and out of the back seat of a vehicle. A lot more emphasis is being placed on the weight of the wheelchair because lightweight wheelchair users can gain more independence. Lighter weight wheelchairs are more expensive, but their cost must be weighed against the value of increased mobility and independence. It is a goal of this research to develop a wheelchair mechanism that can be retrofitted into a standard weight wheelchair and cost less than a lightweight wheelchair, but provide more mobility and independence than a lightweight wheelchair.

\subsubsection{Wheelchair User Qualification List}

The needs of various wheelchair users can be very different. It is often necessary to assess the ability of the user in order to gain a better fit to the individual. These questions are often used to start a physical assessment:

$>$ Is the user able to self propel?

$>$ What are the postural requirements?

What is the visual and cognitive ability of the user?

$>$ How does the user transfer?

The issues of self propelled motion, postural requirements, and transfer will give the technician, doing the assessment, an understanding of the chair for a particular individual. In addition, the issue of propulsion type must be considered to define the proper wheelchair mechanism for a specific person. The following is a list of how most propulsion issues are fitted:

$>$ With both arms

$>$ With one arm

$>$ Foot propelled 
Once the issue of propulsion has been addressed, the user can test several chairs and configurations to determine which meets his or her needs ${ }^{7}$. Each of the above mentioned types of propulsion are possible with today's wheelchairs, and the following sections will outline the different types of wheelchair propulsion that are available.

\subsubsection{Types of Wheelchair Propulsion}

\subsubsection{Prelude}

In this section of the literature review various assist devices and mechanisms are described, along with a description of their advantages and disadvantages. This helped the researcher to decide the best type of mechanism that could be developed at WVU. The five types of wheelchair propulsion that will be looked at are geared hubs, power assists, one arm drives, lever drives, and specialty wheelchairs.

\subsubsection{Geared Hubs}

A gearing system on a wheelchair provides the user the ability to switch from one gear to the next as the incline or environmental conditions change. The gearing system provides the mechanical advantage necessary to accommodate these changes. In many situations, the gearing systems can be installed and used with standard hand rims. Currently, the geared hubs for wheelchairs only have a limited number of gear ratios available. The gearing system works in the same manner as a transmission works on a bicycle. Whenever the user is going up a hill and needs more power, a lower gear can be used to generate the needed power to transverse the obstacle. However, the user can then switch back to a higher gear once the obstacle has been conquered and proceed as 
normal. There is an infinite amount of gearing options that should be available with this system, but without a demand and standardization, the system will never be used to its full capacity. This system has the ability to be adjusted to meet each person's individual needs. This could be a customized application.

There are drawbacks to geared hub propulsion systems. (1) The act of switching from one gear to the next can be "sloppy" and cause "play" in the system. (2) Whenever a low gear is used, the user will have to propel the hand rims more than when a higher gear is used. The added power comes at the expense of physical exertion. (3) This type of system also adds extra weight to the wheelchair. Since these types of wheelchairs have extra weight added, maneuverability may be a problem. (4) An automatic braking system may need to be added to help the user slow the wheelchair down. (5) Some geared systems inhibit the user from folding the chair. This feature adds an extra burden to the user and makes independent automobile use almost non-existent for all automobiles except vans. (6) With this type of system, the user could actually be at a disadvantage when traveling for long distances due to the mechanical loss in the gearing system and added weight of the wheelchair. (7) Above all, wheelchair users have not accepted the geared hub systems as a viable solution to the current wheel-mobility problems ${ }^{1}$. 


\subsubsection{Power Assists}

The power assist system is an add-on used to turn a manual wheelchair into a power wheelchair. This type of system gives the user the ability to use the wheelchair as a standard manual chair or as a power chair with the add-on feature. The add-on power assist feature is much cheaper than a power chair, but at the same time, it gives the user all of the advantages a power chair. The power assist add-on is used whenever the user wants to go up hills or over terrain that is beyond their physical ability to navigate. This feature allows greater mobility and increased independence in the surrounding environment. Another valuable feature of the power assist chair is that it can aid in stopping the chair without grabbing the wheels or using wheel locks.

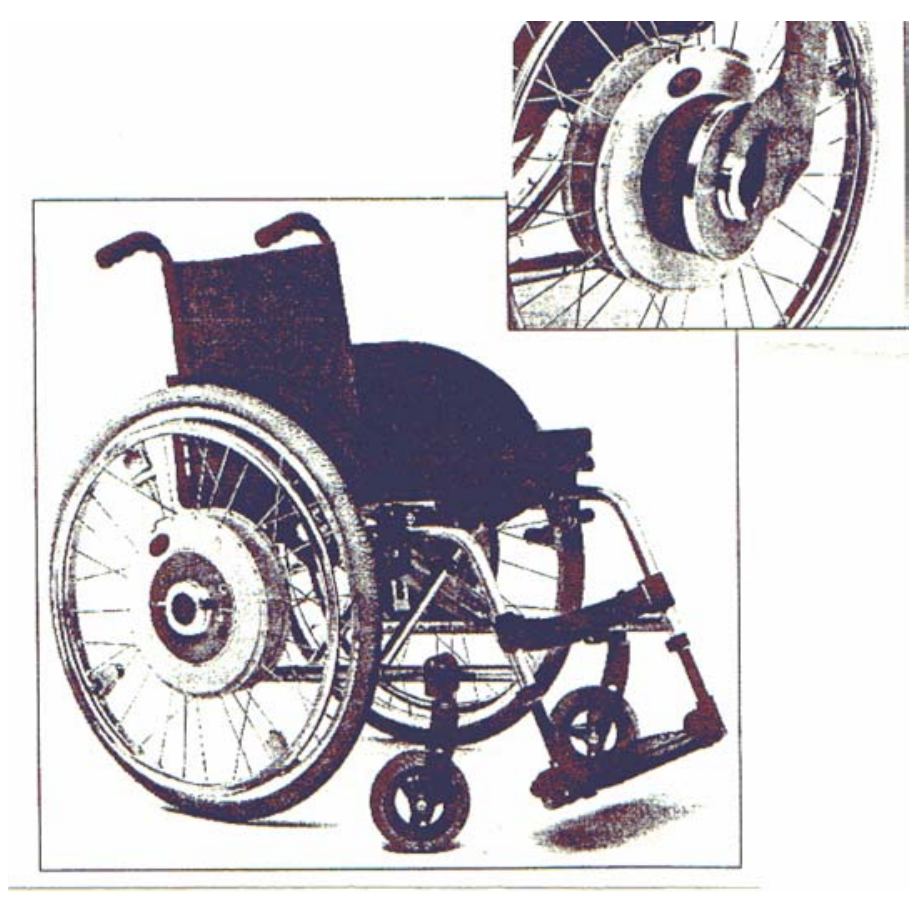

Figure 2 - Example of Power Assist Device ${ }^{8}$ 
With the advantages of this system come a number of disadvantages. (1) The current power assists are not manufactured so that they can be fit onto a wide variety of wheelchair styles. (2) Many of the wheelchairs that use power assists are hard to fold and do not allow the user to put the wheelchair into the back seat of a car easily. (3) Another concern, that many people have, is that the user could get the chair into a situation that he or she would not normally venture into with a standard manual wheelchair. (4) Once again, one of the biggest disadvantages of the power assist system is that it adds weight and complexity to the wheelchair. (5) By adding weight to the chair, an individual will not be able to get the wheelchair in and out of a car as easily. (6) The complexity of the power assist mechanism will add more maintenance to the wheelchair ${ }^{4}$.

\subsubsection{One Arm Drive}

The one arm drive wheelchair is a type of wheelchair that you do not see frequently. The wheelchair is propelled by a double hand rim system located on one side of the chair. The user has the ability to lock the hand rims together and propel both at the same time, or the rims can be propelled separately to give control to one side of the wheelchair or the other. The users of these types of wheelchairs ordinarily encounter coordination problems when the wheelchair is first acquired. In addition, the complexity of trying to negotiate a hill or even a slope can be an almost impossible task for this type of propulsion system ${ }^{9}$. Most people do not have the strength needed in only one arm to propel themselves on relatively flat ground let alone a slope or hill. The operation of this type of chair requires a lot of practice and co-ordination to use correctly. 
A second type of one arm drive chair exists that uses a lever on one side of the chair to propel the entire chair. Figure 3 shows an example of one such chair.

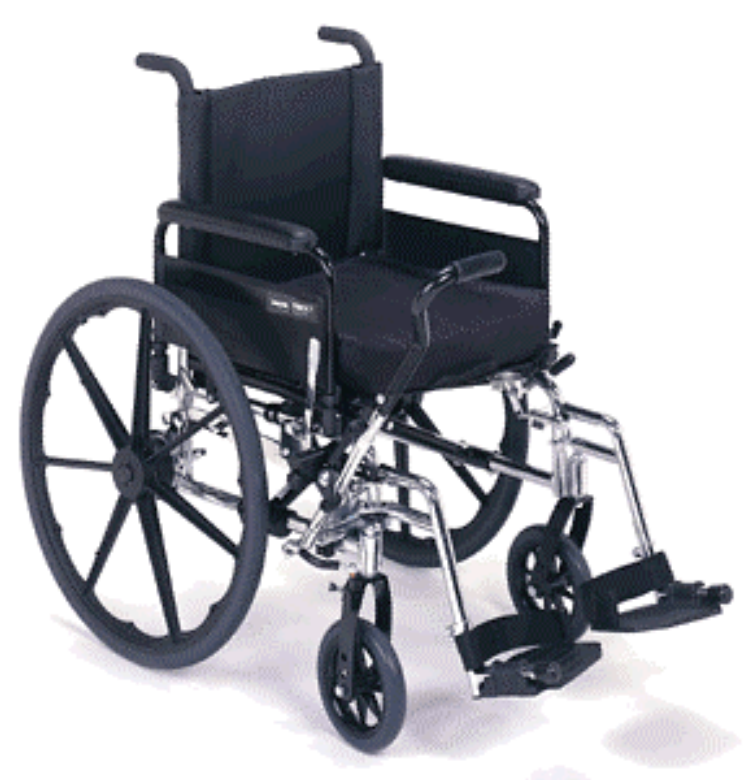

Figure 3 - Lever One Arm Drive Wheelchair ${ }^{10}$

The lever on the side of the wheelchair can be adjusted and positioned on either side of the chair, thus it is ambidextrous ${ }^{10}$. The lever style design will give the user a more natural feel and requires less time to adjust to the wheelchair design. But, this type of chair still has the disadvantage of having to switch power from one wheel to the other in order to propel the wheelchair around turns and corners. Consequently, the lever one arm drive chair has the same disadvantages on hills and slopes as the push rim one arm drive chair. In order to use either wheelchair, a person must be able to generate enough power with one arm as the standard wheelchair users do with two arms for a given distance. This type of design can be used to give a person with the use of only one arm 
exercise, and it helps to keep these patients from becoming totally dependant on a power wheelchair.

\subsubsection{Lever Drive}

Lever propulsion systems for wheelchairs are not a new idea. For years people have been working on specialty wheelchair lever mechanisms. Many of the early lever systems resembled the propulsion systems from bicycles. Some of these systems are only called lever drives because they use a handle attached to a lever to provide a mechanical advantage on the chain mechanism. The systems that are used to propel the wheelchair on these models simply look like the pedals of a bicycle mounted above the frame of the wheelchair.

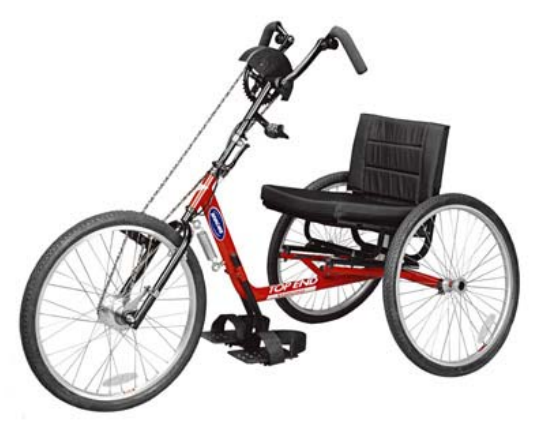

Figure 4 - Example Of Lever Drive Wheelchair ${ }^{10}$

In many cases, the user needs to be strapped into the chair to be sure that he or she does not fall out during operation. Placing a different type of seat that allows the user to set back further and in a reclined position in the wheelchair could solve this problem. 
Another type of lever drive wheelchair that has been developed uses a chain drive on both sides that allows for independent operation of the wheels. Figure 5 gives an example of one such lever drive wheelchair.

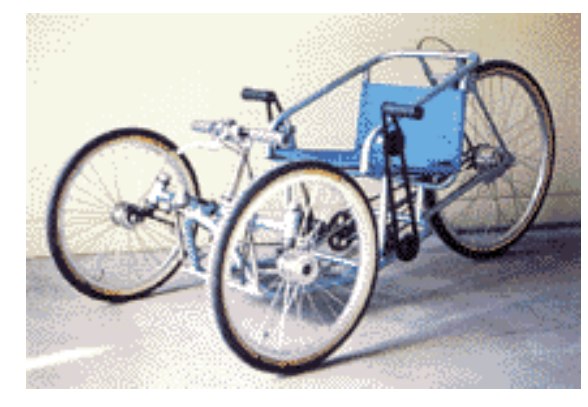

Figure 5 - Example of Lever Drive Wheelchair ${ }^{11}$

This type of wheelchair gives the user a more reclined position so that the user is not falling out of the chair while it is being propelled. In addition, this wheelchair gives the user a more standard feel by allowing two-sided propulsion. The motion is more natural for the user and not a big change from a standard wheelchair design.

Another assistive lever device that has been invented for wheelchair propulsion is the $\mathrm{Wijit}^{12}$. The Wijit is a device that was developed as a result of nine years of research. It is a wheelchair propulsion and braking device that consists of levers on both sides of the chair. The figure below shows an example of the Wijit system. 


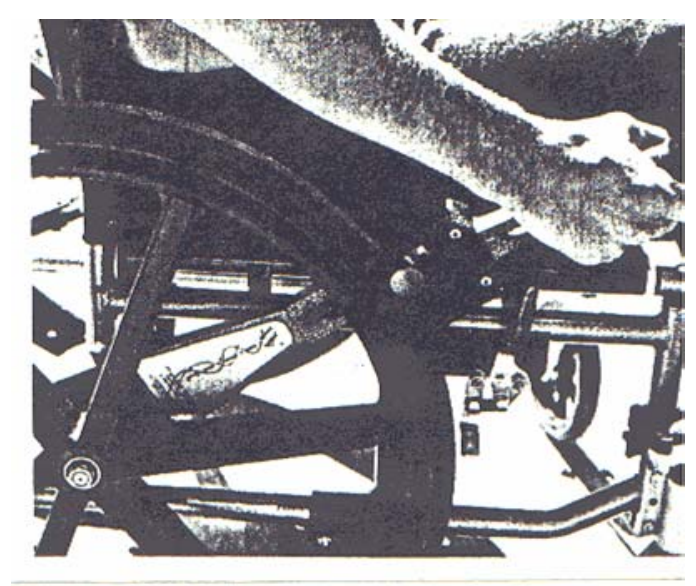

Figure 6 - Wijit Assistive Device ${ }^{12}$

The assistive technology of the Wijit reduces the stress that is normally placed on the upper extremities during propulsion of a standard wheelchair, and amplifies the users force by approximately $50 \%$. In addition, the Wijit allows the user to sit erect in the chair that provides better back support. This device permits wheelchair propulsion with minimal grip changes and offers a variety of hand positions to accommodate a wider range of impairments. The Wijit weighs less than 10 pounds and does not add more than 2 inches to the width of a wheelchair. However, this device only allows for a propulsion stroke in one direction. The user will still have the asymmetric muscle development associated with standard wheelchair propulsion.

Lever drive wheelchairs provide the user with a mechanical advantage over a standard drive wheelchair through the use of chains and gearing. In addition, lever drive wheelchairs also provide the user with a less tiresome method of propulsion. Instead of the unnatural method of a conventional wheelchair, the user is able to use his or her arm in a more natural and powerful manner. Additional advantage can be achieved by 
changing the wheel size based on the user's mobility needs, or changing the lever position on the wheelchair to meet the comfort needs of the user.

On the other side, levers have a lower acceptance by users than standard wheelchairs. The lever systems add weight to the wheelchair and in some cases inhibit the wheelchair from being folded. This in turn inhibits the user from transporting the chair in the back of automobiles. One of the biggest drawbacks of lever systems is that they make side transfers very difficult ${ }^{4}$. Unless, the lever is mounted in a way that makes it removable, the user is unable to transfer out the side of the wheelchair.

The following section is an example of research that has been done on the mechanical advantage of lever drive propulsion.

\subsection{Case Study III}

This study was conducted to test the premise that in general manual wheelchair propulsion is an inefficient form of human transportation. Handrim propulsion will lead to relatively high strain on the musculoskeletal and cardio respiratory systems. The net result will be high-energy consumption, high heart rate, low mechanical efficiency, and future complaints related to the structures of the upper limb. Past research had shown that crank and lever-propelled wheelchairs appeared to be less straining forms of transportation. It had been shown that lever-propelled wheelchairs lead to lower physical strain compared to handrim-propelled wheelchairs. Another advantage of lever-propelled mechanisms is that they allow for a more ergonomic optimization to the individual physical characteristics of the user. For this given study, the levers on the chair were coupled together with a Bowden cable, and their orientation only allowed asynchronous 
arm use, at a fixed position 180 degrees out of phase. A figure of the tested wheelchair can be found below.

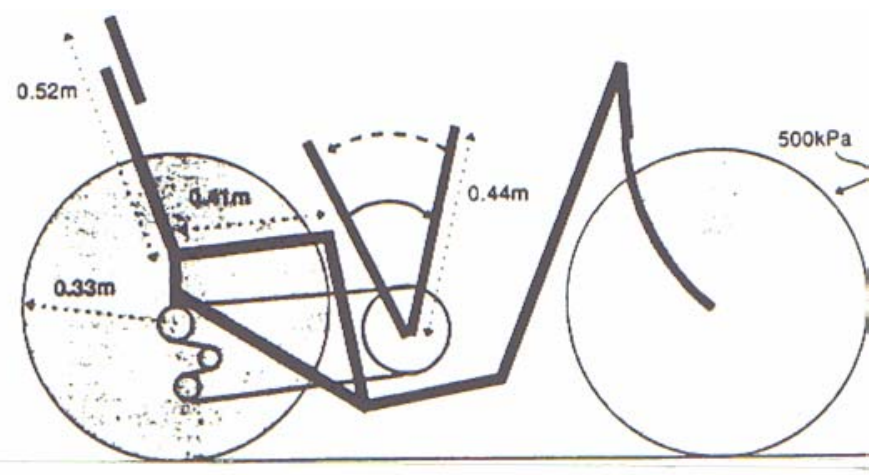

Figure 7- Lever Asynchronous Propelled Wheelchair

For all of the given tests, the mechanical advantage was controlled by using a five-gear transmission (gear box). The current lever system that was used for the test does not have an idle phase, and it does not have a "dead spot" at both ends. With this design, the external force varies sinusoidally with the lever orientation. The mechanical advantage of the gearing system was shown to have an effect on oxygen uptake, mechanical efficiency, and energy expenditure. At the same power output level, the mechanical efficiency of lever wheelchair propulsion in this study tended to increase and energy expenditure tended to decrease as the mechanical advantage decreased ${ }^{13}$. Similar studies on handrim propulsion were used to confirm these findings. Lastly, in this study, the mechanical advantage was studied using a varied gearbox. The study also stated that the mechanical advantage should be studied using varied lever lengths and changing other aspects of the given wheelchair ${ }^{13}$. This study only used the mechanical advantage of a gearbox. These results could be different if a longer lever were used, or if the seat 
were positioned differently for the user. These are all aspects that must be considered when testing for mechanical advantages on any type of system.

Most lever-powered wheelchairs are still developed to encourage asymmetric muscle development. In addition, extra weight is still being added to the wheelchairs, and these wheelchairs have not shown a real distinct advantage and thus they are not widely accepted by the community of wheelchair users.

\subsubsection{Specialty Chairs}

In the scope of this paper, specialty wheelchair design includes everything from standard power wheelchairs to wheelchairs that have the ability to climb stairs. The one specialty chair that will be considered for discussion in this section is a power wheelchair that has the means to give the user the ability to reach objects on higher shelves, and it can climb stairs. Figure 8 contains a picture of the new revolutionary wheelchair.

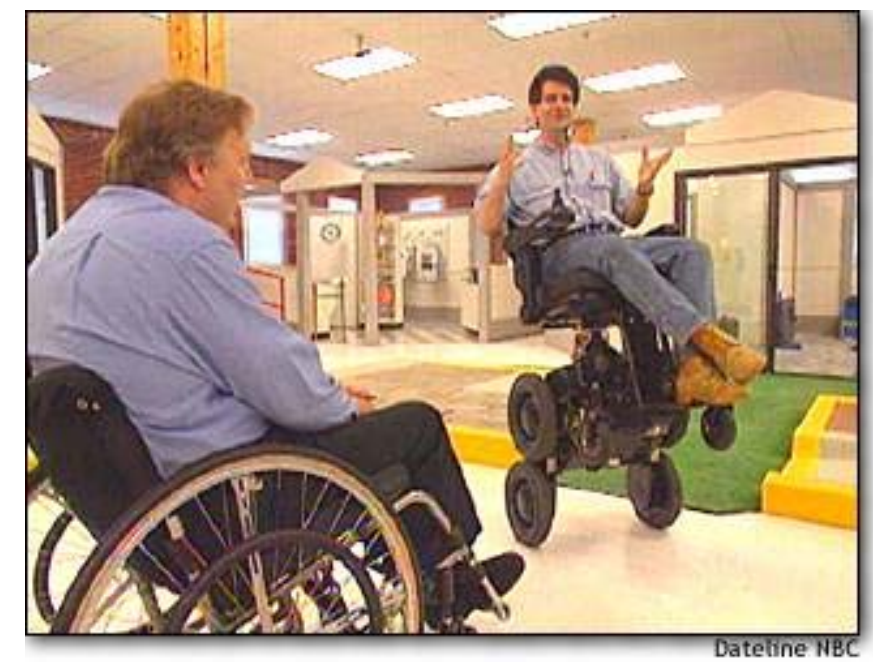

Figure 8- Example of Specialty Wheelchair ${ }^{14}$ 
The inventor created this new wheelchair design after he watched people struggling to use a standard wheelchair. The new wheelchair design uses sophisticated gyroscopes, electric motors and computers to accomplish the goal of wheeled mobility.

The price and the inability to provide physical exercise are real drawbacks to electric wheelchairs and this type of specialty wheelchair. Since the wheelchair is powered by electric motors, the user will not get the exercise that is involved with the operation of a standard manual wheelchair. However, the benefits that the chair provides in mobility around a given environment could possibly be enough to offset the drawbacks. It would be up to the given patient to weigh all the options. With this wheelchair people would once again be able to go places and take part in activities that they thought were once beyond their abilities.

\subsection{Problem Statement}

Upon completion of this research endeavor of an innovative wheelchair mechanism, this thesis will show that the investigator completed the following tasks:

$>$ Designed an innovative mechanism that incorporates the elliptical path of the semi-circular stroke pattern that can be used to power a standard wheelchair. This mechanism allows for simple construction and can be able to be retrofit onto existing wheelchairs. The mechanics of this new design should not inhibit symmetric muscle usage during its operation. Thus, it should have the potential of reducing repetitive motion injuries common to standard manual wheelchair users. 
$>$ Provided theoretical and practical modeling of the innovative mechanism.

The function of the innovative mechanism can be easily seen.

$>$ Designed and constructed a prototype of the innovative mechanism that was retrofitted into a standard wheelchair.

Designed and constructed a testing station for the sole purpose of analyzing and comparing the innovative mechanism to standard wheelchair propulsion.

Showed a comparative analysis of the innovative mechanism to the standard wheels on a wheelchair. This analysis included tables, graphs, and good engineering data and assumptions to support the hypothesis.

\section{Mechanism Development}

The new mechanism that has been conceived is unlike any of the conventional wheelchair or lever-actuated propulsion systems on the market today. Many of the other lever-actuated motion devices use a ratcheting motion, that in turn only allows for propulsion in one direction. These types of devices do not strengthen both sides of the shoulder and upper arm complex simultaneously. Instead, addition exercise and strength training are needed to reduce the risk of rotator cuff and other wheelchair related injuries $^{3}$. The new mechanism operates on a push/pull motion. Power is provided during the entire stroke, and not just in one direction. This should lead to a more desired symmetric muscle development. This would eliminate problems that are associated with only developing one set of muscles. In addition, this mechanism may be able to reduce the injuries that occur from harsh accelerations of the shoulder, elbow, and 
hands. From the past research presented in the literature review section of the report, it can be seen that the best stroke pattern for wheelchair users was found to be the semi-circular (SC) stroke ${ }^{5}$. It would be ideal if the new mechanism had the handle path of an ellipse. This new innovative mechanism travels recreates the SC stroke pattern. An additional advantage could be a decrease in acceleration and a smaller flexion/extension and shoulder abduction/adduction acceleration ${ }^{5}$. These advantages coupled with the fact that the mechanism propels the wheelchair during its entire elliptical travel path should give the user a more symmetric muscle development. It was hypothesized that the new mechanism being proposed will relieve the burden of using the smaller muscles that are injury-prone, and place more emphasis on the larger muscle groups that have the ability to sustain more effort without injury.

\subsection{Proposed Design}

This new mechanism employs a lever-actuated elliptical input motion and a Cardan gear system that changes the elliptical input into rotary output. The new mechanism will not be easily understood until the Cardan gear system is explained.

\subsection{Cardan Gear System}

A Cardan gear mechanism is a hypocycloidal gear train that is used to convert rotation (circular motion) into straight-line motion. A hypocycloidal curve is generated when one circle (gear) is rolled along the inside of another circle (gear). Whenever the ratio of the diameters of the gears is 1:2 the output arm will translate the rotation to a linear path. The following figure gives an illustration of a true Cardan Gearing System. 


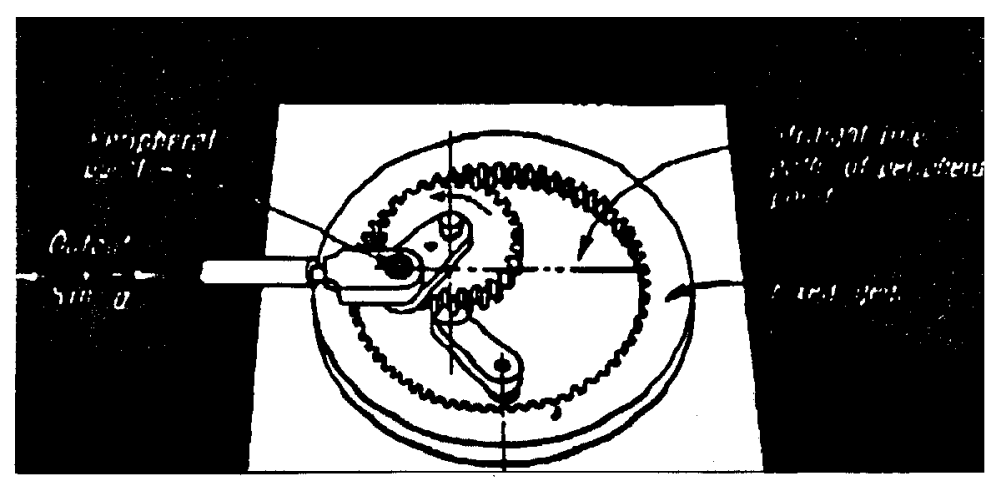

Figure 9- Cardan Gearing System

One of the basic design criteria for most manual wheelchair manufacturing is to minimize the equipment weight. The Cardan system can be made lighter by excluding the use of an outside internal gear. The use of internal gearing added complexity and weight to the design that was needed to power a wheelchair. In the proposed mechanism, the use of an internal gear can be neglected by inserting an idler gear in between the inner fixed spur gear (sun) and the smaller outside spur gear (planet). Figure 10 gives an example of this new configuration.

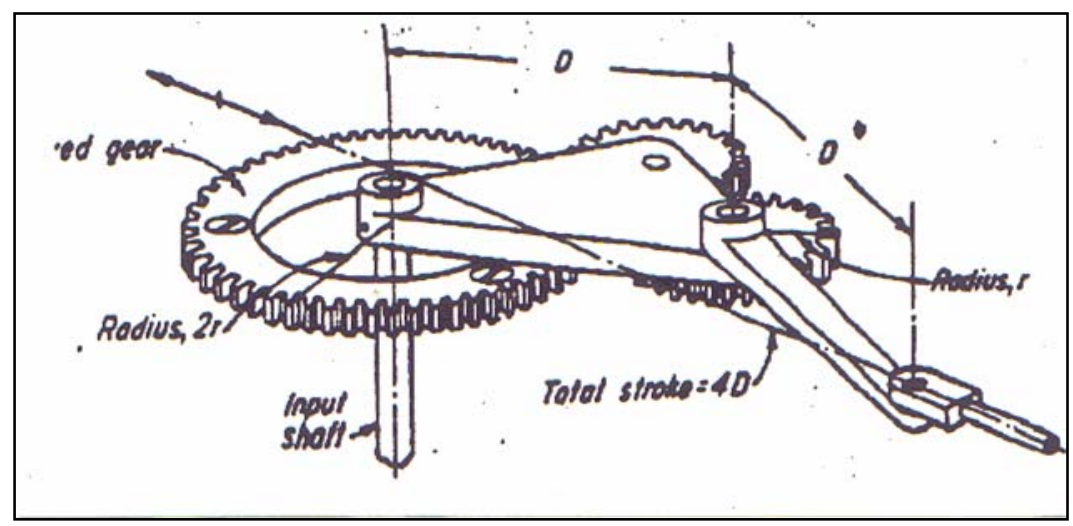

Figure 10 - Cardan Gearing Without Internal Gear 
In Figure 10, it can be seen that only standard spur gears are needed, and that the entire design has been reduced in complexity. The only requirement was that the fixed gear and the outermost gear must be in the 1:2 ratio. The idler gear (middle gear) does not add to the mechanical advantage of the mechanism. The idler gear was used to change direction of rotation of the planet gear. As long as the outer arm and the inner arm are the same length, the output motion will be linear. If the length of either arm is changed with respect to the other, eccentricity can be added to the gear system and the path will be elliptical. In the proposed mechanism, these lengths were changed and an elliptical path recreating the SC motion was obtained.

To further simplify the mechanism and reduce its weight, one change was needed. The idler gear was removed and replaced with a roller chain connecting the sun and planetary gears. The spur gears were replaced with roller chain sprockets. The following figure gives an example of the current system that is being used for wheelchair propulsion. 


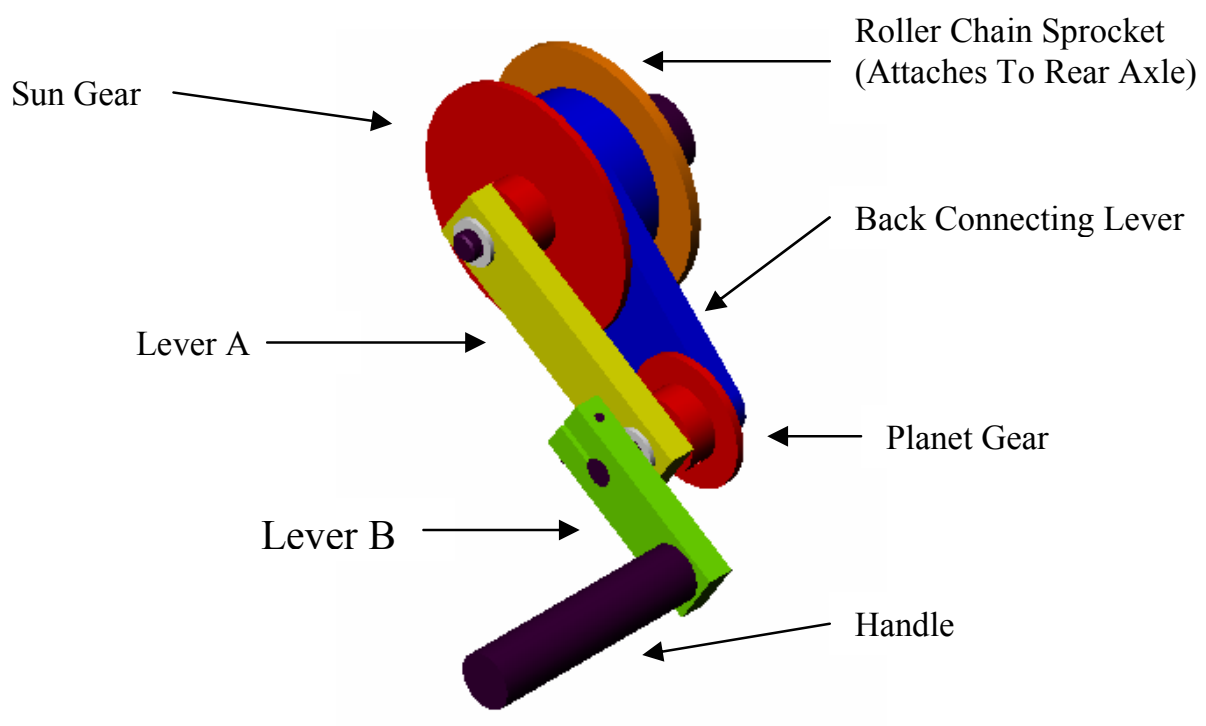

Figure 11 - Simplified Cardan System With Eccentricity

Whenever the user propels the handle, the planet gear turns about the sun gear. The back connecting lever in turn also rotates around the sun gear. A roller chain sprocket was attached to the back connecting lever. The roller chain sprocket on the back connecting lever was connected to a roller chain sprocket on the axle of the rear wheel through a roller chain. So, as the back connecting lever rotates around the sun gear, the wheelchair is propelled in a forward or backward motion. It can be seen that the simplified Cardan gear system is a compact mechanism that produces the desired elliptical output. This discussion of the Cardan gear system gives a general description of the innovative mechanism used to power the wheelchair. A detail discussion of the parameters for each of the components of the new innovative mechanism will be given later. The innovative mechanism must be fitted into a standard wheelchair. This thesis will continue with a discussion of how the mechanism can be retrofitted into an existing wheelchair frame. 


\subsection{Adapting the Innovative Mechanism to a Wheelchair Frame}

A sprocket was attached to the innovative mechanism that was then mounted on a shaft on the side of the wheelchair. The inside sprocket on the innovative mechanism was attached to a sprocket on the axle of the wheelchair by a roller chain. A figure of the entire drive system without the driving chains can be found in Figure 12.

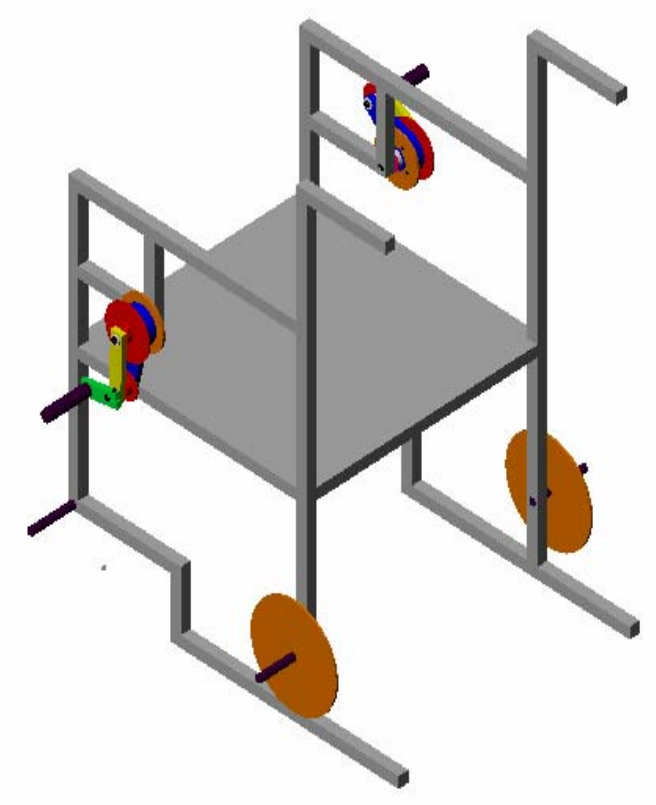

Figure 12 - Wheelchair View With Mechanism and Sprockets

The front and back wheels have been eliminated from the model for ease of visualization. The inside sprocket of the mechanism on the front of the wheelchair attaches to the sprocket shown on the rear axle of the wheelchair by a driving chain (not shown). As stated earlier the handle of the innovative mechanism follows an elliptical path of travel. The following figure gives an example of the elliptical path of the mechanism handle. 


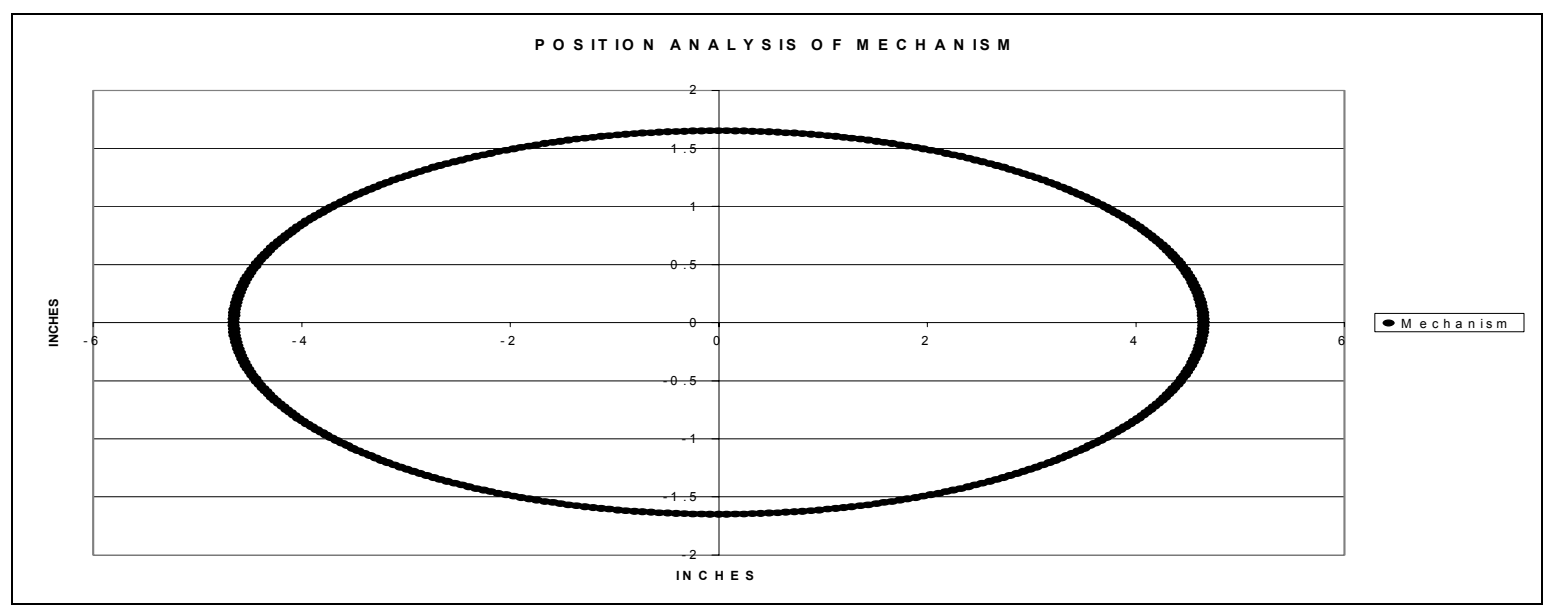

Figure 13 - Example of Elliptical Path of Mechanism Handle

The elliptical path of the handle was designed to serve the same function as the SC stroke pattern does for wheelchair users. In addition, the initial starting angle (major axis of orientation of the elliptical path) of the mechanism handle can be adjusted so that it can be initially set at any angular displacement along the inner radius. Thus its parameters can be customized to the user. The following two figures are used to demonstrate this feature.

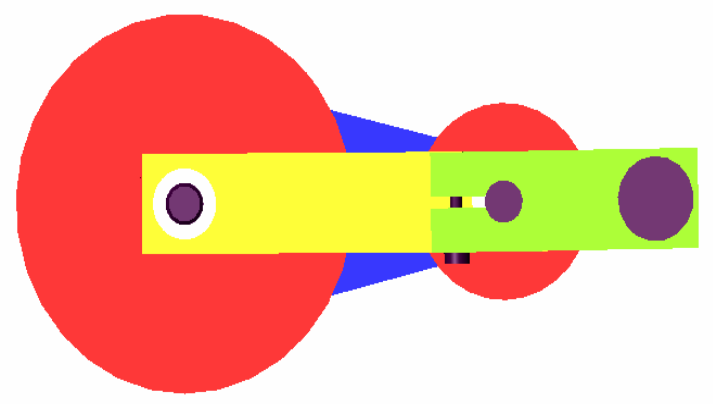

Figure 14 - Mechanism Position 0 Degrees Offset 


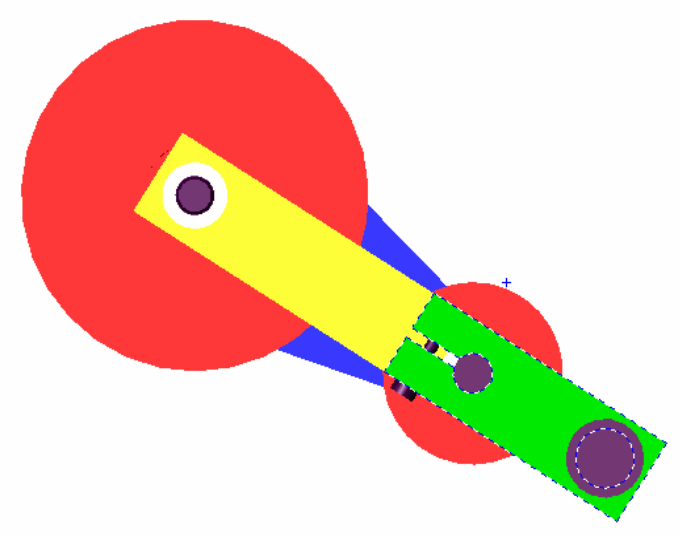

Figure 15 - Mechanism Position 45 Degrees Offset

There are different initial angle positions that can be calculated for each

individual user. The initial angle at which the innovative mechanism is set allows for the torque curve for the mechanism to be adjusted. Results of the tests of this concept are presented in the analysis section.

\subsection{Parametric Design Criteria of the Components of the Innovative Propulsion system}

\subsubsection{Gear Selection}

As it was discussed earlier, one of the requirements was to have the ratio between the sun and planetary gears to be $2: 1$. The following figure gives a view of how the various parts were defined. 


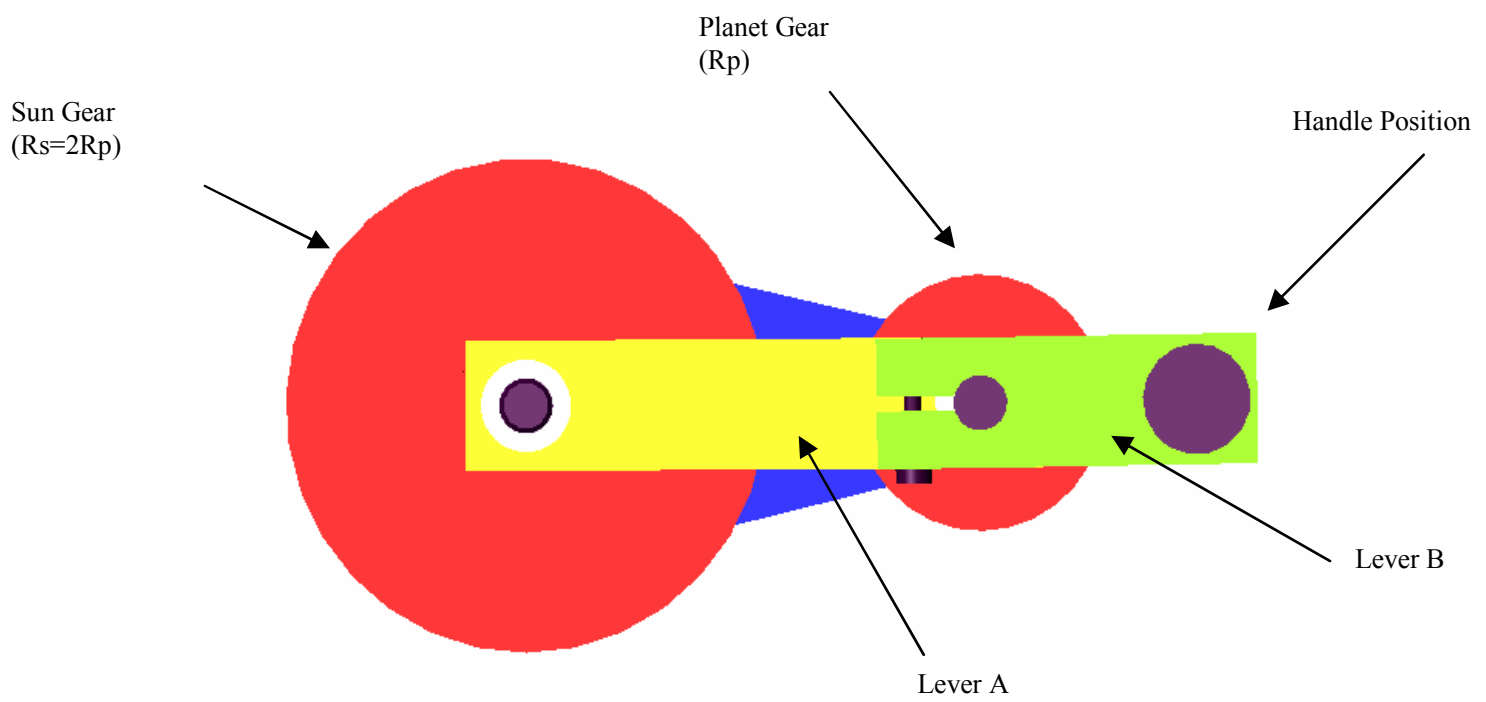

Figure 16- Labeling System for Gear Selection

As seen in Figure 16, only two sprockets are used to create the elliptical handle motion.

The sun and planet gear must be in a 2:1 ratio. In addition, for a true linear motion Lever A and Lever B would have to be the same length. But, for this application, elliptical motion was achieved by making Lever B shorter than Lever A. The actual dimensional drawings of the gears can be found in Appendix A.

\subsubsection{Roller Chair Selection}

The planet gear and the sun gear on the innovative mechanism were connected using a roller chain. In addition, the inside sprocket on the mechanism and the sprocket on the axle of the wheelchair were connected using a roller chain. The equation that was used to find the proper length of the length roller chain is given below.

$$
\mathrm{L} / \mathrm{P}=2 \mathrm{C} / \mathrm{P}+\left(\mathrm{N}_{1}+\mathrm{N}_{2}\right) / 2+\left(\mathrm{N}_{1}-\mathrm{N}_{2}\right)^{2} /\left(4 \pi^{2}(\mathrm{C} / \mathrm{P})\right) \quad \text { Equation } \mathbf{1}^{15}
$$

Where $\mathrm{L}$ is the chain length, $\mathrm{P}$ is the chain pitch, $\mathrm{C}$ is the center distance between sprockets, $\mathrm{N}_{1}$ is the number of teeth on the small sprocket, and $\mathrm{N}_{2}$ is the number of teeth 
on the larger sprocket. The length of the roller chain is measured in inches, but can also be converted to pitches for chain selection. It is preferable to have an even number of pitches, or an offset link will be needed for the application ${ }^{15}$.

\subsubsection{Gear Arm Design}

The gear arm (Lever A) was designed to maintain the position of the plant gear with respect to the sun gear. In addition, Lever A must contain a bearing so that it can rotate about a shaft. The dimensions were selected based on basic stress and moment calculations. It is not within the scope of this thesis to carry out an entire force analysis of the innovative mechanism and size each component accordingly.

To allow Lever A to rotate on the given shaft, needle bearings were chosen. Needle bearings have a small outside diameter for a given inside diameter. This saves on radial space in the design of the arm.

Figure 17 shows the gear arm (Lever A). As you can see, the size of the lever was actually a function of the size of bearing that will be used.

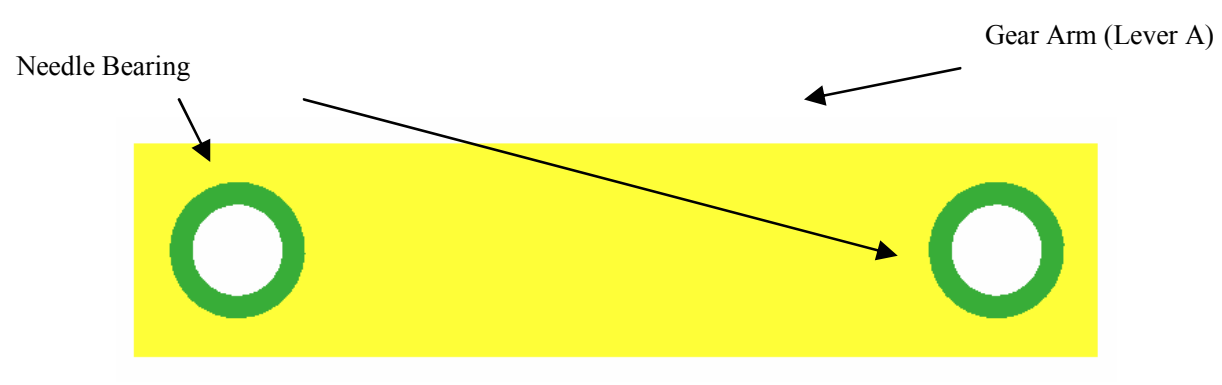

Figure 17 - Design of Gear Arm (Lever A) 


\subsubsection{Lever B Design}

The same design process was followed for Lever B as was followed for Lever A. Lever B needed to be attached to Lever A, and be able to rotate about Lever A, and be able to accommodate a handle attachment. Fixing Lever B to a shaft and allowing it to rotate with the planet gear accomplished the rotation of Lever B about Lever A. This in turn gave one rotation of Lever B for each rotation of the planet gear. Lever B was attached to the shaft through a gripping-type attachment. The screw was tightened until a secure fit was obtained between the shaft and Lever B. The handle was simply attached to Lever B by a threaded stud and nut. The handle contains its own rotational ability. The following figure gives an example of the Lever B, handle, and shaft assembly.

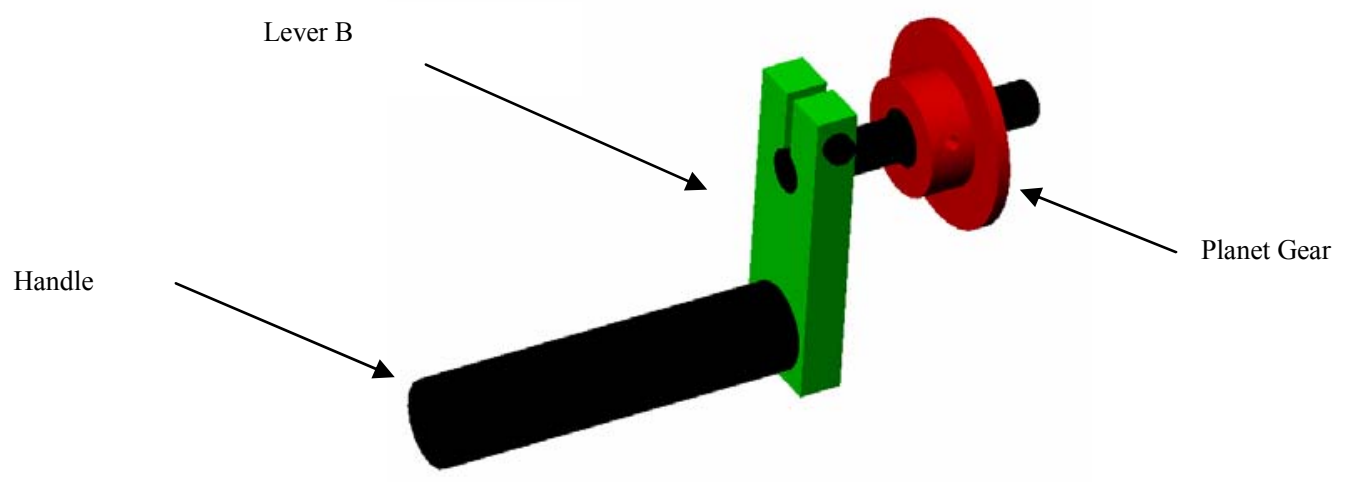

Figure 18 - Lever B, Handle, and Shaft Complex 


\subsubsection{Back Connecting Lever}

The final component of the mechanism developed was the back connecting lever. The back connecting lever was used to add strength to the mechanism so that a moment applied on the handle will not have to be loaded totally on Lever A. In addition, the back connecting lever has the roller chain sprocket attached to it that was also connected to the sprocket on the axle of the rear wheel by a roller chain. The following figure shows the back connecting lever complete with needle bearings.

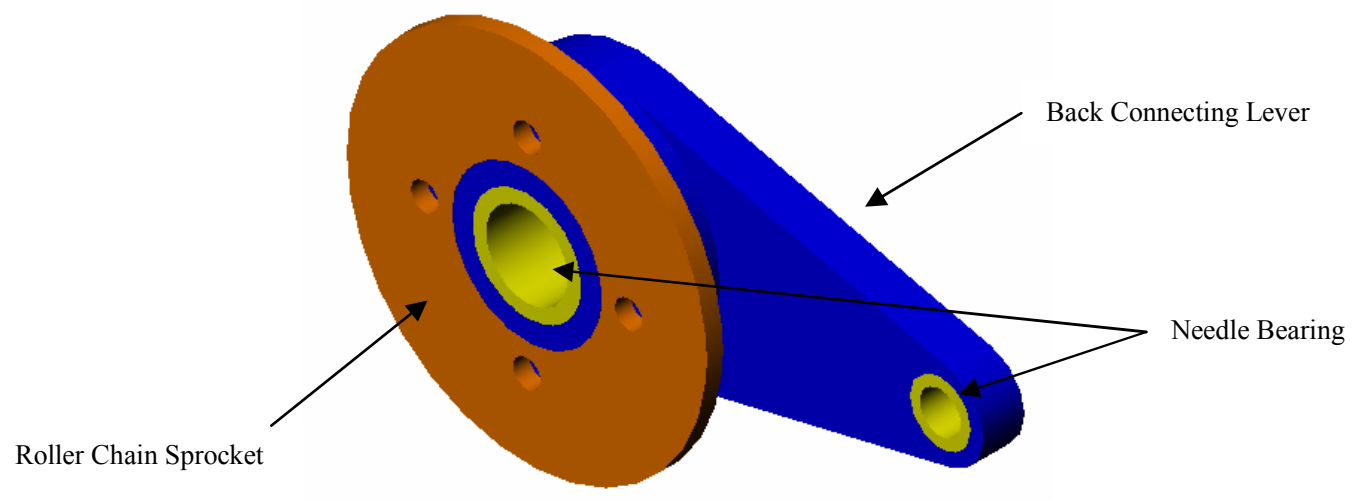

Figure 19 - Back Connecting Lever

\subsection{Innovative Mechanism Parameters}

Drawings of each of the above mentioned parts can be found in Appendix A. The following table gives a compilation of some of the important dimensions for various parts of the innovative mechanism. 
Table 2 - Compilation Table of Various Mechanism Parameters

\begin{tabular}{|lrc|}
\hline Length of Lever A & $=$ & $3.15 \mathrm{In}$ \\
\hline Length of Lever B & $=$ & $1.5 \mathrm{In}$ \\
\hline Length of Back Connecting Lever & $=$ & $3.15 \mathrm{In}$ \\
\hline Pitch of Planet Sprocket & $=$ & 12.5 teeth/in \\
\hline Pitch Diameter of Planet Sprocket & $=$ & 20 teeth \\
\hline Number of Teeth Planet Sprocket & $=$ & 14.43 inches \\
\hline Chain Length (Plant-Sun) & \\
\hline
\end{tabular}

\begin{tabular}{|lrc|}
\hline Pitch Sun Sprocket & $=$ & 12.6 teeth/in \\
\hline Pitch Diameter Sun Sprocket & $=$ & 3.187 in \\
\hline Number of Teeth Sun Sprocket & $=$ & 40 teeth \\
\hline Pitch Chair Connecting Sprocket & $=$ & 8.4 teeth/in \\
\hline Pitch Diameter Chair Connecting Sprocket & $=$ & 3.11 in \\
\hline Number of Teeth Chair Connecting Sprocket & $=$ & 26 teeth \\
\hline Chain Length (Chair - Axle) & $=$ & 59.19 inches \\
\hline
\end{tabular}

In addition, the following figure and table gives data about the elliptical path that the handle on the innovative mechanism follows.

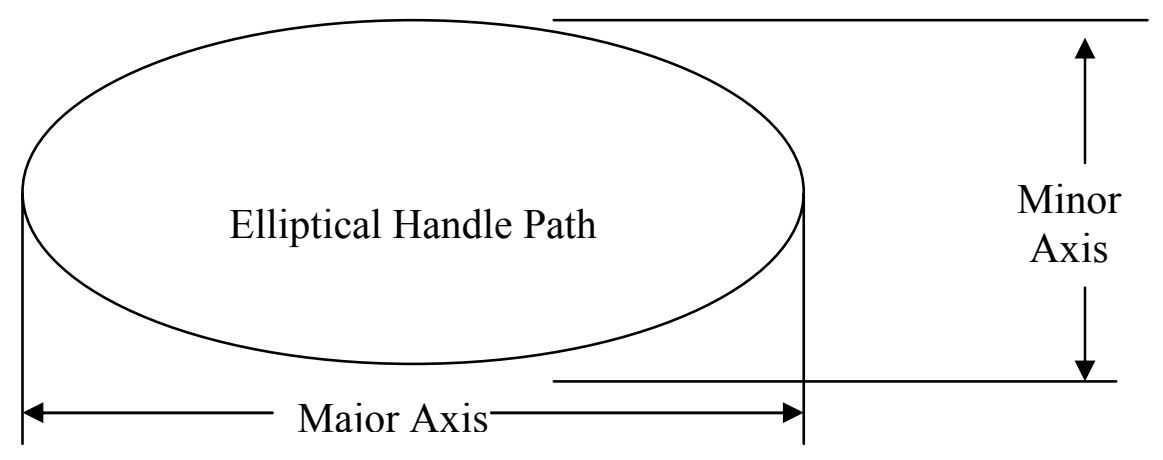

Figure 20 - Elliptical Path Labels 
Table 3 - Ellipse Compilation Data

\begin{tabular}{|lcr|}
\hline Major Axis (Stroke Length) & $=$ & 9.3 inches \\
\hline Minor Axis & $=$ & 3.3 inches \\
\hline Circumference & $=$ & 21.921 inches \\
\hline
\end{tabular}

\subsection{Mechanism Assembly}

Each of the entities described above were fit together to obtain the innovative mechanism. Figure 21 shows an exploded view of the entire mechanism complete with Teflon washers and bushings.

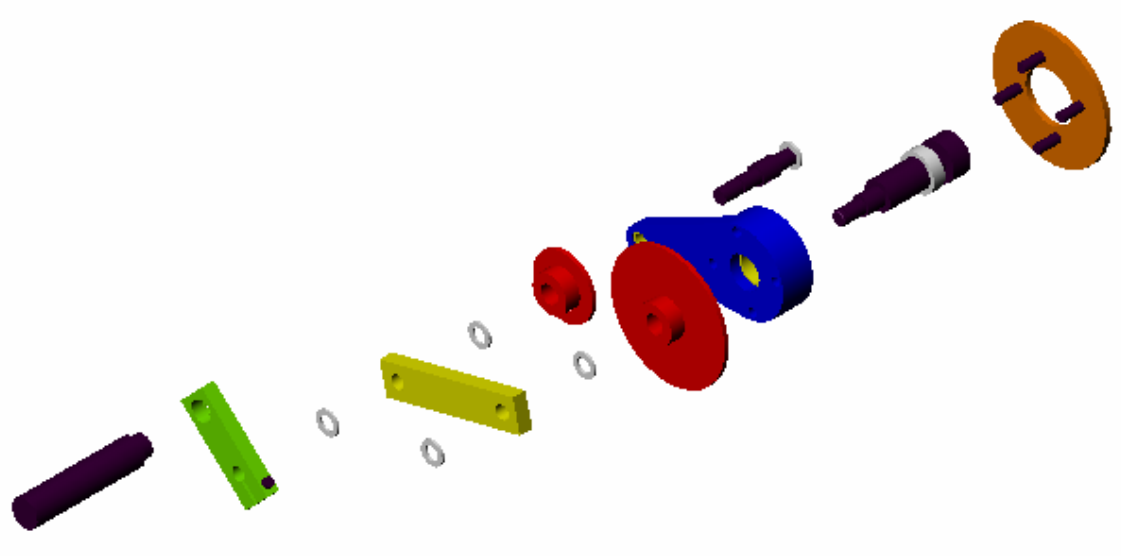

Figure 21 - Exploded View of Innovative Mechanism 


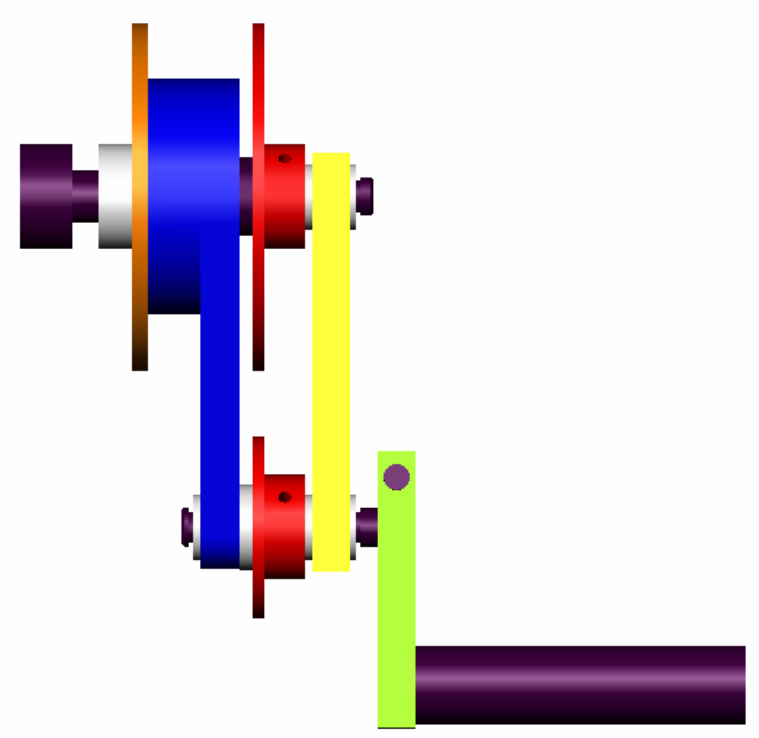

Figure 22 - Side View Of Innovative Mechanism

The stroke length for the innovative mechanism was found by measuring the distance that a person's hand travels in the propulsion phase of the wheelchair. This measurement was taken on members of the original Innovative Wheelchair Team. This distance was converted in the innovative mechanism to one complete stroke. The two strokes to one advantage results from the fact that the innovative mechanism gives propulsive force around the entire path of the ellipse. After the innovative mechanism was developed, the next step was to start analyzing the current mechanism. The first step in this process was to develop a program or spreadsheet that would allow the researcher to visualize the path of travel for the handle of the innovative mechanism.

\subsection{Visualization of Mechanism Handle Motion}

In order to visualize the movements and path that the handle of the mechanism will take, an Excel spreadsheet was formulated. The following figure shows the coordinates that will be used for the analysis. 


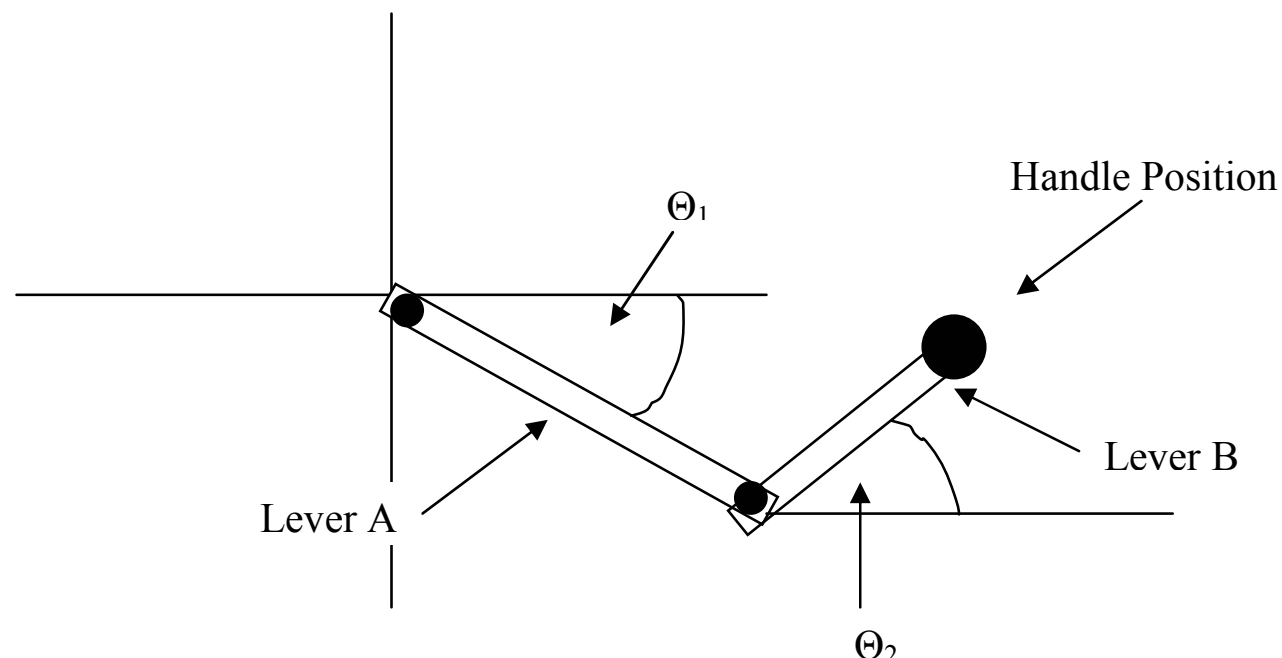

Figure 23 - Coordinate System Definition for Mechanism Position Analysis

From Figure 23, it can be seen that Lever A moves in a clockwise rotation, while Lever B rotates counterclockwise. The joint at the origin and the joint between the two levers were considered pin joints. These joints only allow rotation and not translation. The analysis was conducted by first calculating the position of Lever A, and then the Position of Lever B and adding the two positions together to get the final position of the handle. The following set of equations was used to find the position of the end of Lever A.

$$
\begin{aligned}
& \operatorname{LA}_{\mathbf{X}}=(\text { Length of Lever } A) * \operatorname{COS}\left(\theta_{1}\right) \quad \text { Equation } 2 \\
& \text { LA }_{\mathbf{Y}}=(\text { Length of Lever } \mathbf{A}) * \operatorname{SIN}\left(\theta_{1}\right) \quad \text { Equation } 3
\end{aligned}
$$

The position of Lever B was found in a similar manner to Lever A using the following relationship.

$$
\Theta_{2}=-\Theta_{1}
$$

Equation 4 
The above equation was used because the rotation of Lever B was in the opposite direction of the rotation of Lever A. One rotation of Lever A will equal one rotation of Lever B. The following equations were used to find the location of the end of Lever B.

$$
\begin{array}{lr}
L B_{X}=(\text { Length of Lever } B) * \operatorname{COS}\left(\theta_{2}\right) & \text { Equation } 5 \\
L B_{Y}=(\text { Length of Lever B }) * \operatorname{SIN}\left(\theta_{2}\right) & \text { Equation } 6
\end{array}
$$

The final position of the handle was found by using a moving coordinate system. The global coordinate system was placed at the origin, and a moving coordinate system was placed at the end of Lever A. With these conditions in place, the $\mathrm{X}$ and $\mathrm{Y}$ position of the handle could be found by simply adding the respective $\mathrm{X}$ and $\mathrm{Y}$ components of Equations 2,3,5, and 6. The following are equations that were used to figure the $\mathrm{X}$ and $\mathrm{Y}$ positions of the handle.

$$
\begin{array}{ll}
\mathrm{H}_{\mathrm{X}}=(\text { Length of Lever } \mathrm{A}) * \operatorname{COS}\left(\theta_{1}\right)+(\text { Length of Lever } \mathrm{B}) * \operatorname{COS}\left(\theta_{2}\right) & \text { Equation } 7 \\
\mathrm{H}_{\mathrm{Y}=}(\text { Length of LeverA }) * \operatorname{SIN}\left(\theta_{1}\right)+(\text { Length of Lever } \mathrm{B}) * \operatorname{SIN}\left(\theta_{2}\right) & \text { Equation } 8
\end{array}
$$

This spreadsheet gives a visual concept of the path of the mechanism. It also provided the researcher with a way of analyzing various handle motions of the mechanism. A torque analysis was incorporated into the Excel spreadsheet.

\subsection{Manufacturing of Prototype}

The spreadsheet was used to design the parameters that were incorporated into engineering drawings. These drawings were submitted to Laser Processing, our industrial partner, where components were $\mathrm{CNC}$ machined. The appropriate sprockets and roller chains were purchased from McMaster Carr Supply Company. A wheelchair was obtained from the Civil Engineering Department at WVU. Steel plates were welded 
to the side of the wheelchair to support the mechanism, and the appropriate diameter sprockets were welded to the rear wheel axles. The assembled mechanism was fitted into the side plates on the frame, and the driving gears were connected via roller chain.

A testing platform on which a mock-up of a standard wheelchair could be mounted was designed and manufactured in the MAE shop. An X-Y table was purchased from McMaster Carr and mounted to the testing platform. A dynamometer, purchased from Magtrol, was mounted on the X-Y table were it could be adjusted to proper tension. With this work completed, the researcher could develop an experimental design and protocol to compare the effectiveness of the new innovative mechanism and the standard manual wheelchair.

\section{Experimental Setup}

After the basic idea for the innovative mechanism was conceived, a prototype of the mechanism was developed. The goal of the research project then shifted to finding a way to test the new innovative mechanism against a standard manually powered wheelchair. The researcher established the following criteria to be met by the testing apparatus:

$>$ The testing station had to be portable.

Be able to simulate actual wheelchair use.

The researcher had to be able to change the testing procedures between standard wheelchair wheels, and innovative mechanism sprockets.

The first consideration that was analyzed was a source from which a load could be 
applied to the wheelchair test subjects. A number of different ways of applying loads were considered. The researcher looked at applying a load with a friction style brake, such as the friction load system of a stationary exercise bicycle. This method of applying a load was simple, but there was not a simple way to get a reading on the amount of load that was being applied to the wheelchair test subjects. The researcher settled on a dynamometer system to apply the load. A dynamometer is a device that allows for a load to be applied as a torque on a shaft. The idea of using dynamometers was not new. For years, many members of the innovative wheelchair team have worked with engine testing dynamometers.

Before any final design was settled on, the researcher looked at many other research projects that involved wheelchair testing to get ideas on how to design the dynamometer testing station. Many of the research projects that were analyzed used a SMART $^{\text {Wheel } 5}$ wheel design. The SMART ${ }^{\text {Wheel }}$ measures the amount and direction of force the user applies to a given wheelchair wheel. Since this design consists of an innovative mechanism, the SMART ${ }^{\text {Wheel }}$ design will not meet the needs of this testing. In addition, a way of applying a load would still be needed with the SMART ${ }^{\text {Wheel }}$ approach. The next step was to look at other dynamometer testing stations. The University of Pittsburgh has done work in the past using wheelchair testing techniques. But, all of the testing machines that were found in the literature reviewed by the researcher from the University of Pittsburgh used a drum system that allowed the wheels of the wheelchair to turn on a drum. This type of testing apparatus is very useful but was beyond the scope of this preliminary research. The researcher was looking for a procedure for collecting data to evaluate the innovative mechanism. 
After reviewing several other research designs, the researcher concluded that a replica of a standard wheelchair would be fabricated and attached to a solid base. The dynamometer would be mounted behind the wheelchair and attached to a solid shaft by a belt drive. For engine testing purposes, a dynamometer is normally mounted on the side of the engine and the load is directly applied to a shaft on the motor. But, for this application, the load applied was small in comparison to normal motor testing loads, and the angular velocities (RPM's) of the wheels would not be large enough to create a significant error. The following two figures provide a view of the total dynamometer setup.

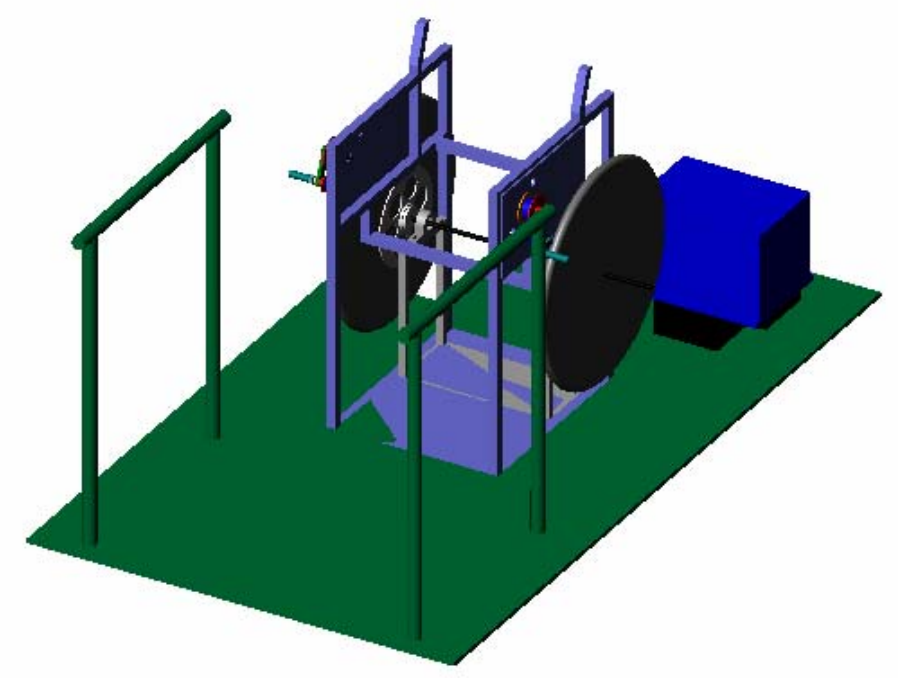

Figure 24 - Isometric View of Dynamometer Setup 


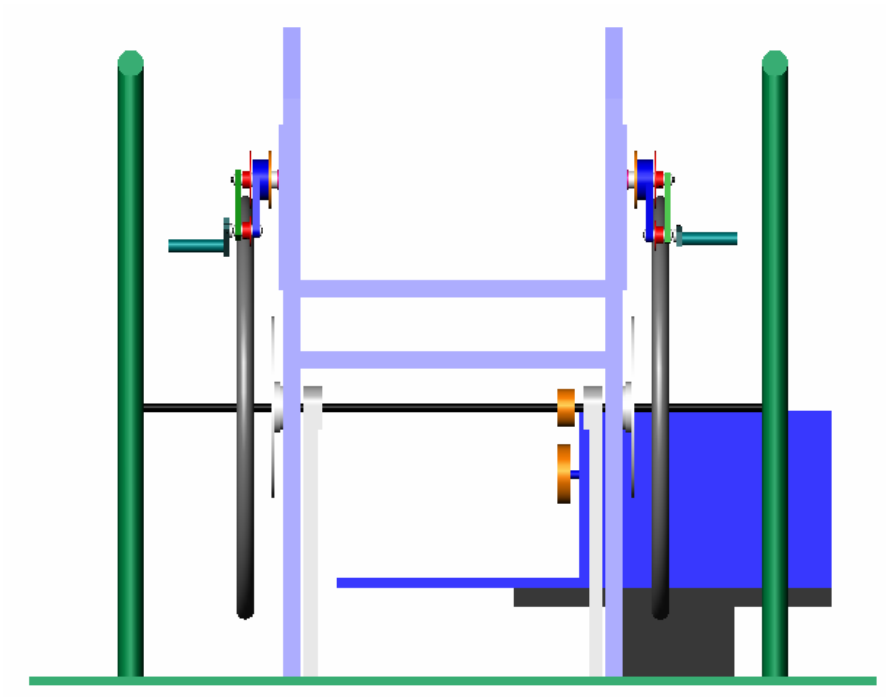

Figure 25 - Rear View of Dynamometer Setup

Figure 24 and Figure 25 show that a timing belt was fitted across the pulley on the dynamometer and the pulley on the shaft connecting the wheels. The wheelchair wheels are attached together through a solid axle system. The solid axle system does not allow for independent rotation of the wheels. This design was selected because it was difficult to attach a dynamometer to evaluate the power from two independent wheels. The following sections will explain the various features and parts of the dynamometer testing apparatus. Figure 145 is contained in Appendix $\mathrm{C}$ and has the labels for all of the below mentioned features.

\subsection{Dynamometer}

Based on human design requirements, several dynamometer manufacturers were contacted. Upon talking to the sales and technical teams for each manufacturer, the Magtrol HD-705-6N dynamometer (Figure 26) was selected ${ }^{16}$. The following table gives an overview of the capabilities and requirements of the Magtrol dynamometer. 
Table 4 - Magtrol Dynamometer Requirements

\begin{tabular}{|lrc|}
\hline \multicolumn{2}{|c|}{ Magtrol HD-705-6N Dynamometer } \\
\hline Maximum Torque Range & $=$ & $50 \mathrm{lb}^{*}$ in \\
\hline Digital Torque Resolution & $=$ & $0.1 \mathrm{lb}^{*}$ in \\
\hline Maximum Power Rating (5 Minutes) & $=$ & 1400 Watts \\
\hline Maximum Power Rating (Continuous) & $=$ & 300 Watts \\
\hline Maximum Speed & $=$ & Convection \\
\hline Brake Cooling Method & $=$ \\
\hline
\end{tabular}

From inspection of Table 4, it can be seen that our application will never reach the maximum angular speeds that are allowed by the dynamometer. The real application of this dynamometer is for testing small electric motors. The level of control that can be obtained with this dynamometer will probably never be used for this project. This dynamometer has the capabilities of being able to test our subjects, with both the innovative mechanisms and the standard wheelchair wheels, and show preliminary data on the conception of the mechanism.

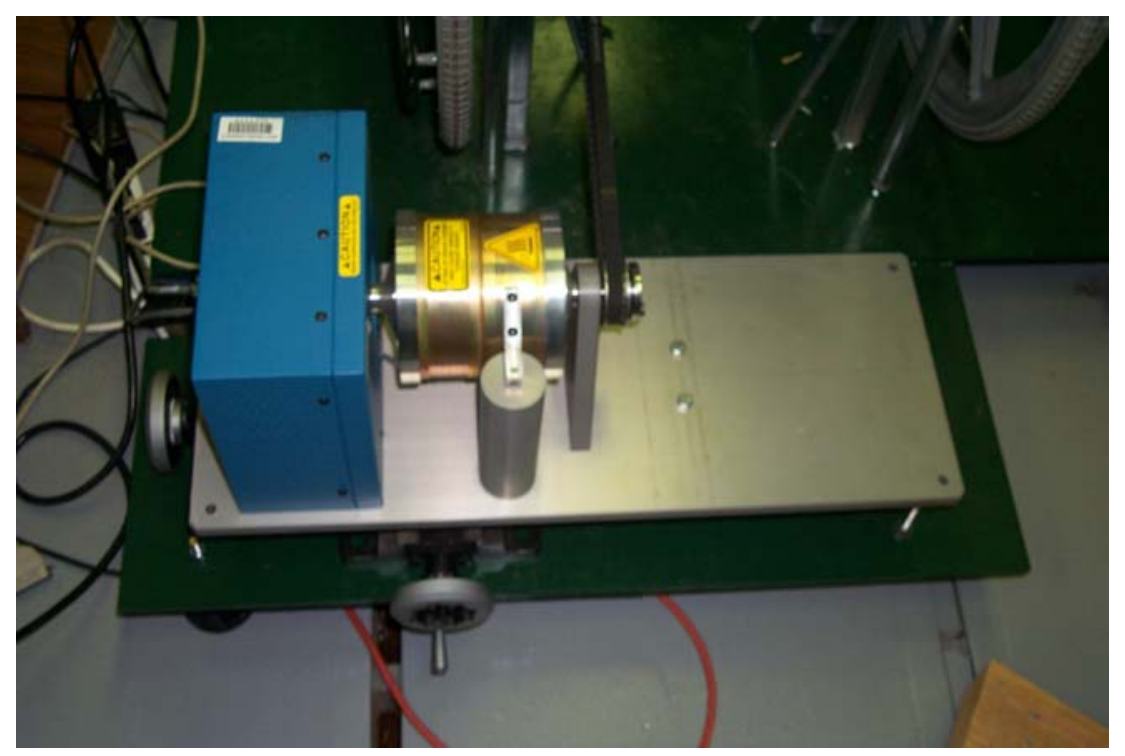

Figure 26 - Picture of Magtrol Dynamometer 


\subsection{Dynamometer Controller}

The controller that was selected for this application was a DSP6000 from Magtrol (Figure 27). This controller allowed for full control over the torque loading of the dynamometer, and it allowed for a computer to be used to collect the needed output data.

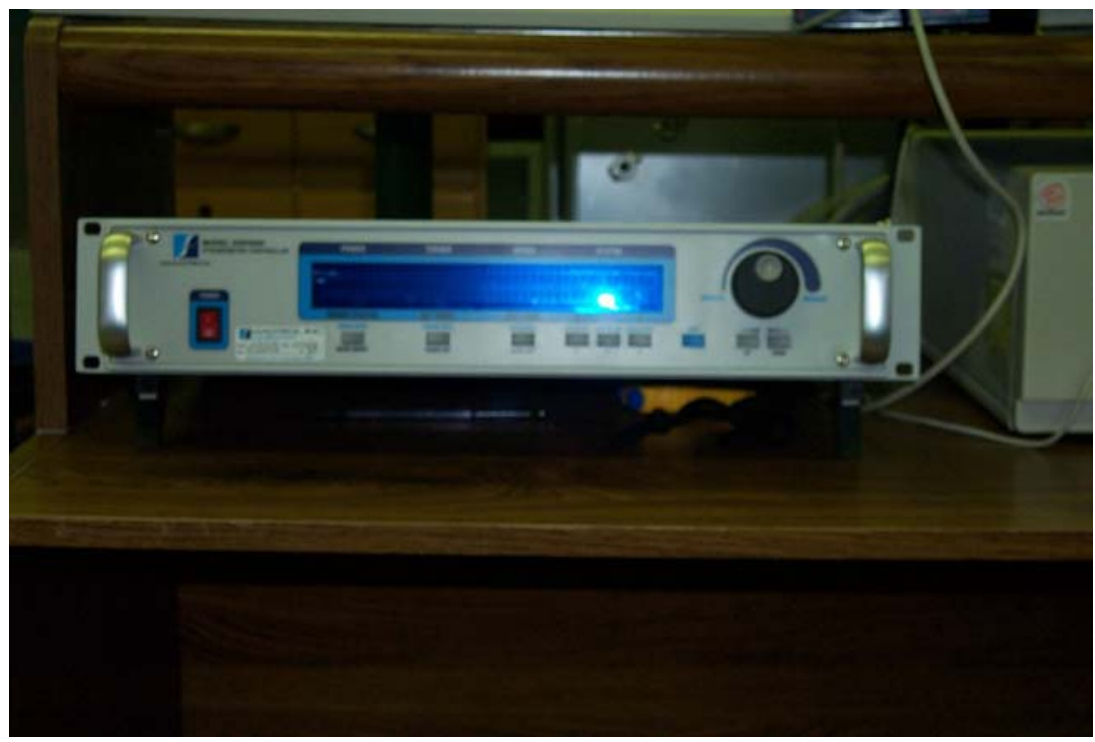

Figure 27 - Magtrol DSP6000 Controller

\subsection{Rear Axle}

Upon first inspection, the rear axle of the dynamometer testing station may not seem important, but that is not true. The amount of stress that was being applied to the shaft was of concern because if the user applies too much stress, the shaft will fail, and injury to the user could result. In addition, the deflection of the shaft had to be controlled because too much deflection at the dynamometer connection could lead to inaccurate or false data. The following section will outline the design process that was employed for the rear axle. 
For the analysis of the rear axle, a series of singularity functions were formulated for the axle using the innovative mechanism, and another set for the standard wheelchair wheels. Whenever the innovative mechanisms were in use, the standard wheelchair wheels will be taken off of the testing apparatus. In addition, the sprockets for the innovative mechanism were taken off for testing with the standard wheelchair wheels. The singularity functions for the standard wheelchair wheels will be presented first.

\subsubsection{Singularity Function - Standard Wheels}

The first step was to draw a free body diagram for the rear axle. The following two figures show free body diagrams for both the $\mathrm{X}$ and $\mathrm{Y}$ directions of the rear axle.

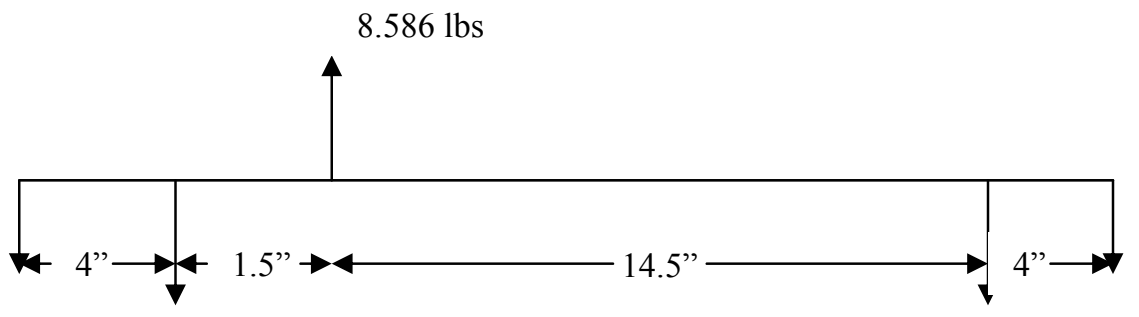




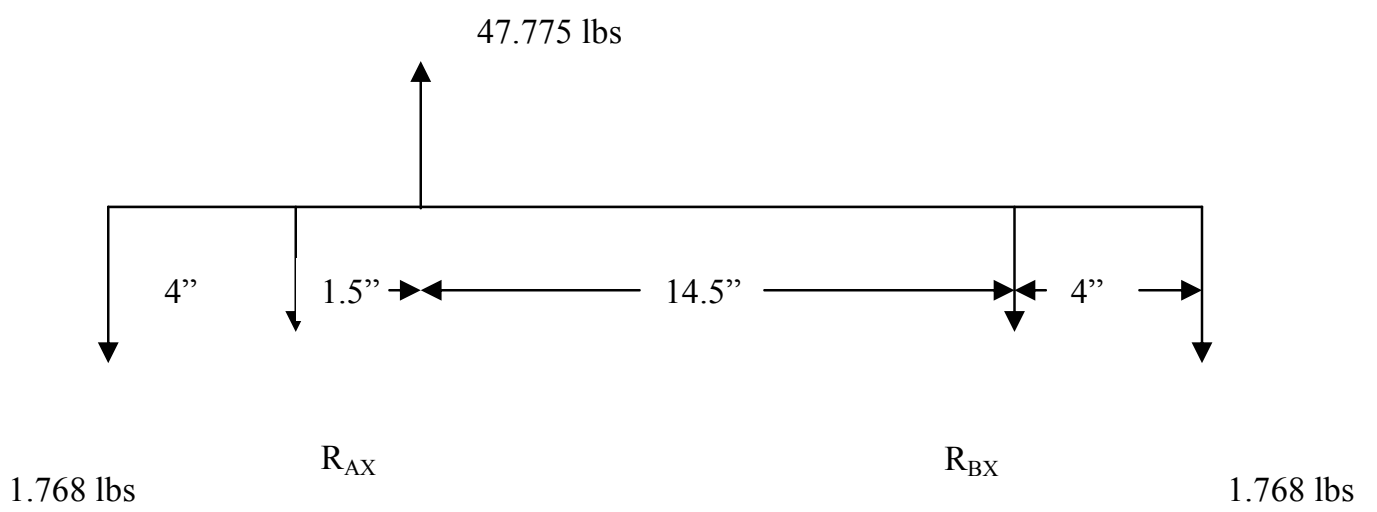

Figure 29 - X - Direction Free Body Diagram (Wheels)

Where $\mathrm{R}_{\mathrm{AX}}, \mathrm{R}_{\mathrm{AY}}, \mathrm{R}_{\mathrm{BX}}, \mathrm{R}_{\mathrm{BY}}$ are the support reactions for the rear axle which sets in pillow blocks. The $7.768 \mathrm{lb}$ and $1.768 \mathrm{lb}$ in the preceding figures are the amount of hand force that the user must apply to the wheel to reach the dynamometer maximum load of 50 in*lbs. The $8.585 \mathrm{lbs}$ and the $47.775 \mathrm{lbs}$ are the component forces for the dynamometer at a rated condition of 50 in*1bs.

The next step was to formulate the equations to solve for the reaction forces. These are seen below.

$$
\begin{array}{ll}
\Sigma M_{R A Y}=4(7.768)-1.5(8.580)+R_{B Y} * 16-20(7.768)=0 & \text { Equation } 9 \\
\Sigma F_{Y}=0=-7.768+R_{A Y}-8.586+R_{B Y}-7.768 & \text { Equation 10 } \\
\Sigma M_{R A X}=0=4(1.768)+1.5\left(47.775-16\left(R_{B X}\right)-20(1.768)\right. & \text { Equation } 11 \\
\Sigma F_{Y}=0=-1.768-R_{A X}+47.775-R_{B X}-1.768 & \text { Equation } 12
\end{array}
$$

The following set of results was obtained for the reaction in the previous equations.

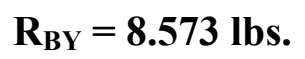




$$
\begin{aligned}
& R_{\mathrm{AY}}=15.549 \mathrm{lbs} . \\
& \mathbf{R}_{\mathrm{BX}}=2.7115 \mathrm{lbs} . \\
& \mathbf{R}_{\mathrm{AX}}=41.528 \mathrm{lbs} .
\end{aligned}
$$

Next, the shear and moment diagrams were drawn for the $\mathrm{X}$ and $\mathrm{Y}$ directions. The following figures contain the given shear and moment diagrams for the $\mathrm{X}$ and $\mathrm{Y}$ directions.

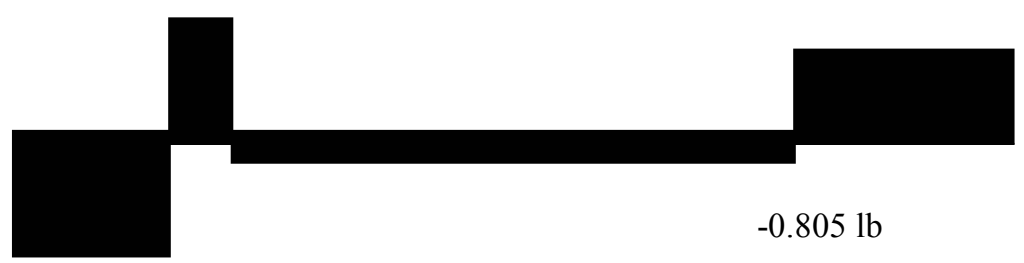

$-7.768 \mathrm{lb}$

Figure 30 - Y-Direction Shear Diagram For Wheels

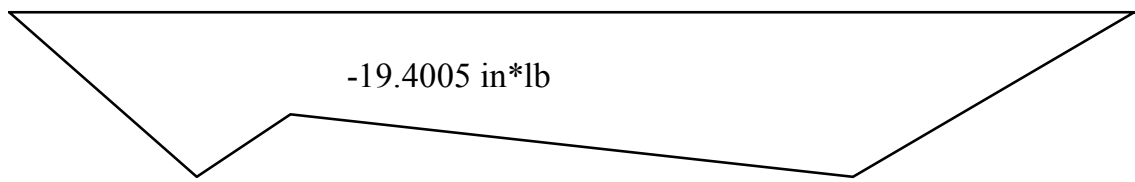

$-31.072 \mathrm{in} * \mathrm{lb}$

$-31.072 \mathrm{in} * \mathrm{lb}$

Figure 31 - Y-Direction Moment Diagram For Wheels 


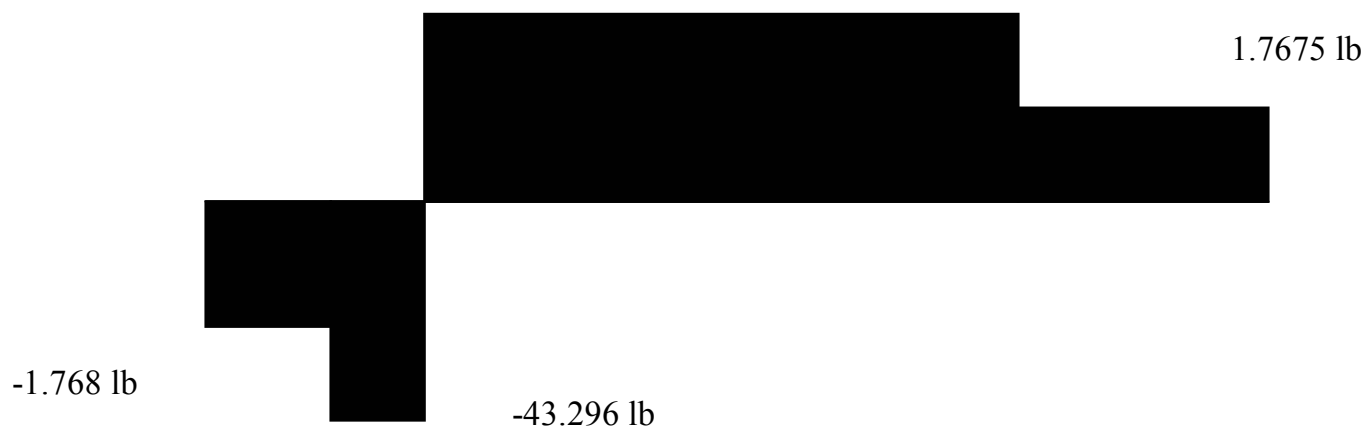

Figure 32 - X-Direction Shear Diagram for Wheels

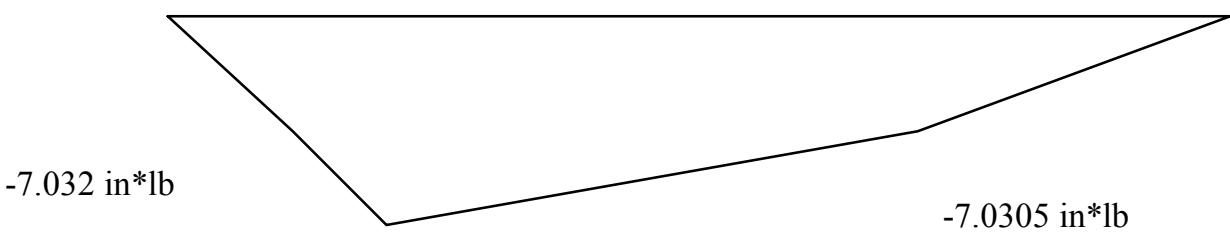

$-71.976 \mathrm{in} * \mathrm{lb}$

Figure 33 - Y-Direction Moment Diagram For Wheels

The shear and moment diagrams were then used to set the boundary conditions for the singularity functions. The following equations contain the singularity functions for the condition with the wheelchair wheels in use in the $\mathrm{X}$ direction.

$\mathbf{q}=-\mathrm{F}_{\mathrm{X}-\mathrm{ARM}}<\mathrm{X}>^{-1}-\mathbf{R}_{\mathrm{AX}}<\mathrm{X}-4>^{-1}+\mathbf{F}_{\mathrm{DYNO}}<\mathrm{X}-5.5>^{-1}-\mathbf{R}_{\mathrm{BX}}<\mathrm{X}-20>^{-1}-\mathbf{F}_{\mathrm{X}-\mathrm{ARM}}<\mathrm{X}-24>^{-1} \quad$ Equation 13

$\mathrm{V}=-\mathrm{F}_{\mathrm{X}-\mathrm{ARM}}<\mathrm{X}>^{0}-\mathrm{R}_{\mathrm{AX}}<\mathrm{X}-4>^{0}+\mathrm{F}_{\mathrm{DYNO}}<\mathrm{X}-5.5>^{0}-\mathrm{R}_{\mathrm{BX}}<\mathrm{X}-20>^{0}-\mathrm{F}_{\mathrm{X}-\mathrm{ARM}}<\mathrm{X}-24>^{0}+\mathrm{C}_{1} \quad$ Equation 14

$M=-F_{X-A R M}<X>^{1}-R_{A X}<X-4>^{1}+F_{D Y N O}<x-5.5>^{1}-R_{B X}<X-20>^{1}-F_{X-A R M}<X-24>^{1}+C_{1}(x)+C_{2}$ Equation 15 
$\mathrm{EI \Theta}=-\mathrm{F}_{\mathrm{X}-\mathrm{ARM}} / 2<\mathrm{X}>^{2}-\mathrm{R}_{\mathrm{AX}} / 2<\mathrm{x}-4>^{2}+\mathrm{F}_{\mathrm{DYNO}} / 2<\mathrm{x}-5.5>^{2}-\mathrm{R}_{\mathrm{BX}} / 2<\mathrm{X}-20>^{2}-\mathrm{F}_{\mathrm{X}-\mathrm{ARM}} / 2<\mathrm{x}-24>^{2}+\mathrm{C}_{1} / 2\left(\mathrm{x}^{2}\right)+\mathrm{C}_{2}(\mathrm{x})+\mathrm{C}_{3} \quad$ Equation 16

$\mathrm{EIY}=-\mathrm{F}_{\mathrm{X}-\mathrm{ARM}} / 6<\mathrm{X}>^{3}-\mathrm{R}_{\mathrm{AX}} / 6<\mathrm{X}-4>^{3}+\mathrm{F}_{\mathrm{DYNO}} / 6<\mathrm{X}-5.5>^{3}-\mathrm{R}_{\mathrm{BX}} / 6<\mathrm{X}-20>^{3}-\mathrm{F}_{\mathrm{X}-\mathrm{ARM}} / 6<\mathrm{X}-24>^{3}+\mathrm{C}_{1} / 6\left(\mathrm{x}^{3}\right)+\mathrm{C}_{2} / 2\left(\mathrm{x}^{2}\right)+\mathrm{C}_{3}(\mathrm{x})+\mathrm{C}_{4}$ Equation 17

The following set of equations contains the singularity functions for the condition with the wheels in use in the $\mathrm{Y}$ direction.

$\mathrm{q}=-\mathrm{F}_{\mathrm{Y}-\mathrm{ARM}}<\mathrm{X}>^{-1}+\mathrm{R}_{\mathrm{AY}}<\mathrm{X}-4>^{-1}-\mathrm{F}_{\mathrm{DYNO}}<\mathrm{X}-5.5>^{-1}+\mathrm{R}_{\mathrm{BY}}<\mathrm{X}-20>^{-1}-\mathrm{F}_{\mathrm{Y}-\mathrm{ARM}}<\mathrm{X}-24>^{-1} \quad$ Equation 18

$\mathrm{V}=-\mathrm{F}_{\mathrm{Y}-\mathrm{ARM}}<\mathrm{X}>^{0}+\mathrm{R}_{\mathrm{AY}}<\mathrm{X}-4>^{0}-\mathrm{F}_{\mathrm{DYNO}}<\mathrm{x}-5.5>^{0}+\mathrm{R}_{\mathrm{BY}}<\mathrm{X}-20>^{0}-\mathrm{F}_{\mathrm{Y}-\mathrm{ARM}}<\mathrm{x}-24>^{0}+\mathrm{C}_{1} \quad$ Equation 19

$\mathrm{M}=-\mathrm{F}_{\mathrm{Y}-\mathrm{ARM}}<\mathrm{X}>^{1}+\mathrm{R}_{\mathrm{AY}}<\mathrm{X}-4>^{1}-\mathrm{F}_{\mathrm{DYNO}}<\mathrm{X}-5.5>^{1}+\mathrm{R}_{\mathrm{BY}}<\mathrm{X}-20>^{1}-\mathrm{F}_{\mathrm{Y}-\mathrm{ARM}}<\mathrm{X}-24>^{1}+\mathrm{C}_{1}(\mathrm{x})+\mathrm{C}_{2}$ Equation 20

$\mathrm{EI \Theta}=-\mathrm{F}_{\mathrm{Y}-\mathrm{ARM}} / 2<\mathrm{X}>^{2}+\mathrm{R}_{\mathrm{AY}} / 2<\mathrm{X}-4>^{2}-\mathrm{F}_{\mathrm{DYNO}} / 2<\mathrm{X}-5.5>^{2}+\mathrm{R}_{\mathrm{BY}} / 2<\mathrm{X}-20>^{2}-\mathrm{F}_{\mathrm{Y}-\mathrm{ARM}} / 2<\mathrm{X}-24>^{2}+\mathrm{C}_{1} / 2\left(\mathrm{x}^{2}\right)+\mathrm{C}_{2}(\mathrm{x})+\mathrm{C}_{3} \quad$ Equation 21

$\mathrm{EIY}=-\mathrm{F}_{\mathrm{Y}-\mathrm{ARM}} / 6<\mathrm{x}>^{3}+\mathrm{R}_{\mathrm{AY}} / 6<\mathrm{x}-4>^{3}-\mathrm{F}_{\mathrm{DYNO}} / 6<\mathrm{x}-5.5>^{3}+\mathrm{R}_{\mathrm{BY}} / 6<\mathrm{x}-20>^{3}-\mathrm{F}_{\mathrm{Y}-\mathrm{ARM}} / 6<\mathrm{x}-24>^{3}+\mathrm{C}_{1} / 6\left(\mathrm{x}^{3}\right)+\mathrm{C}_{2} / 2\left(\mathrm{x}^{2}\right)+\mathrm{C}_{3}(\mathrm{x})+\mathrm{C}_{4}$ Equation 22

Where $\mathrm{F}_{\mathrm{Y} \text {-ARM }}$ and $\mathrm{F}_{\mathrm{X} \text {-ARM }}$ are the $\mathrm{X}$ and $\mathrm{Y}$ components of the arm force exerted by the user to reach the rated dynamometer load, and $\mathrm{F}_{\mathrm{DYNO}}$ is the $\mathrm{X}$ and $\mathrm{Y}$ components of the dynamometer force whenever the dynamometer is at the rated load, while $\mathrm{C}_{1}$ through $\mathrm{C}_{4}$ are the constants of integration.

The results for the boundary conditions and the results for the constants of integration are presented in the following table. 
Table 5 - Results Of Boundary Conditions and Integration Constants

\begin{tabular}{|c|c|}
\hline With Wheel & With Wheel \\
\hline $\mathbf{R}_{\mathrm{AY}}(\mathrm{Ib})$ & $\mathbf{R}_{\mathrm{BY}}(\mathrm{Ib})$ \\
\hline 15.549 & 8.573 \\
\hline$R_{\text {Ax }}(\mathrm{Ib})$ & $R_{\mathrm{Bx}}(\mathrm{Ib})$ \\
\hline 41.528 & 2.711 \\
\hline Y-Direction & X-Direction \\
\hline at $x=3 V=-7.768$ & at $x=3 V=-1.768$ \\
\hline $\mathrm{C}_{1}$ & $\mathrm{c}_{1}$ \\
\hline-7.768 & -1.768 \\
\hline at $x=4 M=-31.072$ & at $x=4 M=-7.032$ \\
\hline $\mathrm{C}_{2}$ & $\mathrm{C}_{2}$ \\
\hline 0.0028 & 0.0391 \\
\hline $\mathrm{C}_{3}$ & $\mathrm{C}_{3}$ \\
\hline 1170.642 & 660.387 \\
\hline at $x=4 y=0$ & at $x=4 y=0$ \\
\hline $\mathrm{C}_{4}$ & $\mathbf{C}_{4}$ \\
\hline-9026.252592 & -6785.072814 \\
\hline
\end{tabular}

\subsubsection{Singularity Function - Roller Chain Sprockets}

The following section uses the singularity function approach for the condition with the innovative mechanisms and roller chain sprockets on the testing apparatus, and the wheels taken off. The first step was to draw a free body diagram for the rear axle. The following two figures show free body diagrams for both the $\mathrm{X}$ and $\mathrm{Y}$ directions on the rear axle. 
$47.775 \mathrm{lb}$

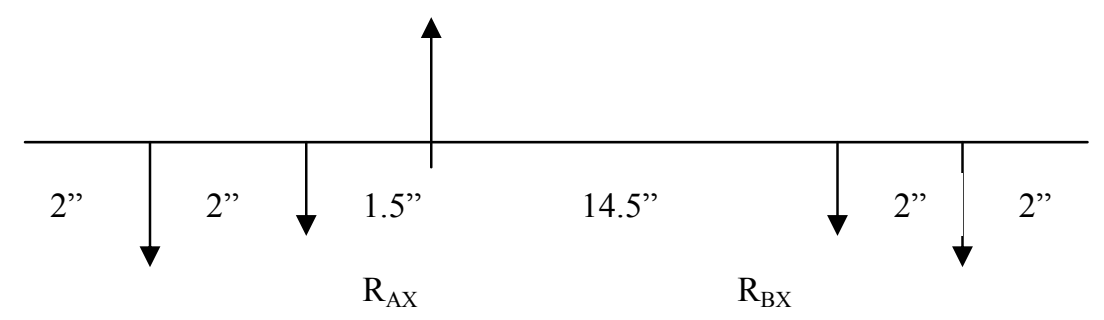

$3.581 \mathrm{lbs}$

$3.581 \mathrm{lb}$

Figure 34 - X - Direction Free Body Diagram (Sprocket)

$3.903 \mathrm{lb}$

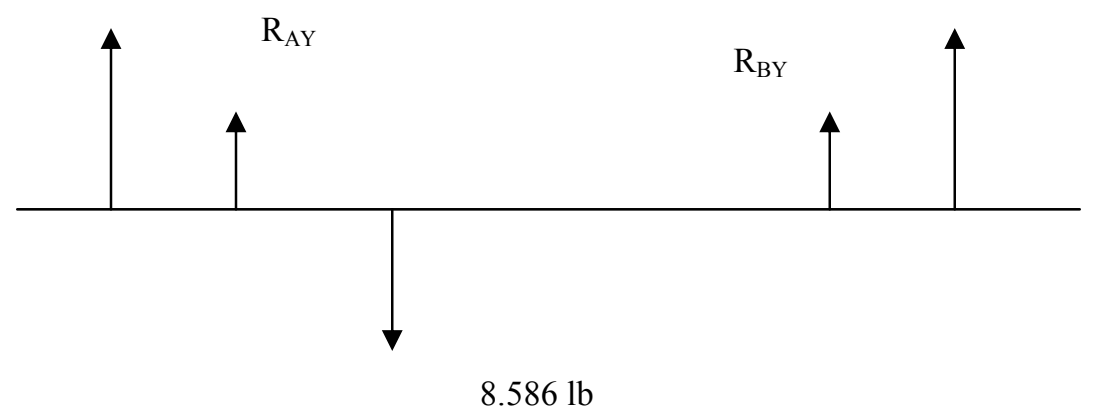

Figure 35 - Y - Direction Free Body Diagram (Sprocket)

Where $3.903 \mathrm{lbs}$ and $3.903 \mathrm{lbs}$ are the $\mathrm{X}$ and $\mathrm{Y}$ components of the arm force that was applied to the wheels at maximum torque. The forces were applied at 2 inches from the end of the shaft to obtain a tighter clearance with the side of the wheelchair apparatus.

The next step was to formulate the equations to solve for the reaction forces in the above equations. The following set of equations was used to solve for these reaction forces.

$$
\Sigma M_{R a x}=0=2(3.581)+1.5(47.775)+16 * R_{B X}-18(3.581)
$$

Equation 23 


$$
\begin{aligned}
& \Sigma F_{Y}=0=-3.581-3.581-R_{A X}-R_{B X}+47.775 \\
& \Sigma M_{A Y}=0=2(3.903)+8.586(1.5)-18(3.903)-16 * R_{B Y} \\
& \Sigma F_{Y}=0=3.903+R_{A Y}-8.586+R_{B Y}+3.903 \\
& R_{B Y}=\mathbf{- 3 . 0 9 8 ~ l b s .} \\
& \mathbf{R}_{\mathrm{AY}}=\mathbf{3 . 8 7 8 \mathrm { lbs } .} \\
& \mathbf{R}_{\mathrm{BX}}=\mathbf{0 . 8 9 7} \text { lbs. } \\
& \mathbf{R}_{\mathrm{AX}}=39.716 \mathrm{lbs} .
\end{aligned}
$$

The following set of results was obtained for the reaction in the previous equations.

Next, the shear and moment diagrams were drawn for the $\mathrm{X}$ and $\mathrm{Y}$ directions. The following figures contain the given shear and moment diagrams.

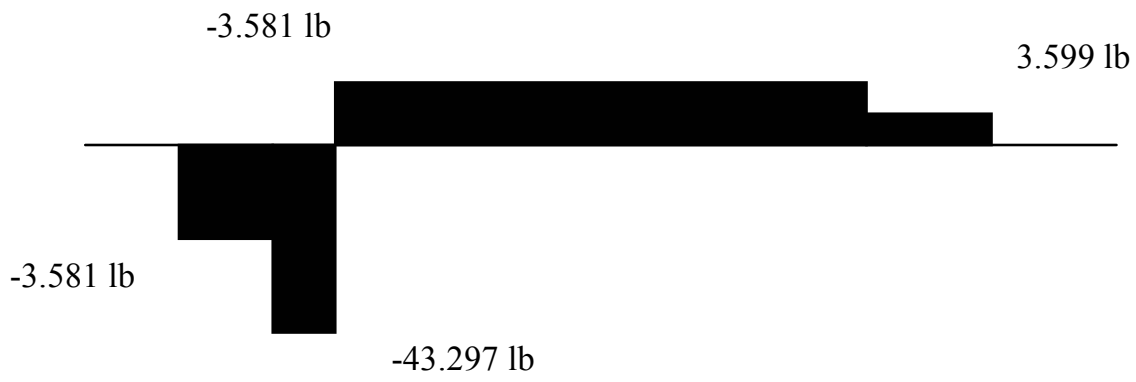

Figure 36 - X - Direction Shear Diagram (Sprockets) 


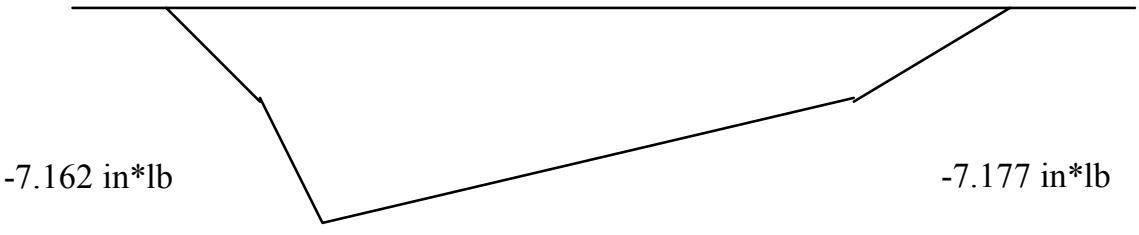

-72.1075 in*lb

Figure 37 - X - Direction Moment Diagram (Sprockets)

$7.781 \mathrm{lb}$

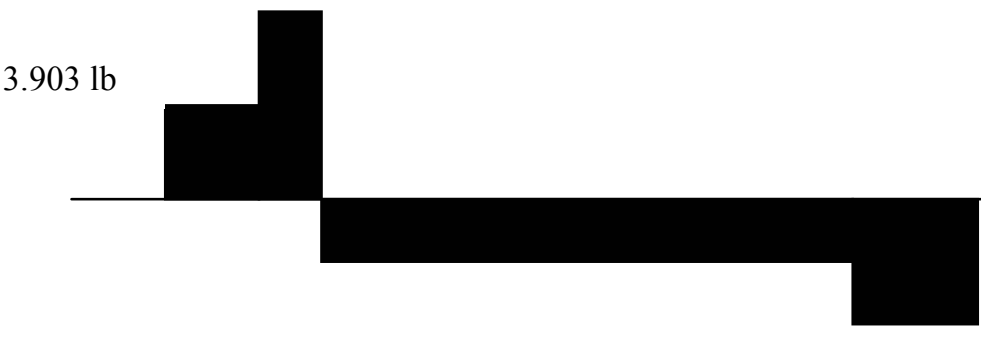

$-0.805 \mathrm{lb}$

$-3.903 \mathrm{lb}$

Figure 38 - Y - Direction Shear Diagram (Sprockets)

$19.4775 \mathrm{in} * \mathrm{lb}$

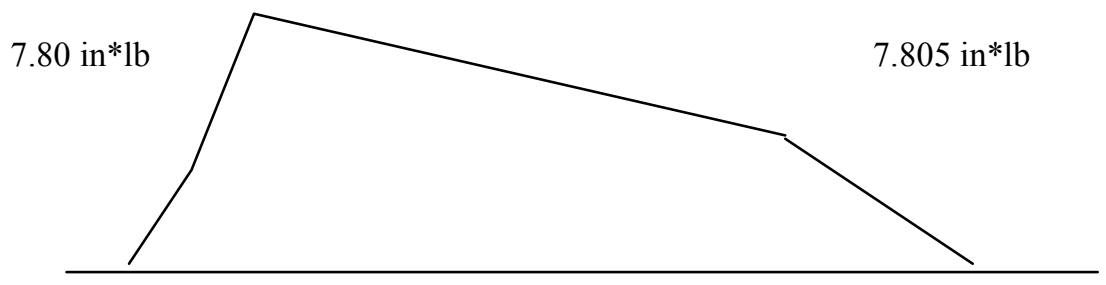

Figure 39 - Y - Direction Moment Diagram (Sprockets) 
The shear and moment diagrams were then used to set the boundary conditions for the singularity functions. The following equations contain the singularity functions for the condition with roller chain sprockets in use in the $\mathrm{X}$ direction.

$$
\begin{aligned}
& \mathrm{q}=-\mathrm{F}_{\mathrm{MX}}<\mathrm{X}-2>^{-1}-\mathrm{R}_{\mathrm{AX}}<\mathrm{X}-4>^{-1}+\mathrm{F}_{\mathrm{DX}}<\mathrm{X}-5.5>^{-1}-\mathrm{R}_{\mathrm{BX}}<\mathrm{X}-20>^{-1}-\mathrm{F}_{\mathrm{MX}}<\mathrm{X}-22>^{-1} \quad \text { Equation } 27 \\
& \mathrm{v}=-\mathrm{F}_{\mathrm{MX}}<\mathrm{X}-2>^{0}-\mathrm{R}_{\mathrm{AX}}<\mathrm{X}-4>^{0}+\mathrm{F}_{\mathrm{DX}}<\mathrm{X}-5.5>^{0}-\mathrm{R}_{\mathrm{BX}}<\mathrm{X}-20>^{0}-\mathrm{F}_{\mathrm{MX}}<\mathrm{X}-22>^{0}+\mathrm{C}_{1} \quad \text { Equation } 28 \\
& M=-F_{M X}<x-2>^{1}-R_{A X}<x-4>^{1}+F_{D X}<x-5.5>^{1}-R_{B X}<x-20>^{1}-F_{M X}<x-22>^{1}+C_{1}(x)+C_{2} \quad \text { Equation } 29 \\
& \mathrm{EI \Theta}=-\mathrm{F}_{\mathrm{MX}} / 2<\mathrm{X}-2>^{2}-\mathrm{R}_{\mathrm{AX}} / 2<\mathrm{X}-4>^{2}+\mathrm{F}_{\mathrm{DX}} / 2<\mathrm{X}-5.5>^{2}-\mathrm{R}_{\mathrm{BX}} / 2<\mathrm{X}-20>^{2}-\mathrm{F}_{\mathrm{MX}} / 2<\mathrm{X}-22>^{2}+\mathrm{C}_{1} / 2(\mathrm{x})^{2}+\mathrm{C}_{2}(\mathrm{x})+\mathrm{C}_{3} \quad \text { Equation } 30 \\
& \mathrm{EI \Theta}=-\mathrm{F}_{\mathrm{MX}} / 2<\mathrm{x}-2>^{3}-\mathrm{R}_{\mathrm{AX}} / 2<\mathrm{x}-4>^{3}+\mathrm{F}_{\mathrm{DX}} / 2<\mathrm{x}-5.5>^{3}-\mathrm{R}_{\mathrm{BX}} / 2<\mathrm{x}-20>^{3}-\mathrm{F}_{\mathrm{MX}} / 2<\mathrm{x}-22>^{3}+\mathrm{C}_{1} / 2(\mathrm{x})^{3}+\mathrm{C}_{2}\left(\mathrm{x}^{2}\right)+\mathrm{C}_{3}(\mathrm{x})+\mathrm{C}_{4} \quad \text { Equation } 31
\end{aligned}
$$

The following set of equations contains the singularity functions for the condition with roller chain sprockets in use in the $\mathrm{Y}$ direction.

$$
\begin{aligned}
& \mathbf{q}=\mathbf{F}_{\mathrm{MY}}<\mathrm{X}-2>^{-1}+\mathbf{R}_{\mathrm{AY}}<\mathrm{X}-4>^{-1}-\mathrm{F}_{\mathrm{DY}}<\mathrm{X}-5.5>^{-1}+\mathbf{R}_{\mathrm{BY}}<\mathrm{X}-20>^{-1}+\mathbf{F}_{\mathrm{MY}}<\mathrm{X}-22>^{-1} \quad \text { Equation } 32 \\
& \mathrm{v}=\mathrm{F}_{\mathrm{MY}}<\mathrm{X}-2>^{0}+\mathrm{R}_{\mathrm{AY}}<\mathrm{X}-4>^{0}-\mathrm{F}_{\mathrm{DY}}<\mathrm{X}-5.5>^{0}+\mathrm{R}_{\mathrm{BY}}<\mathrm{X}-20>^{0}+\mathrm{F}_{\mathrm{MY}}<\mathrm{X}-22>^{0}+\mathrm{C}_{1} \quad \text { Equation } 33 \\
& \mathrm{M}=\mathrm{F}_{\mathrm{MY}}<\mathrm{X}-2>^{1}+\mathrm{R}_{\mathrm{AY}}<\mathrm{X}-4>^{1}-\mathrm{F}_{\mathrm{DY}}<\mathrm{X}-5.5>^{1}+\mathrm{R}_{\mathrm{BY}}<\mathrm{X}-20>^{1}+\mathrm{F}_{\mathrm{MY}}<\mathrm{X}-22>^{1}+\mathrm{C}_{1}(\mathrm{x})+\mathrm{C}_{2} \quad \text { Equation } 34 \\
& \mathrm{EI} \Theta=\mathrm{F}_{\mathrm{MY}} / 2<\mathrm{X}-2>^{2}+\mathrm{R}_{\mathrm{AY}} / 2<\mathrm{X}-4>^{2}-\mathrm{F}_{\mathrm{DY}} / 2<\mathrm{X}-5.5>^{2}+\mathrm{R}_{\mathrm{BY}} / 2<\mathrm{X}-20>^{2}+\mathrm{F}_{\mathrm{MY}} / 2<\mathrm{X}-22>^{2}+\mathrm{C}_{1} / 2(\mathrm{x})^{2}+\mathrm{C}_{2}(\mathrm{x})+\mathrm{C}_{3} \quad \text { Equation } 35 \\
& \mathrm{EI} \Theta=\mathrm{F}_{\mathrm{MY}} / 6<\mathrm{X}-2>^{3}+\mathrm{R}_{\mathrm{AY}} / 6<\mathrm{X}-4>^{3}-\mathrm{F}_{\mathrm{DY}} / 6<\mathrm{x}-5.5>^{3}+\mathrm{R}_{\mathrm{BY}} / 6<\mathrm{X}-20>^{3}+\mathrm{F}_{\mathrm{MY}} / 6<\mathrm{x}-22>^{3}+\mathrm{C}_{1} / 6(\mathrm{x})^{3}+\mathrm{C}_{2} / 2(\mathrm{x})^{2}+\mathrm{C}_{3}(\mathrm{x})+\mathrm{C}_{4} \quad \text { Equation } 36
\end{aligned}
$$


The following table contains the results for the boundary conditions and the results for the constants of integration.

Table 6 - Results of Boundary Conditions and Integration Constants

\begin{tabular}{|c|c|}
\hline $\begin{array}{c}\text { With } \\
\text { Mechanism }\end{array}$ & $\begin{array}{c}\text { With } \\
\text { Mechanism }\end{array}$ \\
\hline $\mathbf{R}_{\mathrm{AY}}(\mathrm{lb})$ & $\mathbf{R}_{\mathrm{BY}}$ (Ib) \\
\hline 3.878 & -3.098 \\
\hline $\mathbf{R}_{\mathrm{Ax}}(\mathrm{Ib})$ & $R_{\mathrm{Bx}}(\mathrm{Ib})$ \\
\hline 39.715 & 0.898 \\
\hline Y-Direction & X-Direction \\
\hline at $x=3 \mathrm{~V}=3.903$ & at $x=3 V=-3.581$ \\
\hline$c_{1}$ & $\mathrm{c}_{1}$ \\
\hline 3.903 & -3.581 \\
\hline at $x=4 M=7.806$ & at $x=2 M=0$ \\
\hline $\mathrm{c}_{2}$ & $c_{2}$ \\
\hline-7.806 & 7.162 \\
\hline At $x=20 y=0$ & at $x=20 y=0$ \\
\hline $\mathrm{c}_{3}$ & $\mathrm{c}_{3}$ \\
\hline-462.96 & 918.238 \\
\hline at $x=4 y=0$ & at $x=4 y=0$ \\
\hline $\mathrm{c}_{4}$ & $\mathrm{c}_{4}$ \\
\hline 3541.428 & -7754.109 \\
\hline
\end{tabular}

\subsubsection{Rear Axle Validation}

The final step in the design of the rear axle was to validate the deflection and stress results. The following two tables give a summary of the deflection data. 
Table 7 - Results of Analysis With Wheelchair Wheels

\begin{tabular}{|c|c|c|c|}
\hline Deflection @ x=24 & Deflection @ x=24 & Magnatude (24) & \\
\hline-0.0539 & -0.0441 & 0.0697 & in \\
\hline Deflection @ x=0 & Deflection @ x=0 & Magnatude (0) & \\
\hline-0.098 & -0.074 & 0.1228 & in \\
\hline Deflection @ x=5.5 & Deflection @ x=5.5 & Magnatude (5.5) & \\
\hline-0.0327 & -0.0356 & 0.0483 & in \\
\hline Deflection @ x=4 & Deflection @ x= 4 & & \\
\hline-0.0490 & -0.0454 & & \\
\hline Deflection @ x = 20 & Deflection @ x=20 & & \\
\hline-0.00081 & -0.02564 & & \\
\hline
\end{tabular}

Table 8 - Results of Analysis With Innovative Mechanisms

\begin{tabular}{|c|c|c|c|}
\hline Deflection @ x=24 & Deflection @ x=24 & Magnitude (24) & \\
\hline 0.0237 & -0.0086 & 0.0253 & in \\
\hline Deflection @ x=0 & Deflection @ x=0 & Magnitude (0) & \\
\hline 0.0385 & -0.084 & 0.0927 & in \\
\hline Deflection @ x=5.5 & Deflection @ x=5.5 & Magnitude (5.5) & \\
\hline 0.0390 & -0.0298 & 0.0491 & in \\
\hline Deflection @ x=4 & Deflection x=4 & & \\
\hline 0.0182 & -0.044208473 & & \\
\hline Deflection @ x=20 & Deflection @ x=20 & & \\
\hline 0.0000 & 0.01033 & & \\
\hline
\end{tabular}

In the previous tables, the left hand column is for the $\mathrm{Y}$ direction, and the right hand column is for the $\mathrm{X}$ direction. It can be seen that the maximum displacement with the wheels attached occurred at one end of the shaft, while the maximum deflection with the innovative mechanisms attached occurred at the dynamometer sprocket connection. Each of these deflections was small in comparison to the total length of the shaft, and thus they were determined to be within the safe operating limits of the dynamometer testing apparatus. 
In Table 16 through Table 18 the results of a stress analysis can also be seen. The bending stress was calculated at the point of the maximum moment and the results yielded a safety factor of approximately 4. This value was within the limits of the yield stress for the material.

\subsection{Rear Axle Sprockets}

The gears were tuned to equal arc distances per stroke with the innovative mechanism and standard wheelchair wheels. The angular velocity of the rear axle sprockets and the inside sprocket of the back connecting lever are related with the following relationship.

$$
\operatorname{ABS}\left(\omega_{1} / \omega_{2}\right)=D_{2} / D_{1}
$$

Equation $37^{15}$

Where $\omega$ is the angular velocity of one of the sprockets in rev/min, and D is the diameter of one of the sprockets in inches. In addition, the rotation of one sprocket with respect to the other can be calculated using the formula

$$
\left(\operatorname{REV}_{1} / \operatorname{REV}_{2}\right)=\mathbf{D}_{2} / \mathbf{D}_{1}
$$

Equation 38

where REV is the revolution of the sprocket, and D is the diameter of the sprocket. Once the desired revolution ratio for the sprockets was determined, the sprockets were sized accordingly. The sprockets that were selected have the following dimensions. 
Table 9 - Summation of Sprocket Sizes

\begin{tabular}{|l|c|c|c|c|}
\hline & $\begin{array}{c}\text { Sprocket } \\
\text { Number }\end{array}$ & $\begin{array}{c}\text { Outside Diameter } \\
\text { (in) }\end{array}$ & Pitch Diameter (in) & \# of Teeth \\
\hline Rear Axle Sprocket & $35 \mathrm{~A} 26$ & 3.31 & 3.111 & 26 \\
\hline Back Connecting Lever & $35 \mathrm{H} 84$ & 10.25 & 10.029 & 84 \\
\hline
\end{tabular}

\subsection{Dynamometer Sprockets}

The sprockets for the dynamometer were selected based on size requirements for the rear axle of the wheelchair on the dynamometer, and on the horsepower requirements of the dynamometer. The only real requirements for the sprockets were that they should be as small as possible to eliminate rotational inertia, and they had to be the same diameter. The sprockets on the rear axle and the dynamometer will be the same size so that a multiplication of torque does not occur.

\subsection{Complete Testing Apparatus}

The following figures contain pictures of the entire wheelchair testing apparatus. These pictures are presented to give a total conceptual view of the testing apparatus. 


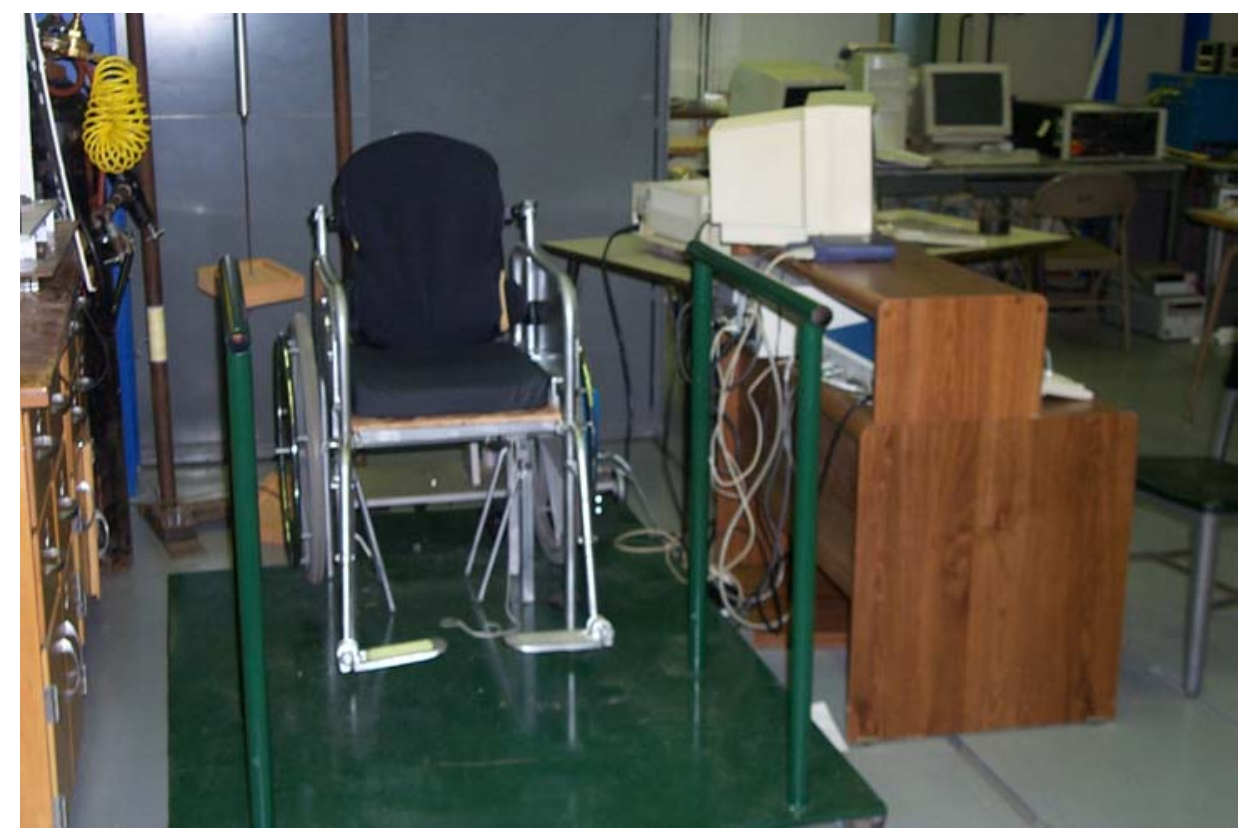

Figure 40 - Testing Apparatus Picture 1

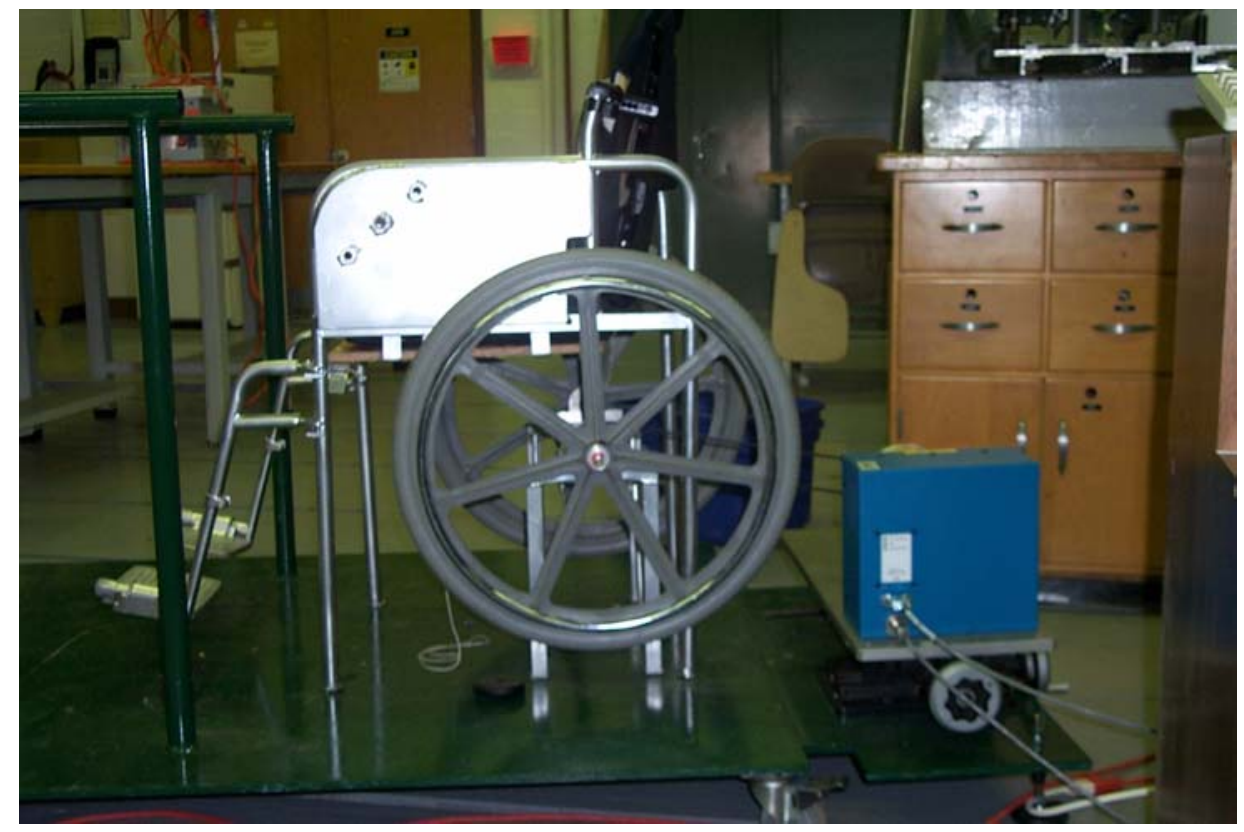

Figure 41 - Testing Apparatus Picture 2 


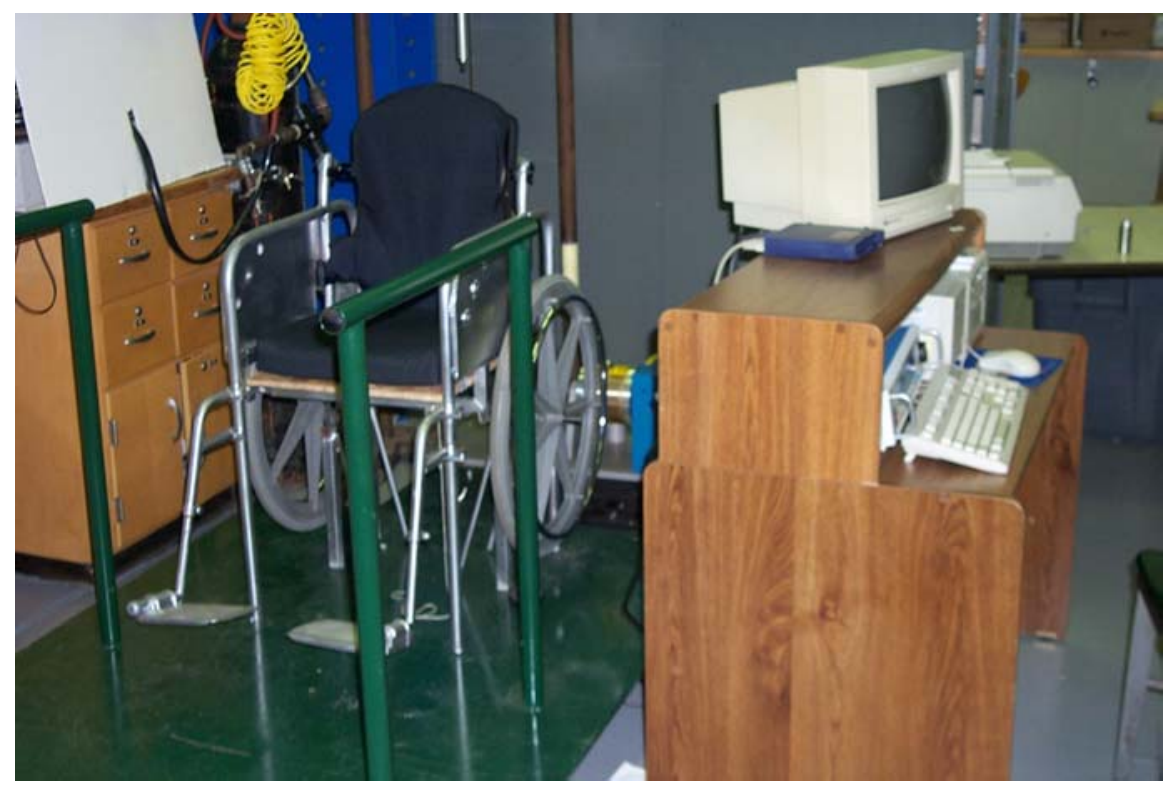

Figure 42 - Testing Apparatus Picture 3

With its current design and application, the dynamometer testing station will allow for the application of a torque load, and for data to be obtained on output RPM.

\section{Experimental Design and Testing}

\subsection{Prelude}

At the present state of development of the wheelchair driven by the innovative mechanism, two types of experiments were done. As described earlier, the orientation of major axis of the elliptical motion could be changed. In the first set of experiments, the change of this axis from horizontal to downward (angular offset) direction of the angle from shoulder to mid-thigh was evaluated against a constant torque load provided by the dynamometer. The results of this test will establish the existence of any advantage in the change of elliptical angle. The second test was a simulation of propelling a wheelchair up an incline plane. To accomplish this simulation, a constant torque was applied to the rear axle of wheelchair by the dynamometer. The test subjects were asked to propel the 
wheelchair at the constant load. A comparison of the angular velocities (RPM's) required by the standard wheelchair and the innovative mechanism will provide a direct evaluation of their comparative efficiencies. The mode of propulsion with the lower RPM will have the higher efficiency.

\subsection{Handle Motion Analysis}

The first set of experimental results that were obtained was for the handle motion analysis. In order to calculate the motion of the mechanism handle, the user must input a few parameters of the mechanism so that the position analysis can be completed. The following table lists the parameters that must be inserted by the user.

Table 10 - Parameter Inputs for Mechanism Handle Position

\begin{tabular}{|lr|}
\hline \multicolumn{2}{|c|}{ MECHANISM PARAMETERS } \\
\hline Length of Lever A & $3.15 \mathrm{In}$ \\
Length of Lever B & 1.5 \\
Initial Angle Lever A & 0 degrees \\
\hline
\end{tabular}

As you can see from Table 10 the spreadsheet allowed the user to input the initial angle of the mechanism, the length of Lever A, and the length of Lever B. The initial angle of Lever A feature was incorporated to allow for the tuning of the angular position of the mechanism. It had always been the vision of the researcher that the mechanism would be positioned with the major axis of the ellipse lying along the path from the user's shoulder to his or her mid-thigh. The following two figures give examples of how the spreadsheet program can be changed and manipulated to give different mechanism handle paths for different configurations. 


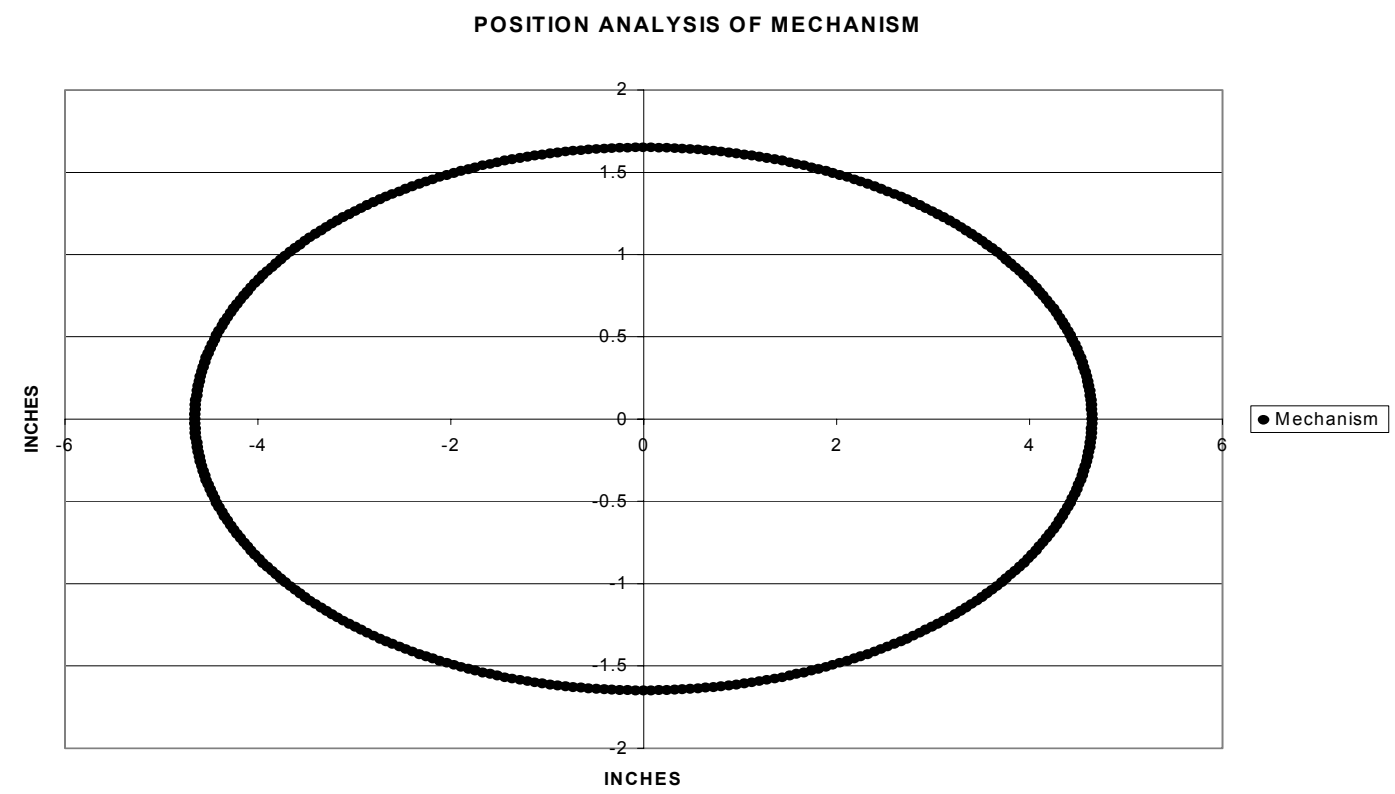

Figure 43 - Example of Handle Path (0-Degrees) 


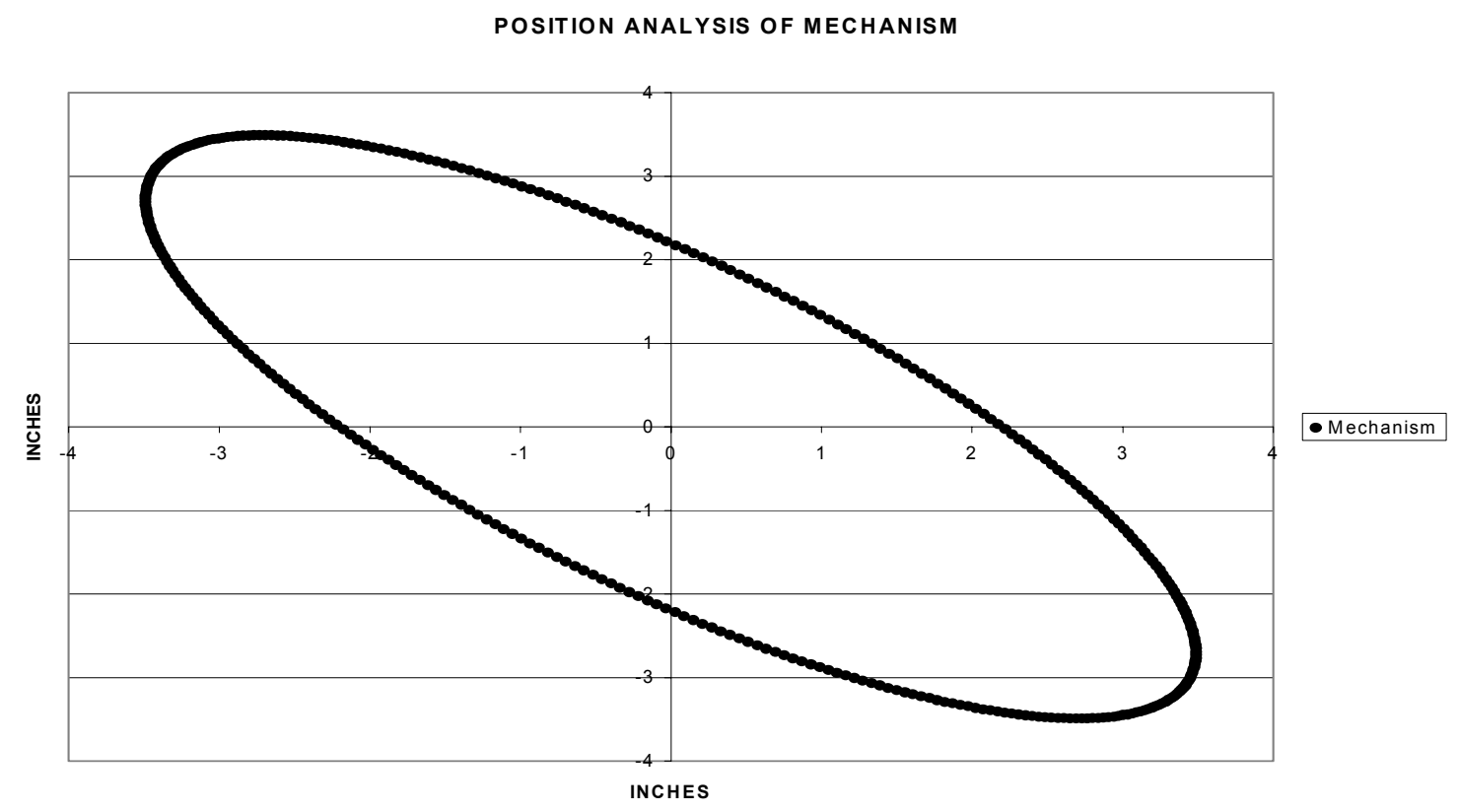

Figure 44 - Second Example of Handle Path (45-Degrees)

\subsection{Torque Analysis}

After the handle position analysis was complete, the next step was to conduct a study to find the parameters of various human subjects and obtain a curve fit for the angle that was obtained by drawing a line from the shoulder through the mid-thigh. This angle was needed to find the angle for the major axis of the ellipse to lie along in order to provide maximum torque. The following figure gives an illustration of the above stated angle. 


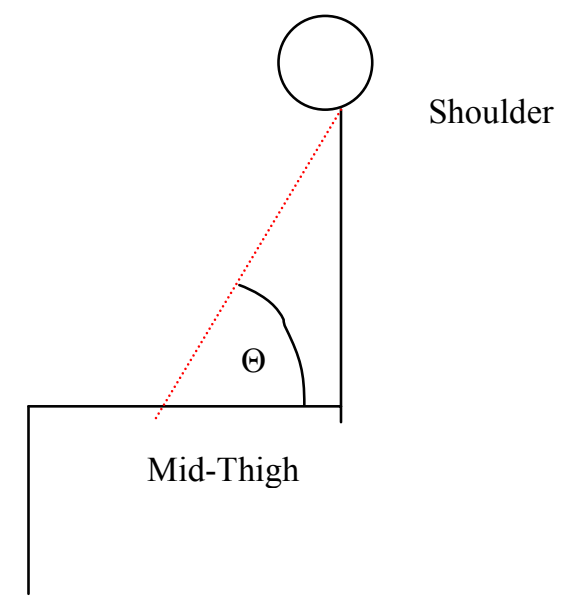

Figure 45 - Measurement of Human Angle

This angle, $\Theta$, would then allow for the innovative mechanism to be positioned in line with the user's physical parameters. By placing the innovative mechanism in the best possible configuration for each user, a true custom match between user and innovative mechanism can be accomplished. In order to obtain the given data, ten random subjects were selected, and the following measurements were made:

\section{Seat to Shoulder Height}

\section{Back to Mid-Thigh Length}

The following table gives the results of the human angle analysis. The human angle is the actual angle $\Theta$ on the human test subject. The test subjects who were recruited were between the ages of 20 and 71 . There were nine males and one female test subject. All were healthy, able-bodied individuals. 
Table 11 - Results of Human Angle Analysis

\begin{tabular}{|c|c|}
\hline Subject \# & Human Angle \\
\hline & (Degrees) \\
\hline 1 & 58.63 \\
\hline 2 & 59.24 \\
\hline 3 & 60.48 \\
\hline 4 & 55.27 \\
\hline 5 & 64.49 \\
\hline 6 & 59.70 \\
\hline 7 & 56.80 \\
\hline 8 & 58.95 \\
\hline 9 & 53.83 \\
\hline 10 & 56.03 \\
\hline
\end{tabular}

Once the human angles were obtained, a torque analysis was then completed on the innovative mechanism. The torque curves for each subject were obtained using the handle position analysis. The torque at each point along the path of the ellipse was calculated by taking the cross product between the force applied by a human subject and the position lever of the handle. The values for the lengths of Lever A and B were kept the same as they can be found on the actual innovative mechanism. Values were then entered for the Initial Angle of Lever A in the spreadsheet. A nominal force of 1 pound was used for the human applied force. The following three figures give an example of how the torque curves change as the initial angle (major axis orientation) of Lever A changes. 


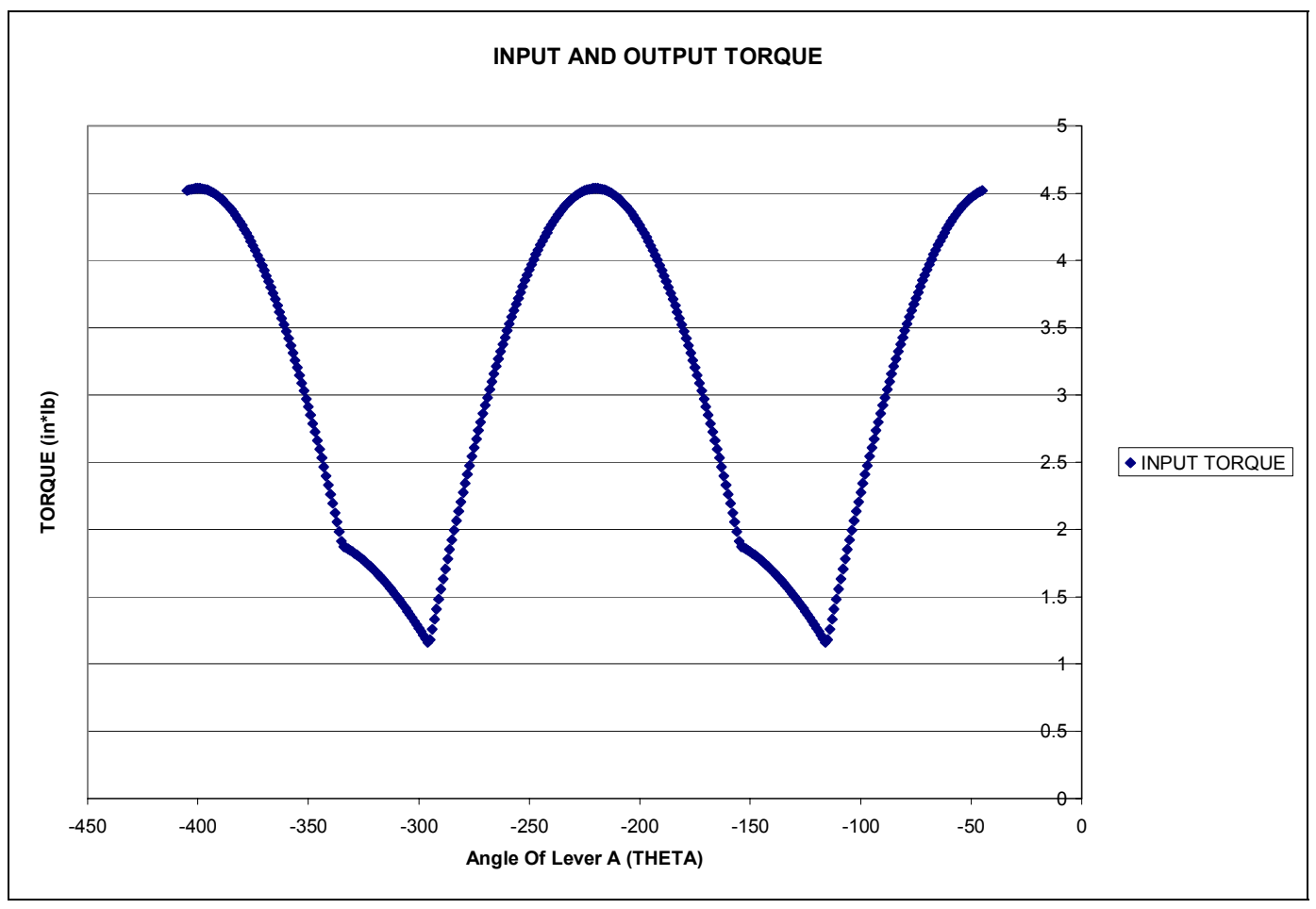

Figure 46 - Torque Analysis - 45 Degrees Offset 


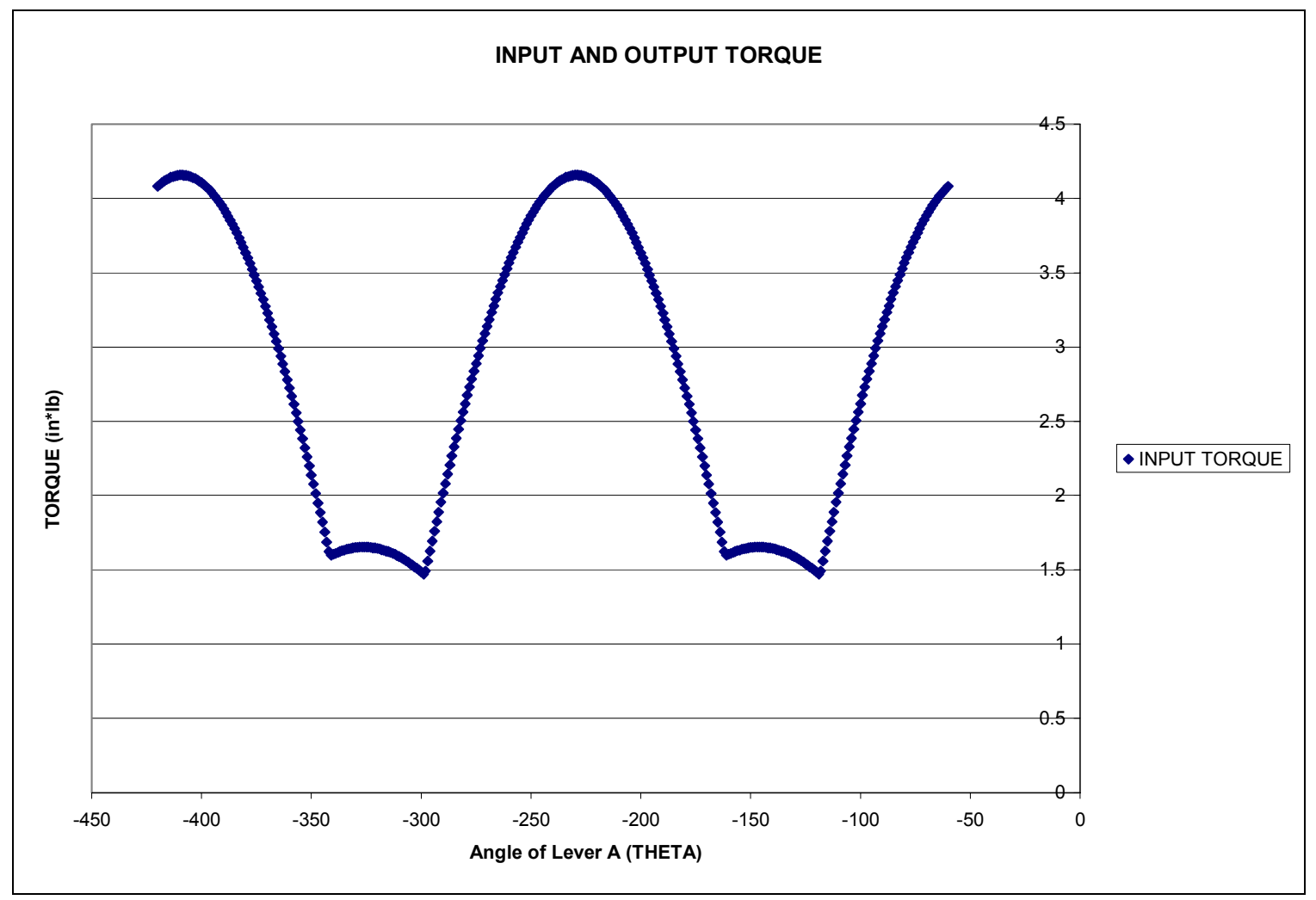

Figure 47 - Torque Analysis - 60 Degree Offset 


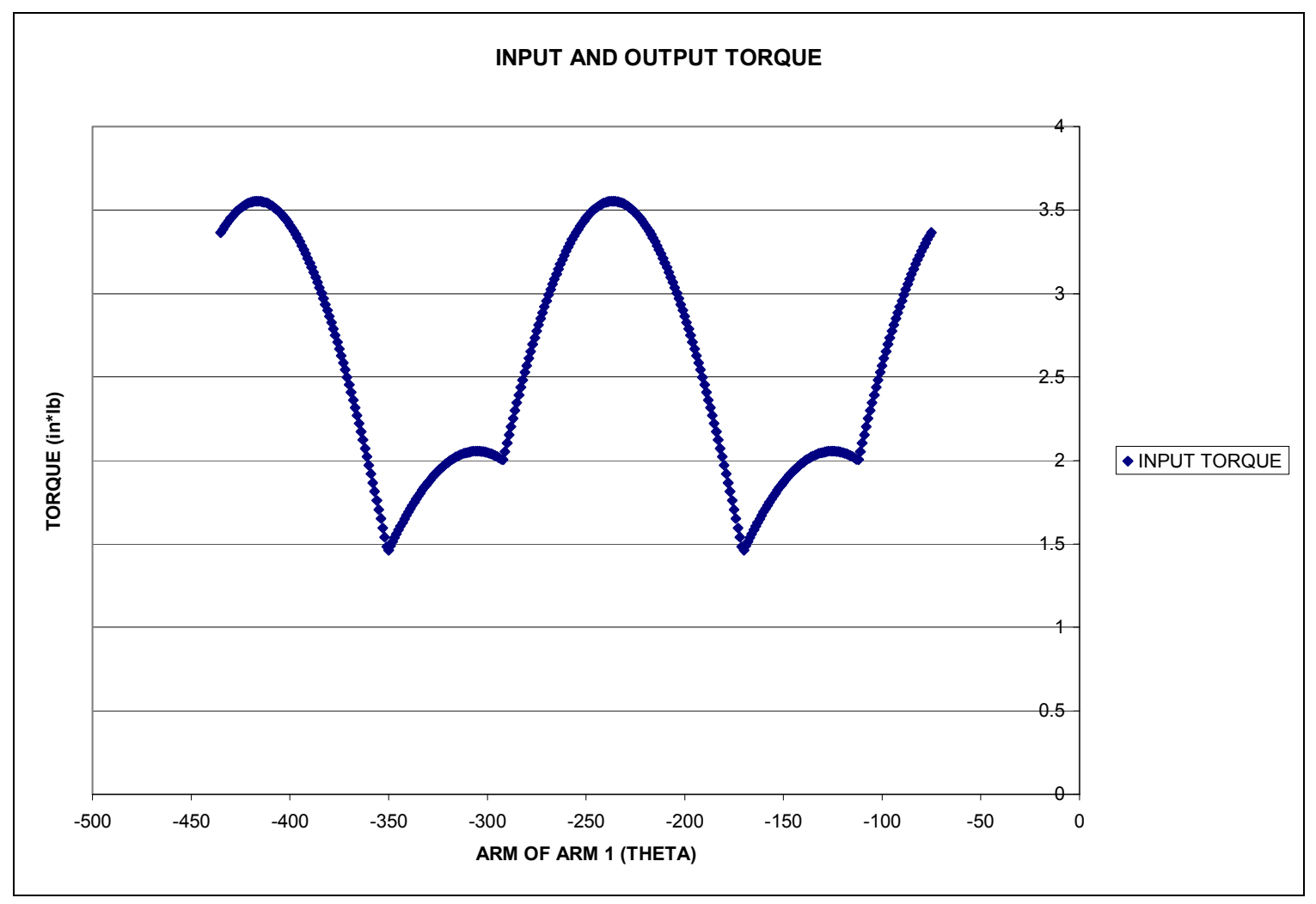

Figure 48 - Torque Analysis - 70 Degrees Offset

The human angles for each of the human subjects were calculated, and a torque curve was developed for each of the subjects. As you can see, there does seem to exist a point at which the minimums on the curves can be maximized. That is to say, the sharply sloping valleys can be maximized. The torque curves for each subject were made as smooth a possible by changing the initial angle of Lever A. The torque curves for each individual subject can be found in the Appendix C.

Once the torque curves were maximized, the maximized angle (derived mechanism angle) of Lever A was plotted verses the human angle to obtain a curve fit and equation for the angle that is needed on Lever A for any given human angle. The following figure contains the results of the curve fit analysis. 


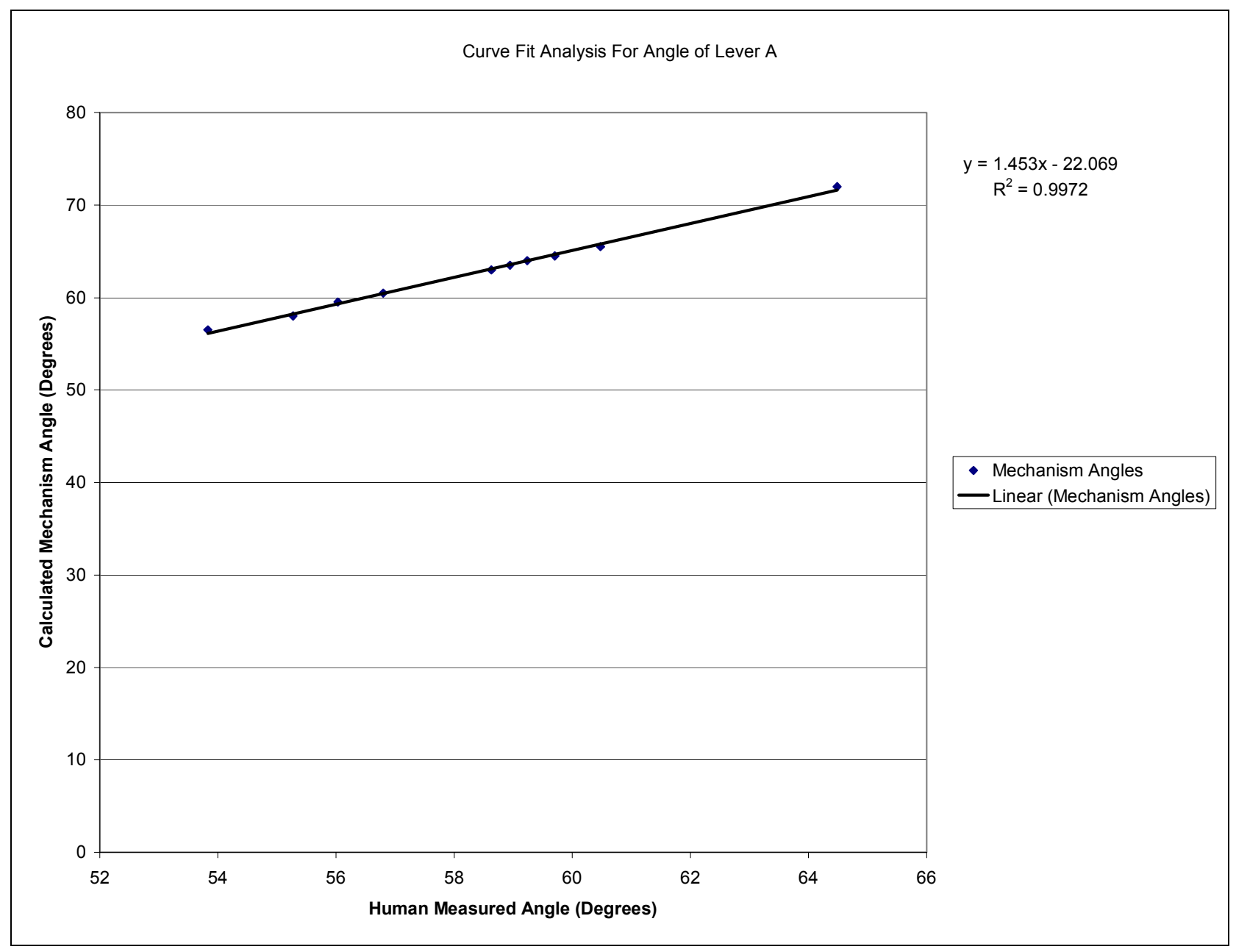

Figure 49 - Results of Curve Fit Analysis

From Figure 49, it can be seen that a curve fit was made with a linear function that resulted in an $\mathrm{R}^{2}$ of 0.9972 . The best possible value of an $\mathrm{R}^{2}$ value is 1.0 . A value of 1.0 would be a perfect fit. The curve was used to accurately calculate the derived mechanism angle. From the above analysis, the mechanism angle can be calculated from the following equation.

Derived Mech. Angle = 1.453*Human Angle -22.069

Equation 39 
The following table contains a comparison of the mechanism position angle calculated from the curve fit analysis compared to the same angle that was calculated from the torque curve method.

Table 12 - Comparison of Results For Mechanism Position Angle

\begin{tabular}{|c|c|c|c|c|}
\hline & Measured & Estimated From Torque Curves & Calculated From Curve Fit Analysis & \\
\hline Subject \# & Human Angle & Mech. Pos. Angle & Mech. Pos. Angle & Percent Difference \\
\hline & (Degrees) & (Degrees) & (Degrees) & (Percent) \\
\hline 1 & 58.63 & 63 & 63.12 & 0.184 \\
\hline 2 & 59.24 & 64 & 64.00 & 0.004 \\
\hline 3 & 60.48 & 65.5 & 65.81 & 0.466 \\
\hline 4 & 55.27 & 58 & 58.24 & 0.412 \\
\hline 5 & 64.49 & 72 & 71.63 & 0.517 \\
\hline 6 & 59.70 & 64.5 & 64.68 & 0.279 \\
\hline 7 & 56.80 & 60.5 & 60.46 & 0.058 \\
\hline 8 & 58.95 & 63.5 & 63.58 & 0.124 \\
\hline 9 & 53.83 & 56.5 & 56.14 & 0.640 \\
\hline 10 & 56.03 & 59.5 & 59.35 & 0.259 \\
\hline
\end{tabular}

These results were then used in the testing of the human subjects. The final step before testing of human subjects could begin was to determine what load should be applied on the dynamometer.

\subsection{Testing Load Calculation}

The standard slopes that a wheelchair user must negotiate shall not exceed 1:20 for curbs coming from streets ${ }^{17}$. 


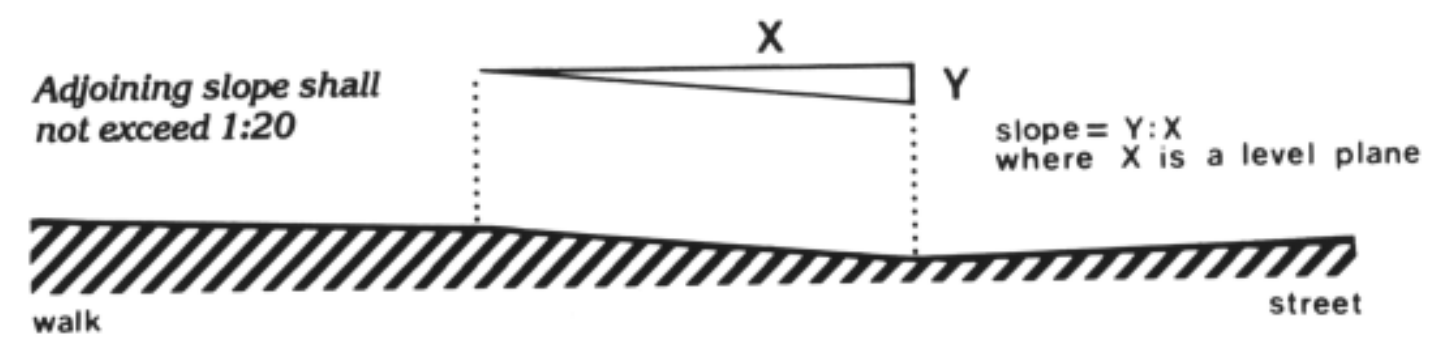

Figure 50 - Diagram of Wheelchair Ramp Requirements ${ }^{17}$

In order to calculate the load that a person must apply to the wheels in order to propel the wheelchair a spreadsheet program was developed. A copy of the spreadsheet can be found in the Appendix C. From the spreadsheet in Appendix C, it can be seen that calculating the load on the wheelchair and user was quite simple. But, this spreadsheet was sensitive to the value that was entered for the coefficient of friction between the wheels and the rolling surface. It was because of this sensitivity that the spreadsheet was never used to its fullest extent. A small error in the coefficient of friction resulted in a large error in the calculated force needed to propel the wheels. Instead, trial runs were completed to compare the two types of wheel propulsion. Once a load was reached that did not allow for the wheels to have a free rotation, this load was used. The next step was to start testing human subjects.

\subsection{Testing of Human Subjects - Different Mechanism Angles}

The first set of human experimental data that was taken was for the innovative mechanism positioned at two different angles. Earlier in the description of the mechanism, the possibility of varying the major axis of the ellipse was described. The benefits of that feature are being tested in this section. The stroke efficiency of two angles was evaluated. The first angle that was used was 0 degrees, that is, with the major axis of the ellipse parallel to the thigh of the subject. The second angle tested was the 
mechanism position angle derived from the human angle measurements described in a previous section. Generally, this angle was based on the angle from the shoulder to the mid-thigh.

For each of the above stated tests, the human subjects had to propel the innovative mechanism against a load of $10 \mathrm{in} * 1 \mathrm{bs}$. This constant load allowed for comparison of the angular velocity (RPM) and horsepower outputs as recorded by the dynamometer, controller, and computer setup. The load of $10 \mathrm{in*}$ lbs was chosen just to give a reference point from which all of the given results can be compared. In addition, the entire test lasted for 3 minutes with data being taken at one second intervals for a total of 180 data points. The subjects were asked to propel the innovative mechanism set at one of the angles during the first testing session, and then the subjects were asked to return at a later date in order to test the other angle.

The data was collected for each of the human subjects, and graphs were configured to show the results. For each subject, a graph was made for output torque, RPM, and horsepower. Whenever each subject was tested on the dynamometer apparatus, the output torque load was first analyzed to make sure that the subject had correctly kept the output torque as close as possible to $10 \mathrm{in} * 1 \mathrm{bs}$. In addition, the output had to be relatively steady, in that large jumps would cause the data to be inconclusive. If the subjects were unable to sustain the load, they were asked to start over, or a new subject was recruited. For our testing procedures, each of the human subjects was able to propel the innovative mechanisms for the test period of three minutes. The torque RPM, and Horsepower graphs for each given subject can be found in the Appendix C labeled in Figure 88 through Figure 117. 


\subsection{Testing of Human Subjects - Mechanism/Wheel Comparison}

One of the main focuses of this research project was to compare the output characteristics of a standard manually powered wheelchair with the innovative mechanism that has been developed. This section contains the comparison, and the results are presented in graphical and tabular form.

For testing purposes, the same ten subjects were recruited for this part of the testing procedure as were tested previously. Although, subject 5 was unable to take part in this portion of the innovative mechanism testing procedure because of scheduling and physical problems. So, a total of nine human subjects were included

The load that was applied on the dynamometer setup for this part of the testing procedure was $10 \mathrm{in*lbs.} \mathrm{This} \mathrm{load} \mathrm{was} \mathrm{applied} \mathrm{in} \mathrm{a} \mathrm{constant} \mathrm{manner} \mathrm{and} \mathrm{will} \mathrm{allow} \mathrm{for} \mathrm{a}$ comparison to be made between the innovative mechanism and the standard manually powered wheelchair. The load was applied to the test subjects for a total of three minutes, with data being taken every 1 second, same as before.

The human test subjects were recruited and asked whether or not they had shoulder or upper arm problems and/or pain before the testing procedure started. By recruiting only able-bodied subjects with no prior wheelchair experience, there will not be a bias toward one method of propulsion or the other. The exact method of wheelchair stroke pattern was not noted. After the initial question session, the subjects were given a couple minutes to familiarize themselves with the testing procedure and the way in which the wheels had to be powered. For each of the tests, the torque that was being applied was carefully observed to make sure that each subject kept the output torque constant, within 
reason, to the input torque of $10 \mathrm{in} * 1 \mathrm{bs}$. There are variations in the output torque, but each variation lies within the given scope of allowed variation from 10 in*lbs. In addition, there are points on some of the subjects torque curves that show a few very low torque values. These points were directly dependant upon a subject's ability to keep the wheels moving during propulsion. A couple subjects momentarily stopped the wheel whenever they applied the propulsion stroke.

Each of the nine subjects powered the wheelchair dynamometer using the innovative mechanisms, and then they were asked to return at a later date or time in order to complete a test using only the standard wheels for propulsion. None of the subjects were allowed to complete the second test procedure immediately after the first due to the possibility of fatigue. After the data was acquired for each of the human test subjects using both the innovative mechanisms and the standard wheelchair wheels for propulsion, the data was tabulated and any necessary conversion factors were applied to the data. The one conversion factor that was needed was a conversion of the power from watts to horsepower. But, this was simply a multiplication operation, and none of the original data was altered in any way. Once the data was compiled in the necessary format, charts and graphs were made for output torque, angular velocity (RPM), and horsepower for each of the nine human test subjects. The graphs of output torque, angular velocity, and horsepower can be found in Appendix C labeled as Figure 118 through Figure 144. The same issue arose with this set of graphs as arose with the set of graphs in the previous section. The horsepower graphs are simply a scaled version of the angular velocity. Once again, this condition exists because horsepower was simply equal to torque multiplied by the angular velocity and divided by a constant. So, if the output torque was 
constant, the only variable that was changing was the angular velocity. This was the reason why the angular velocity and horsepower graphs look very similar to one another.

In order to analyze the given data, a method had to be documented whereby the data could be analyzed in a scientific and objective manner. The following pages contain the data reduction for the comparison between the manually powered wheelchair wheels and the manually powered innovative mechanism.

\section{Results}

\subsection{Results of Testing of Subjects at Different Mechanism Angles}

The following paragraphs will be used to explain the results for the ten human test subjects in detail.

The first graphs that were constructed for each of the 10 subjects were for the output torque. Each output torque was analyzed to make sure the torque was being held at a relatively constant value. However, there are sticking points that exist in the mechanism due to the moment arm that is being produced, and because of the line of action of the subject's input force. If the torque dropped too close to 0 at the same time as the angular velocity (RPM) dropped to a value close to 0 , this was deemed a sticking point and the testing was allowed to progress. Each of the ten subjects data that was analyzed in this part of the Results section had data that fell within the range of the allowable deviation.

The first set of results that will be compared are for subjects 6,7 , and 8 . 


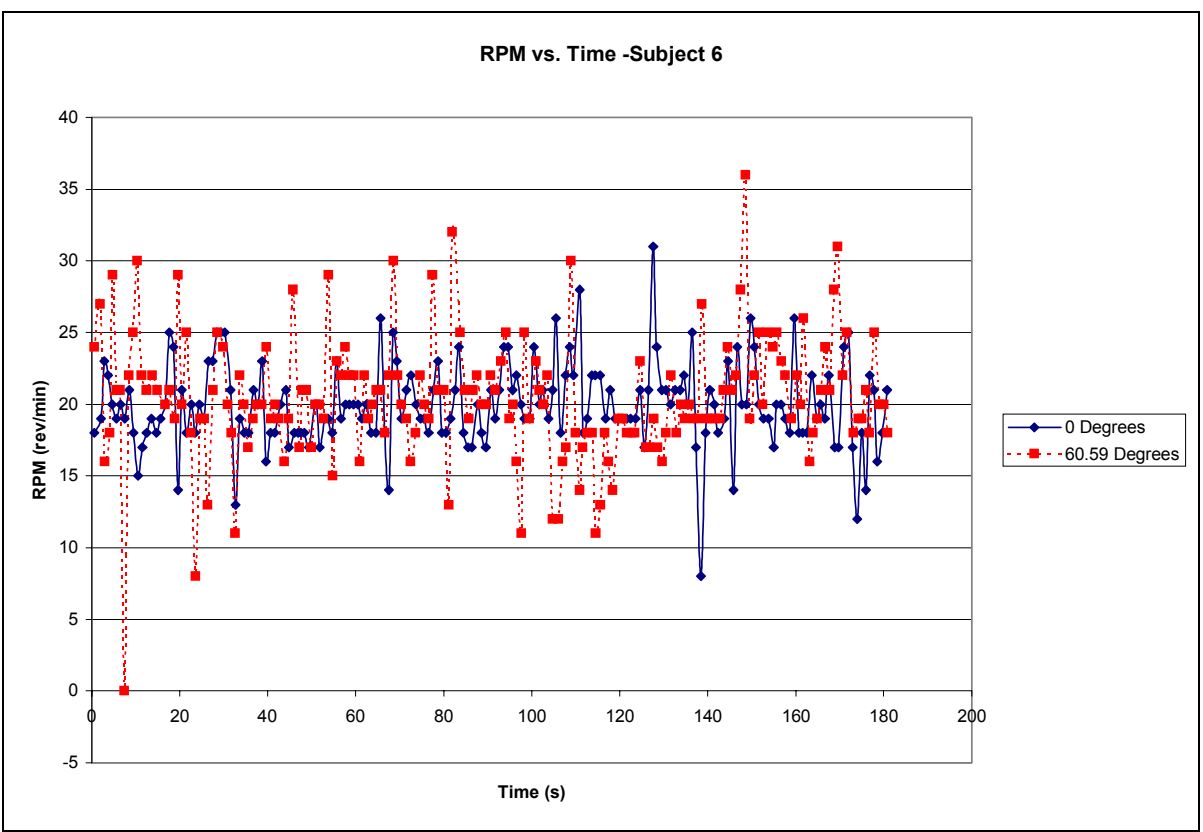

Figure 51 - RPM Results For Subject 6 (10*lbs)

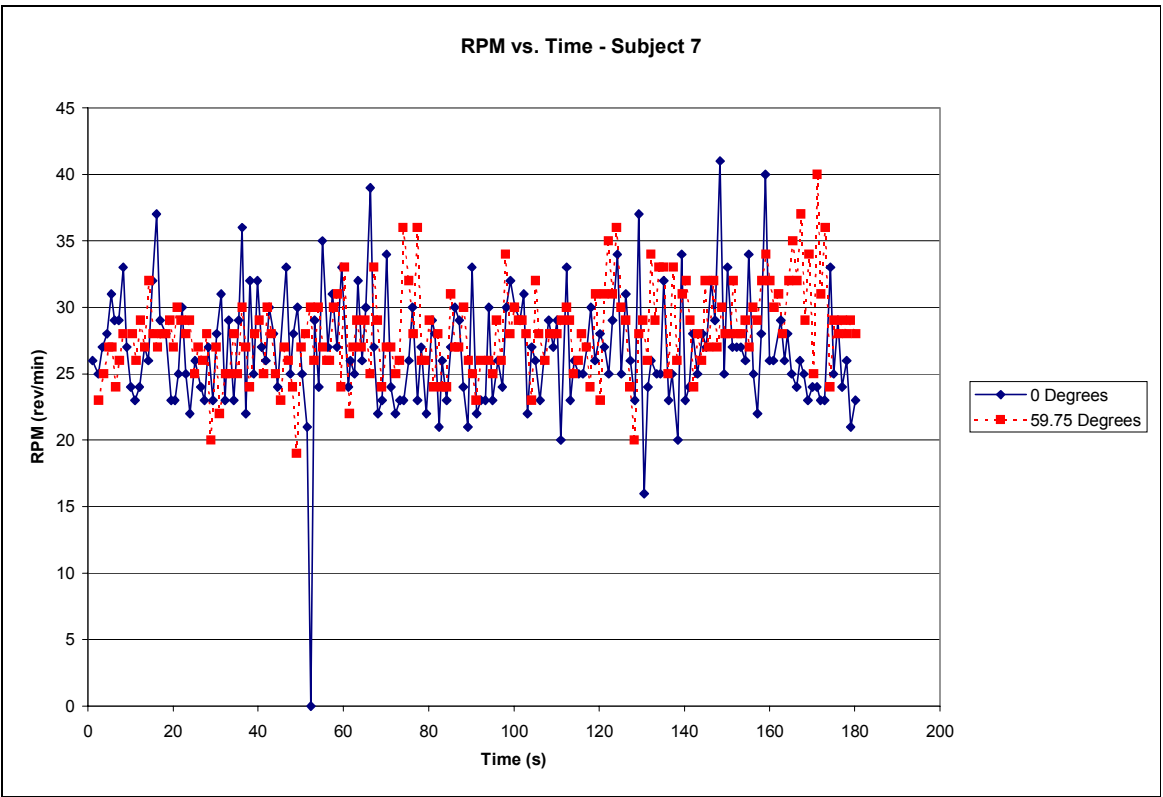

Figure 52 - RPM Results For Subject 7 (10 in*lbs) 


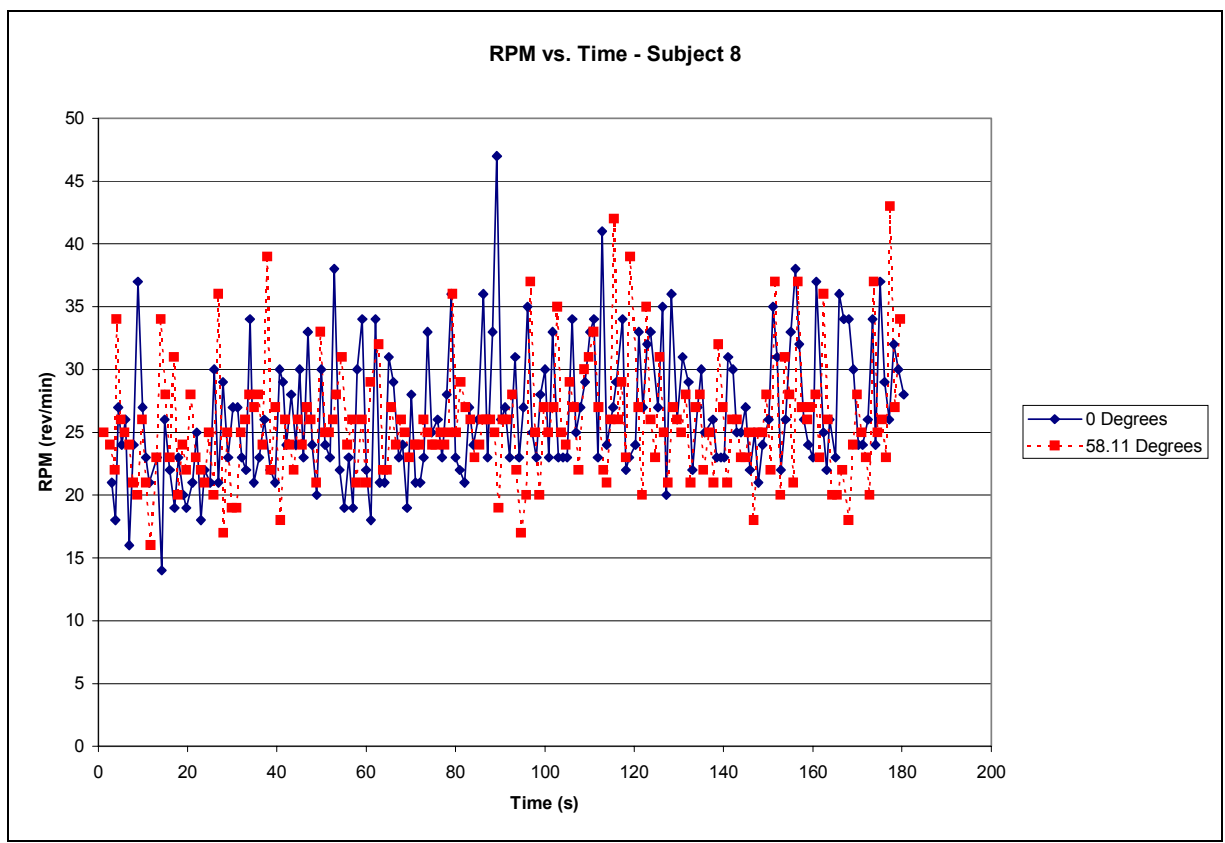

Figure 53 - RPM Results For Subject 8 (10 in*lbs)

By inspection of the RPM curves for these three given subjects, it can be observed that there was not an appreciable difference between the angular velocities that were obtained with the innovative mechanism set at 0 degrees and the angular velocities with the mechanism set at the derived mechanism angle. The horsepower results are similar to the angular velocity results. This phenomenon was expected because horsepower is simply the torque multiplied by the angular velocity and divided by a constant. So, if the angular velocities for a subject were higher for one of the angle orientations, the horsepower for the same subject will also be higher for that angle orientation because the torque output of the mechanism was constant. The points on the angular velocity curve that dip down to 0 are the sticking points. These points are reached where the moment arm becomes equal to 0 . In addition, the line of action of the user's input force can cause these sticking points. The subject's arm was fully extended and no moment arm was present, which resulted in the locking of the mechanism. Also, when the subject's arm 
was fully extended, the subject was propelling along the line of action, so no force was being transmitted.

Subjects 1 and 2 had a higher overall angular velocity (RPM) range with the innovative mechanisms orientated at the derived mechanism angle.

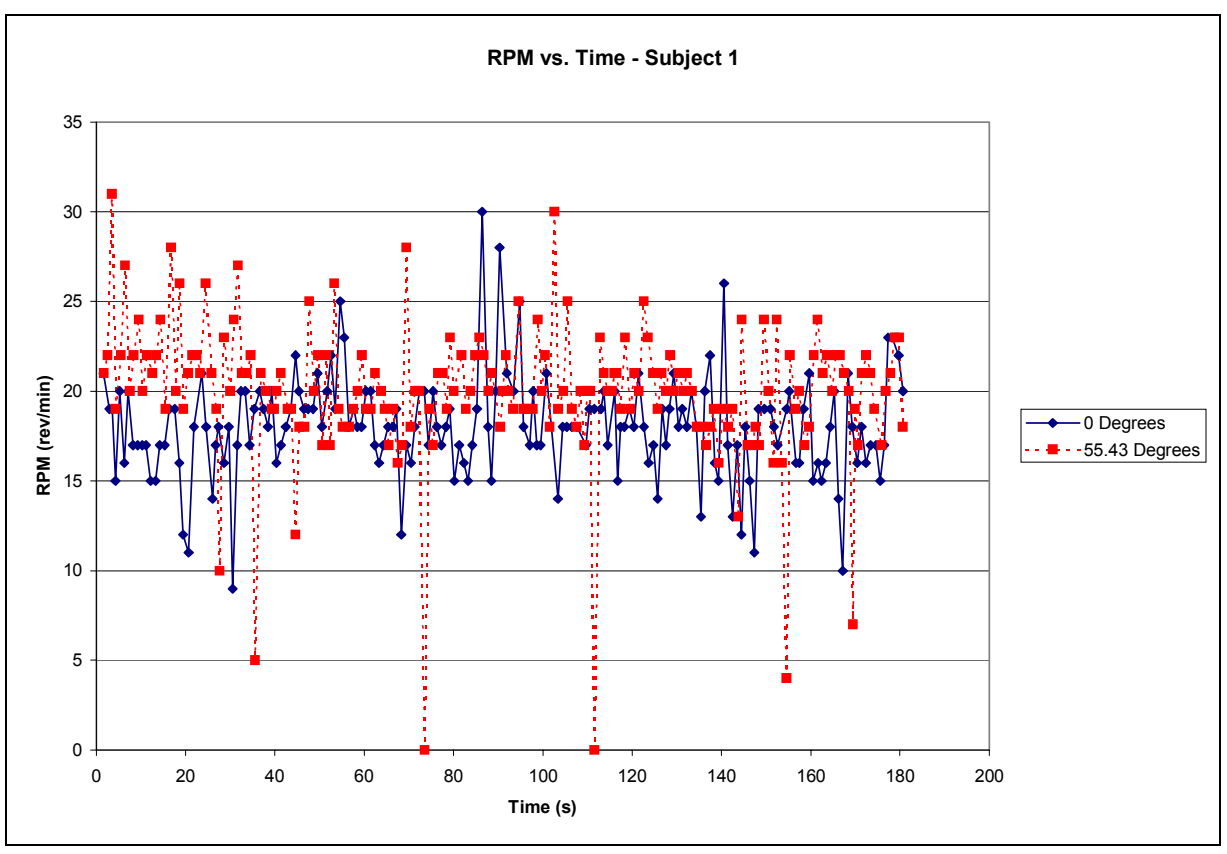

Figure 54 - RPM Results For Subject 1 (10 in*lbs) 


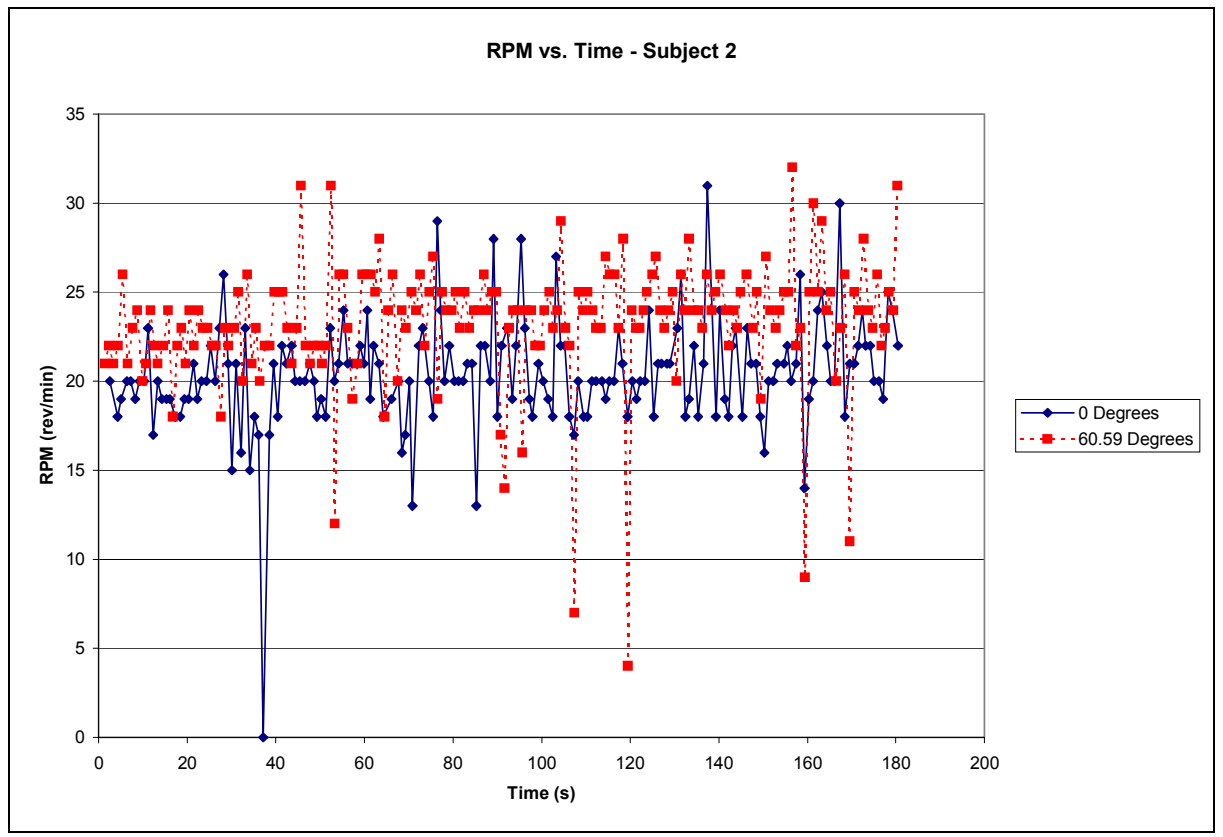

Figure 55 - RPM Results For Subject 2 (10 in*lbs)

In addition, these two subjects experienced angular velocity values that were also higher overall for the derived mechanism angle. The higher overall trend of angular velocity values could stem from the fact that the user was able to supply more bodily force to the mechanism in this configuration, or this configuration may have allowed for the given user to have a higher mechanical advantage.

Subject 3 had a higher range of angular velocity values with the mechanism set at the derived mechanism angle, but there was not a noticeable difference in the overall trends of the angular velocity (RPM) curves. 


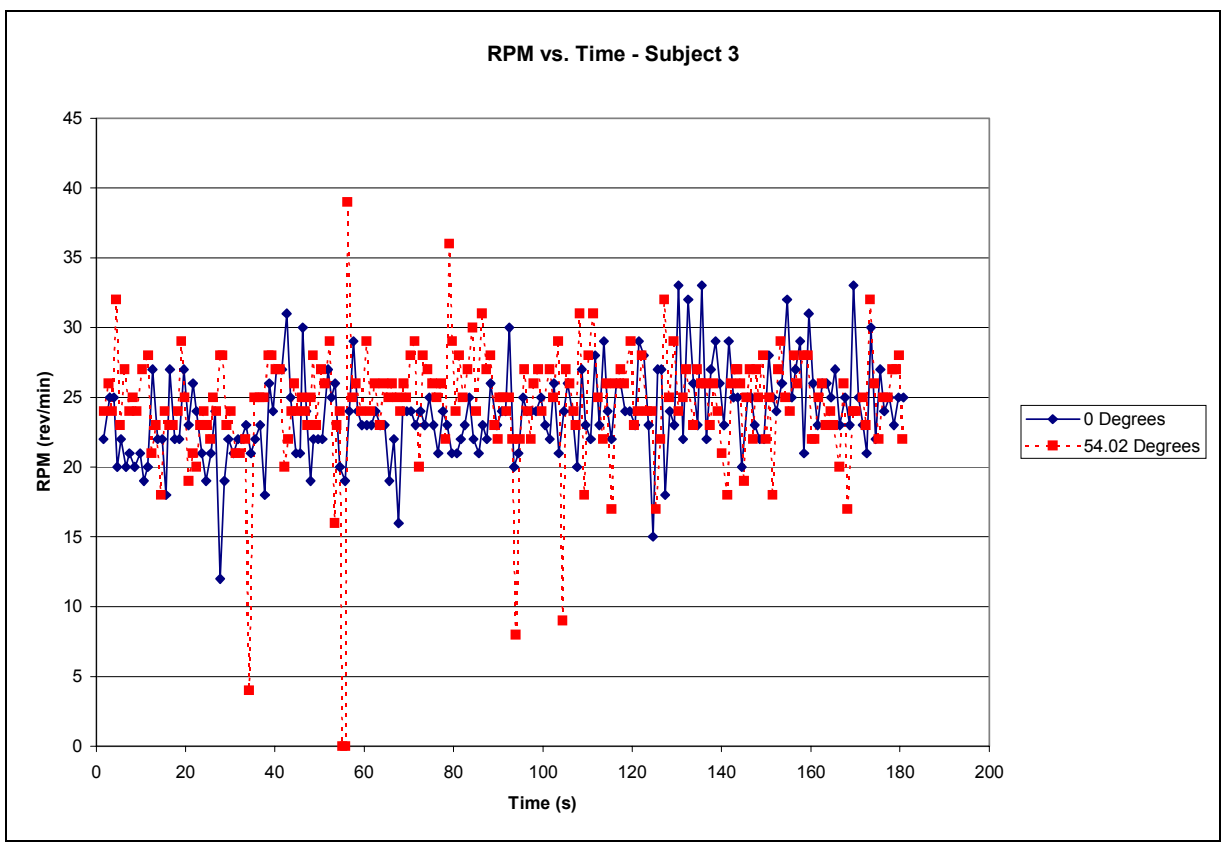

Figure 56 - RPM Results For Subject 3 (10 in*lbs)

Whereas, subject 4 demonstrated a higher overall trend in angular velocity with the mechanism angle set at 0 degrees, but did not have a noticeable shift in the overall range of angular velocity values that were obtained. 


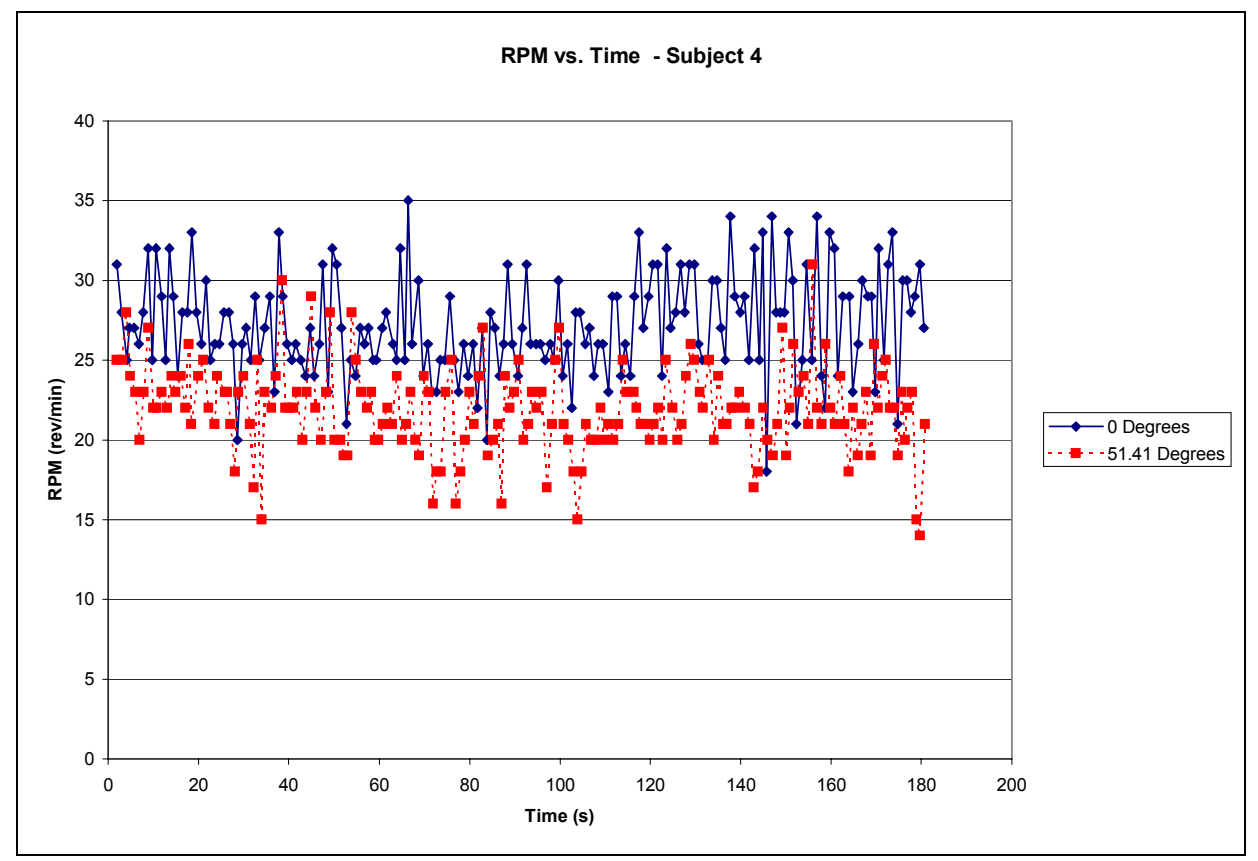

Figure 57 - RPM Results For Subject 4 (10 in*lbs)

Subjects 5, 9, and 10 demonstrated a higher range of angular velocity (RPM) values for the 0 degree mechanism angle condition, in addition to a higher overall angular velocity trend for the 0 degree mechanism position.

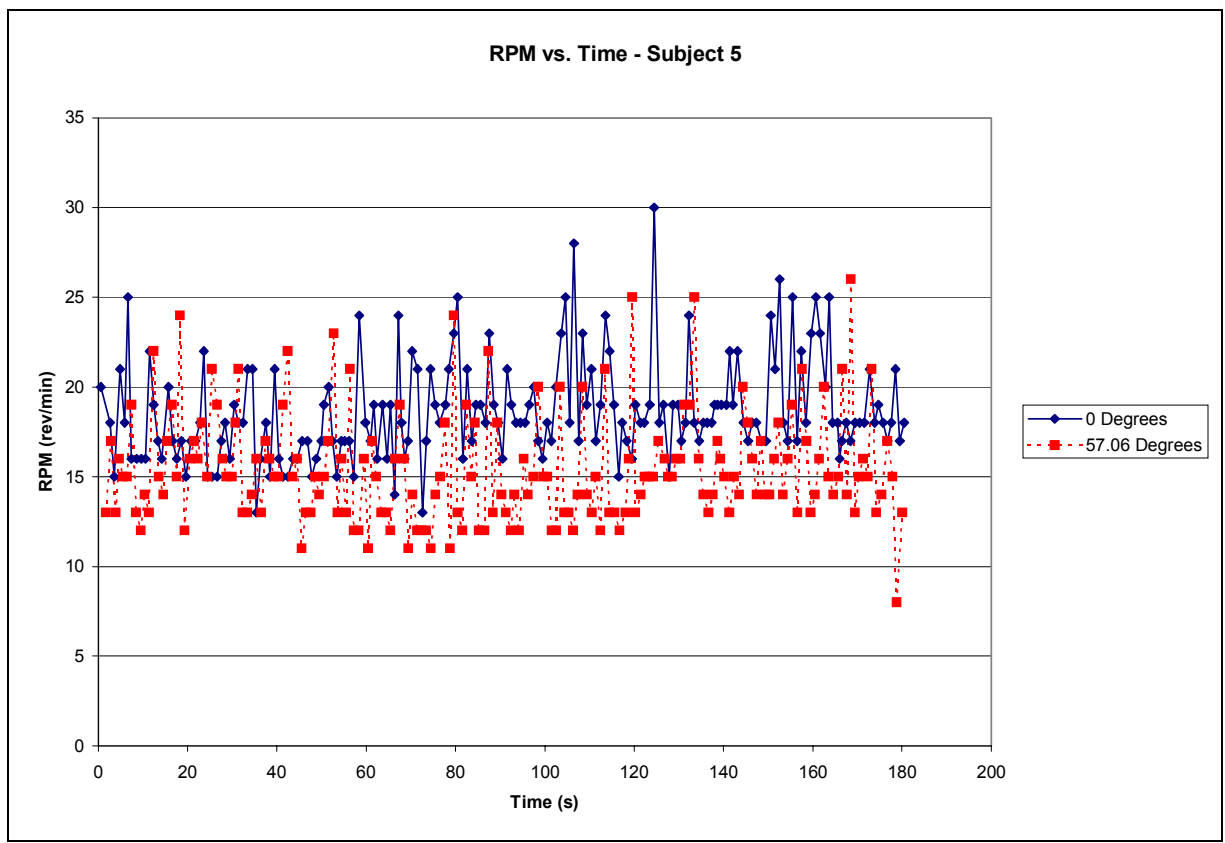

Figure 58 - RPM Results For Subject $5(10$ in*lbs) 


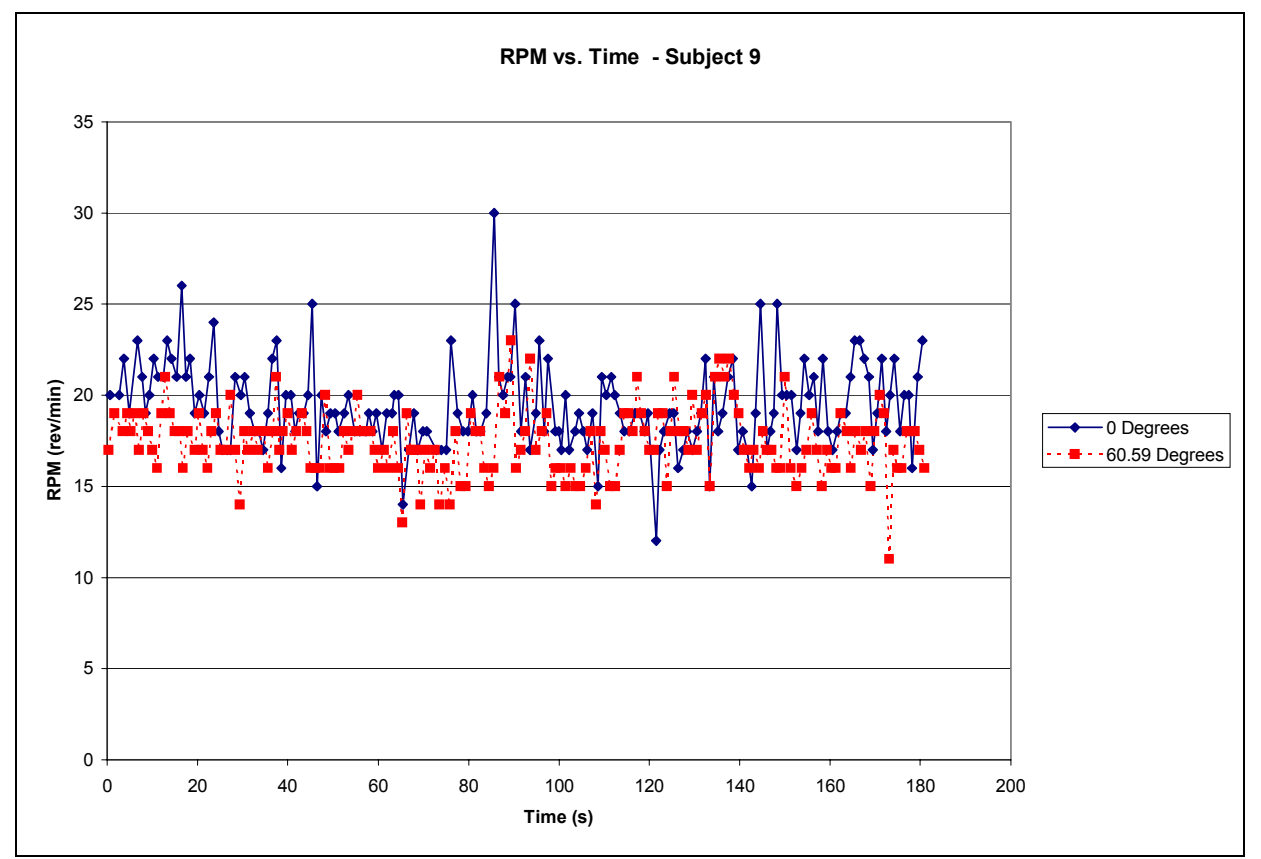

Figure 59 - RPM Results For Subject 9 (10 in*lbs)

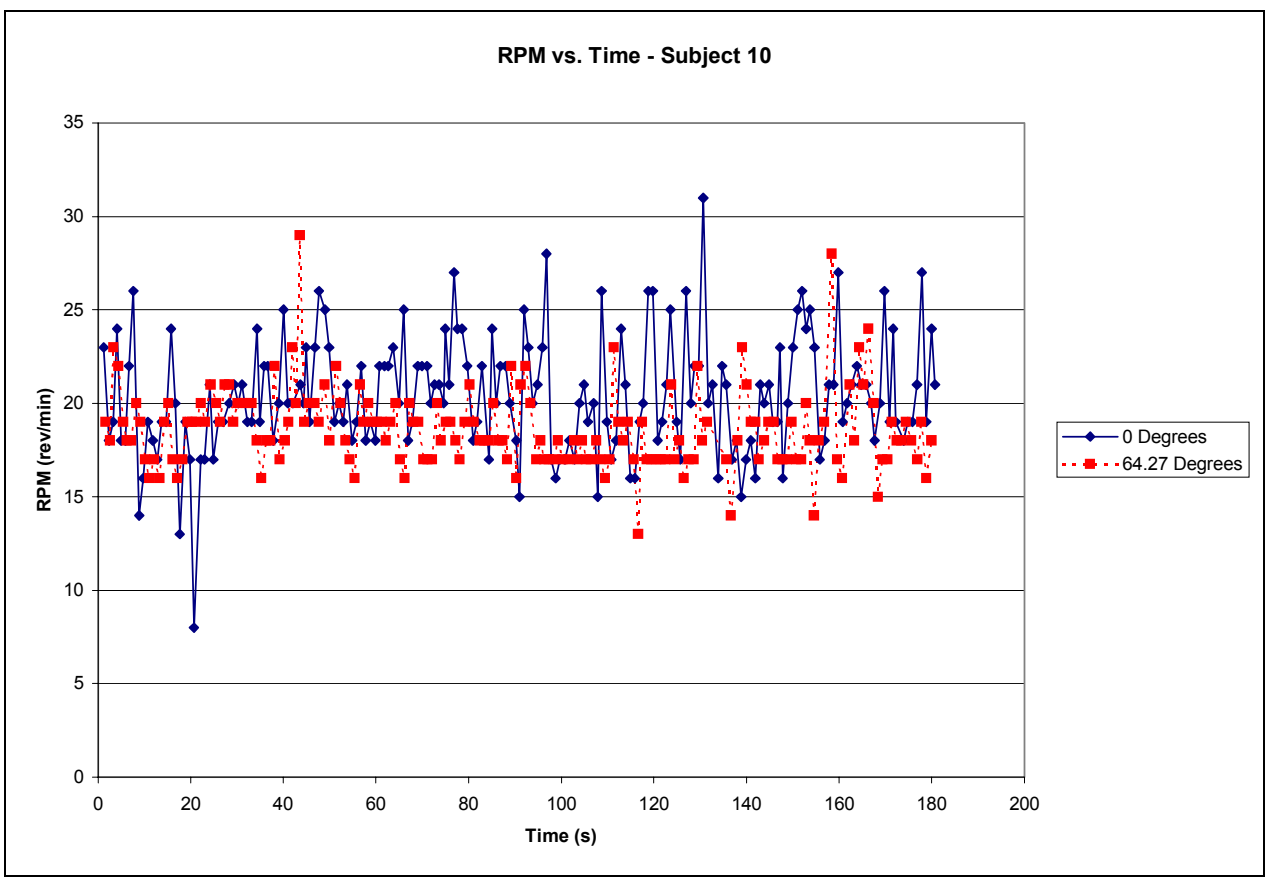

Figure 60 - RPM Results For Subject 10 (10 in*lbs)

The results show that there was not a definitive difference in the angular velocity (RPM) values between the angle orientations of the major axis of the ellipse. 


\subsection{Results of Testing Subjects - Mechanism/Wheel Comparison}

The first set of results that will be presented are the results from the angular velocity (RPM) comparison data. It was originally the goal of the team to design a mechanism that would allow for the user to propel a manually powered wheelchair with less effort. The range of angular velocities that a person must use in order to propel the wheelchair provides a direct relationship to the amount of energy that a person must use to propel the wheelchair. In order to obtain a way of comparing the angular velocity (RPM) graphs for each of the test subjects, a linear curve fit was made for each set of data on the graph. A linear fit was used so that a simple curve or trend could be seen in the data. The linear curve fit for the wheelchair wheel data is marked with a dotted line on the graphs, whereas the linear fit for the innovative mechanism data is marked with a solid line on the graphs. Once the curve fits were completed, a point in time in the middle of the testing window was chosen to evaluate each curve. Since these are linear curve fits, the value in the middle will be equal to approximately the average of the data points. This idea will be further stated later in the results section. The following table gives a comparison of the angular velocity data results for both the standard wheels and the innovative mechanism.

Table 13 - Comparison of RPM Data For Wheels and Innovative Mechanism

\begin{tabular}{|c|c|c|c|}
\hline Subject & RPM (Wheels) & RPM (0 Degrees) & Ratio RPM(W)/RPM(0) \\
\hline 1 & 22.542 & 18.021 & 1.251 \\
\hline 2 & 31.099 & 20.381 & 1.526 \\
\hline 3 & 30.373 & 23.808 & 1.276 \\
\hline 4 & 31.794 & 27.181 & 1.170 \\
\hline 5 & Uncompleted & Uncompleted & 1.393 \\
\hline 6 & 27.748 & 19.926 & 1.869 \\
\hline 7 & 49.993 & 26.748 & 1.595 \\
\hline 8 & 42.145 & 26.425 & 2.291 \\
\hline 9 & 44.375 & 19.368 & 2.388 \\
\hline 10 & 48.711 & 20.399 & 1.640 \\
\hline AVERAGE & 36.531 & 22.473 & \\
\hline
\end{tabular}


The angular velocities (RPM's) in Table 13 were compared for a time of 90 seconds. This allowed for a comparison in the middle of the three-minute testing window. It can also be seen that the highest ratio of RPM(W) to RPM(0) was 2.388, whereas the lowest ratio was 1.170 . This wide range of values could be due to each person's own personal way of propelling the wheelchair. Some subjects would set further up in the chair, whereas others would set completely back in the chair. Each subject had a different style of propulsion along with a different cadence at which they propelled the wheels. The only instruction that was given to the test subjects was whether or not they were holding the output torque values within the given range of 10 in*lbs. The cadence and seating position was then left up to the test subjects. The given values of RPM(W) and RPM(0) were then averaged in order to give an average angular velocity (RPM) value for each set of data. The average angular velocity value of the wheel method of propulsion, RPM(W) was 36.531 RPM's, whereas the average angular velocity value for the innovative mechanism method of propulsion, RPM(0) was 22.473 RPM's. The average ratio of the $\mathrm{RPM}(\mathrm{W}) / \mathrm{RPM}(0)$ that was obtained was 1.640 . The ratio of the wheel angular velocity (RPM) to the innovative mechanism angular velocity (RPM) was formulated to demonstrate the mechanical advantage that was being created by the innovative mechanism at a given load of $10 \mathrm{in*lbs}$. This value of 1.640 means that the standard wheelchair propulsion system requires 1.640 times the angular velocity (RPM) required by the innovative mechanism to sustain the same load.

By inspection of the graphs in Appendix C, it can be seen that subjects 1, 3, 4, 6, 8, and 10 demonstrated a general trend of slowly decreasing RPM values for the wheel 
method of propulsion, whereas they demonstrated a slightly increasing RPM value for the innovative mechanism method of propulsion.

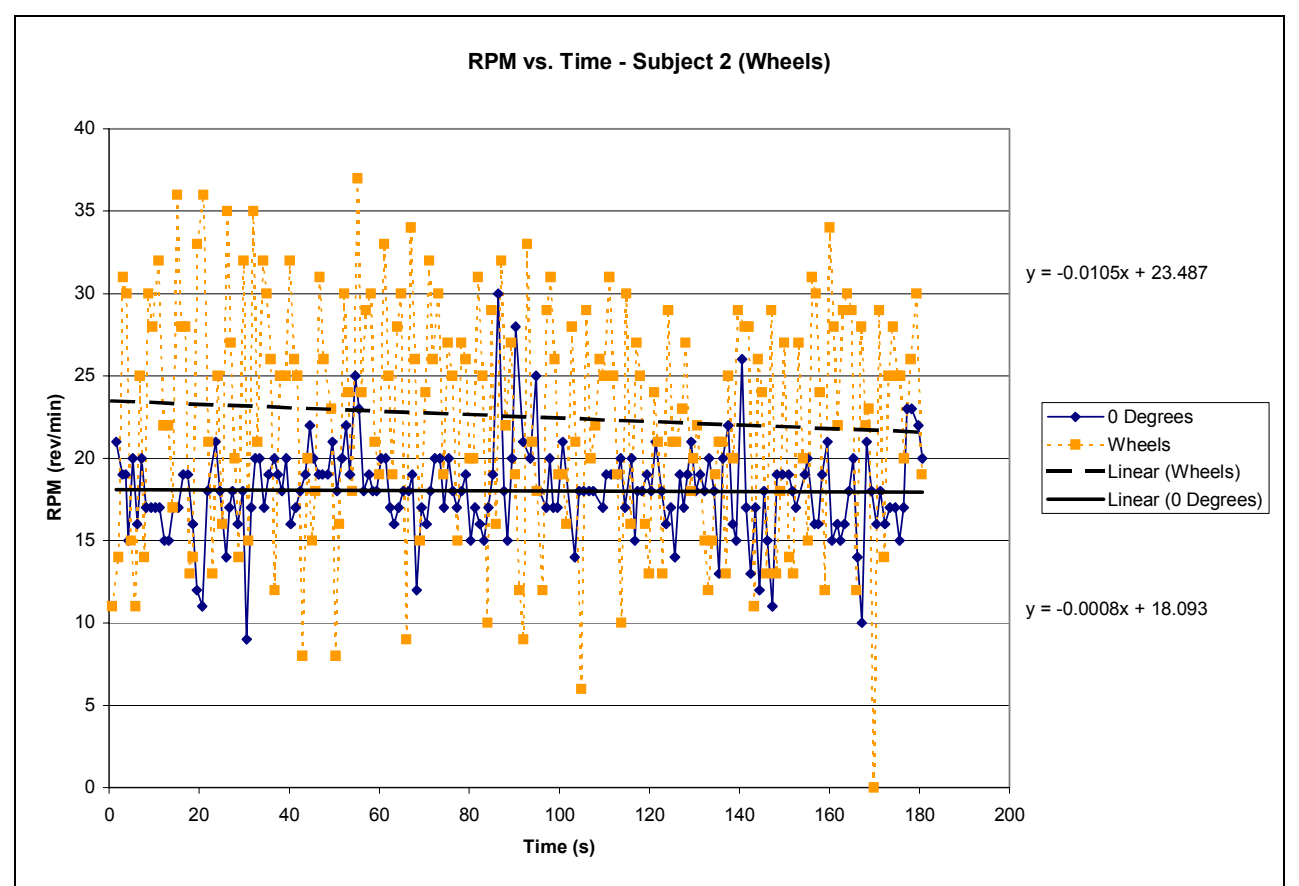

Figure 61 - RPM Results For Subject 1 - Wheels (10 in*Ibs) 


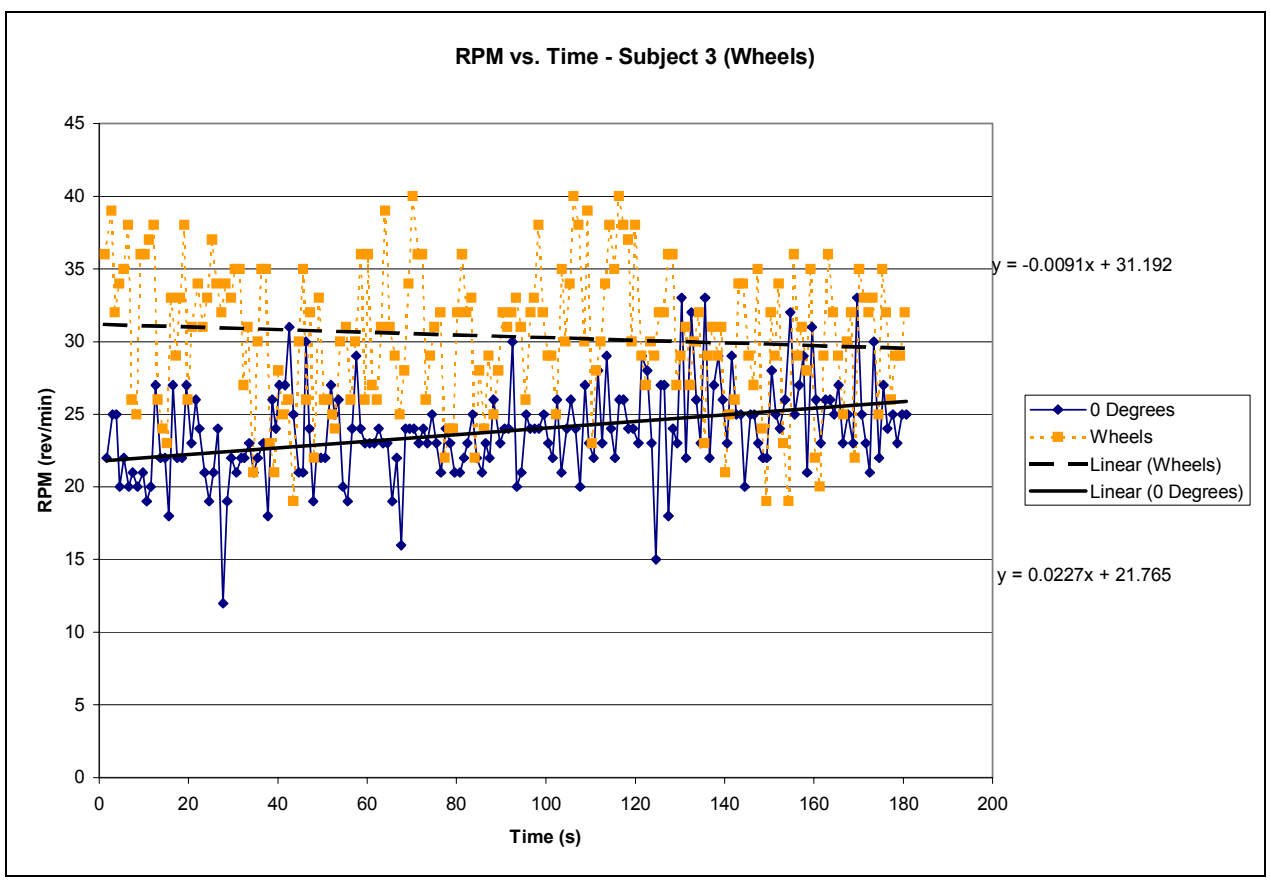

Figure 62 - RPM Results For Subject 3 - Wheels (10 in*lbs)

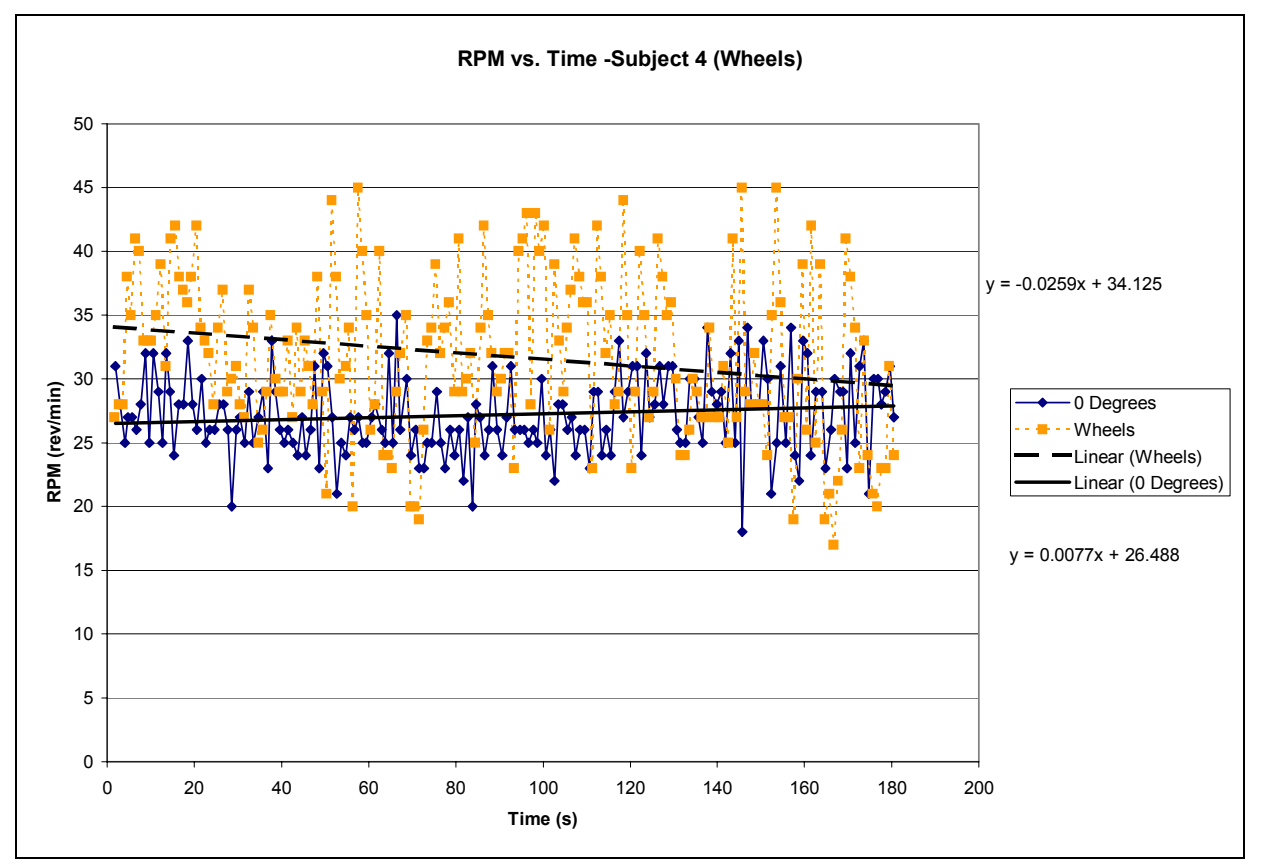

Figure 63 - RPM Results For Subject 4 - Wheels (10 in*lbs) 


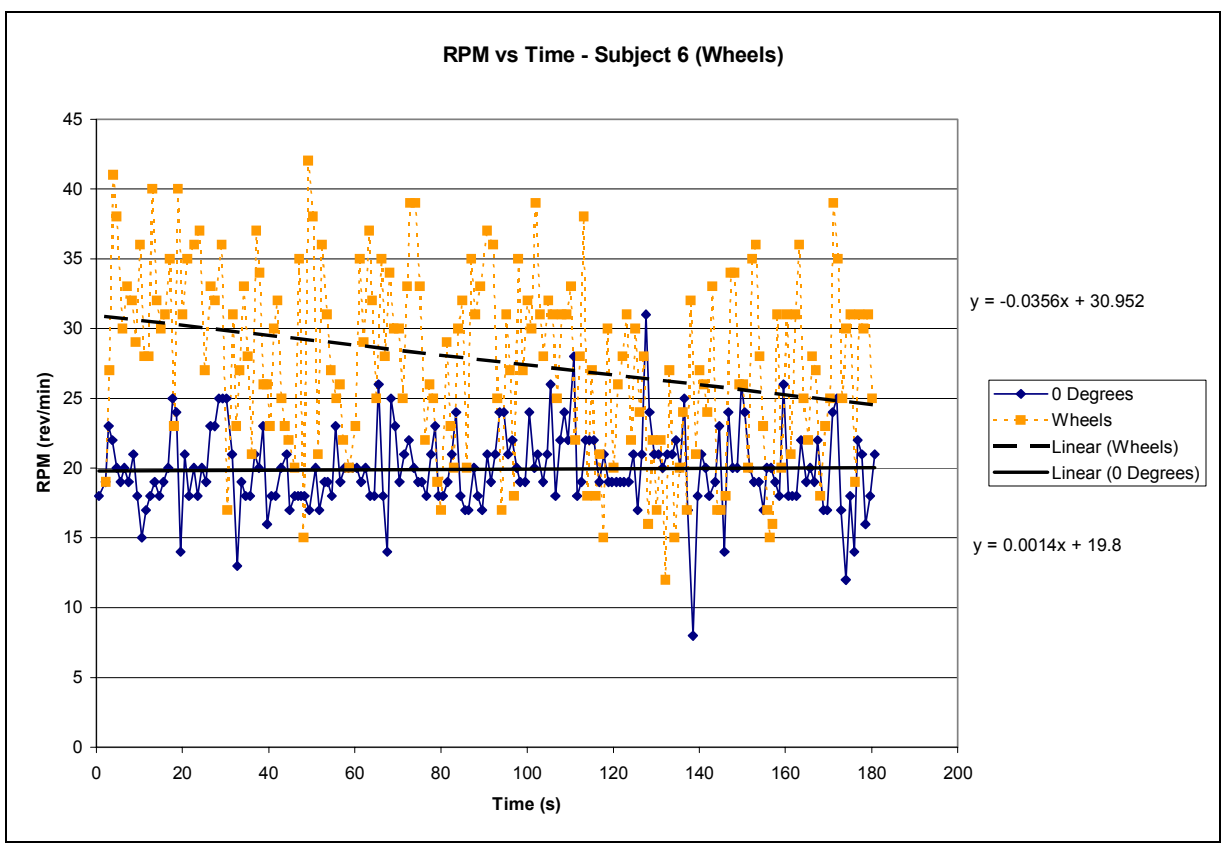

Figure 64 - RPM Results For Subject 6 - Wheels (10 in*lbs)

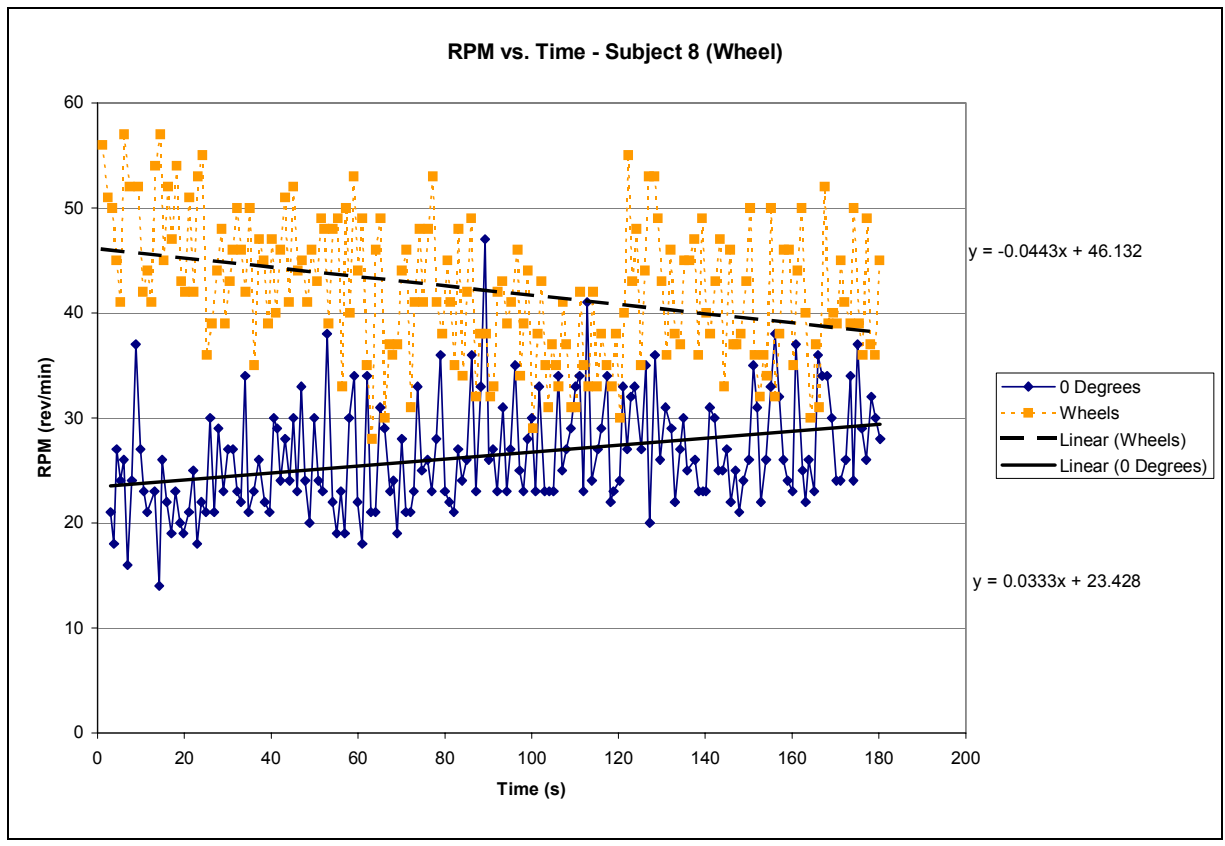

Figure 65 - RPM Results For Subject 8 - Wheels (10 in*lbs) 


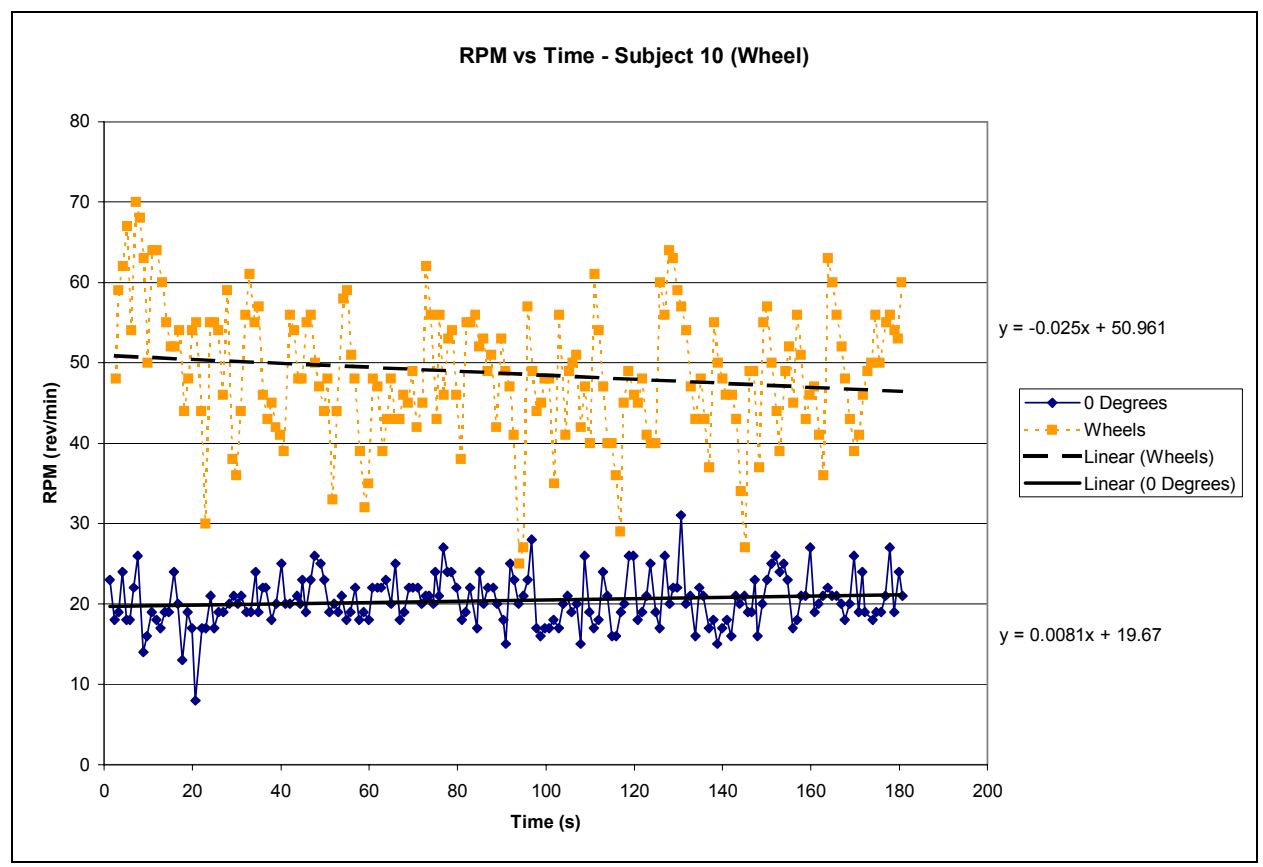

Figure 66 - RPM Results For Subject 10 - Wheels (10 in*lbs)

This general trend could mean that fatigue was setting in during the wheel method of propulsion, but the innovative mechanisms did not result in the subjects entering the fatigue state as quickly. Subject 7 was the only subject that showed a steady RPM curve for each of the two types of propulsion, but with the RPM values of the wheel propulsion method still higher than the RPM range for the innovative mechanism propulsion. 


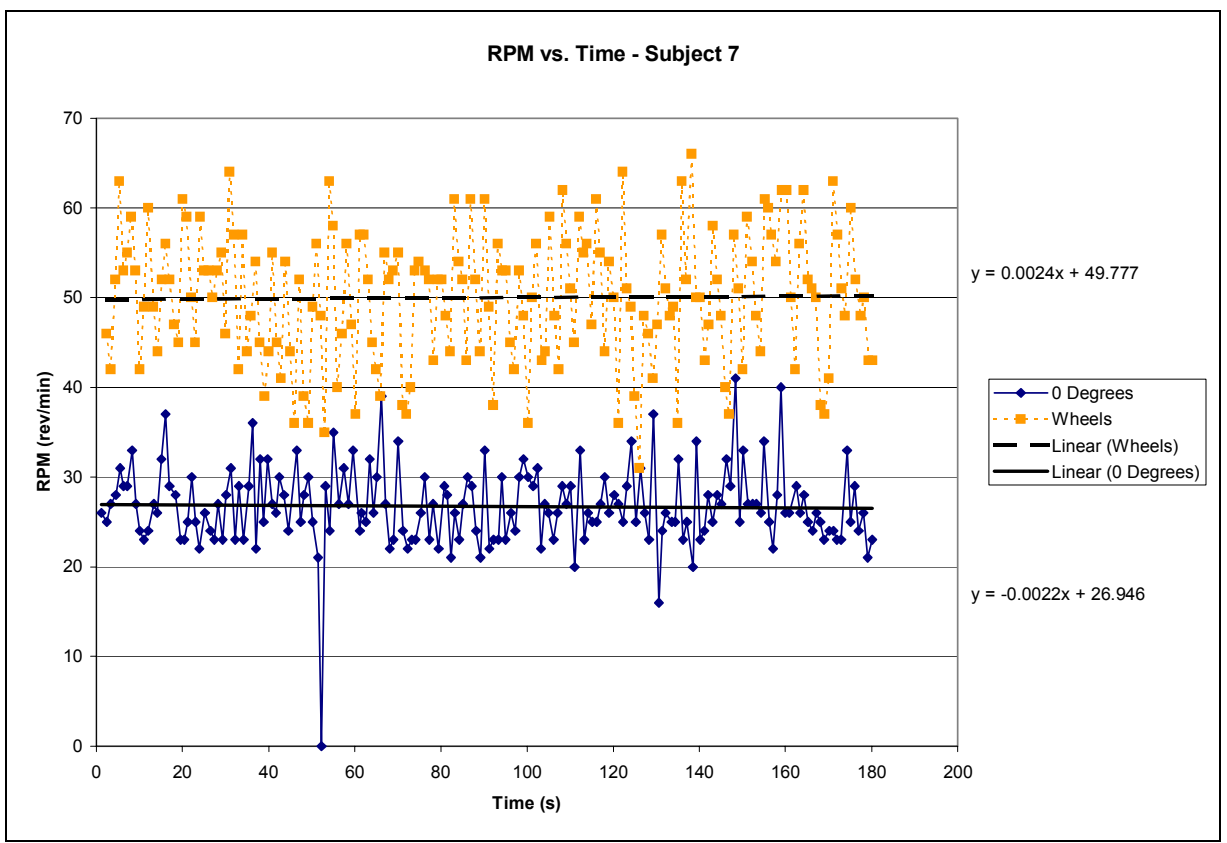

Figure 67 - RPM Results For Subject 7 - Wheels (10 in*lbs)

Subject 2 demonstrated an RPM increase in both the wheel and innovative mechanism methods of propulsion. Whereas, subject 9 demonstrated an increase in RPM for the wheel method of propulsion, but a decline in RPM for the innovative mechanism method of propulsion. 


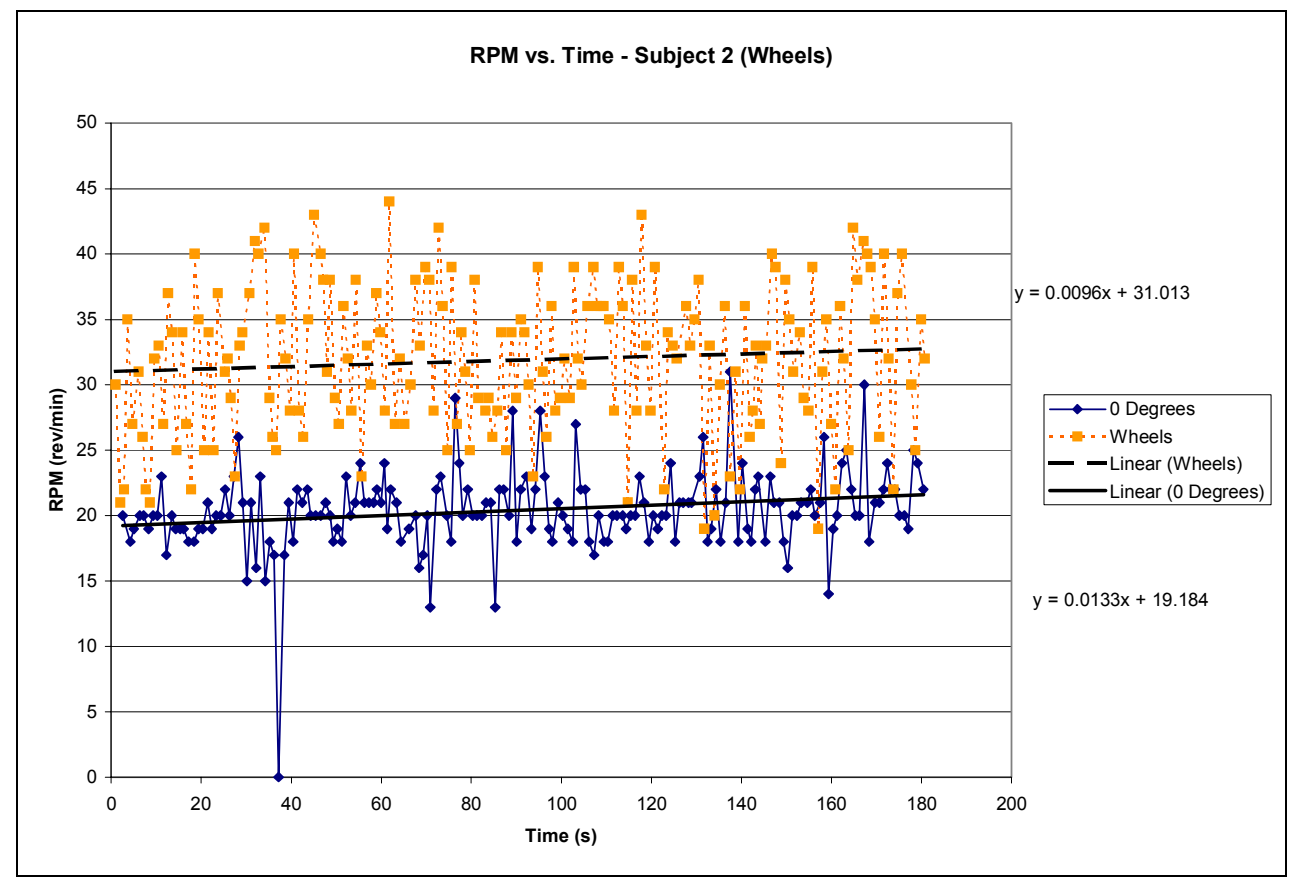

Figure 68 - RPM Results For Subject 2 - Wheels (10 in*lbs)

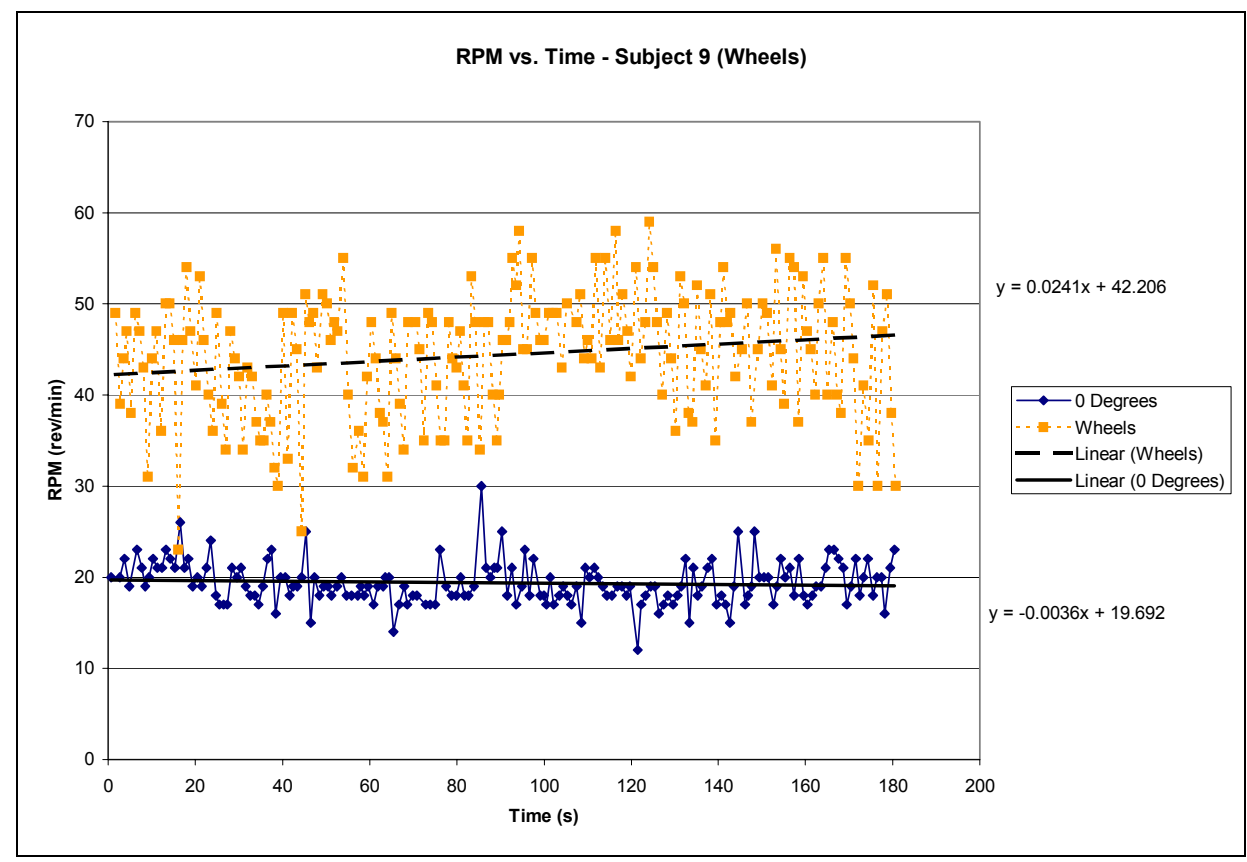

Figure 69 - RPM Results For Subject 9 - Wheels (10 in*lbs)

The overall range of the RPM values was larger in each case for the wheel method of propulsion as compared to the innovative mechanism method of propulsion. 
This general trend could explain the fact that eight of the nine subjects experienced shoulder or upper-arm discomfort after the testing procedure. The shoulder was being made to rapidly accelerate and move in an abnormal range of motion. This reiterates the conclusions that have been drawn by other investigators, see Literature Review for examples.

The next set of data that was analyzed was for horsepower results of the nine human test subjects. The horsepower results look very reminiscent of the RPM value results, but the horsepower results are shown to give validity to the analysis procedure that was used. The horsepower curves were also fitted with a linear curve fit and point at 90 seconds was analyzed. Once again, this provided a way of comparing the actual graphs of the horsepower. The following table contains the results of the horsepower section of the analysis.

Table 14 - Horsepower Comparison of Wheel and Innovative Mechanism Propulsion Methods

\begin{tabular}{|r|r|r|r|}
\hline Subject & $\mathrm{HP}$ (Wheels) & $\mathrm{HP}(0$ Degrees) & Ratio HP(W)/HP(0) \\
\hline 1 & 0.00342 & 0.0028 & 1.221 \\
\hline 2 & 0.00508 & 0.00318 & 1.597 \\
\hline 3 & 0.00481 & 0.00376 & 1.279 \\
\hline 4 & 0.00504 & 0.00429 & 1.175 \\
\hline 5 & Uncompleted & Uncompleted & 1.205 \\
\hline 6 & 0.00436 & 0.003618 & 1.855 \\
\hline 7 & 0.007927 & 0.004273 & 1.607 \\
\hline 8 & 0.00667 & 0.00415 & 2.315 \\
\hline 9 & 0.00706 & 0.00305 & 2.426 \\
\hline 10 & 0.00774 & 0.00319 & 1.63128 \\
\hline AVERAGE
\end{tabular}

The same general trends can be seen in Table 14 as were seen for the RPM results. The average ratio of the horsepower used to propel the wheels, $\mathrm{HP}(\mathrm{W})$, to the horsepower used to propel the innovative mechanism, $\operatorname{HP}(0)$, was 1.631 . This value is essentially the same as the value that was obtained for the $\mathrm{RPM}(\mathrm{W})$ to $\mathrm{RPM}(0)$ results. Any differences 
are simply a result of rounding error in the calculations. The same general trends in the horsepower curves can also be seen for each subject. Once again, the horsepower results look very similar to the RPM results because there is simply a scaling factor used to go between the two values.

The final set of results that were tabulated were for an energy analysis on the wheel and innovative mechanism methods of propulsion. The data that was obtained from the human testing included a column of data in watts. In order to give an energy comparison the watts were divided by 1000 and multiplied by the number of hours each subject spent in the test procedure. Each subject spent a total of 3 minutes in each test. 3 minutes gives a total of 0.05 hours. The energy results were then in kw-hrs. This is a basic unit of energy that most people understand. In order to obtain one solid number for the number of kilowatts that were used, an average was taken of all of the data points that were obtained over the three-minute testing period. The comparison of the energy results to the RPM and horsepower results will provide of method of verifying the various methods of analysis. The following table gives a comparison of energy analysis for each of the propulsion methods. 
Table 15 - Results of Energy Analysis for Wheels and Innovative Mechanism Propulsion

\begin{tabular}{|c|c|c|c|}
\hline Subject & $\begin{array}{l}\text { Energy (Wheels) } \\
\text { (kw-hrs) }\end{array}$ & $\begin{array}{l}\text { Energy ( 0-Degrees) } \\
\text { (kw-hrs) }\end{array}$ & Ratio Energy(W)/Energy(0) \\
\hline 1 & \begin{tabular}{|l|}
0.000126246 \\
\end{tabular} & 0.000105652 & 1.194918215 \\
\hline 2 & 0.000188653 & 0.000120706 & 1.562906623 \\
\hline 3 & 0.000179672 & 0.000140006 & 1.283322372 \\
\hline 4 & 0.000188008 & 0.000160881 & 1.168620612 \\
\hline 5 & Uncompleted & Uncompleted & \\
\hline 6 & 0.00016287 & 0.000117425 & 1.387008574 \\
\hline 7 & 0.000295986 & 0.000158439 & 1.868140048 \\
\hline 8 & 0.000249042 & 0.000156508 & 1.591234871 \\
\hline 9 & 0.000262593 & 0.000114663 & 2.290134863 \\
\hline 10 & 0.000288119 & 0.000120254 & 2.395922038 \\
\hline AVERAGE & 0.000215688 & 0.000132726 & 1.638023135 \\
\hline
\end{tabular}

By inspection of Table 15 it can be seen that the average ratio of the energy used to propel the wheels, Energy(W), to the energy used to propel the innovative mechanism, Energy(0), was 1.638. This value of 1.638 means that is takes 1.638 times that energy to propel the wheels as it takes to propel the innovative mechanism. In addition, the energy ratio average of 1.638 was very comparable to the RPM ratio average of 1.640 and the horsepower ratio average of 1.631. Since approximately the same advantage was found throughout the three different analysis techniques, the results are confirmed. The conclusion section contains a summary of the results that were obtained.

\section{Conclusions}

$>$ A new innovative mechanism that can be adapted to traditional wheelchairs has been designed, modeled, constructed, and tested.

$>$ The test results indicate that preferential orientation of the major axis of the ellipse on the propulsion system creates no distinct mechanical advantage. There was evidence 
of significant frequency of sticking in the offset angle condition. It is believed this was due to the lack of moment arm as the human arm was locked at the elbow, and the because of the line of action of the human input force.

When compared with the innovative mechanism propulsion system, it was shown that an increase of 1.640 times the angular velocity of the innovative mechanism propulsion system was required by the standard wheelchair propulsion system to sustain a constant torque load of $10 \mathrm{in} * \mathrm{lbs}$.

Subjects that were used to test both methods of propulsion inevitably experienced and complained of shoulder pain while using the traditional method of wheelchair propulsion. No complaints of discomfort were experienced for the innovative mechanism method of propulsion.

The innovative mechanism propulsion system has been shown to allow for advantages over standard wheelchair propulsion. However, it must be noted that data was only taken on the output side. Data needs to be taken on the input parameters to determine the amount of work that is actually going into propelling the different modes of propulsion.

The methods of testing and obtaining data should be revised. The experimental procedures that were used in this project were only concerned with maintaining a constant torque load. A testing regime should be developed that uses the dynamometer to apply a load, and the subjects are instructed to hold the RPM's as constant to a given value as possible. This new testing methods would then assure that each of the propulsion methods allowed the wheelchair to travel approximately the same distance. 
The oxygen, heart rate, and muscle activation data could then be obtained to give a true comparison between the two propulsion methods.

\subsection{Specific Accomplishments of This Research (What's New)}

$>$ A new innovative propulsion system based on Cardan gearing was invented for wheelchair propulsion application.

$>$ Engineering drawings for the mechanism were compiled based on mathematical models to simulate the SC wheelchair propulsion stroke. These drawings were used by Laser Processing to manufacture four complete propulsion units.

$>$ The propulsion units were retrofitted onto a standard wheelchair frame in the MAE shop.

$>$ A testing station was design and fabricated to test wheelchair propulsion methods in the MAE shop. A dynamometer was sized, purchased, and mounted on the testing station.

Human subjects were recruited and tested for both mechanism angle efficiency and propulsion method comparison.

$>$ Testing has shown that angular orientation does not demonstrate any efficiency in the innovative mechanism propulsion system.

$>$ Testing has shown that the innovative propulsion system required less angular velocity (RPM) to maintain a constant load as compared to the standard method of wheelchair propulsion. 


\section{Recommendations}

The work that has been done so far on the innovative wheelchair project has laid the groundwork upon which further work can be based. The innovative mechanism has already been shown to work, and it has also been shown that the innovative mechanism has advantages over standard wheelchair propulsion. The next step of this design process should include data on which muscles are being used, and on the amount of work that the person is actually doing in the wheelchair. This thesis has shown an energy advantage by using the innovative mechanism, but this was only based on the outputs of the system. Tests should be run to obtain the oxygen consumption, heart rate, and breathing rate of test subjects using both the innovative mechanism and the standard wheelchair wheels. All of this data may not be able to be collected during the same phase of the project, but the investigators should look at the amount of energy consumption that is required for a person to propel both modes of propulsion. In addition, an EKG machine or some other method of obtaining muscle contraction data should be used to validate which muscles are being used with both the innovative mechanism and the standard wheelchair wheels.

It is my belief that once these future steps are accomplished, a real advantage will be seen in the innovative mechanism.

On the design side of the project, a method should be investigated as to how the play in the mechanism, especially around the bearings, could be prevented. Whenever the user pushes on the handle, a large moment is generated at the bearings, and subsequent wear of the shaft follows. In addition, before the innovative mechanism can be marketed, a housing should be made that encloses the working parts of the mechanism. This 
housing will keep people's clothes and other objects form coming in contact with the sprockets and roller chains.

Work also needs to be done on installing a gearing or transmission system on the retrofitted wheelchair. There also needs to be work done on the scotch yoke system that has been talked about. In addition, a method needs to be designed to add a coast phase into the gearing of the innovative mechanism. Hand brakes will also have to be designed in conjunction with the coast mechanism phase of development.

Funding has also been a problem, but now that the initial groundwork has been laid and data has been taken to initially validate the innovative mechanism, funding should be easier to come by, and more doors will be open.

This may seem like a lot of work that still should be done on the project, but when I started, all that I had was the basic design of the innovative mechanism. This project has come a long way in the past 18 months. One of my main concerns on this project was accessing the benefits of the innovative mechanism because there are serious health and social benefits that can be accomplished with this project! 


\section{References}

${ }^{1}$ http://cosmos.ot.buffalo.edu/t2rerc/programs/demandpull/mobility/problem-statements/ps-geared-hubs.html

2 “State Makes Advances For People With Disabilities”. WV Retirement Times. April/May/June 1999. P1.

${ }^{3}$ http://asb-biomech.org (January 2002)

${ }^{4}$ http://cosmos.ot.buffalo.edu (January 2002)

${ }^{5}$ Sean D. Shimada, PhD; Rick N. Robertson, PhD; Michael L. Bonninger, MD; Rory A. Cooper, PhD, "Kinematic characterization of wheelchair propulsion." Journal of Rehabilitation Research and Development Vol. 35 No. 2 (June 1998) : Pages 210-218.

${ }^{6}$ www.wheelchairnet.org (January 2002)

${ }^{7}$ http://www.ilcnsw.asn.au/ability.cfm (January 2002)

${ }^{8}$ www.frankmobility.com (April 2002)

${ }^{9}$ http://factsheets.disabledliving.org.uk (January 2002)

${ }^{10} \mathrm{http}$ ://catalog.invacare.com (January 2002) OR www.invacare.com (May 2002)

${ }^{11}$ http://www.jbtc.or.jp/current/english/wheelchairs/ (January 2002)

12 www.wijit.com

${ }^{13}$ Lucas H.V. van der Woude, PhD; Eugenie Botden, MsC; Ingrid Vriend, MsC; Dirtjan Veeger, PhD. "Mechanical advantage In wheelchair lever propulsion: Effect on physical strain and efficiency." Journal of Rehabilitation Research and Development Vol 34 No. 3. (July 1997): Pages 286-294.

${ }^{14}$ http://www.msnbc.com/news/285231.asp\#BODY (January 2002)

${ }^{15}$ Shigley and Mishke. Mechanical Engineering Design, Firth Edition. McGraw-Hill, Inc., 1989.

${ }^{16}$ http://www.magtrol.com

${ }^{17}$ http://www.access-board.gov/adaag/html/fig11.html (May 2002). 


\section{Acknowledgements}

When I graduated with my Bachelor's Degree, I never thought that I would be graduating with my Master's Degree. It was my original plans to get a job and make money as soon as possible. But, through the continued efforts (badgering) of Dr. Long I ended up in the Master's Degree program at WVU and began working on the Innovative Wheelchair Project. This project has really allowed me to see how engineers can make a real difference in the world. I'd just like to thank Dr. Long for his continued effort and guidance through my entire Master's Degree tenure. Dr. Long says that he's going on phased retirement, but I'm not sure how working only part time is any different than what he is doing now! And then there's Dr. Stiller. When I first met Al, I wasn't even sure what this "Mad-Man" was doing. I have learned so much from Al. One of the most important things that I have learned is how to play the "GAME" very successfully. I will always remember the famous words of Dr. Stiller: "No really, I'm innocent, ..., Thank you very much." I'd also like to thank Dr. Wayne for his support as a chairman. I know that you had a lot of things going on with your fuels projects, so thank you for finding the time to help with this project. I'd like to thank Kevin Swisher for his help on the project. I don't know whom you made mad at work, but you sure must have rattled some chains to get put on a project with us. Also, I'd like to thank Dr. McMullin for her help before she left for Boeing. I'd also like to thank the various undergraduate students who have worked on this project during the past several years.

I'd like to thank the research funding sources that have contributed to this project:

Laser Processing Inc., WVUCED, Kellogg Partnership Program, WVU Research Corporation, Mon HealthCare, and NIOSH. 
Appendix A 


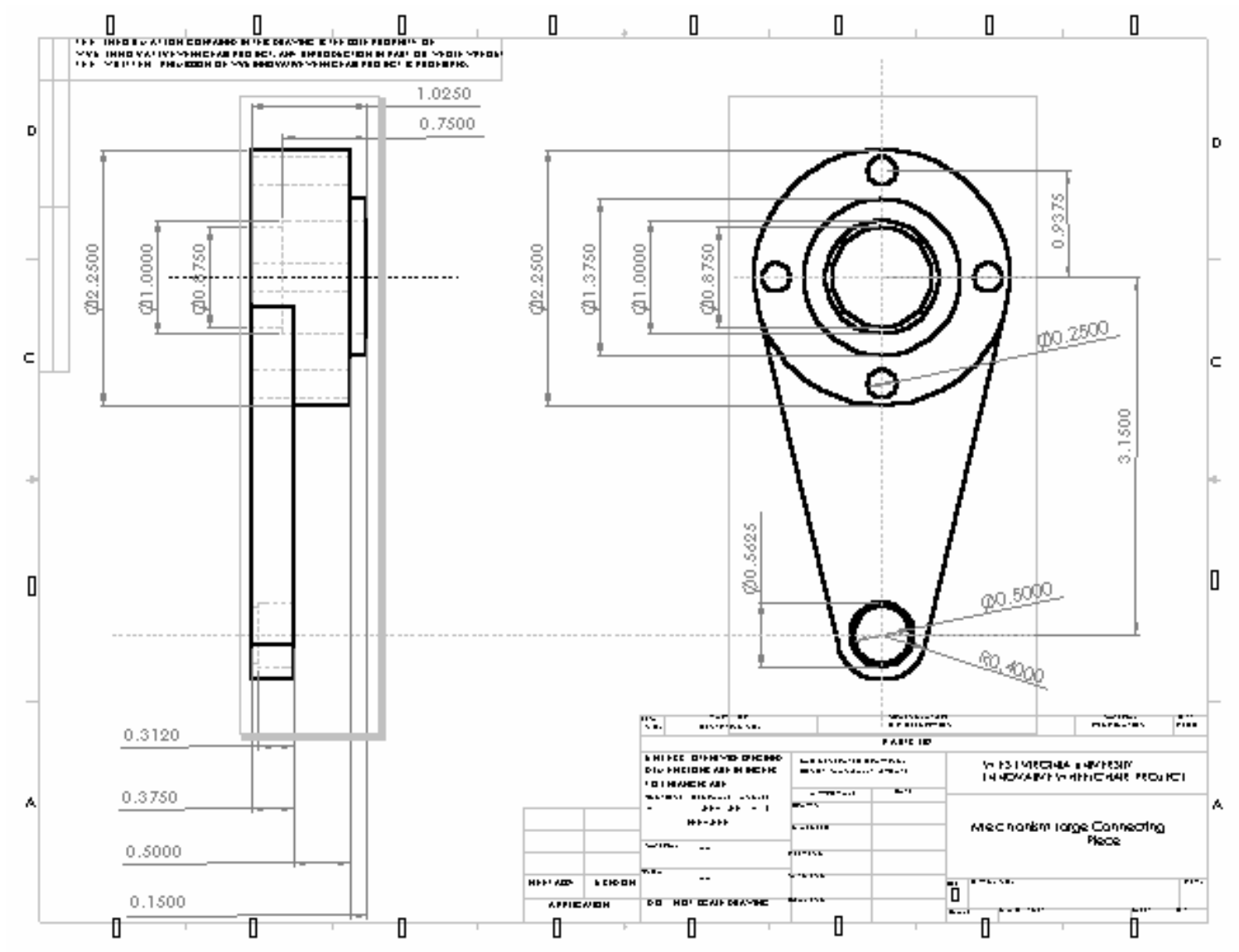

Figure 70 - Drawing Of Back Connecting Lever 


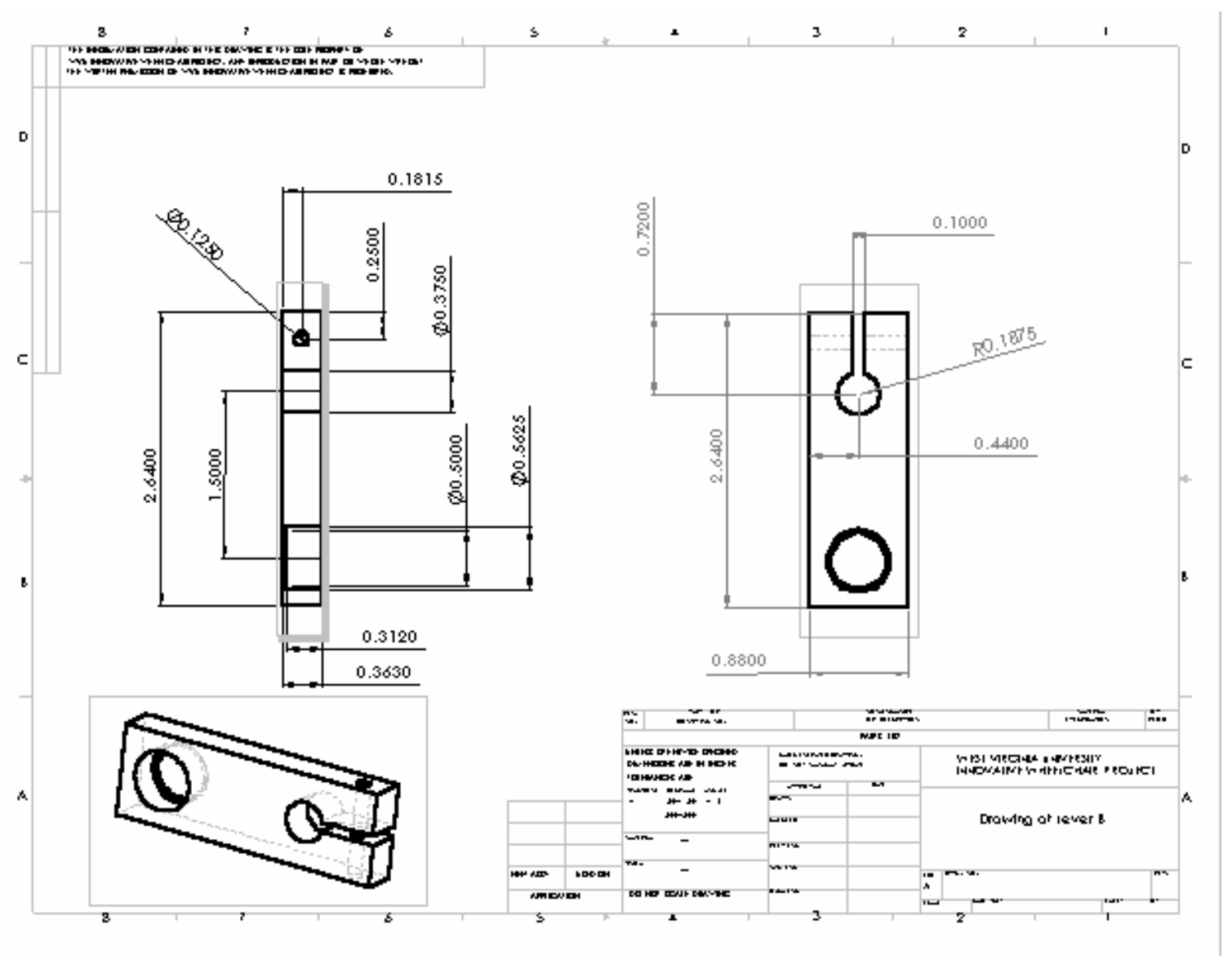

Figure 71 - Drawing Of Lever B 


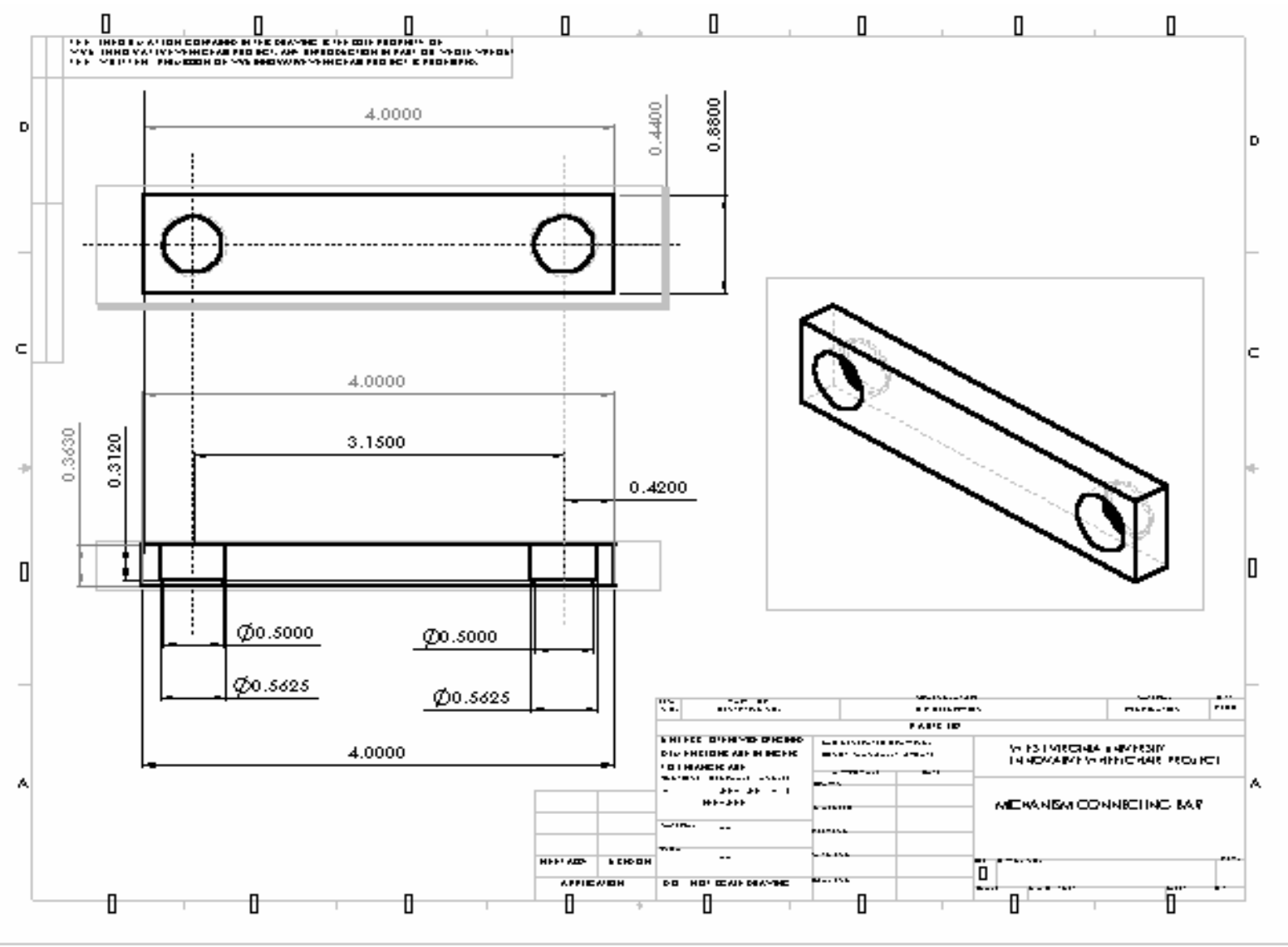

Figure 72 - Drawing Of Lever A (Gear Bar) 


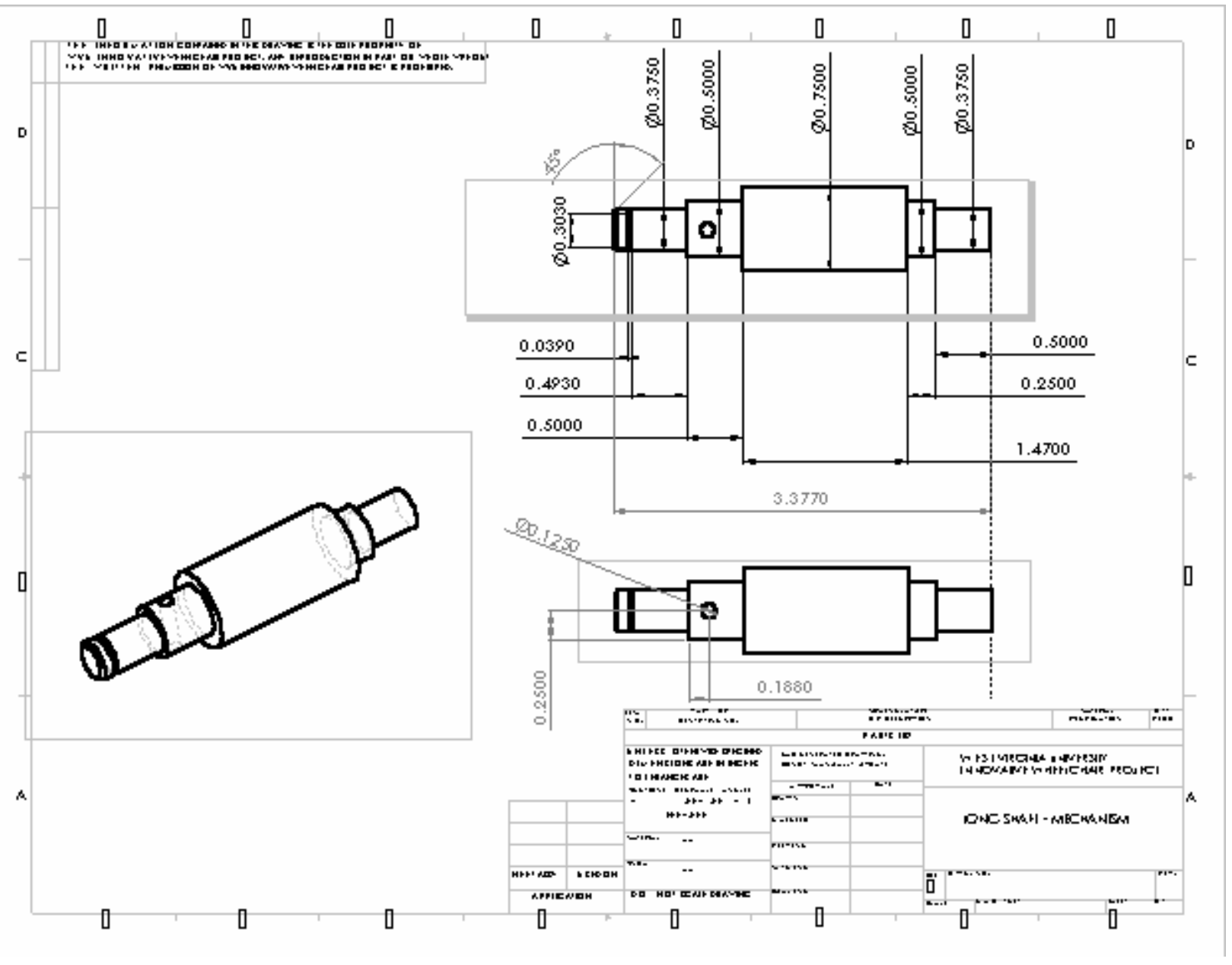

Figure 73 - Drawing Of Mechanism Shaft \#1 


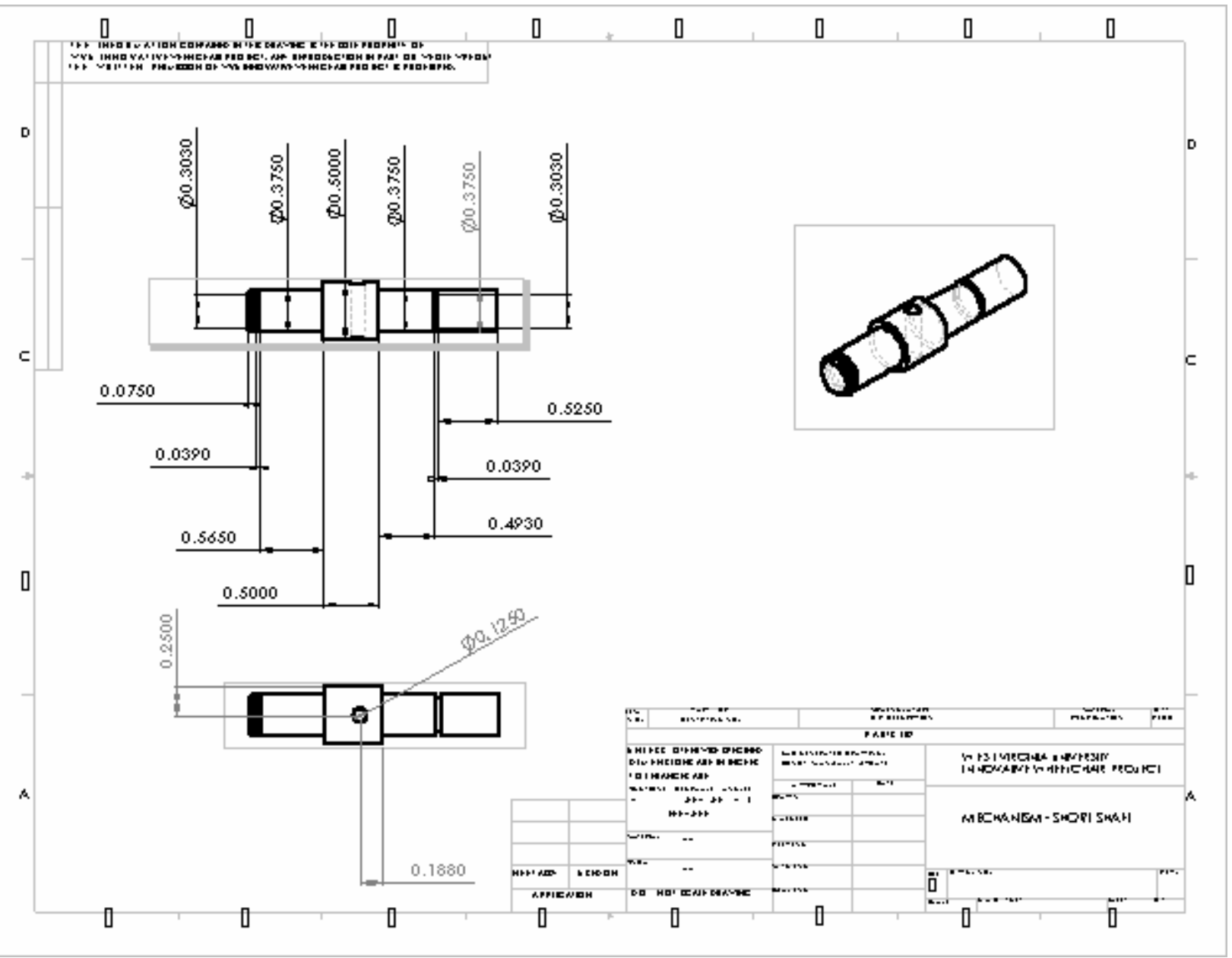

Figure 74 - Drawing Of Shaft \#2 


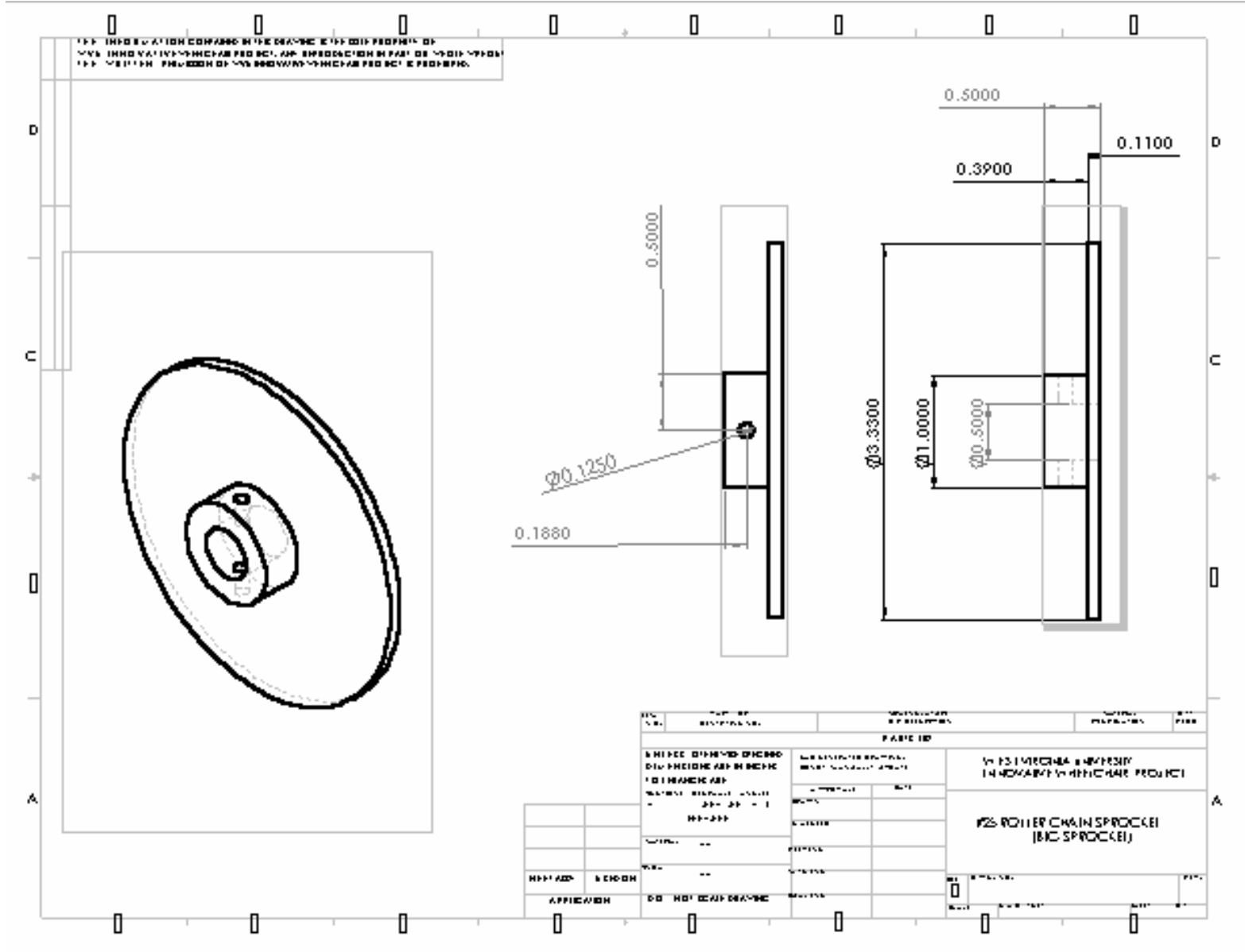

Figure 75 - Drawing Of Sun Sprocket 


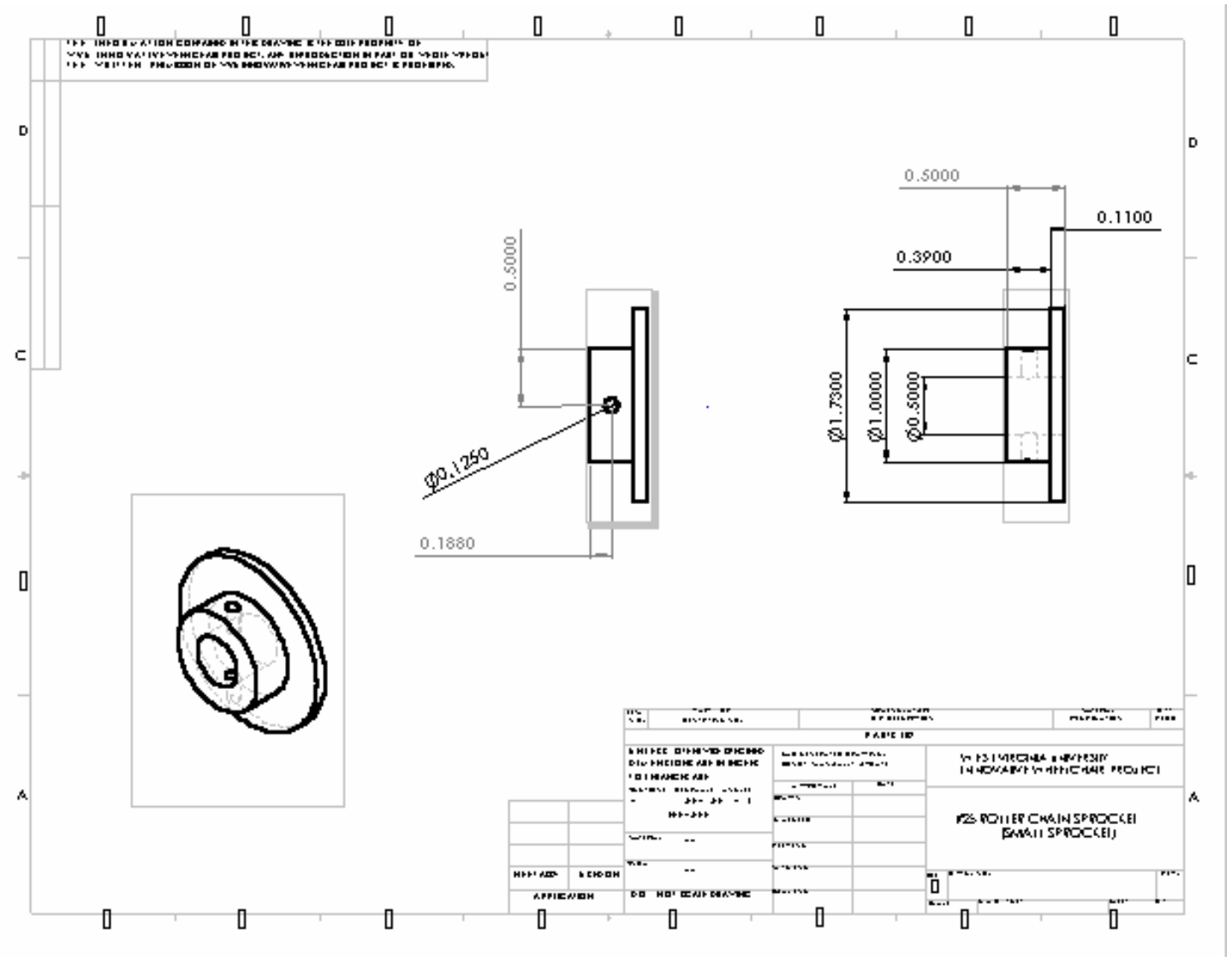

Figure 76 - Drawing Of Planet Sprocket 


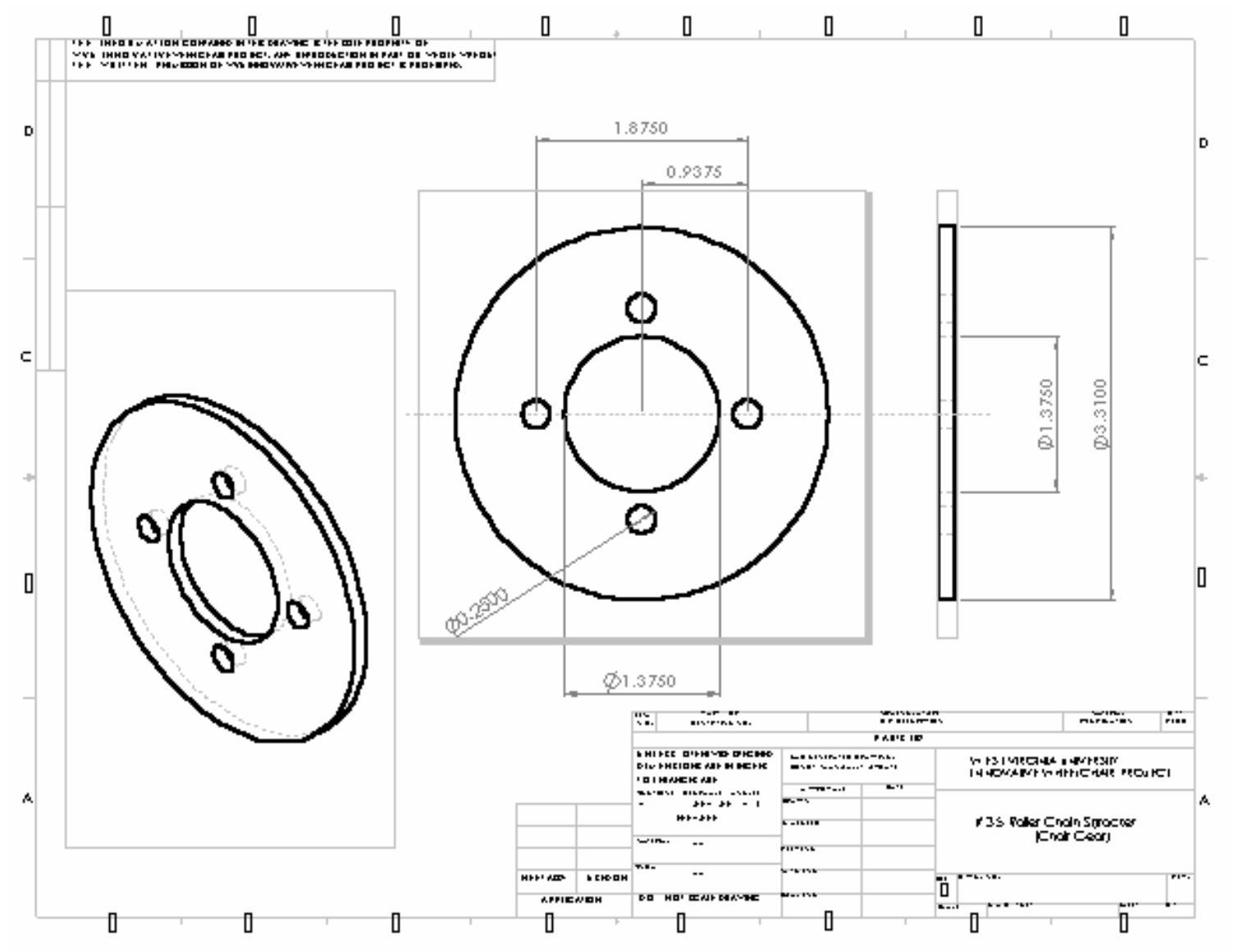

Figure 77 - Drawing Of Connecting Roller Chain Sprocket 
Appendix B 
Table 16 - Results For Deflection and Stress Analysis -Table 1

\begin{tabular}{|c|c|c|}
\hline$\theta_{\text {dyno }}$ & $\theta_{\text {mech }}$ & $\theta_{\text {arm }}$ \\
\hline 10.189 & 47.463 & 45 \\
\hline Fx dyno & 47.775 & \\
\hline Fy dyno & 8.586 & \\
\hline Fx mech & 3.581 & \\
\hline Fy mech & 3.903 & \\
\hline Fx arm & 1.768 & \\
\hline Fy arm & 1.768 & \\
\hline Fy arm\& wheel & 7.768 & \\
\hline E (psi) & $3.00 \mathrm{E}+07$ & \\
\hline I $\left(\mathrm{in}^{\wedge} 4\right)$ & 0.003 & \\
\hline Diameter (in) = & 0.5 & \\
\hline Area (in^2) $=$ & 0.1963 & \\
\hline$C$ (in) $\quad=$ & 0.25 & \\
\hline I (in^4) = & 0.003068 & \\
\hline With Wheel & Safety Factor $=$ & 3.7 \\
\hline With Mechanism & Safety Factor = & 3.4 \\
\hline & & \\
\hline & & \\
\hline & & \\
\hline & & \\
\hline & & \\
\hline
\end{tabular}


Table 17 - Results for Deflection and Stress Analysis -Table 2

\begin{tabular}{|c|c|c|}
\hline \multicolumn{2}{|l|}{ With Wheel } & \\
\hline $\mathbf{R}_{\mathrm{AY}}(\mathrm{lb})$ & $\mathbf{R}_{\mathrm{BY}}(\mathrm{lb})$ & \\
\hline 15.549 & 8.573 & \\
\hline$R_{\mathrm{Ax}}(\mathrm{Ib})$ & $R_{\mathrm{Bx}}(\mathrm{Ib})$ & \\
\hline 41.528 & 2.711 & \\
\hline Y-Direction & X-Direction & \\
\hline at $x=3 V=-7.768$ & at $x=3 V=-1.768$ & \\
\hline $\mathrm{c}_{1}$ & $\mathrm{c}_{1}$ & \\
\hline-7.768 & -1.768 & \\
\hline at $x=4 M=-31.072$ & at $x=4 M=-7.032$ & \\
\hline $\mathrm{c}_{2}$ & $\mathrm{C}_{2}$ & \\
\hline 0.0028 & 0.0391 & \\
\hline$c_{3}$ & $c_{3}$ & \\
\hline 1170.642 & 660.387 & \\
\hline at $x=4 y=0$ & at $x=4 y=0$ & \\
\hline $\mathrm{C}_{4}$ & $\mathrm{C}_{4}$ & \\
\hline-9026.252592 & -6785.072814 & \\
\hline Deflection @ x=24 & Deflection @ x=24 & Magnatude (24) \\
\hline-0.0539 & -0.0441 & 0.0697 \\
\hline Deflection @ x=0 & Deflection @ x=0 & Magnatude (0) \\
\hline-0.098 & -0.074 & 0.1228 \\
\hline Deflection @ x=5.5 & Deflection @ x=5.5 & Magnatude (5.5) \\
\hline-0.0327 & -0.0356 & 0.0483 \\
\hline Deflection @ x=4 & Deflection @ x=4 & \\
\hline-0.0490 & -0.0454 & \\
\hline Deflection @ x = 20 & Deflection @ x=20 & \\
\hline-0.00081 & -0.02564 & \\
\hline
\end{tabular}


Table 18 - Results of Deflection and Stress Analysis - Table 3

\begin{tabular}{|c|c|c|c|}
\hline $\begin{array}{c}\text { With } \\
\text { Mechanism }\end{array}$ & & & \\
\hline $\mathbf{R}_{\mathrm{AY}}(\mathrm{Ib})$ & $\mathbf{R}_{\mathrm{BY}}(\mathrm{Ib})$ & & \\
\hline 3.878 & -3.098 & & \\
\hline $\mathbf{R}_{\mathrm{Ax}}(\mathrm{Ib})$ & $R_{\mathrm{Bx}}(\mathrm{Ib})$ & & \\
\hline 39.715 & 0.898 & & \\
\hline Y-Direction & X-Direction & & \\
\hline at $x=3 \mathrm{~V}=3.903$ & at $x=3 \mathrm{~V}=-3.581$ & & \\
\hline$c_{1}$ & $\mathrm{c}_{1}$ & & \\
\hline 3.903 & -3.581 & & \\
\hline at $x=4 M=7.806$ & at $x=2 M=0$ & & \\
\hline $\mathrm{c}_{2}$ & $c_{2}$ & & \\
\hline-7.806 & 7.162 & & \\
\hline at $x=20 y=0$ & at $x=20 y=0$ & & \\
\hline$c_{3}$ & $c_{3}$ & & \\
\hline-462.96 & 918.238 & & \\
\hline at $x=4 y=0$ & at $x=4 y=0$ & & \\
\hline $\mathrm{C}_{4}$ & $\mathrm{C}_{4}$ & & \\
\hline 3541.428 & -7754.109 & & \\
\hline Deflection @ x=24 & Deflection @ x=24 & Magnitude (24) & \\
\hline 0.0237 & -0.0086 & 0.0253 & in \\
\hline Deflection @ x=0 & Deflection @ x=0 & Magnitude (0) & \\
\hline 0.0385 & -0.084 & 0.0927 & in \\
\hline Deflection @ x=5.5 & Deflection @ x=5.5 & Magnitude (5.5) & \\
\hline 0.0390 & -0.0298 & 0.0491 & in \\
\hline Deflection @ x=4 & Deflection $x=4$ & & \\
\hline 0.0182 & -0.044208473 & & \\
\hline Deflection @ x=20 & Deflection @ x=20 & & \\
\hline 0.0000 & 0.01033 & & \\
\hline
\end{tabular}


Appendix C 


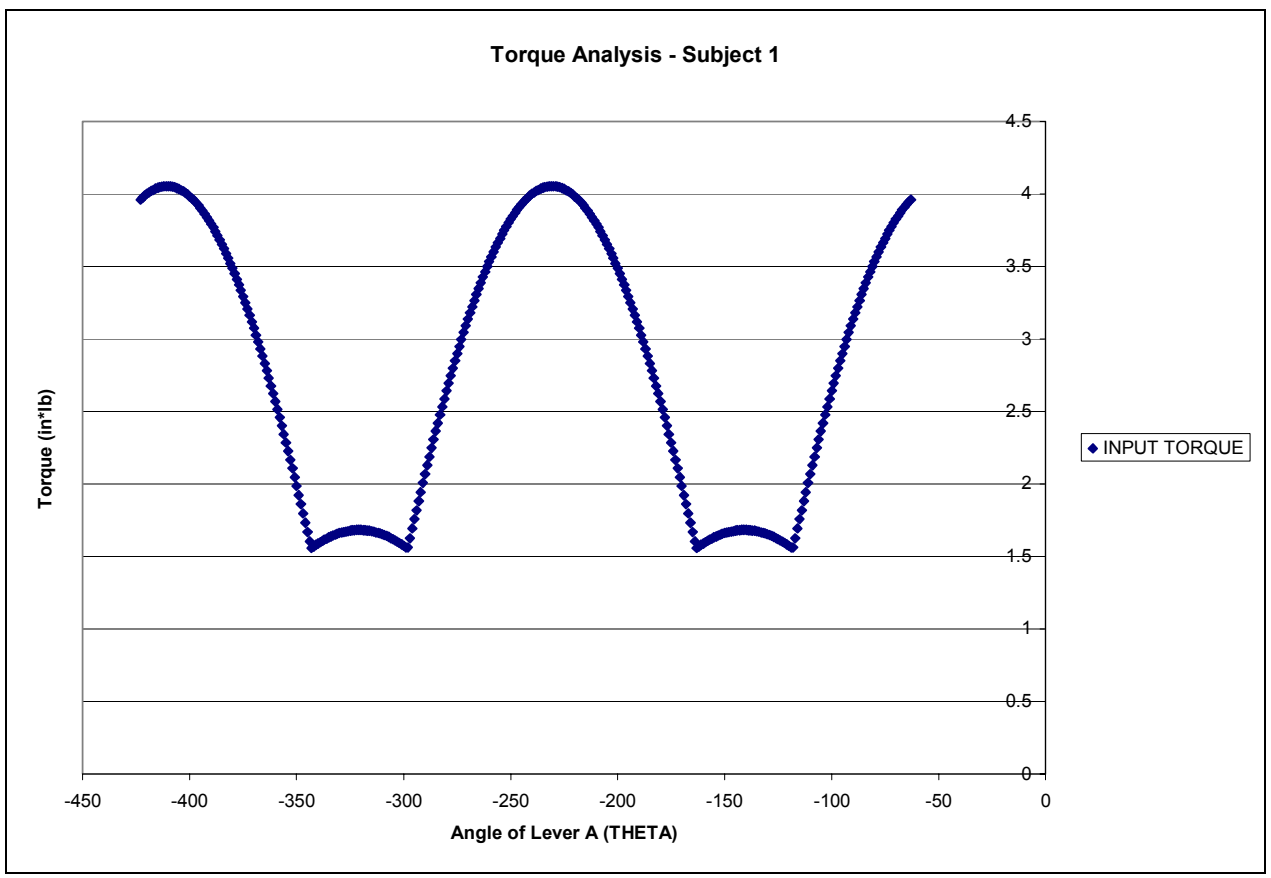

Figure 78 - Results of Torque Analysis For Subject 1

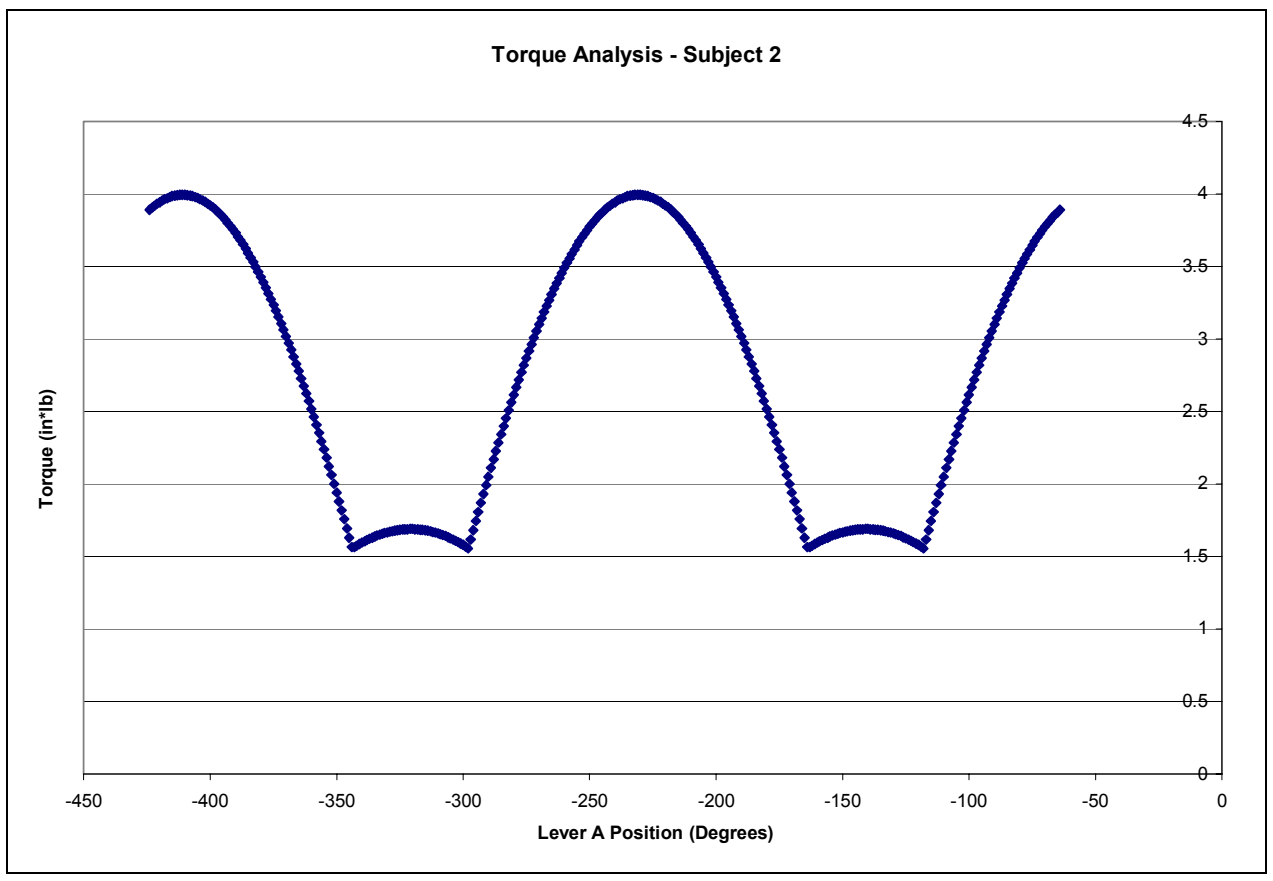

Figure 79 - Results of Torque Analysis For Subject 2 


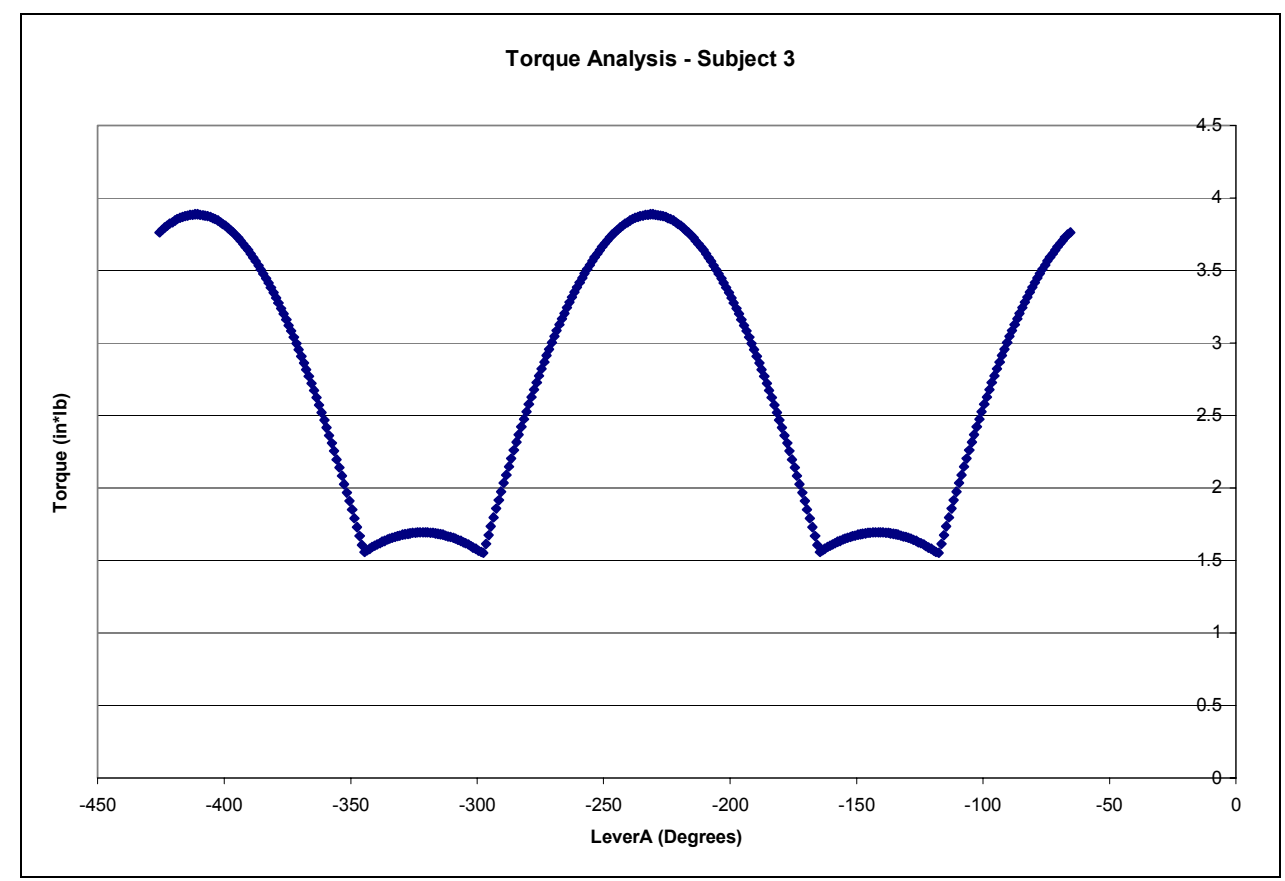

Figure 80 - Results of Torque Analysis For Subject 3

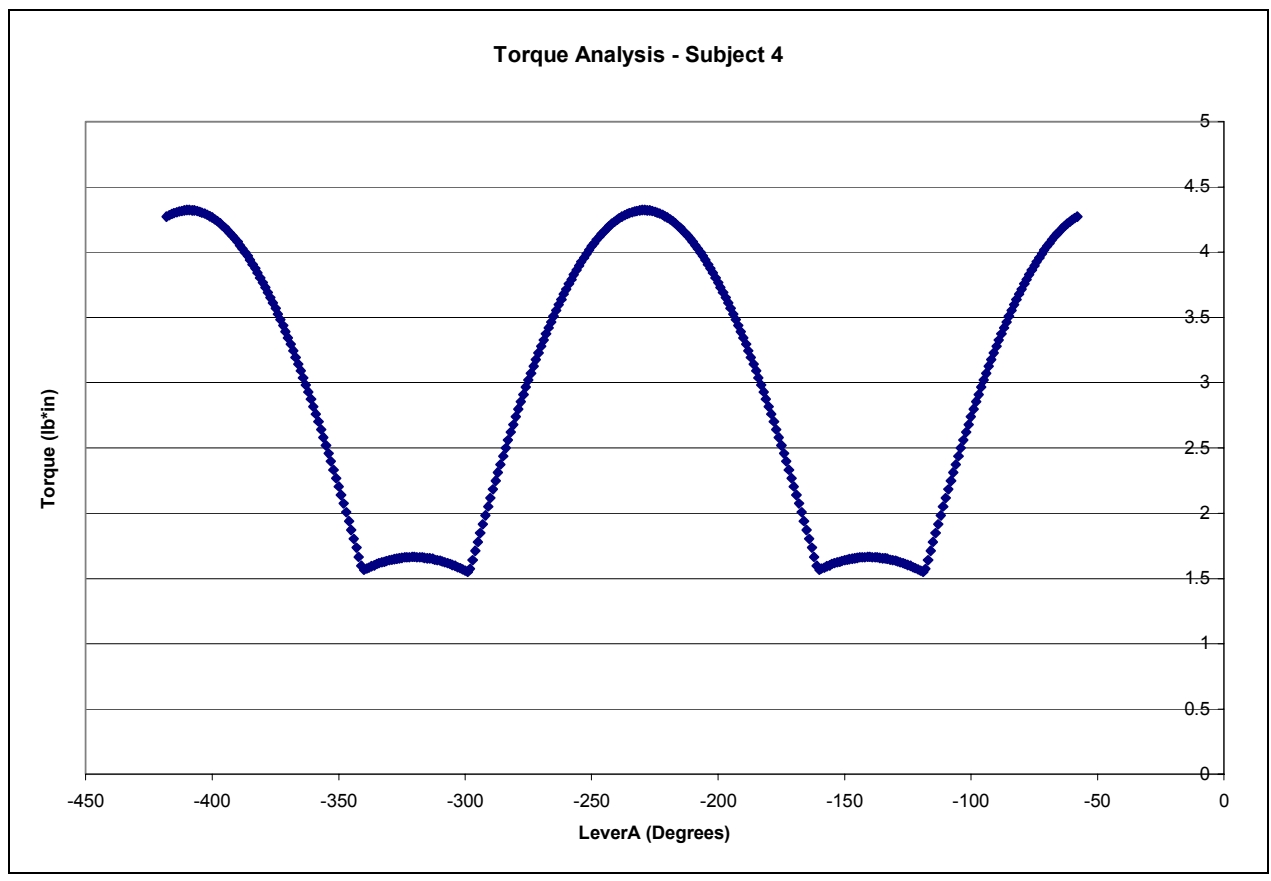

Figure 81 - Results of Torque Analysis For Subject 4 


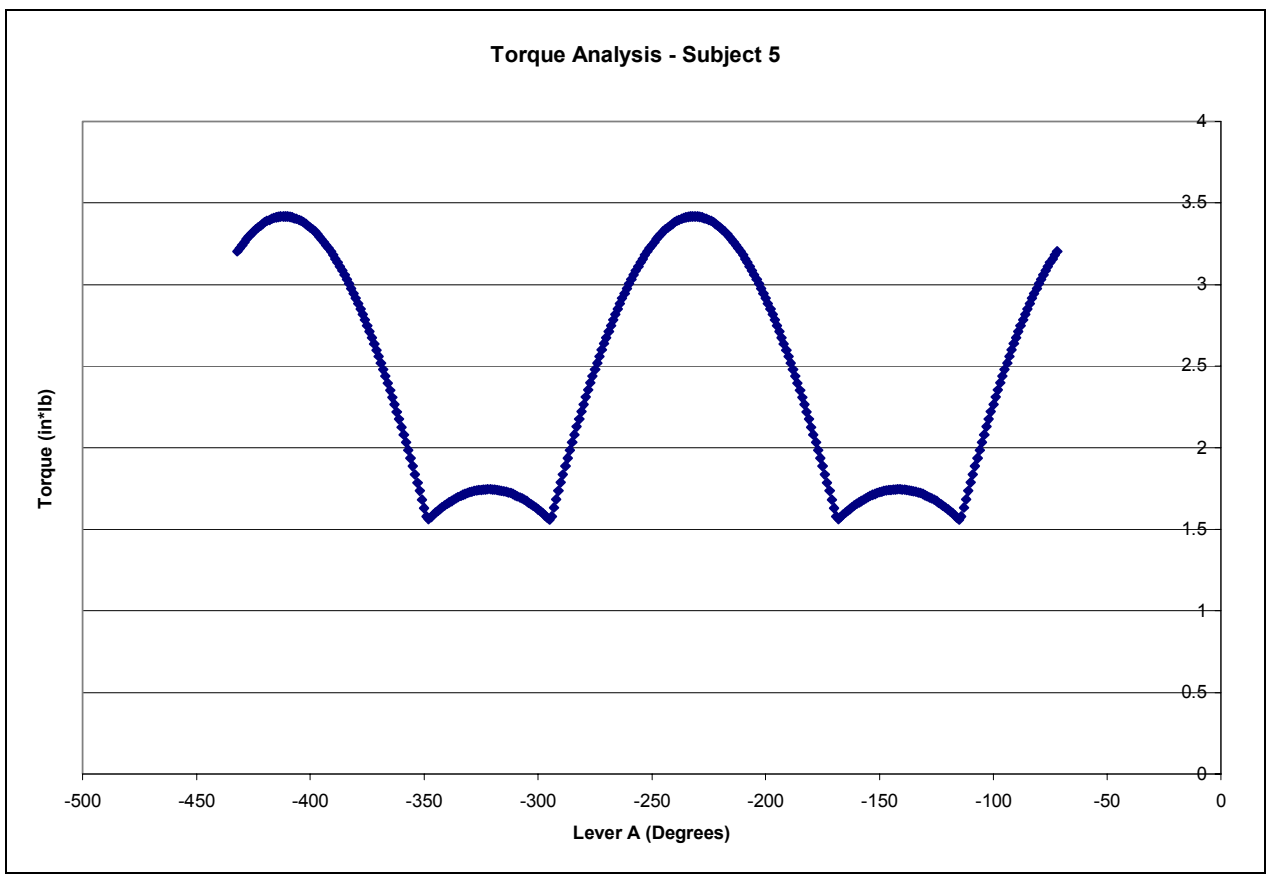

Figure 82 - Results of Torque Analysis For Subject 5

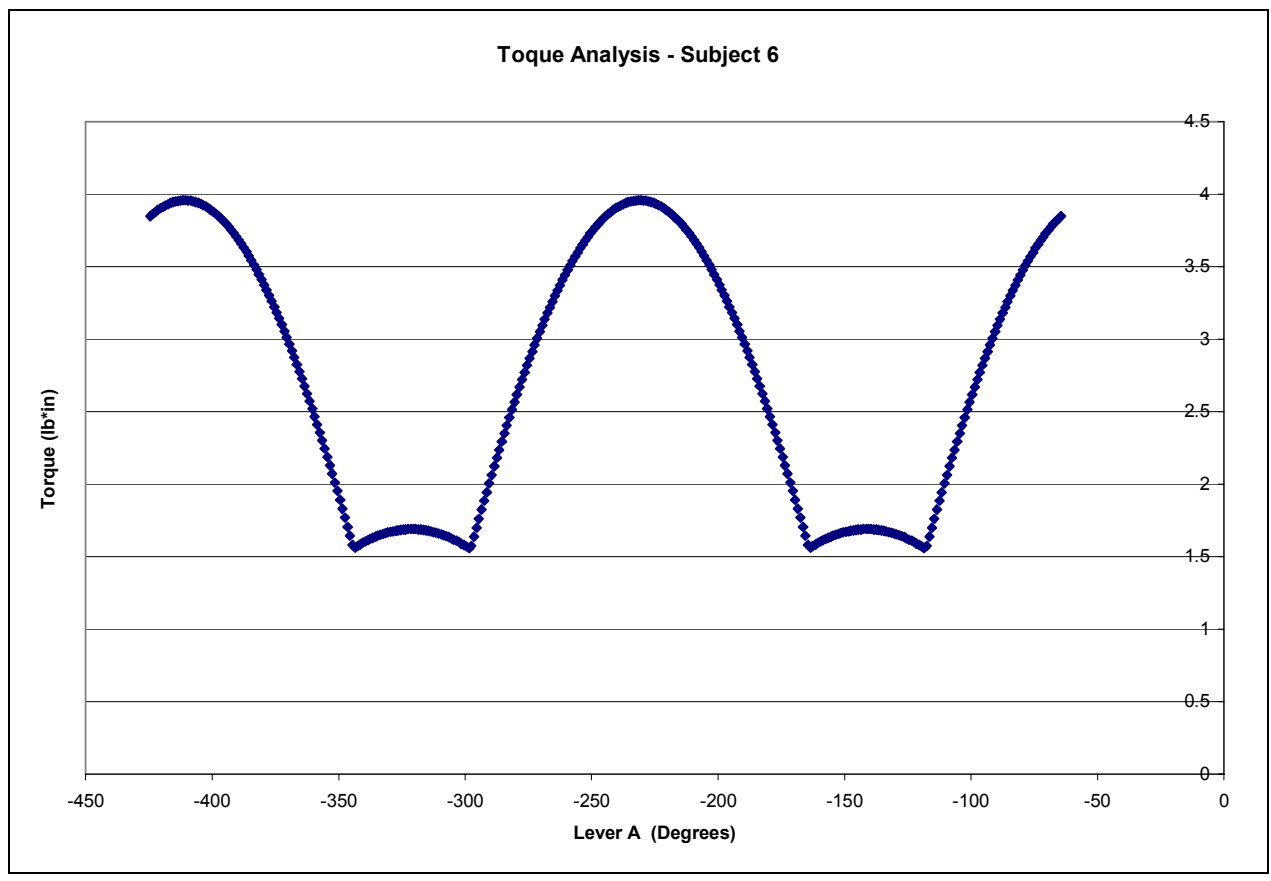

Figure 83 - Results of Torque Analysis For Subject 6 


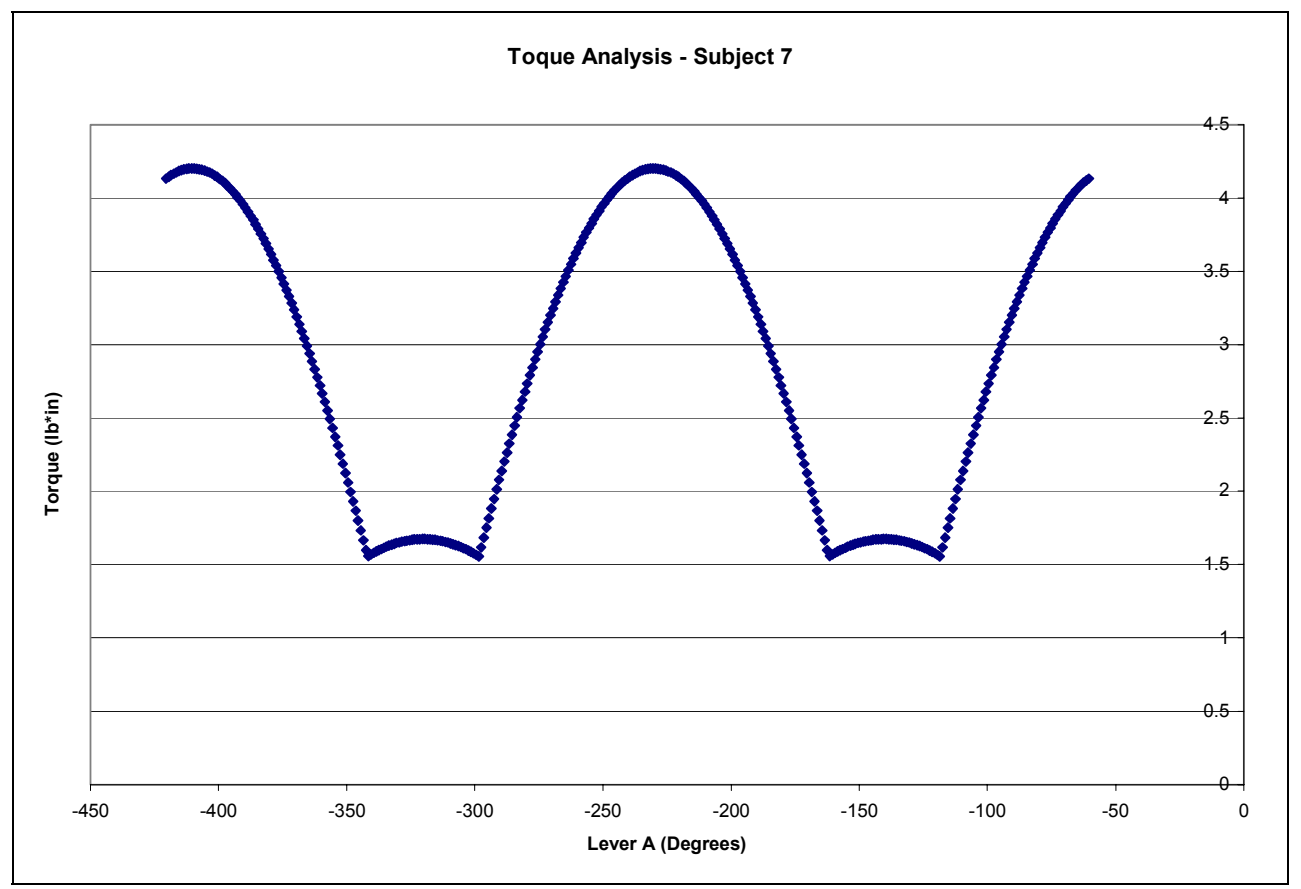

Figure 84 - Results of Torque Analysis For Subject 7

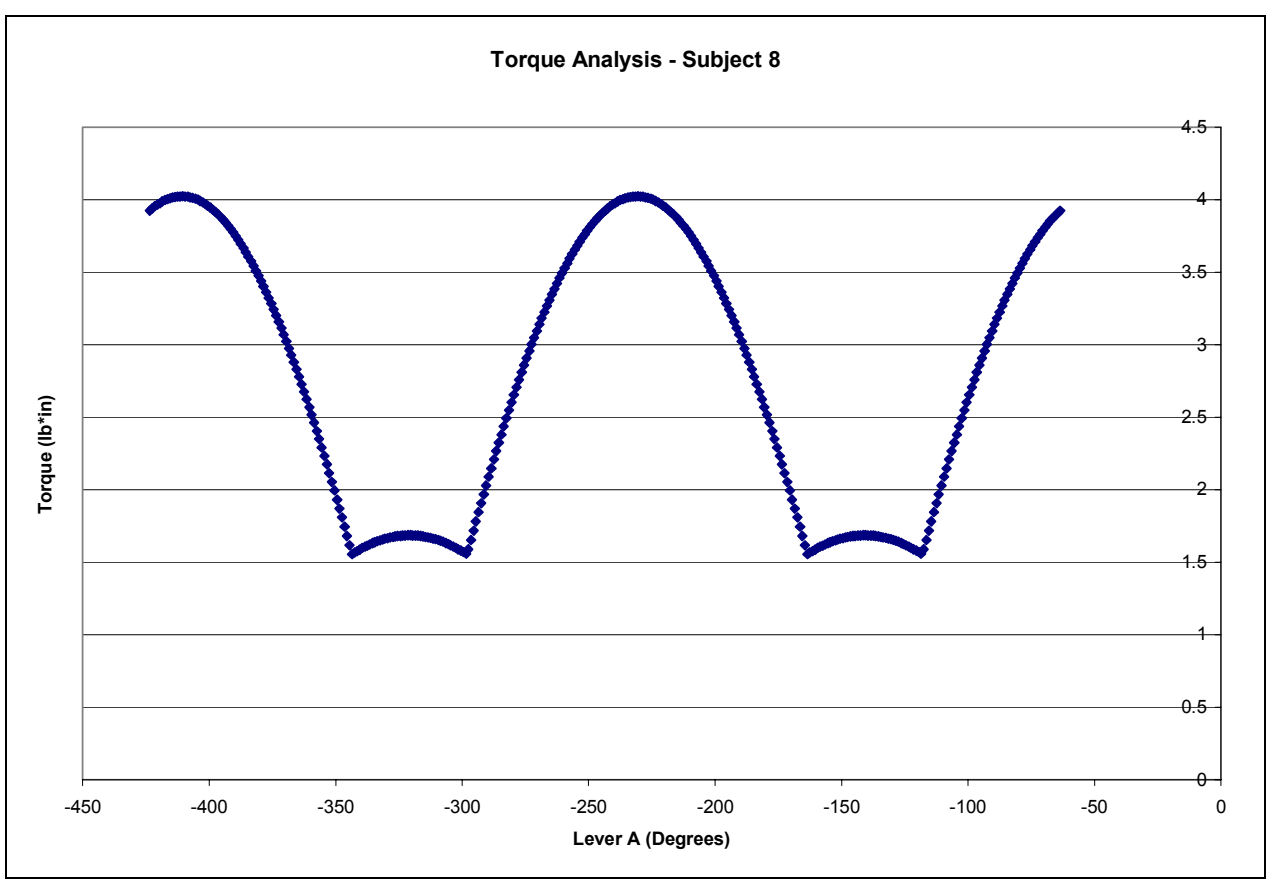

Figure 85 - Results of Torque Analysis For Subject 8 


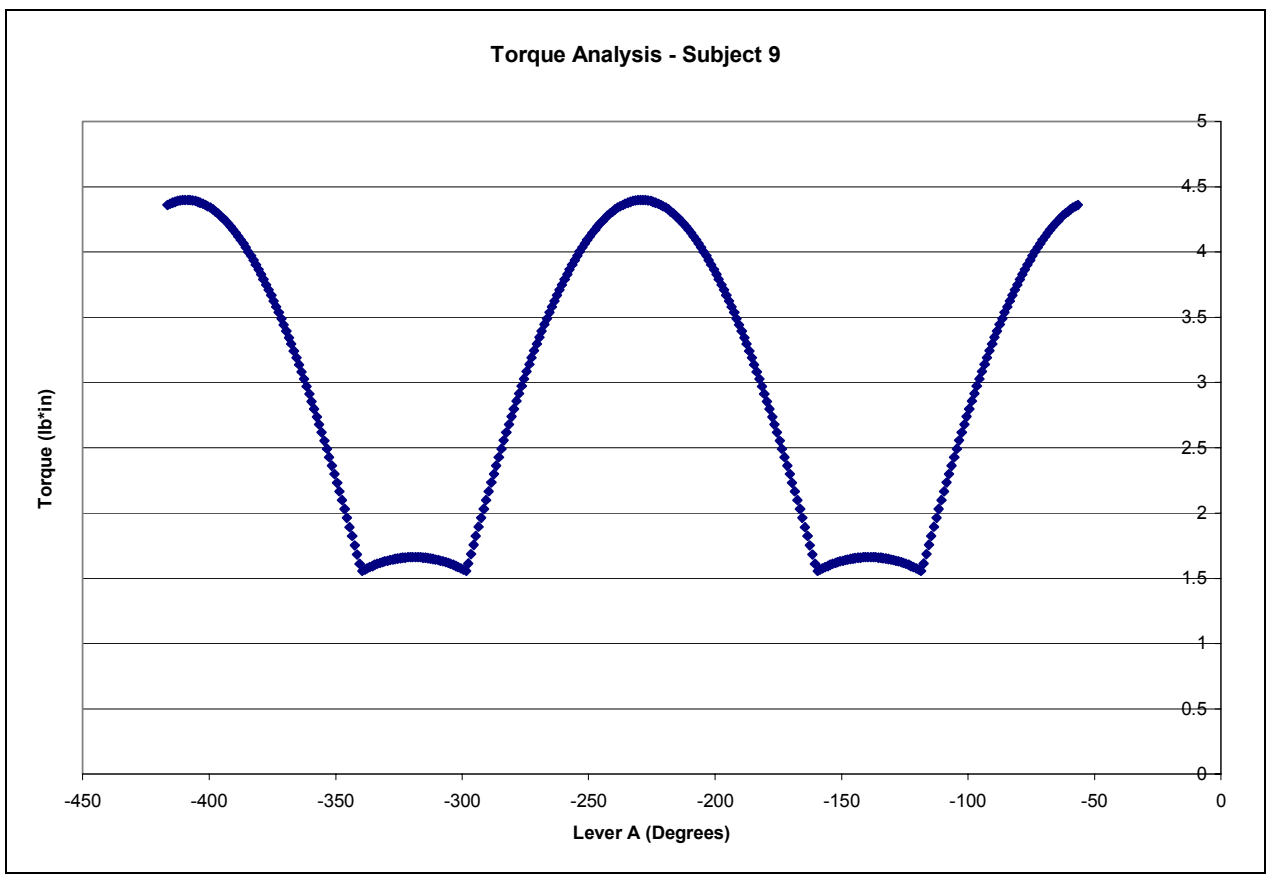

Figure 86 - Results of Torque Analysis For Subject 9

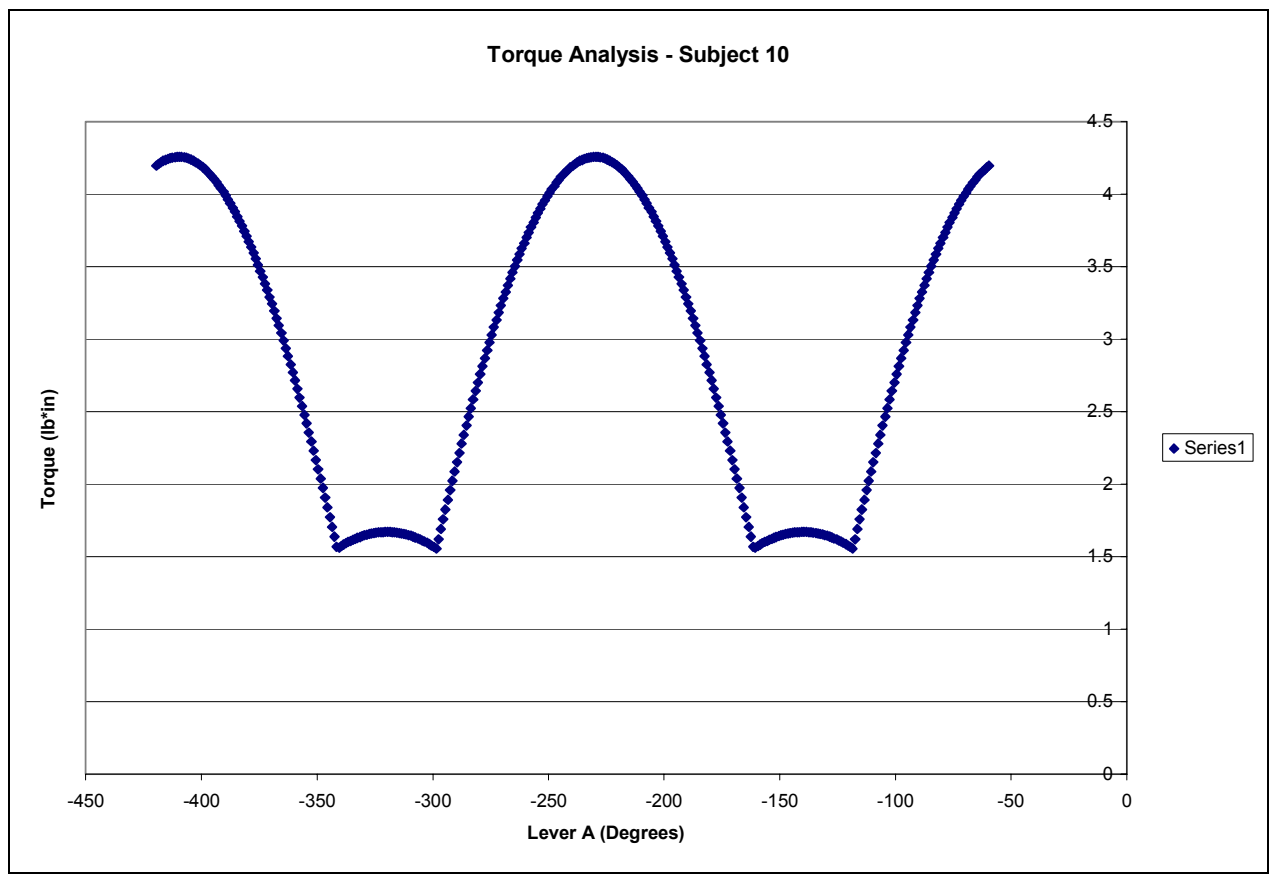

Figure 87 - Results of Torque Analysis For Subject 10 
Table 19 - Testing Torque Calculation Spreadsheet

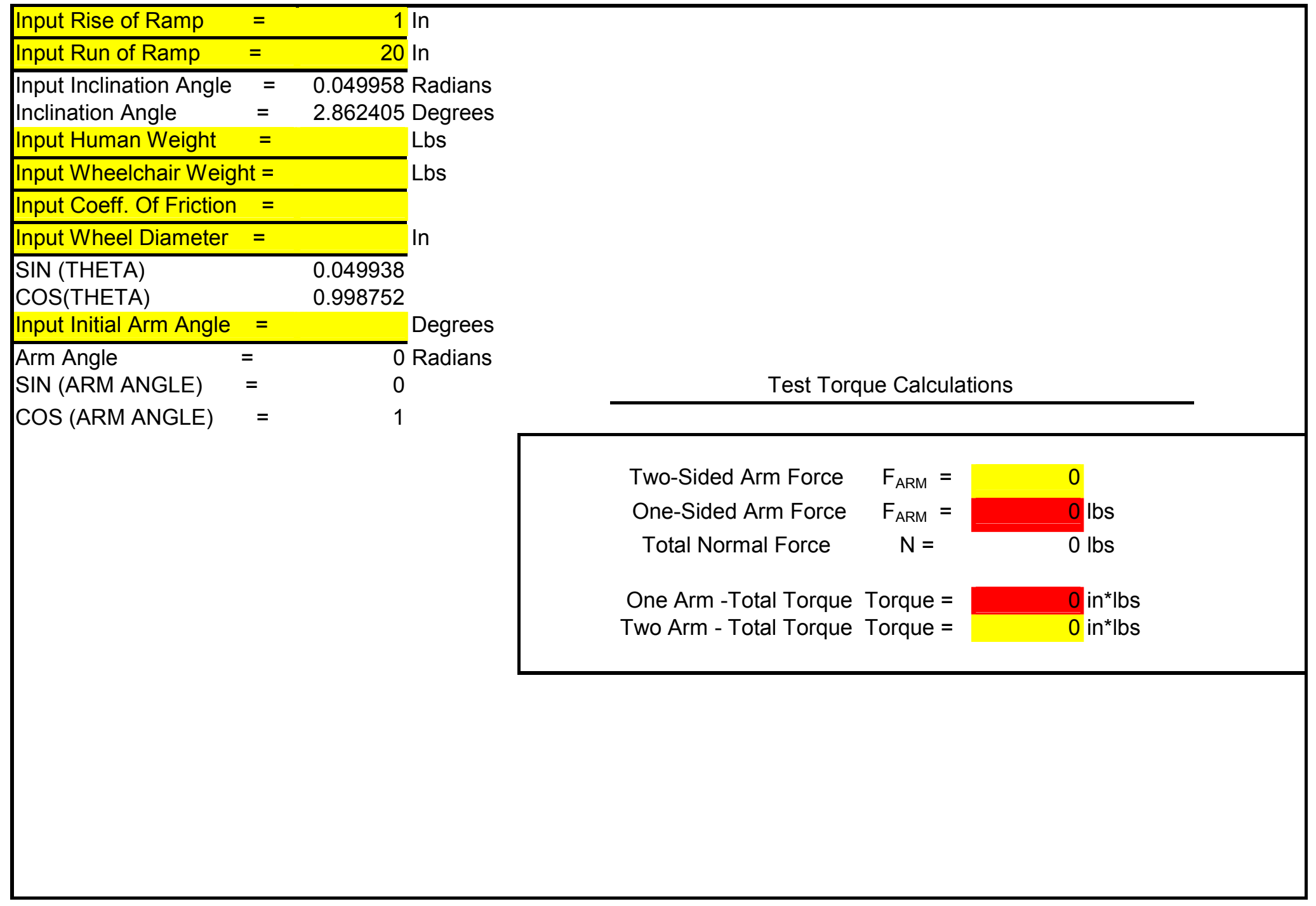




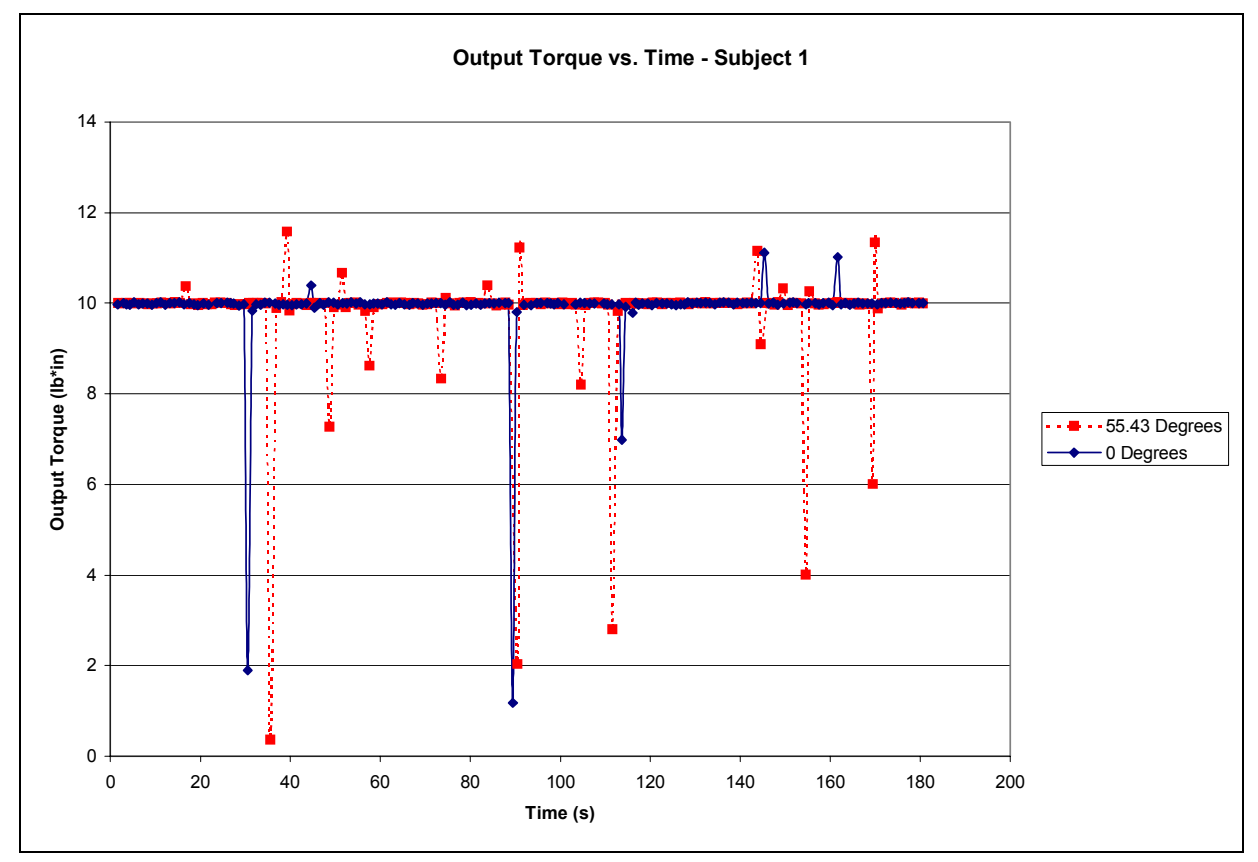

Figure 88 - Torque Results For Subject 1 (10 in*Ibs)

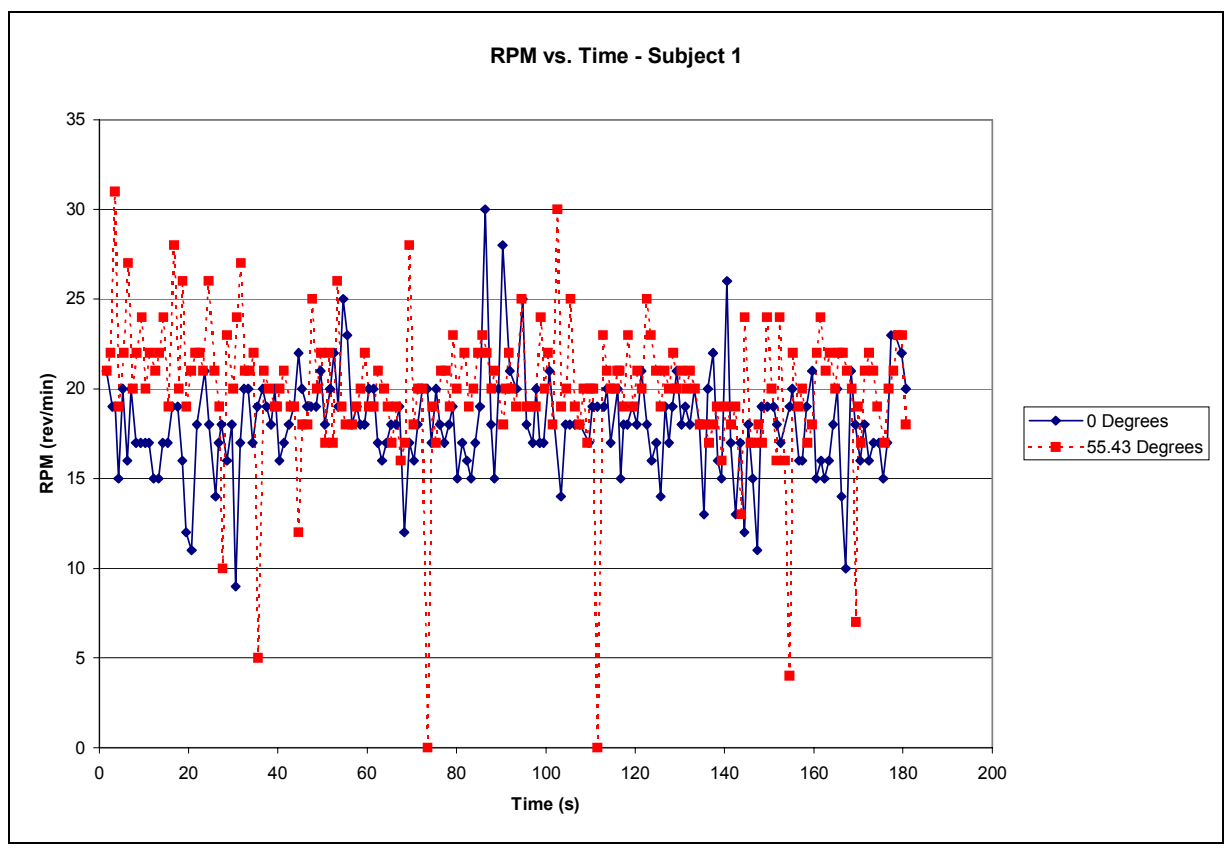

Figure 89 - RPM Results For Subject 1 (10 in*lbs) 


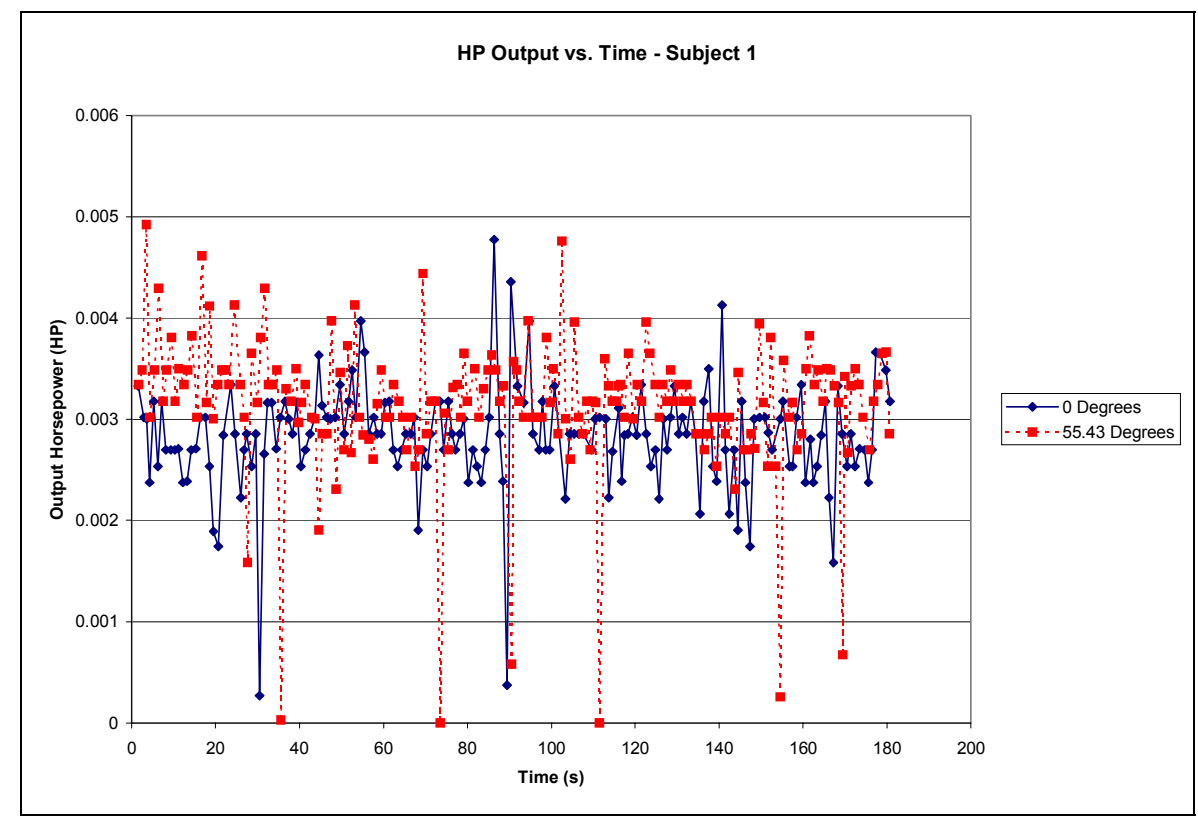

Figure 90 - Horsepower Results for Subject 1 (10 in*Ibs)

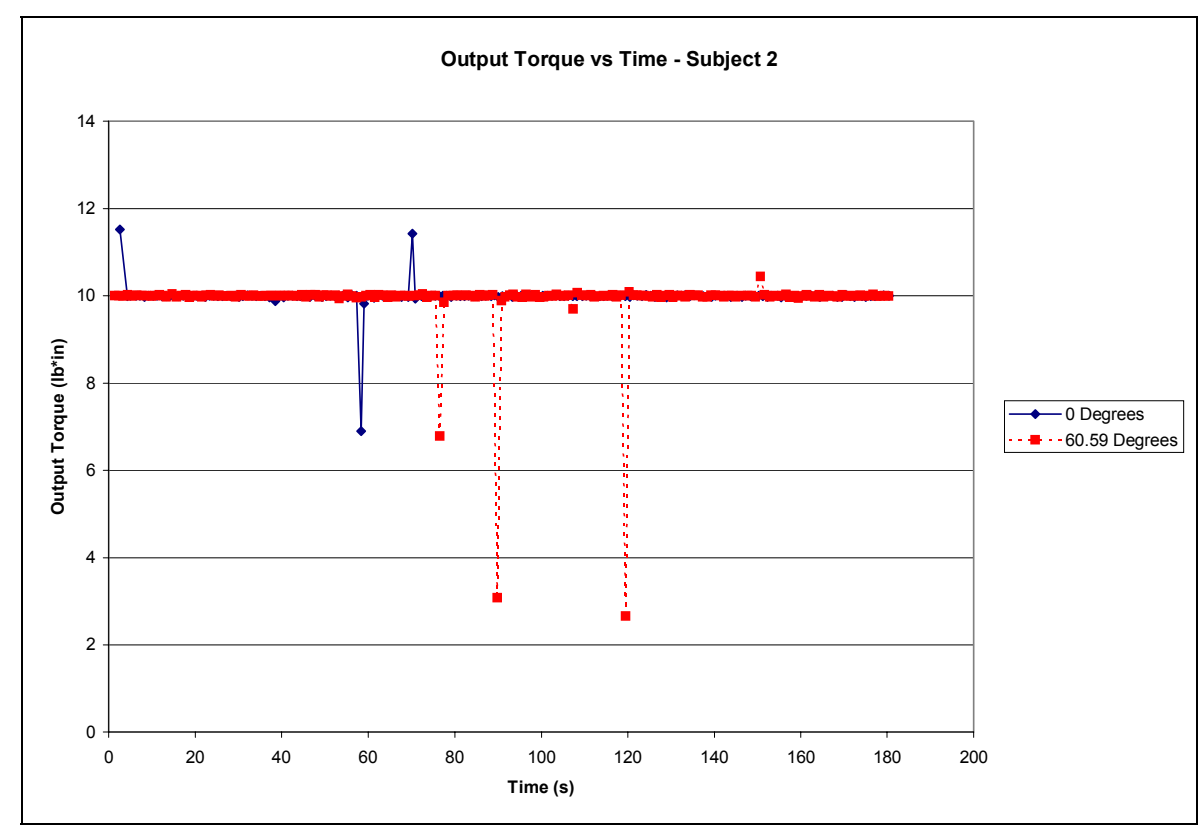

Figure 91 - Torque Results For Subject 2 (10 in*Ibs) 


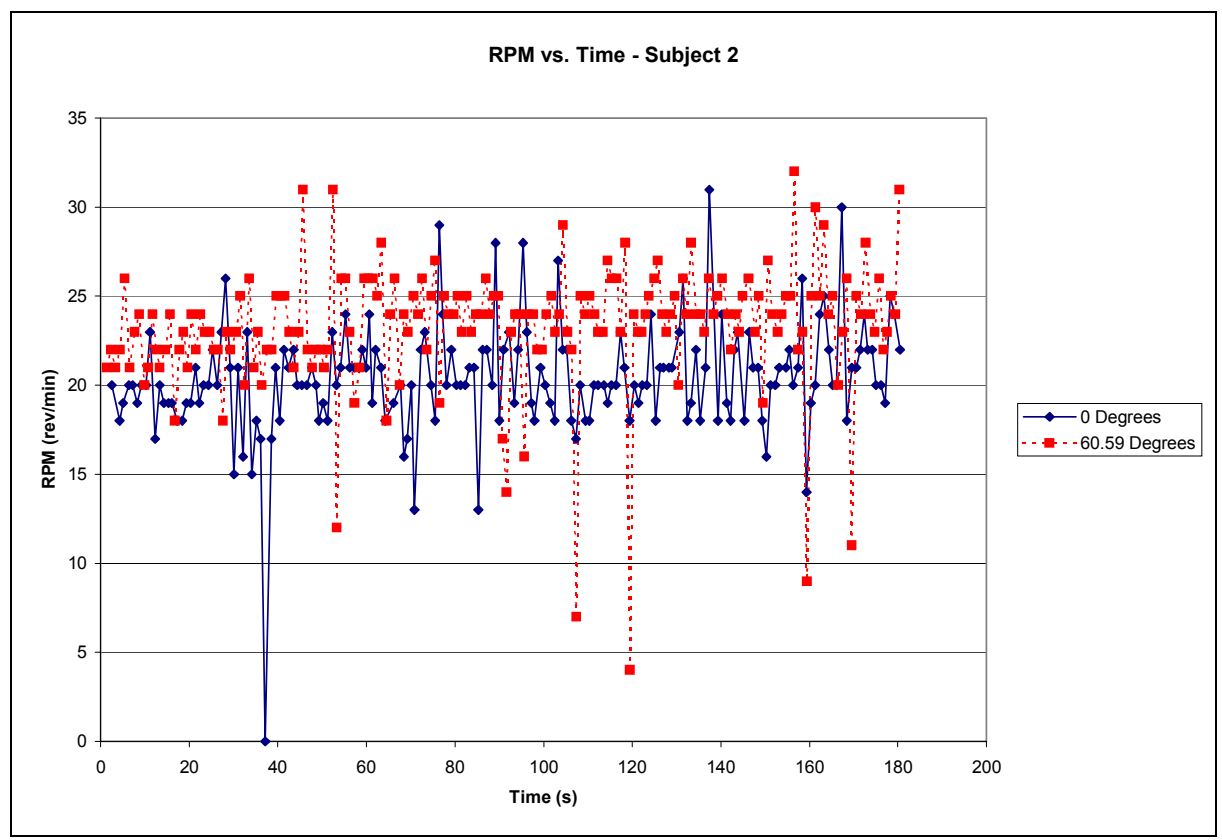

Figure 92 - RPM Results For Subject 2 (10 in*lbs)

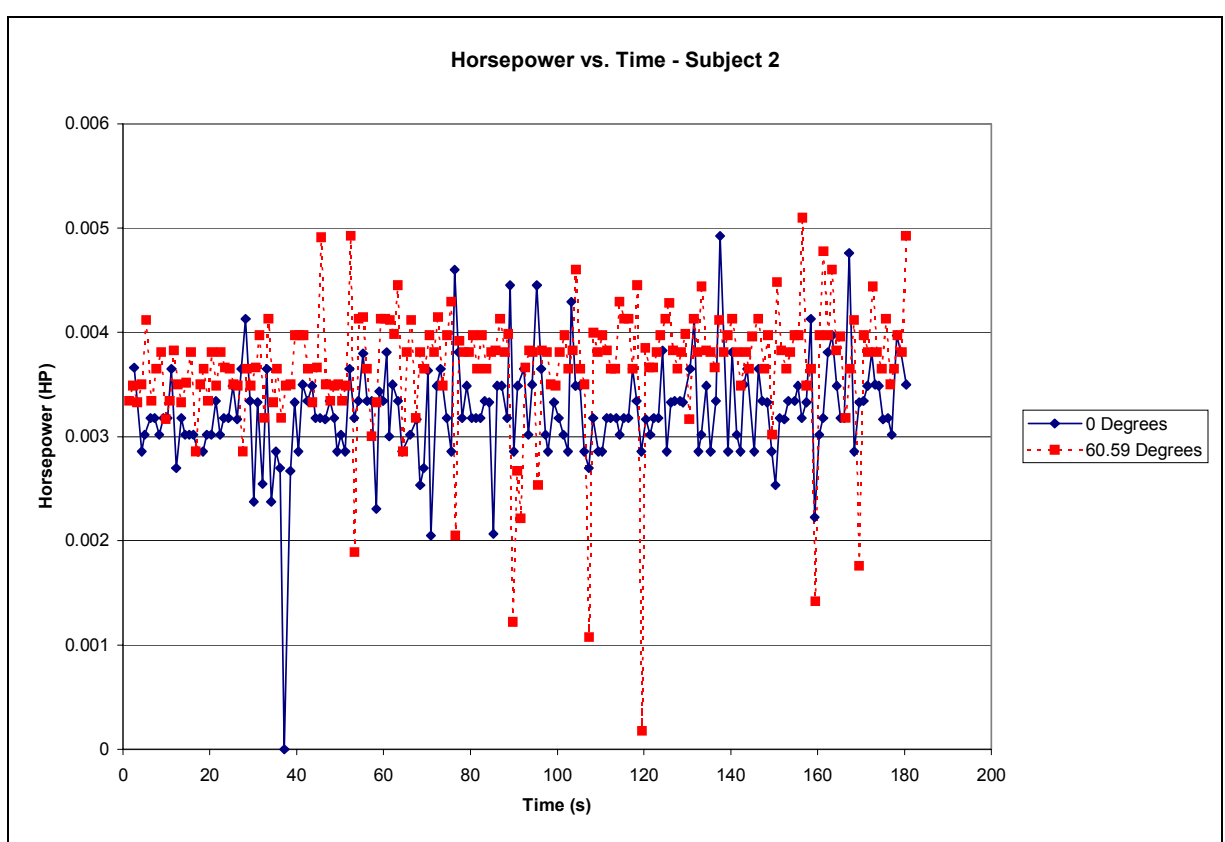

Figure 93 - Horsepower Results For Subject 2 (10 in*lbs) 


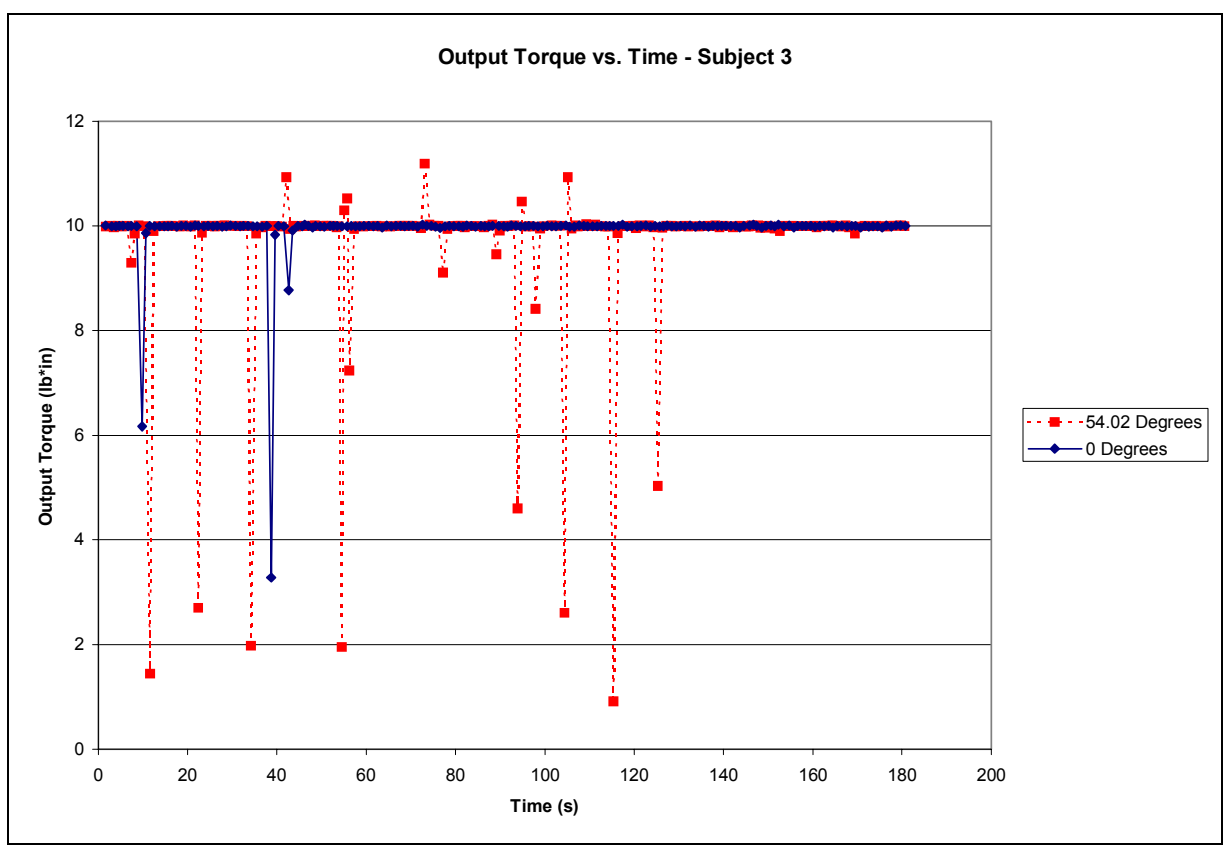

Figure 94 - Torque Results For Subject 3 (10 in*lbs)

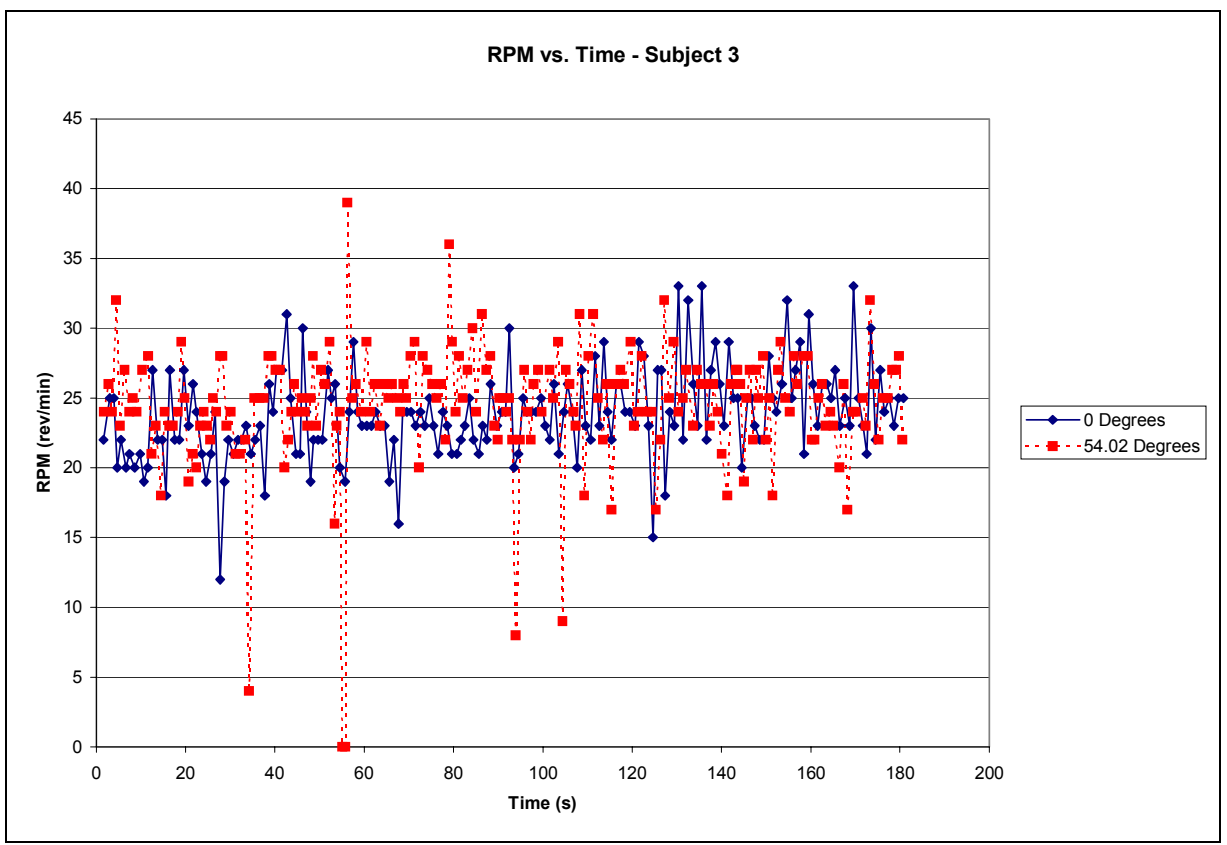

Figure 95 - RPM Results For Subject 3 (10 in*lbs) 


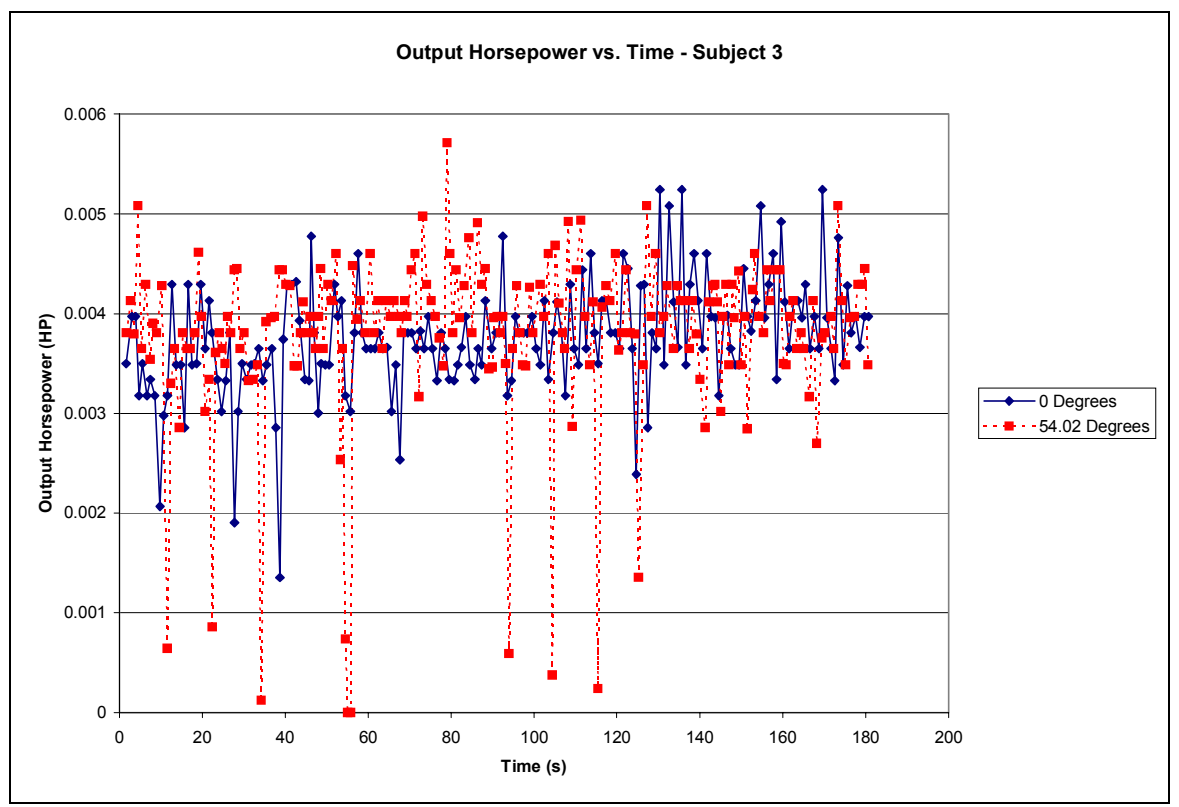

Figure 96 - Horsepower Results For Subject 3 (10 in*lbs)

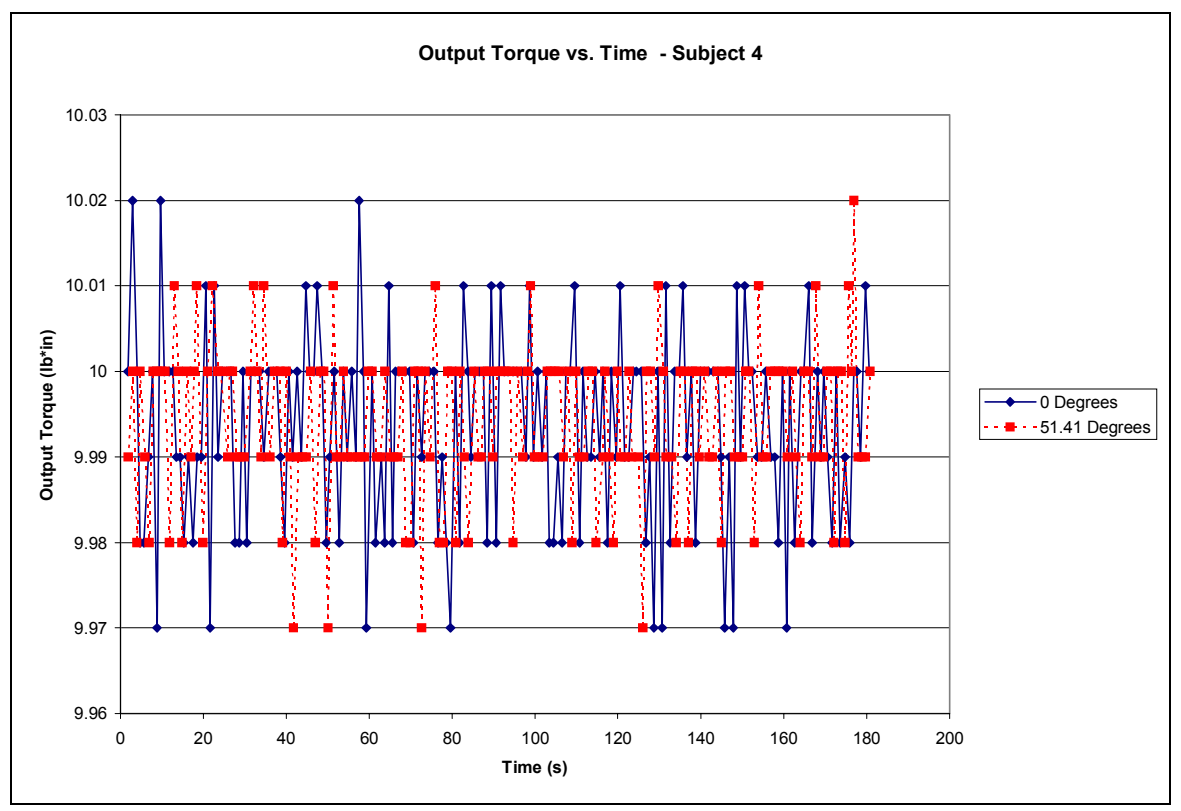

Figure 97 - Torque Results For Subject 4 (10 in*lbs) 


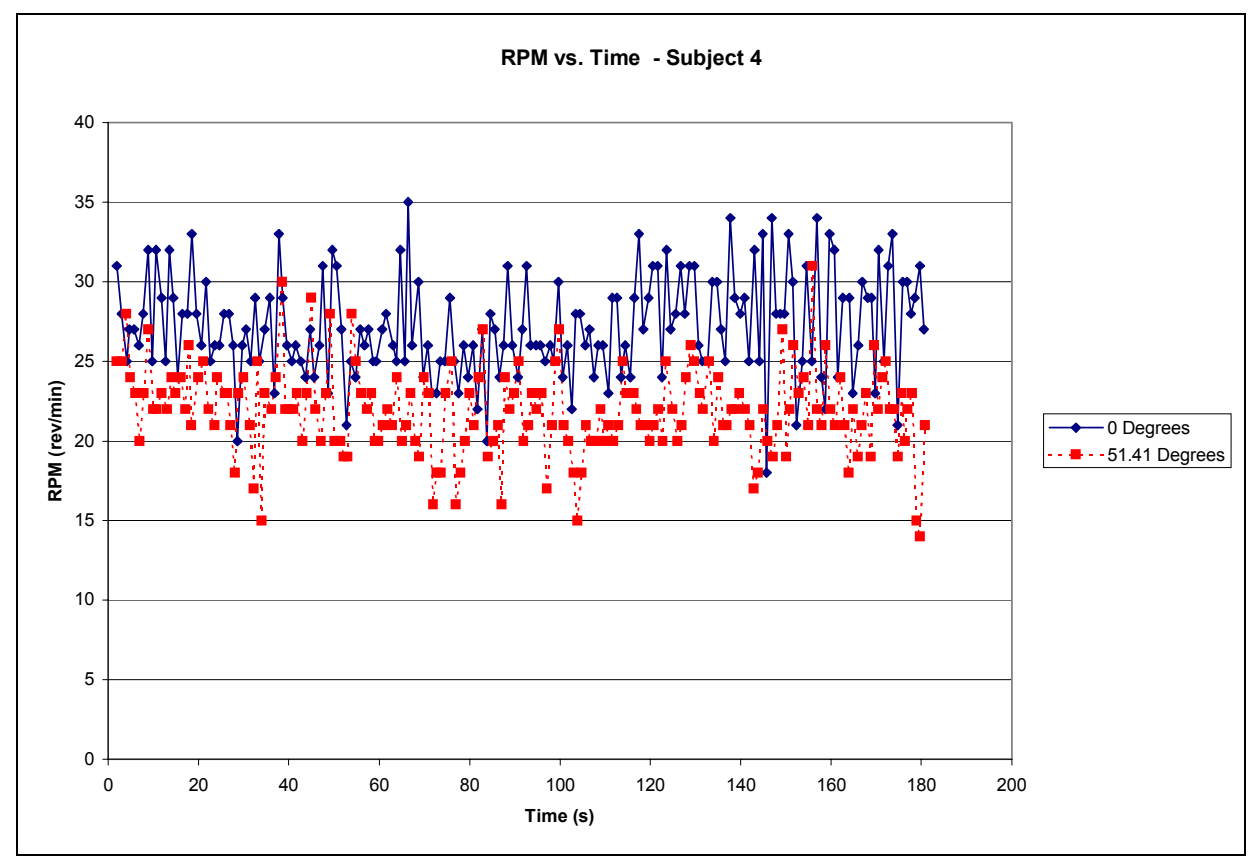

Figure 98 - RPM Results For Subject 4 (10 in*lbs)

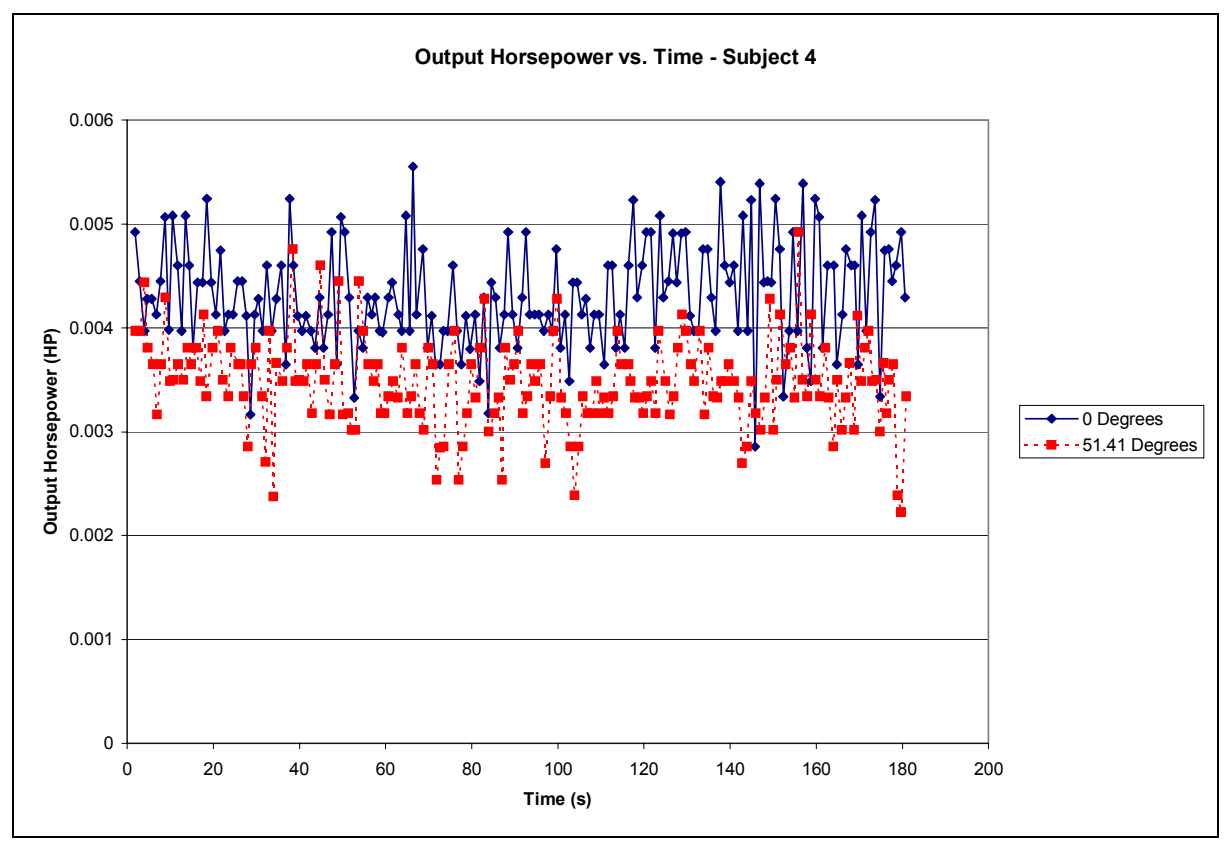

Figure 99 - Horsepower Results For Subject 4 (10 in*lbs) 


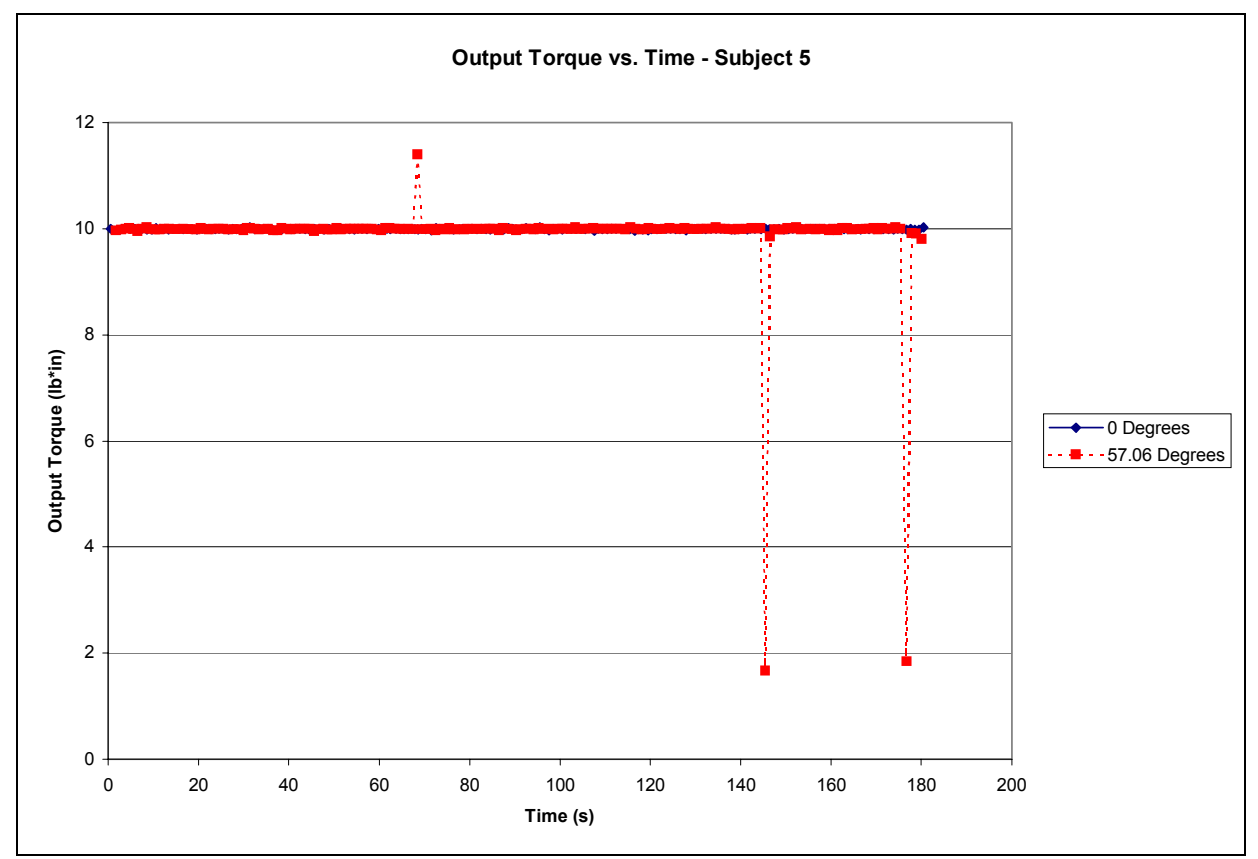

Figure 100 - Torque Results For Subject 5 (10 in*lbs)

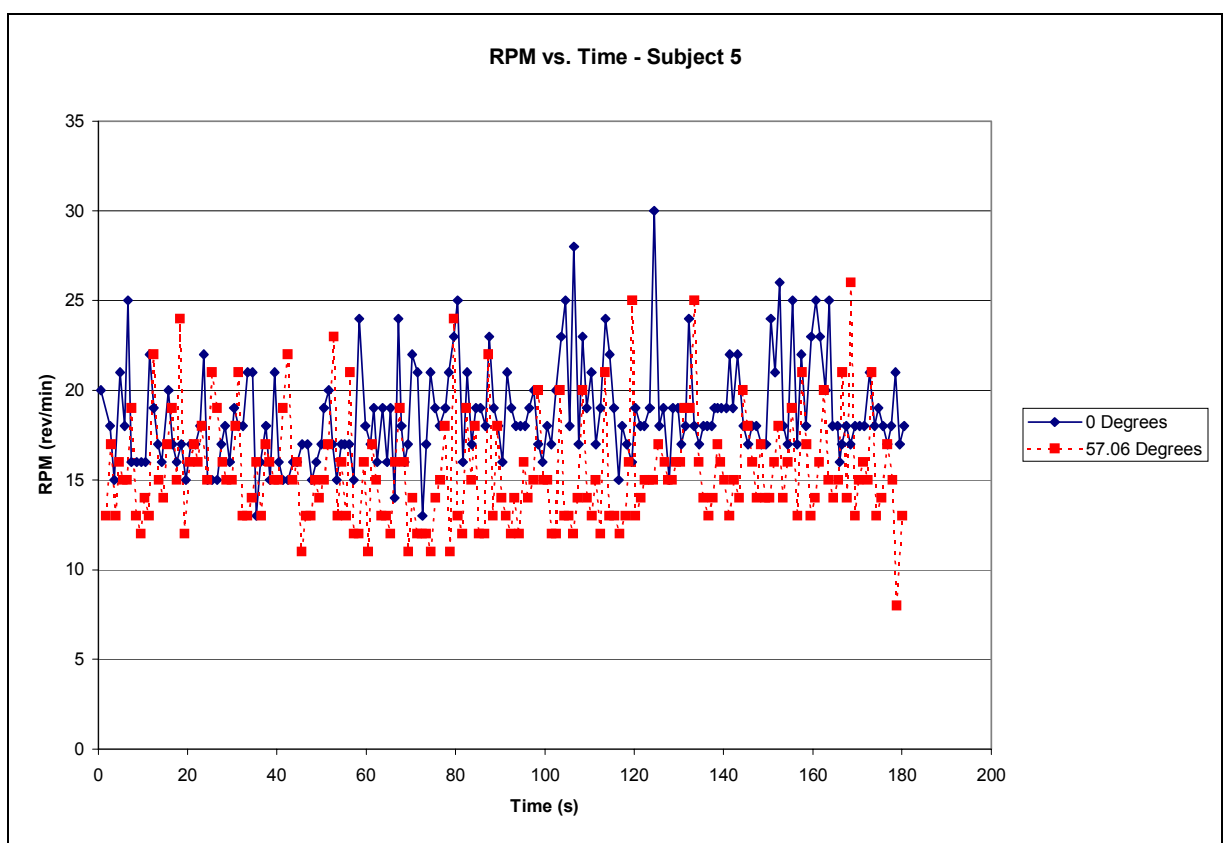

Figure 101 - RPM Results For Subject 5 (10 in*lbs) 


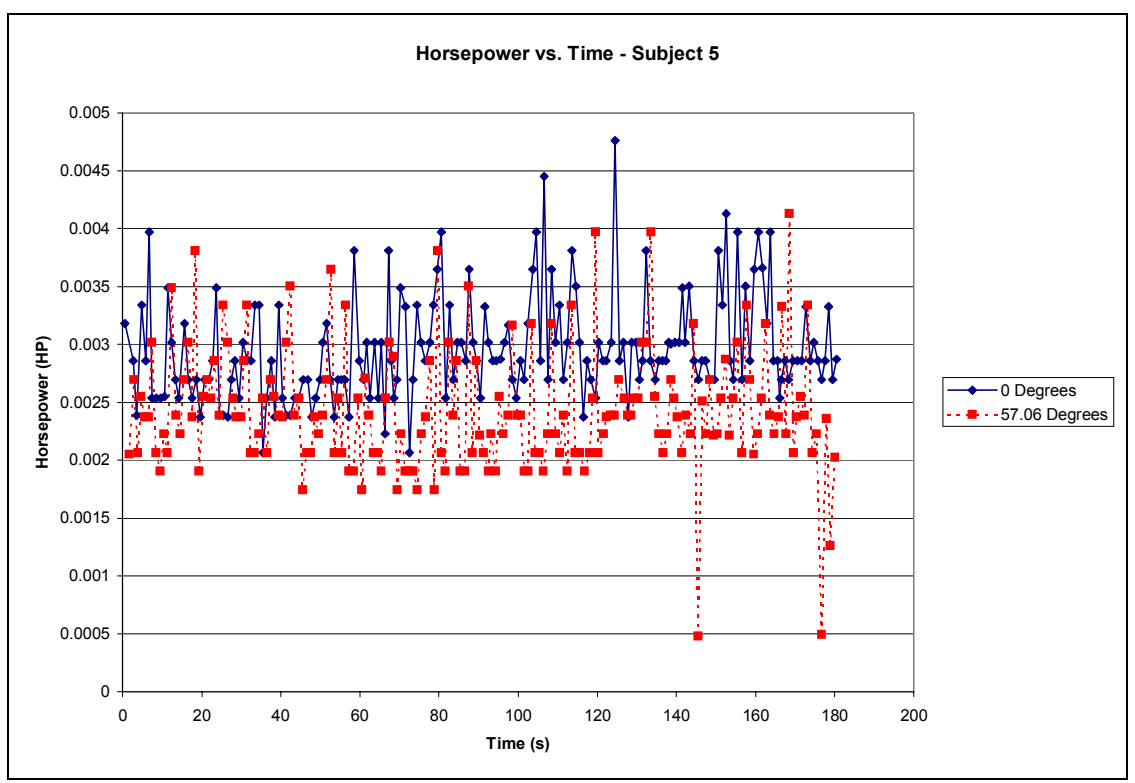

Figure 102 - Horsepower Results For Subject 5 (10 in*lbs)

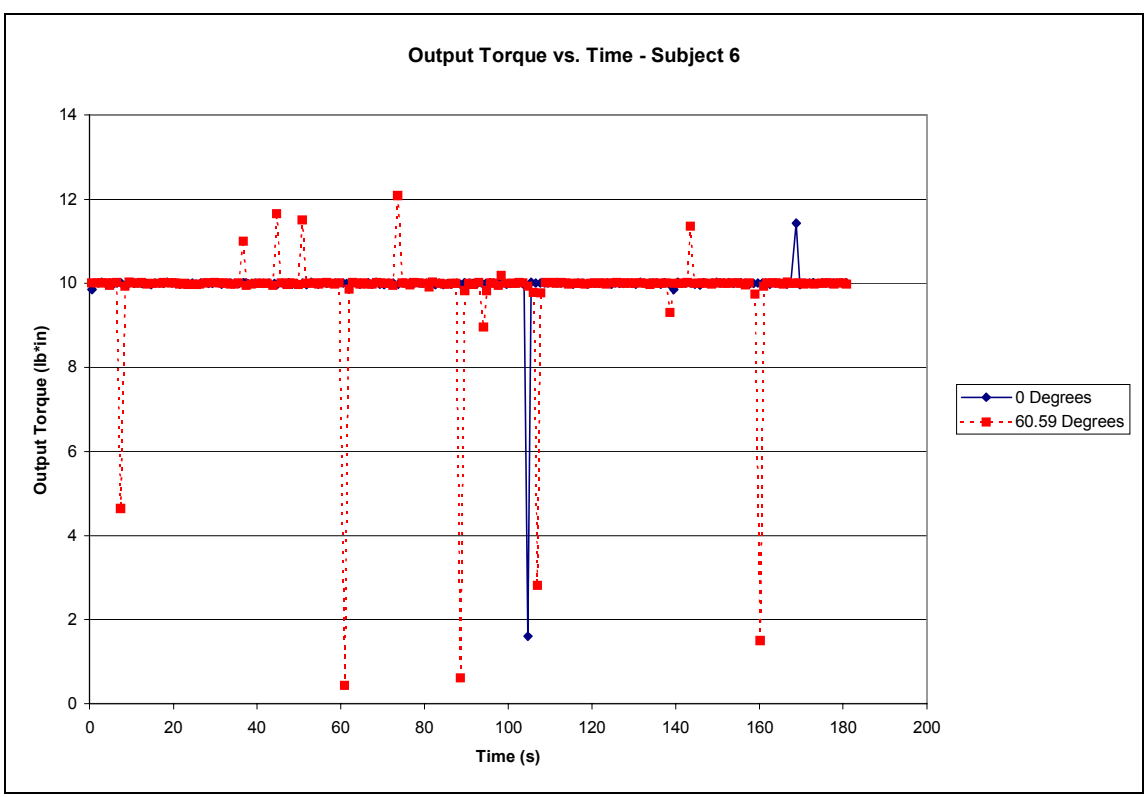

Figure 103 - Torque Results For Subject 6 (10 in*lbs) 


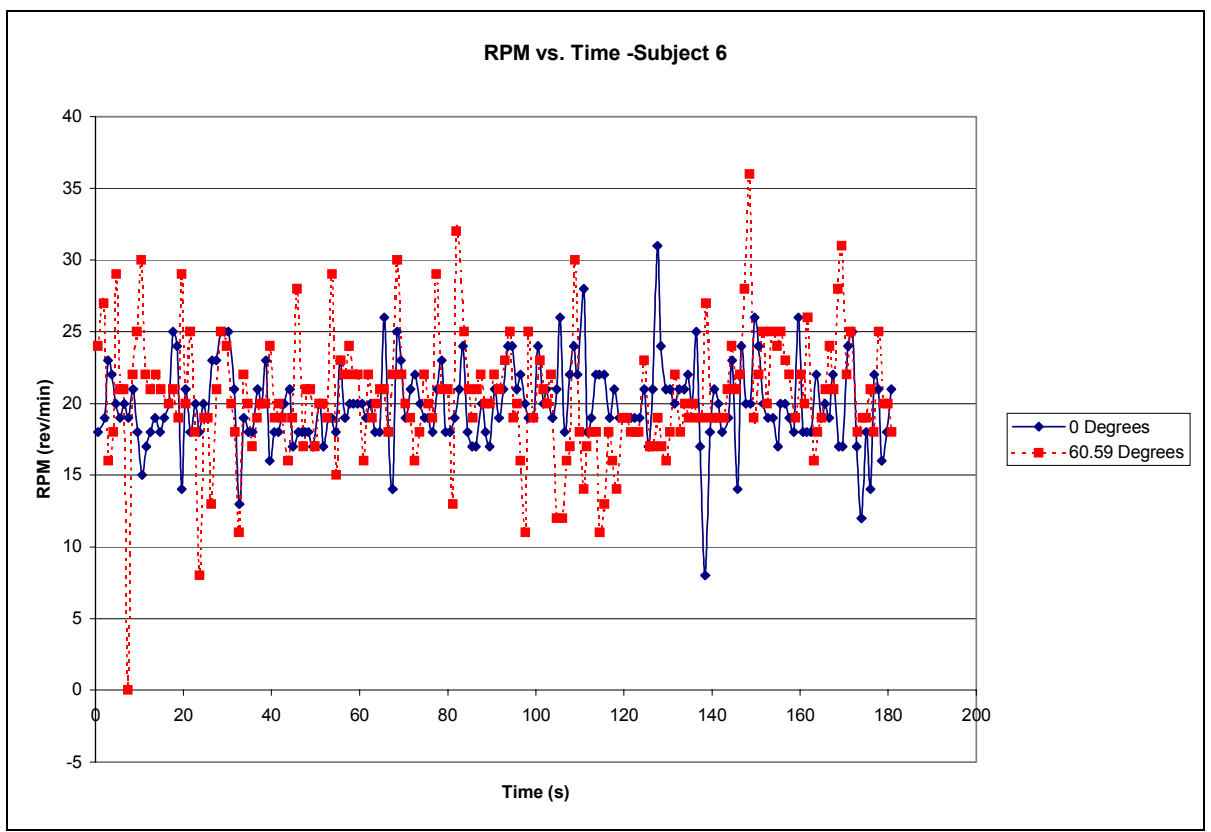

Figure 104 - RPM Results For Subject 6 (10 in*lbs)

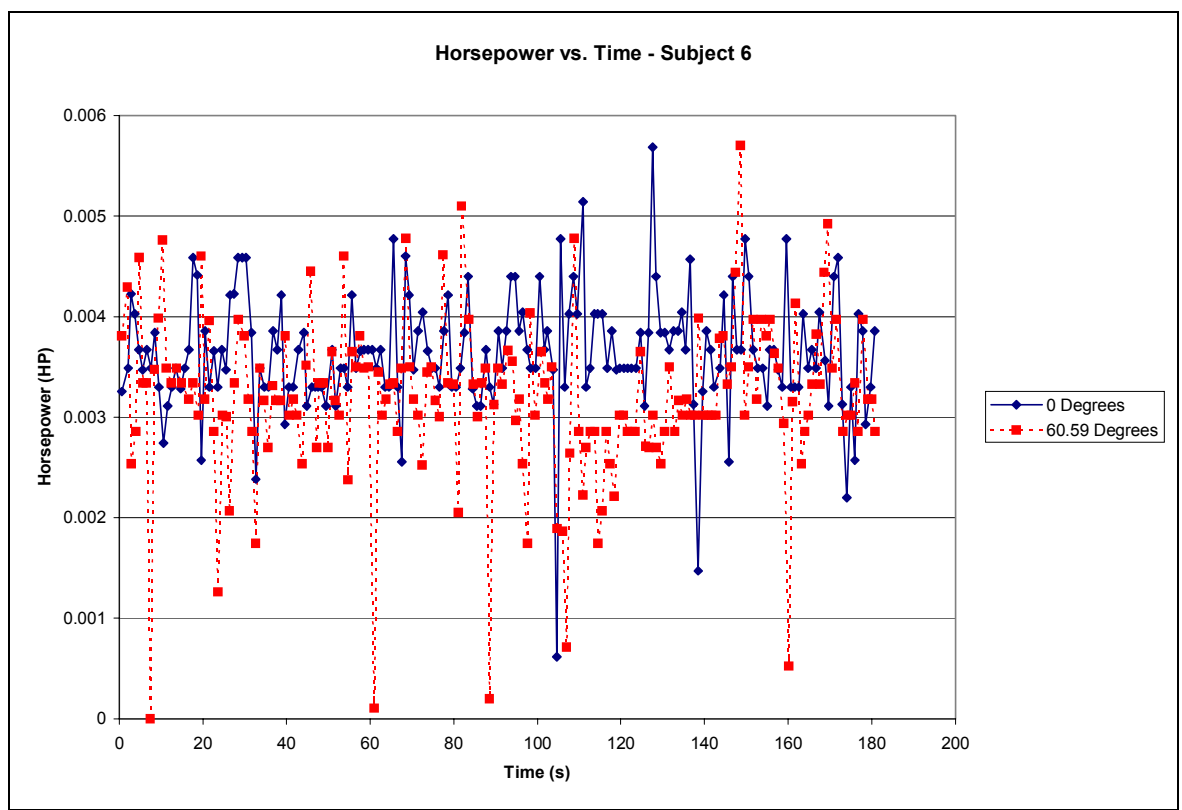

Figure 105 - Horsepower Results For Subject 6 (10 in*Ibs) 


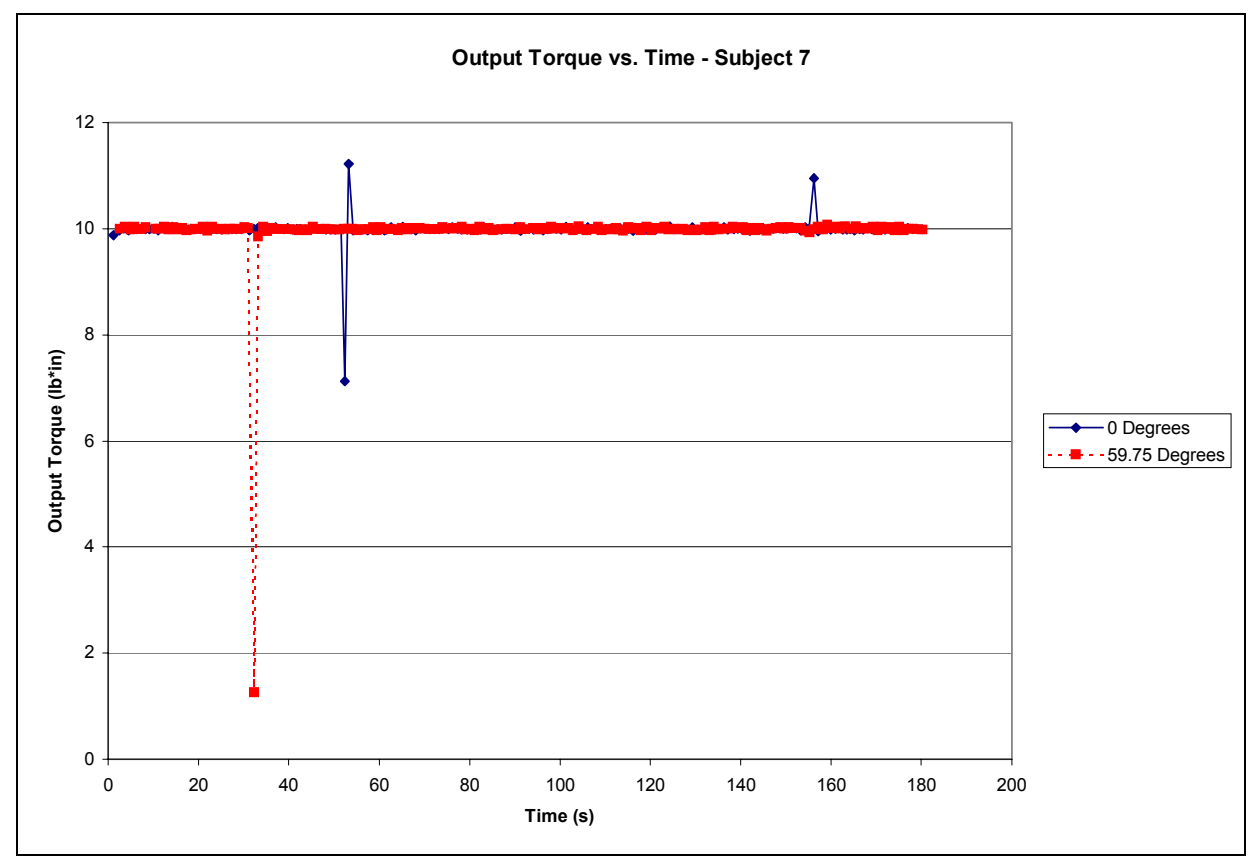

Figure 106 - Torque Results For Subject 7 (10 in*lbs)

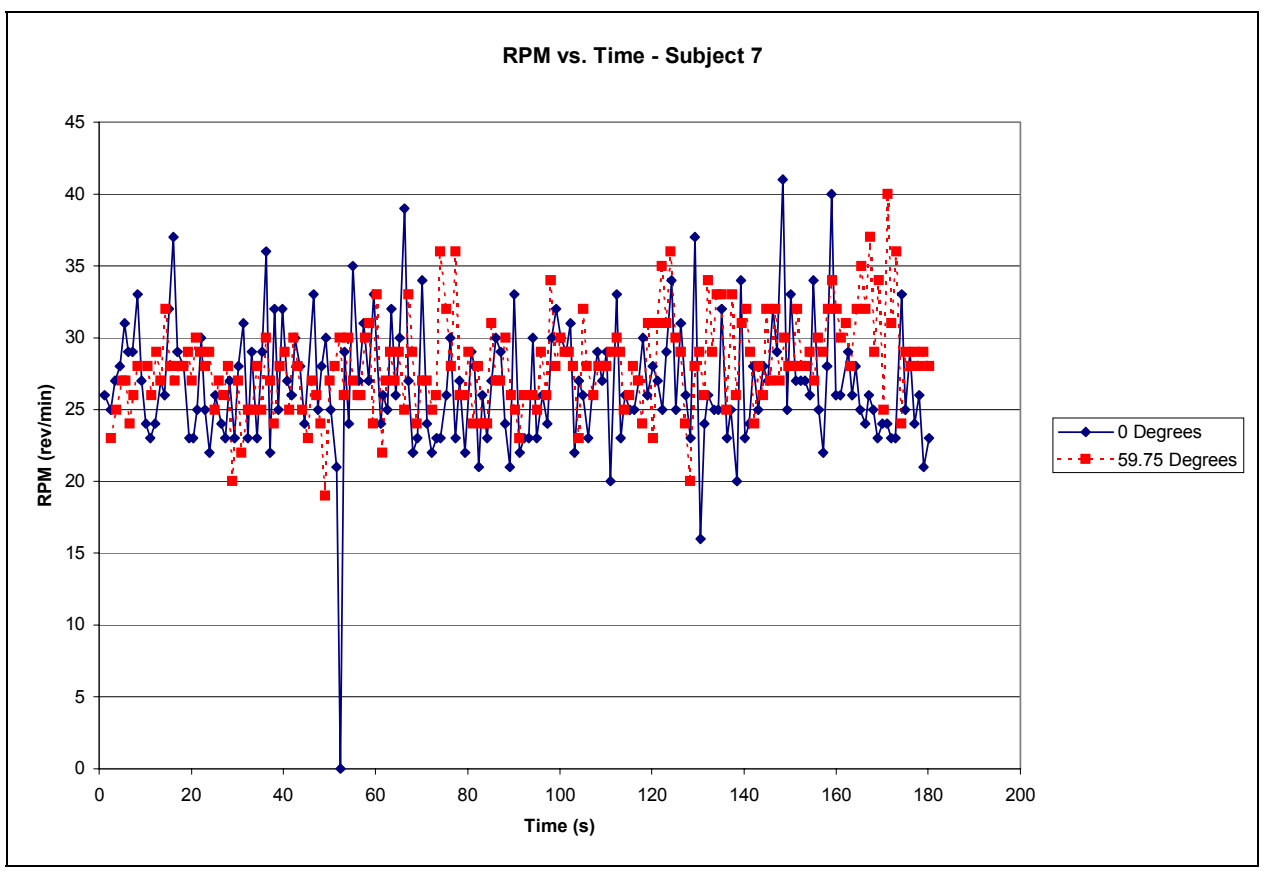

Figure 107 - RPM Results For Subject 7 (10 in*Ibs) 


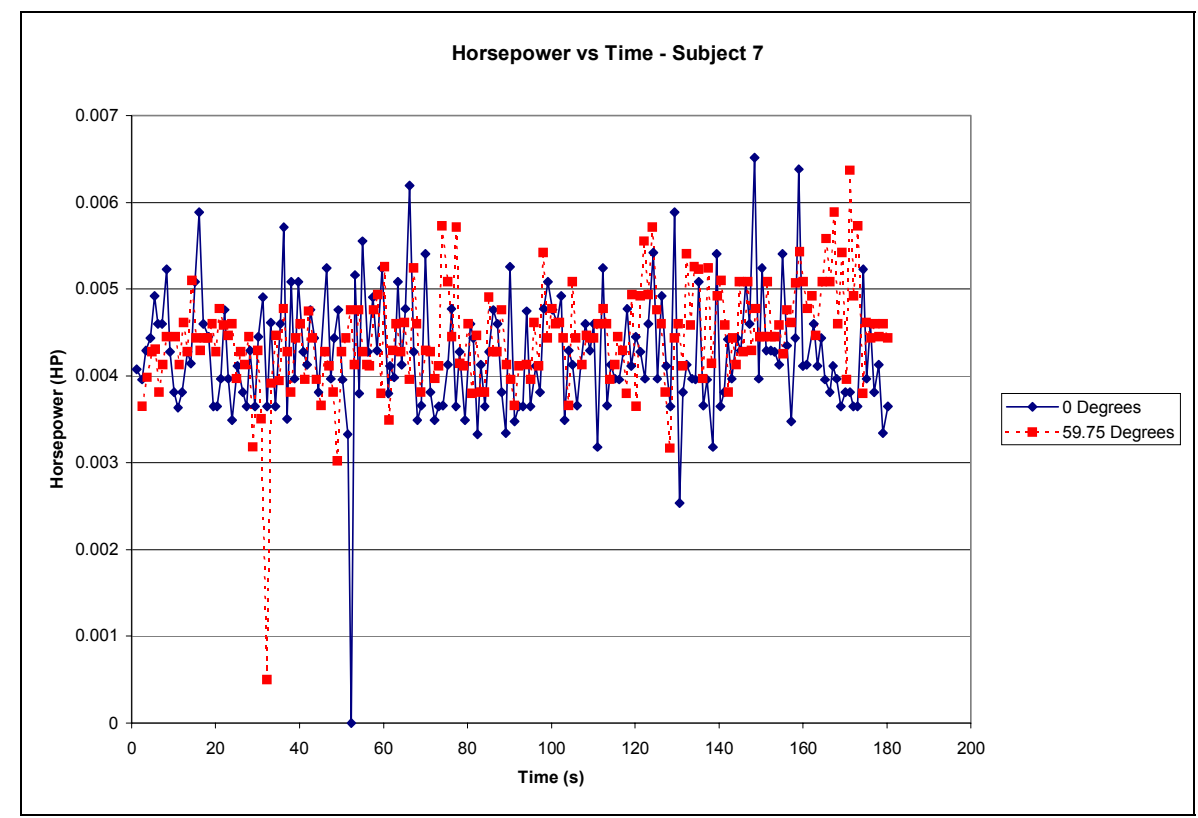

Figure 108 - Horsepower Results For Subject 7 (10 in*lbs)

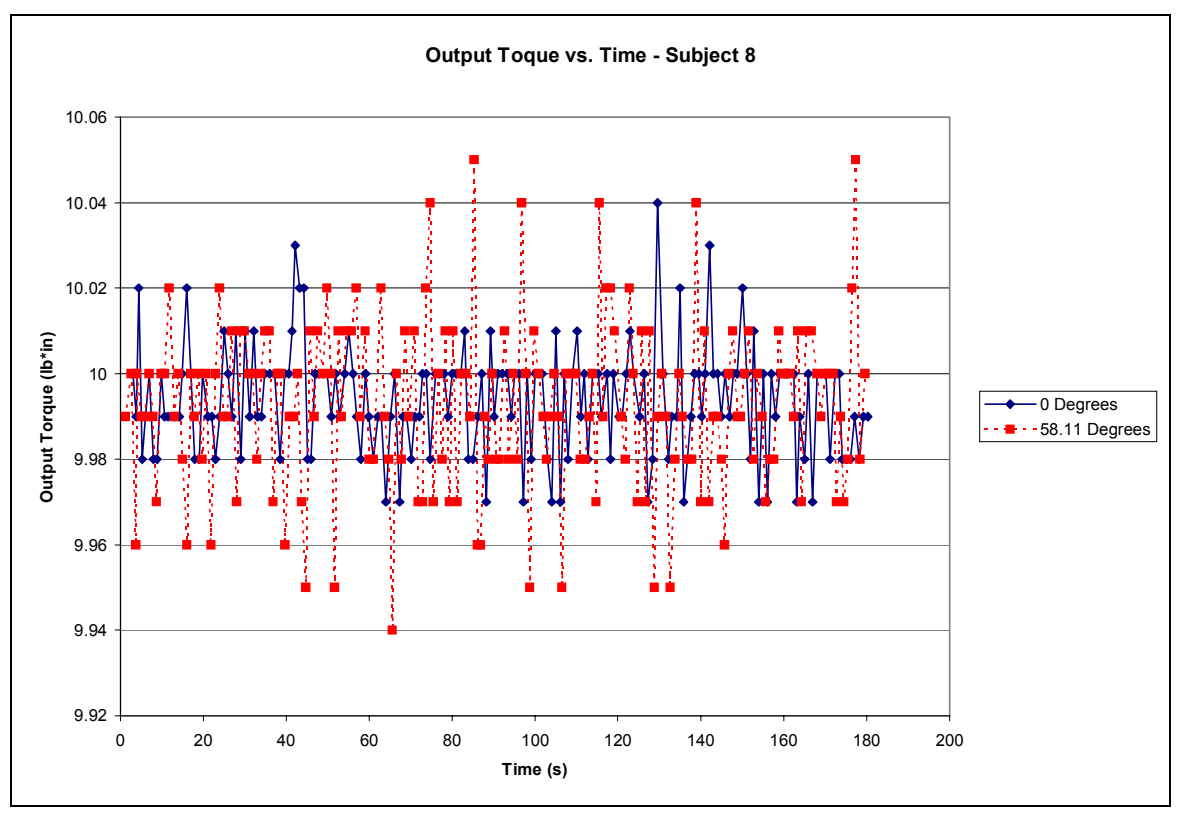

Figure 109 - Torque Results For Subject 8 (10 in*lbs) 


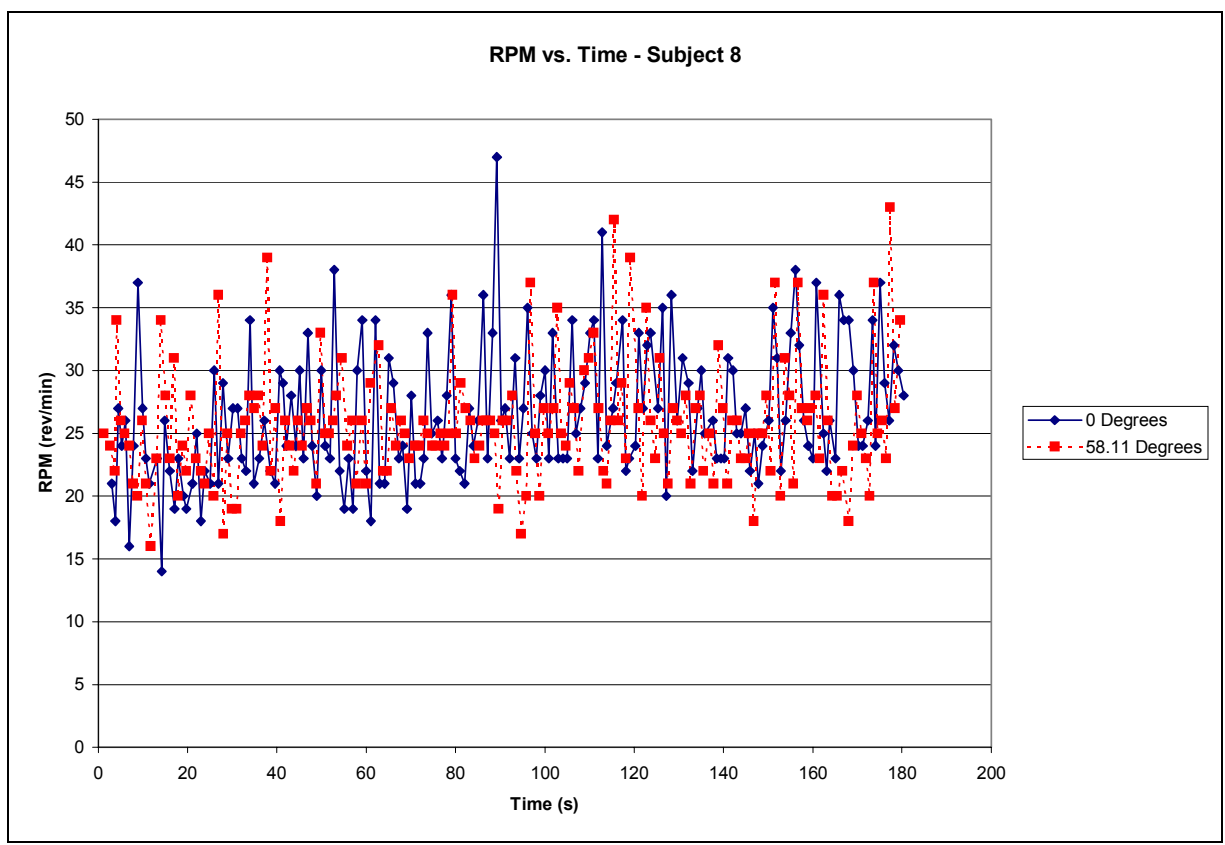

Figure 110 - RPM Results For Subject 8 (10 in*lbs)

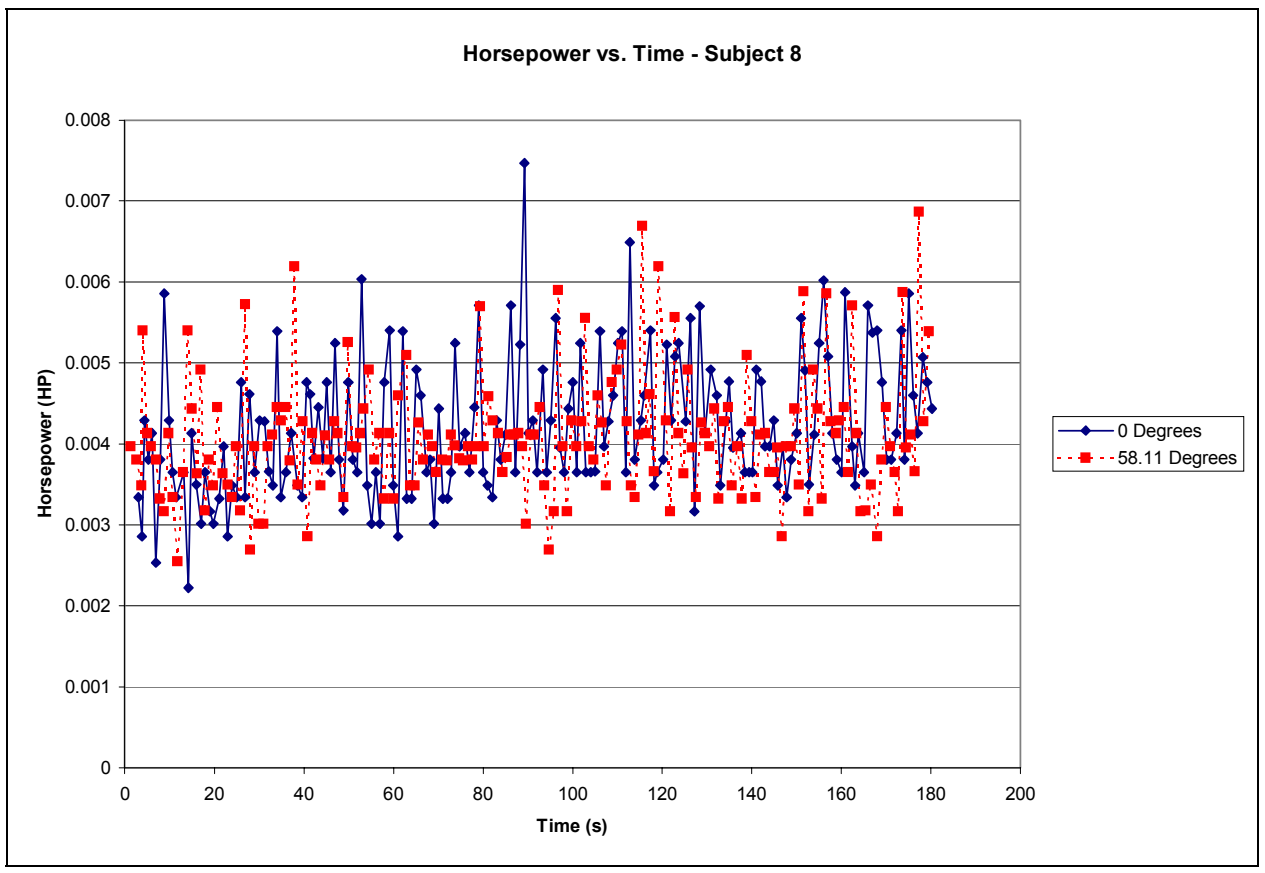

Figure 111 - Horsepower Results For Subject 8 (10 in*lbs) 


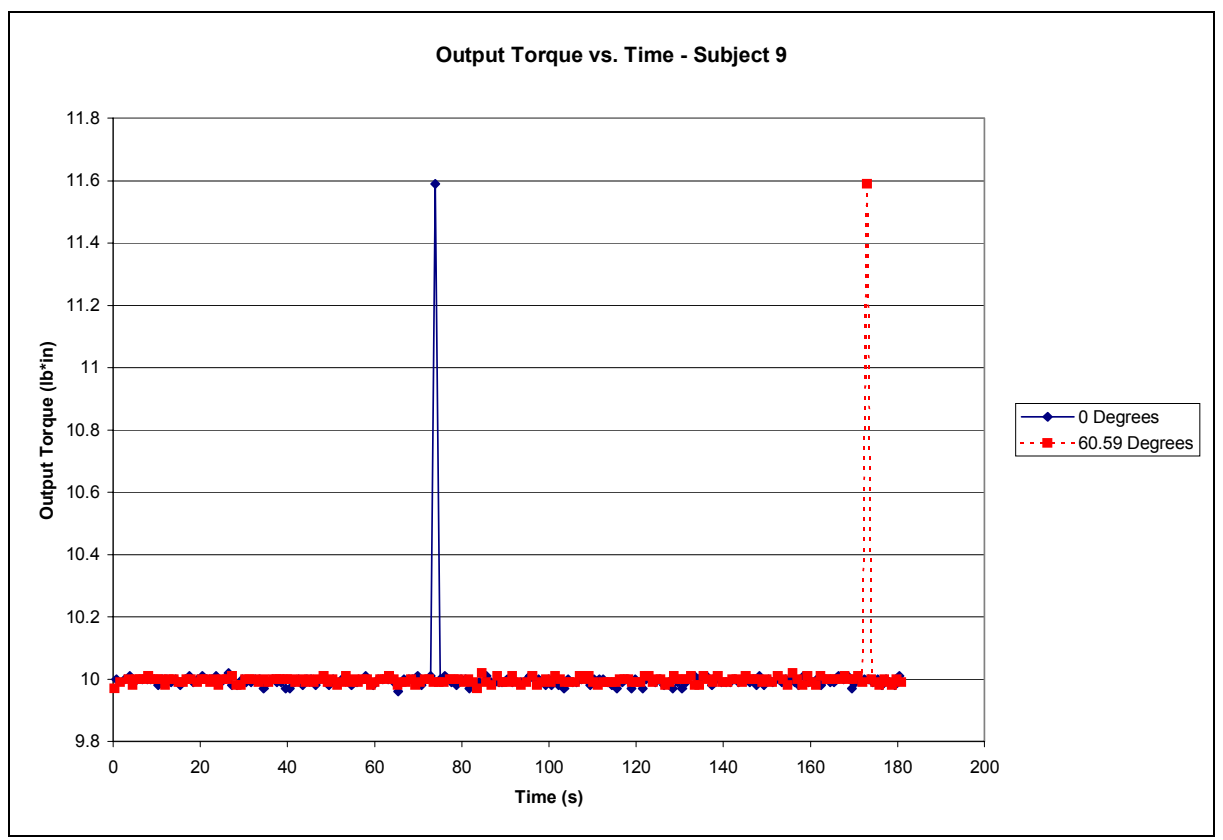

Figure 112 - Torque Results For Subject 9 (10 in*lbs)

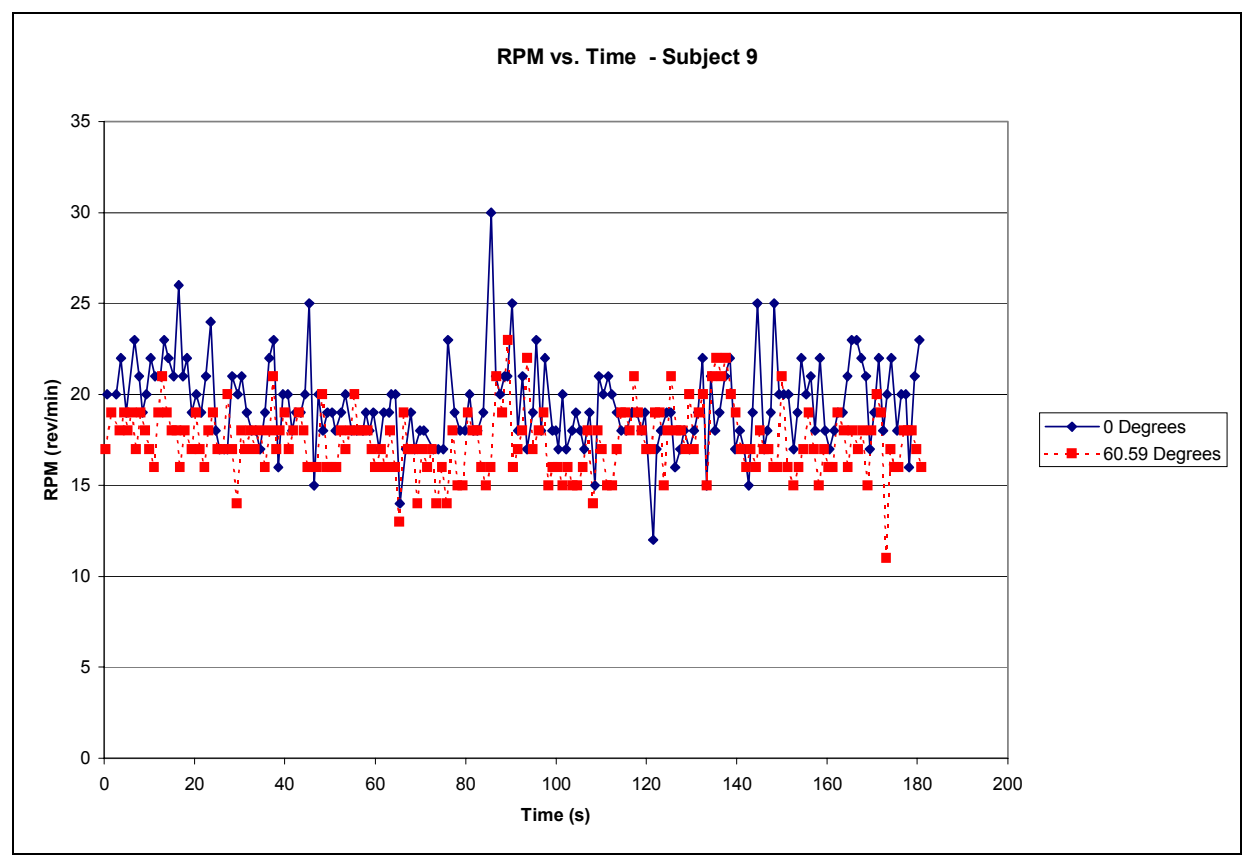

Figure 113 - RPM Results For Subject 9 (10 in*lbs) 


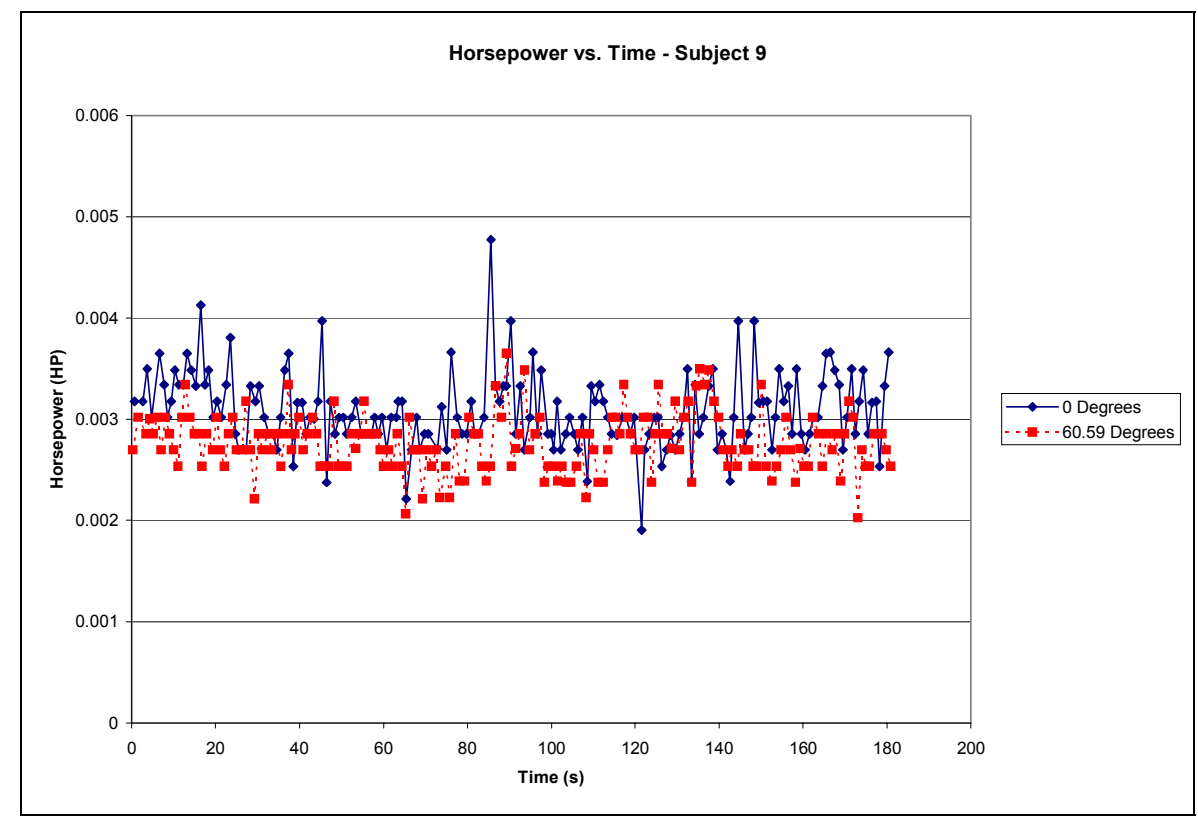

Figure 114 - Horsepower Results For Subject 9 (10 in*Ibs)

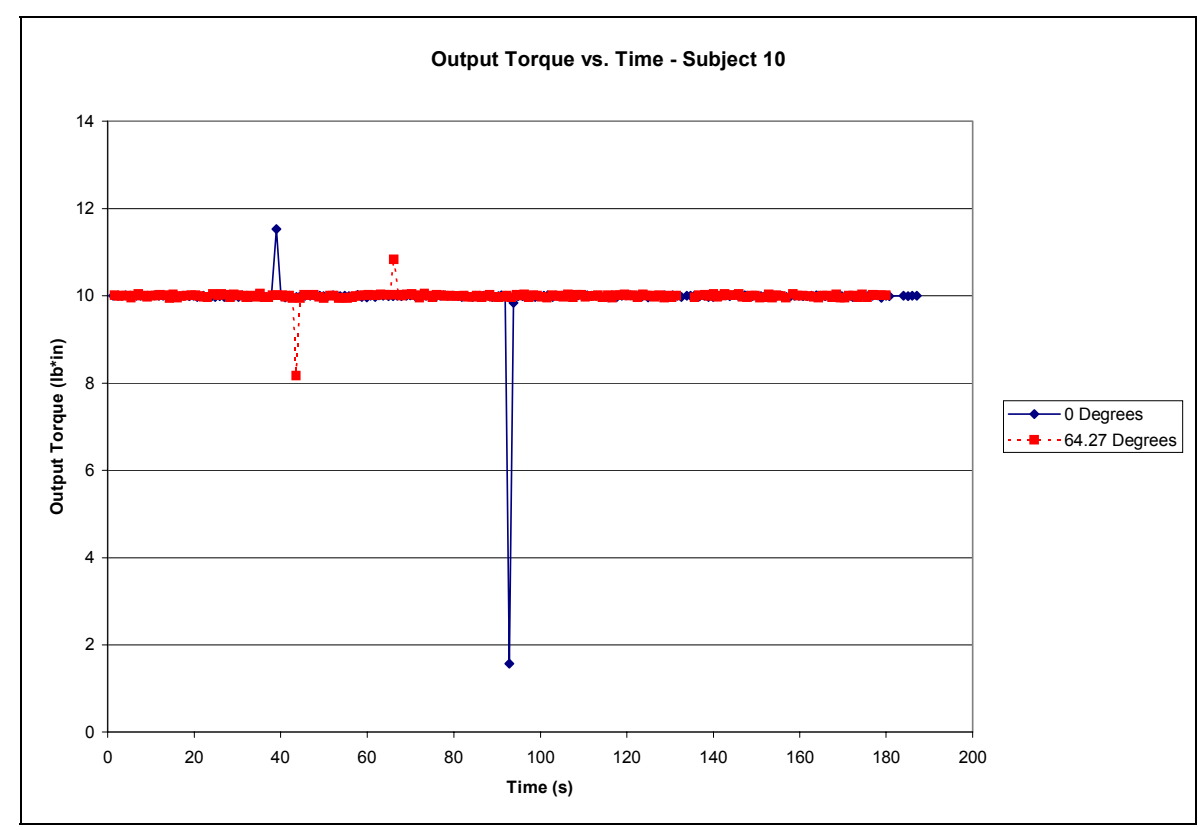

Figure 115 - Torque Results For Subject 10 (10 in*Ibs) 


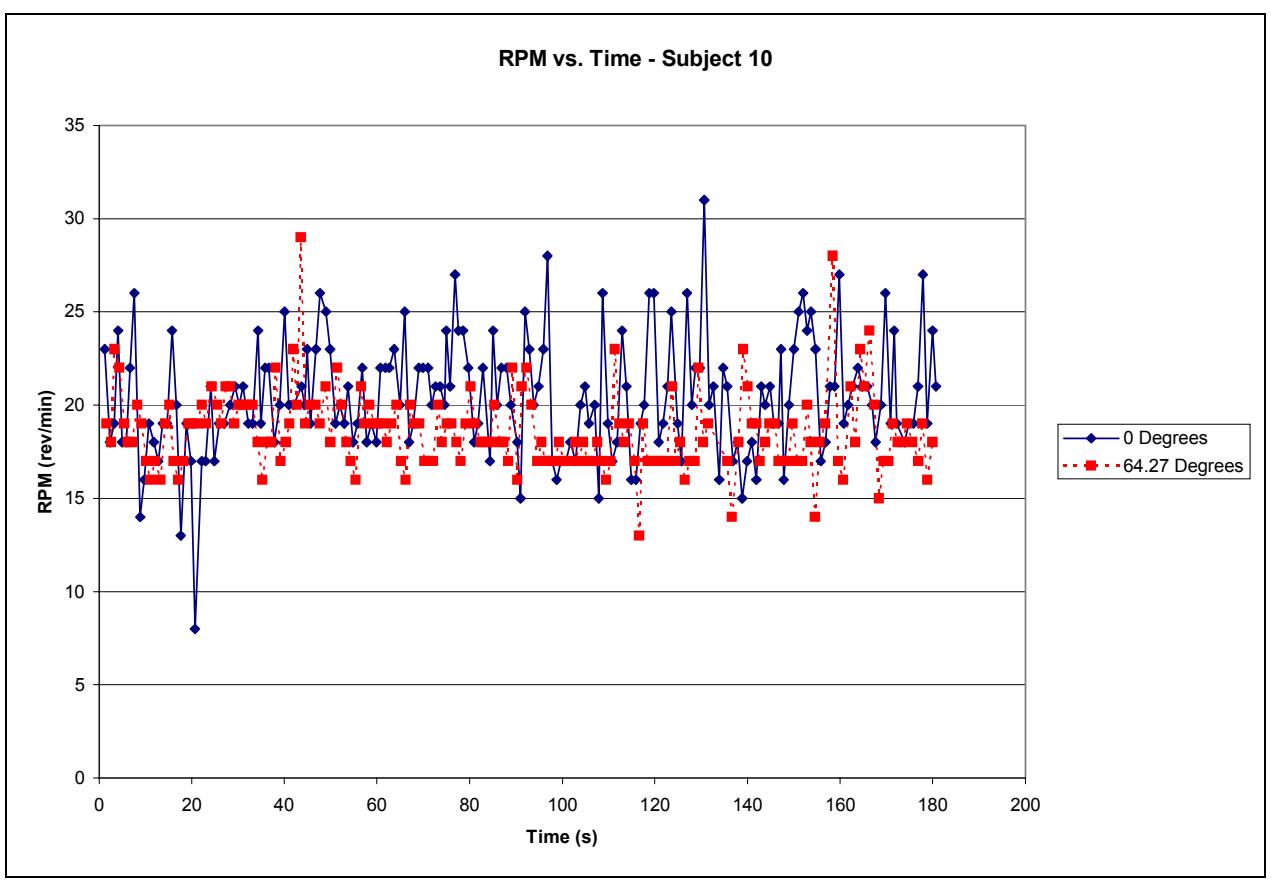

Figure 116 - RPM Results For Subject 10 (10 in*lbs)

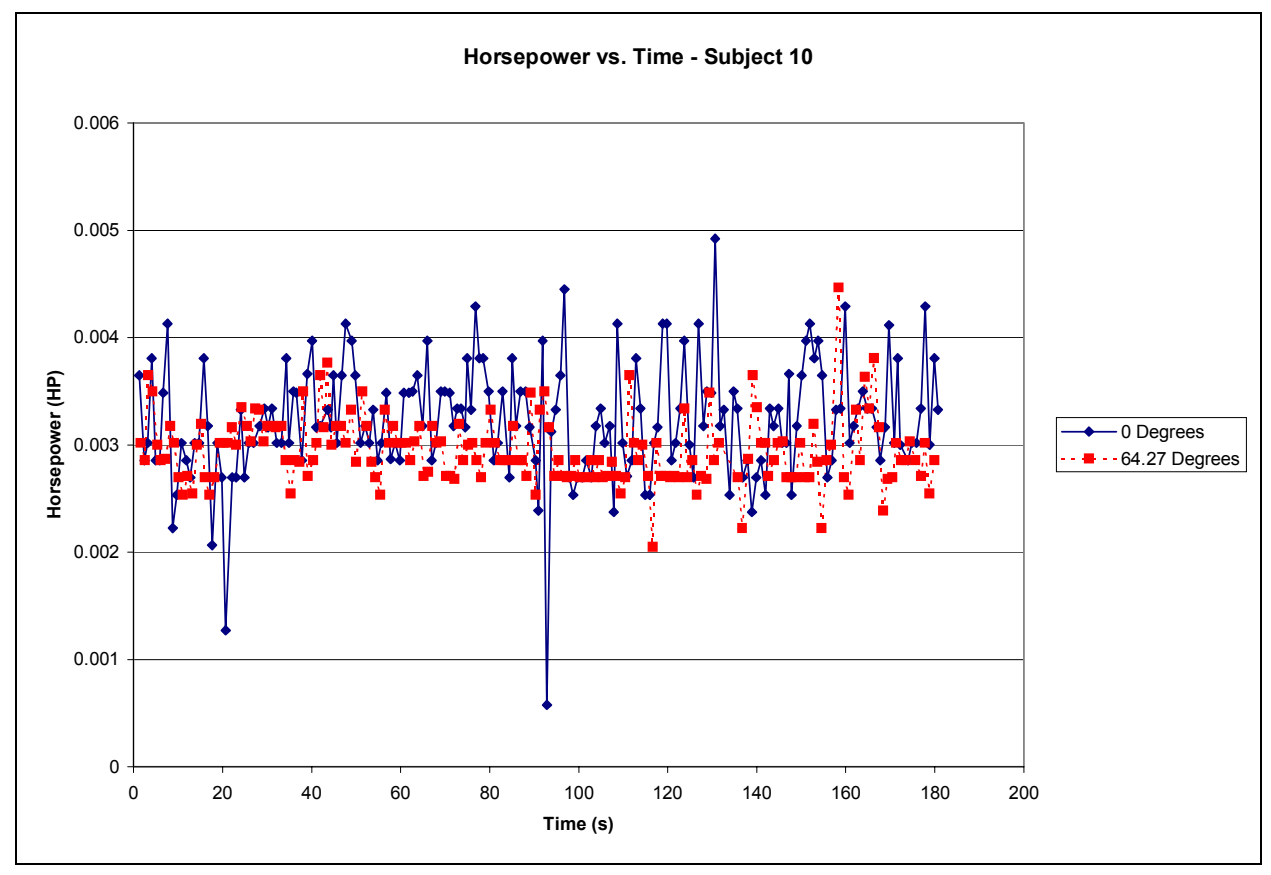

Figure 117 - Horsepower Results For Subject 10 (10 in*lbs) 


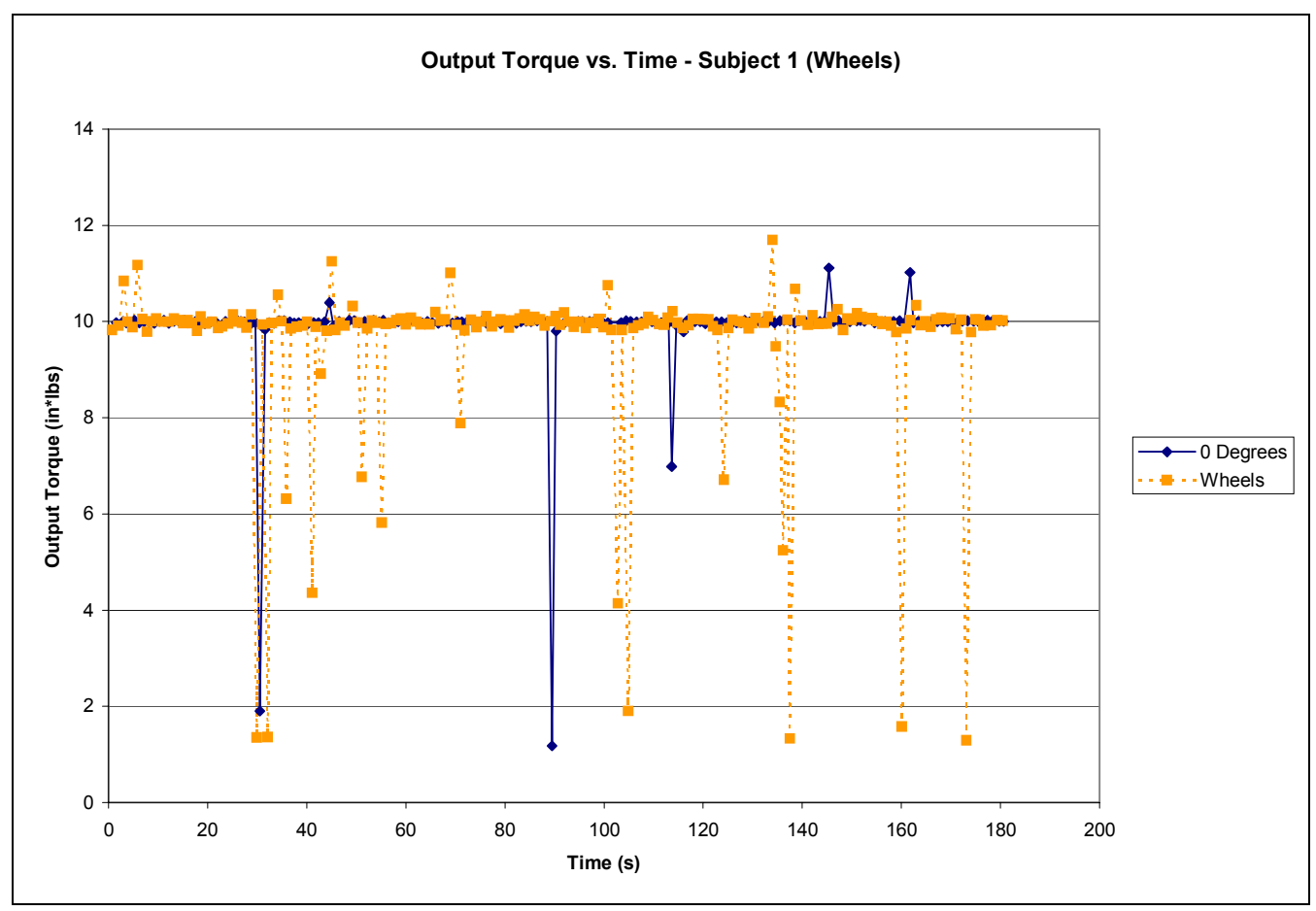

Figure 118 - Torque Results - Subject 1 - Wheels (10 in*lbs)

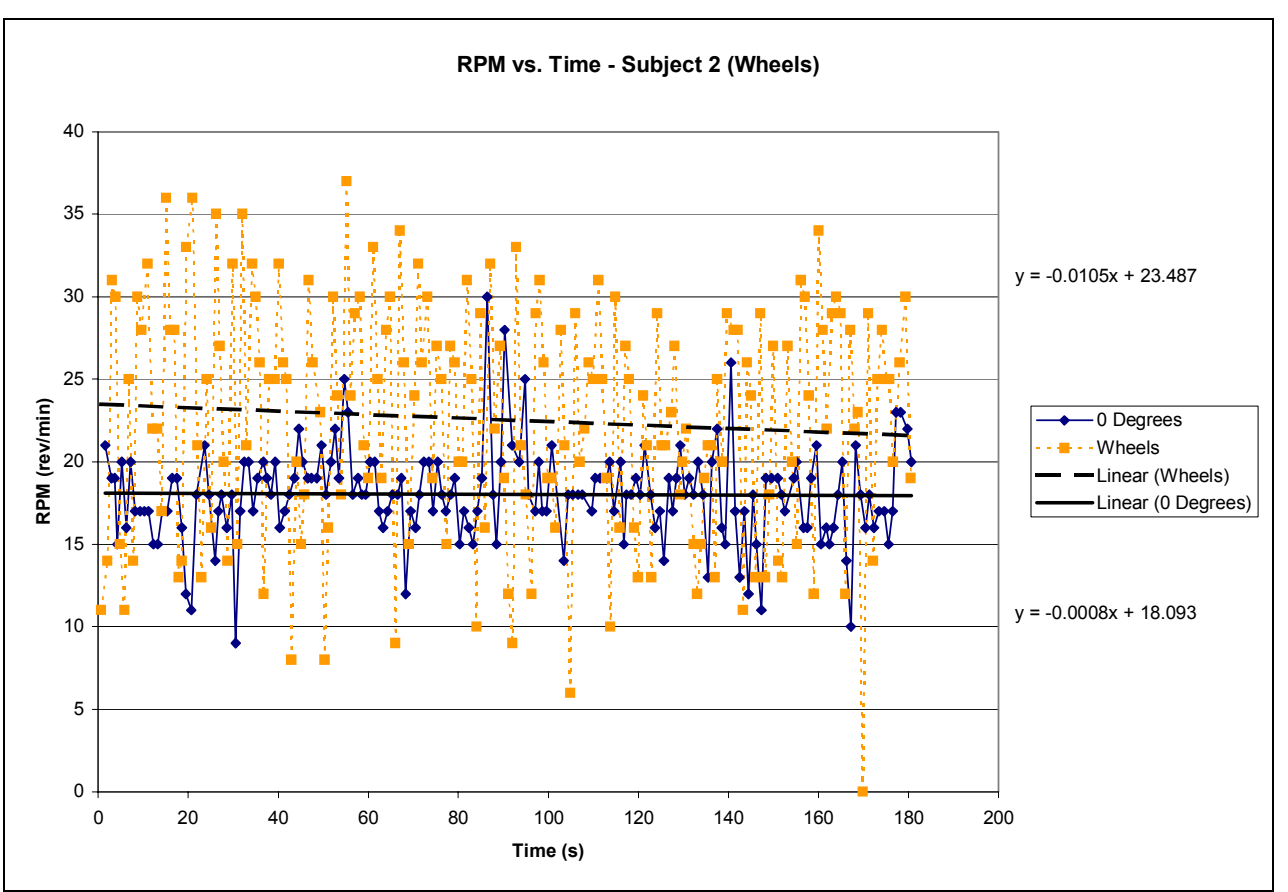

Figure 119 - RPM Results - Subject 1 - Wheels (10 in*lbs) 


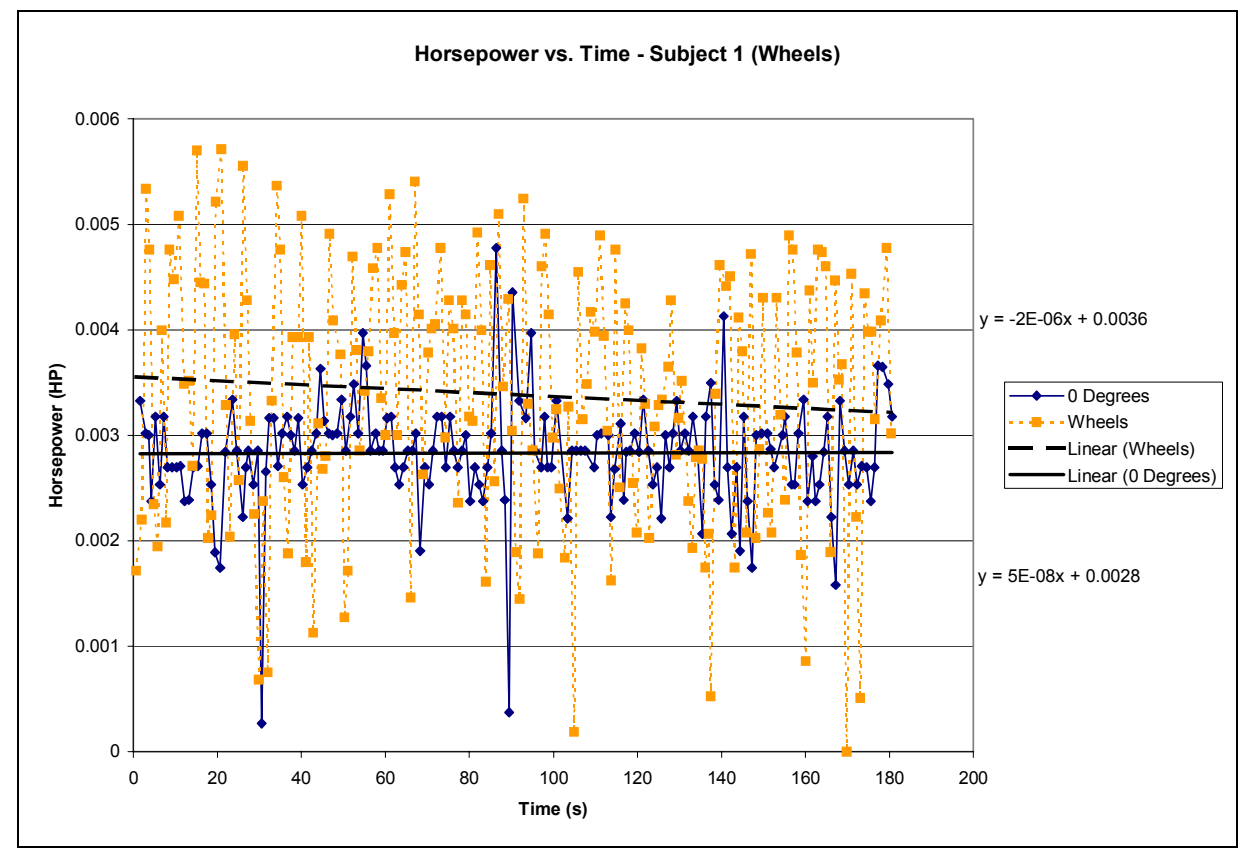

Figure 120 - Horsepower Results - Subject 1 - Wheels (10 in*lbs)

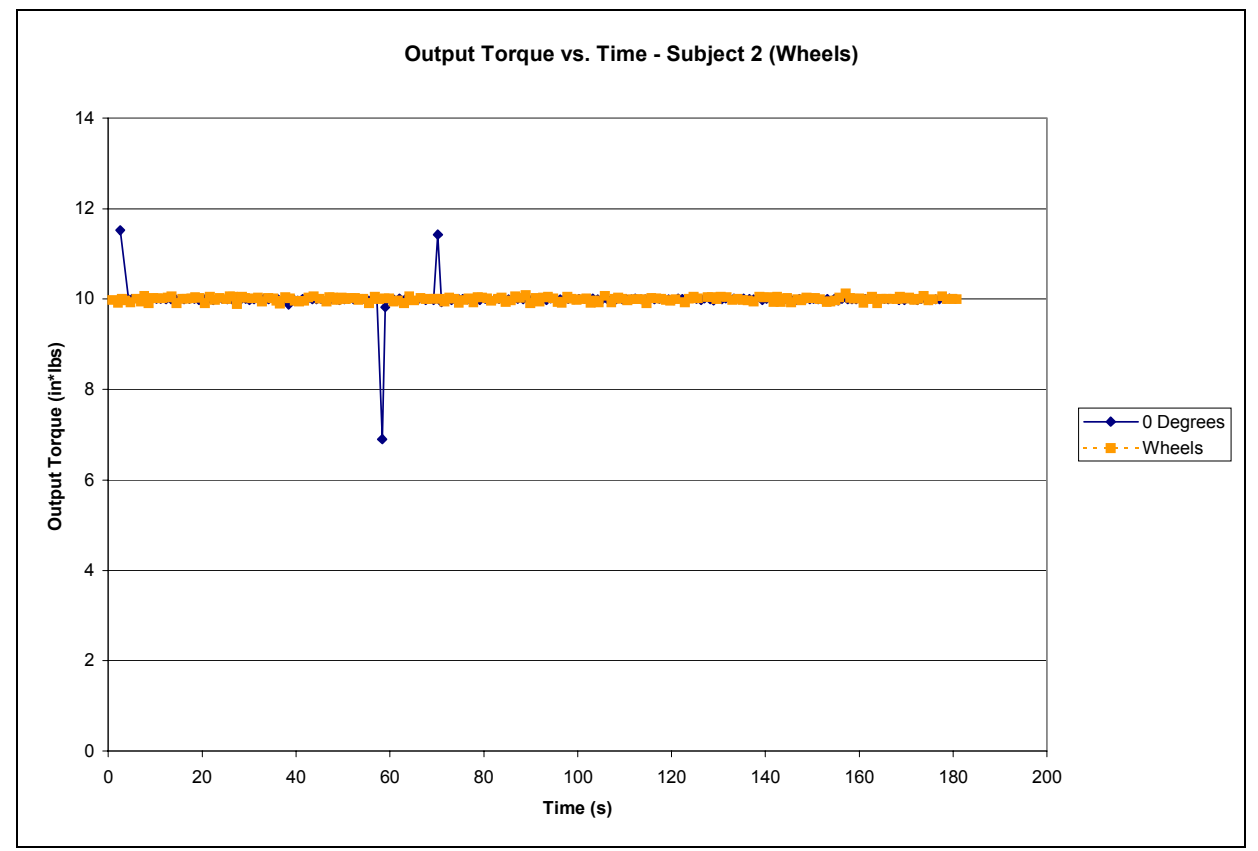

Figure 121 - Torque Results - Subject 2 - Wheels (10 in*Ibs) 


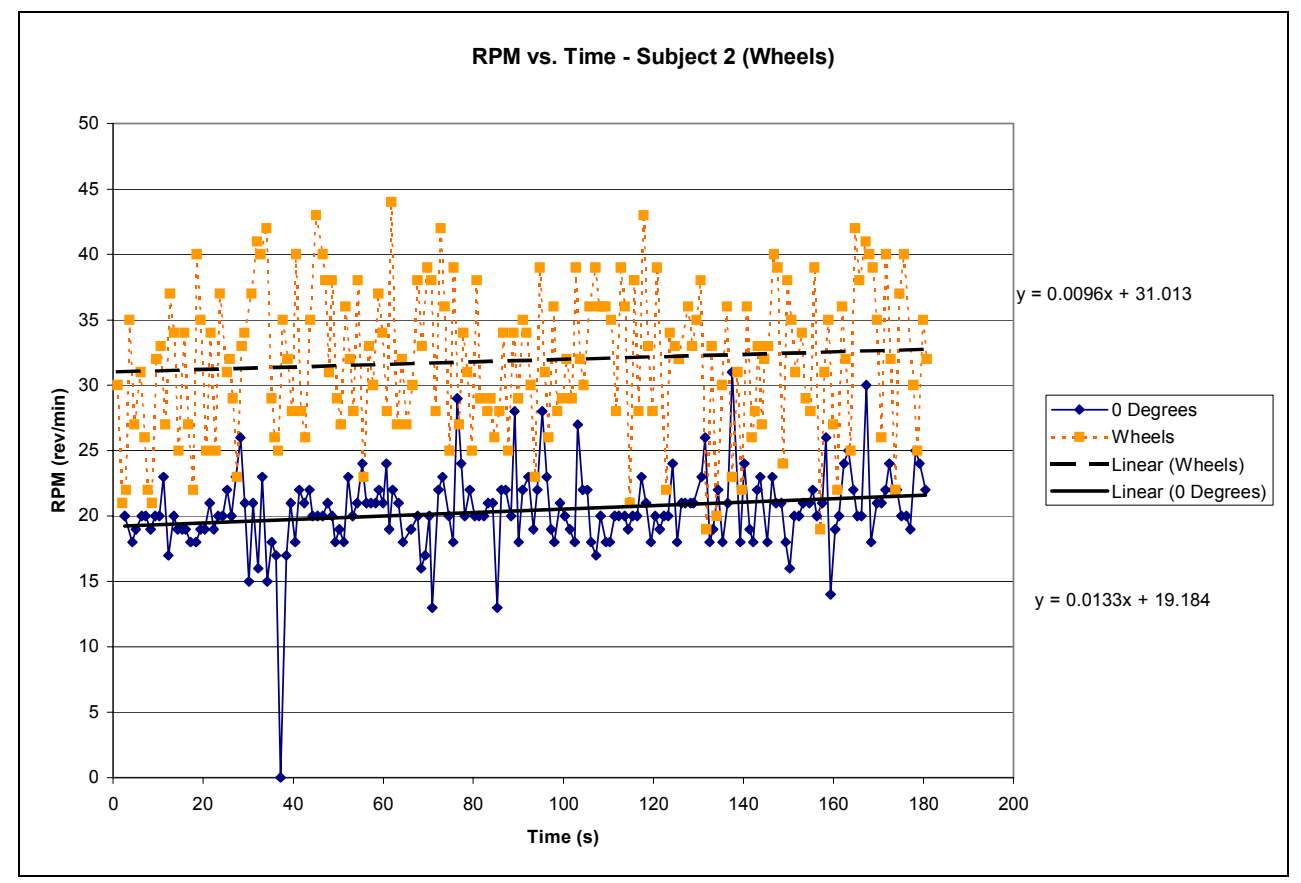

Figure 122 - RPM Results - Subject 2 - Wheels (10 in*lbs)

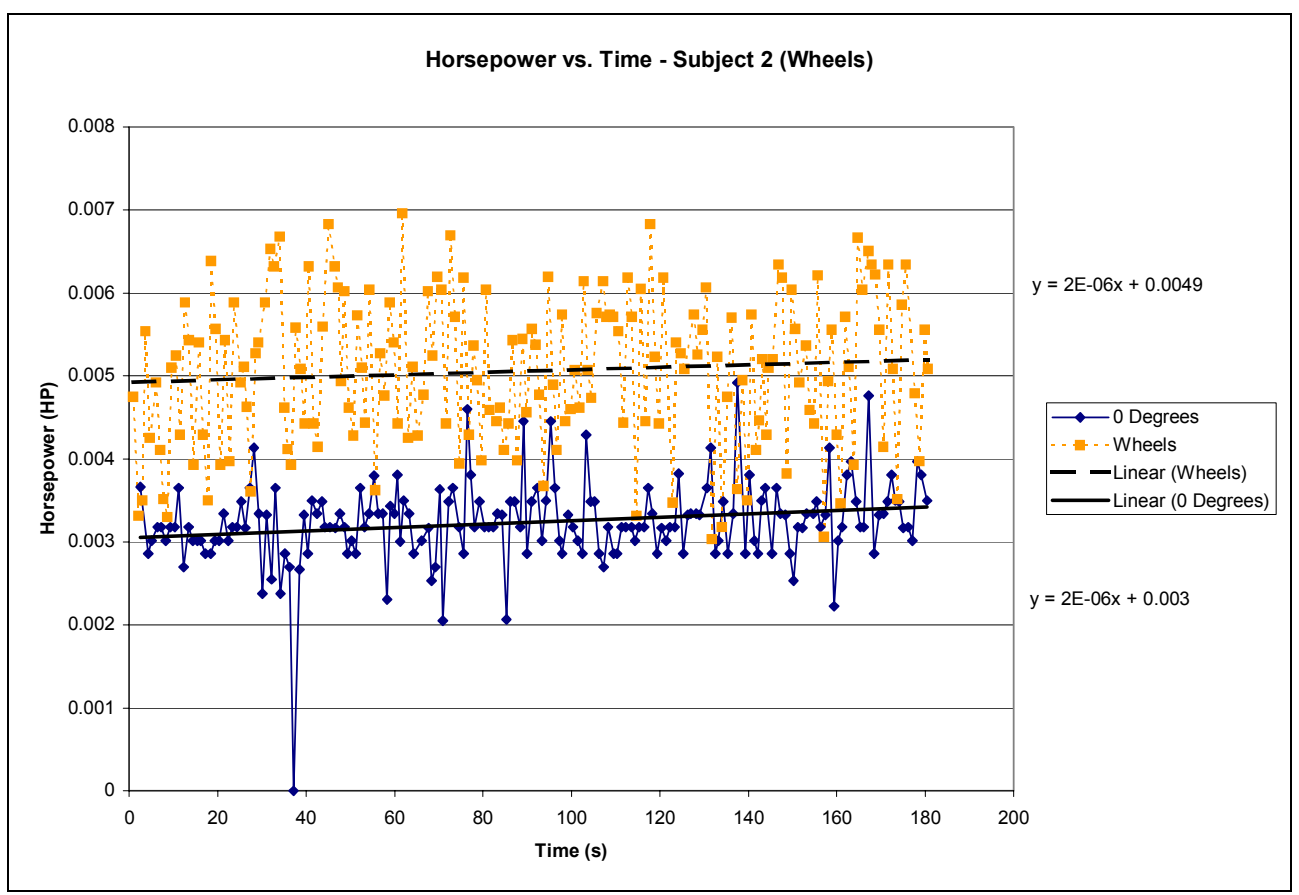

Figure 123 - Horsepower Results - Subject 2 - Wheels (10 in*lbs) 


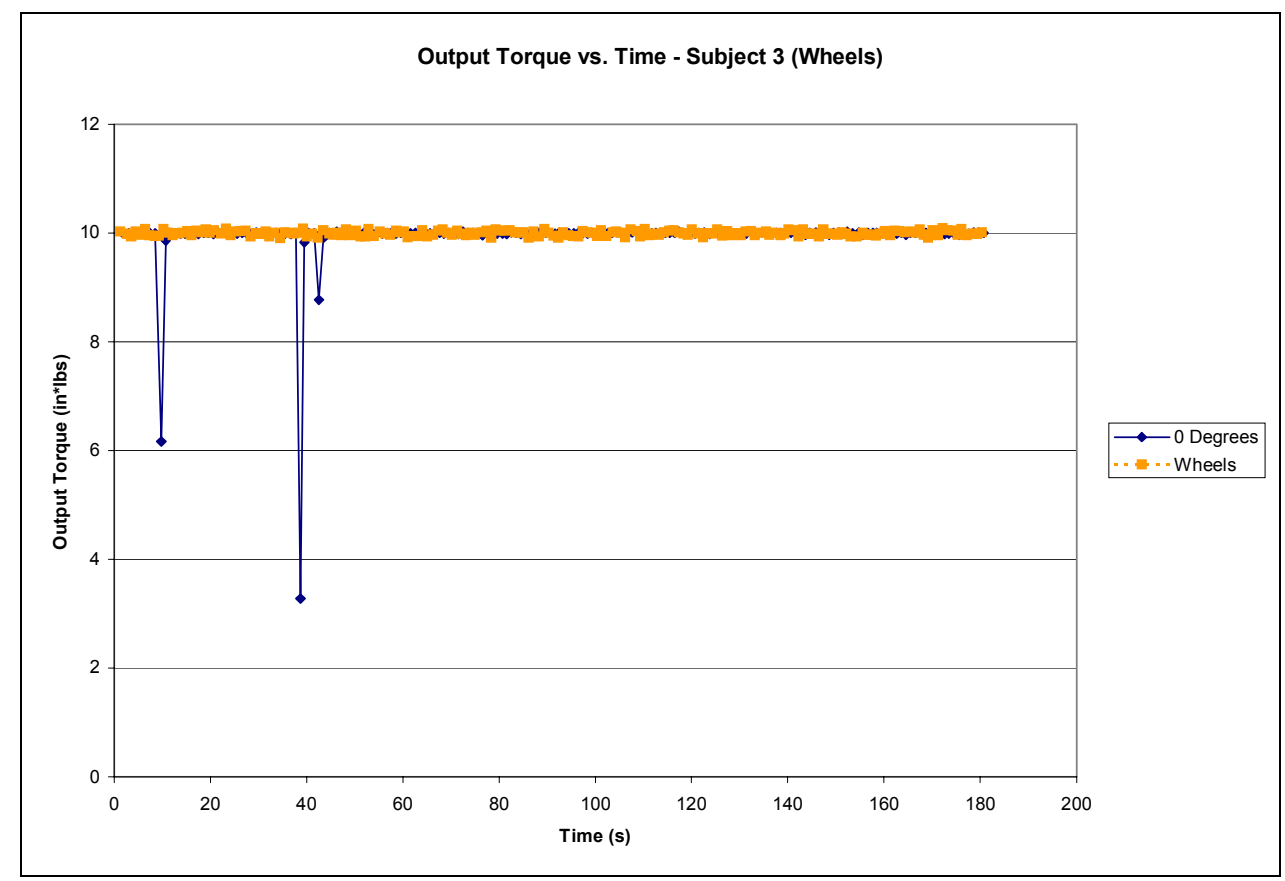

Figure 124 - Torque Results - Subject 3 - Wheels (10 in*lbs)

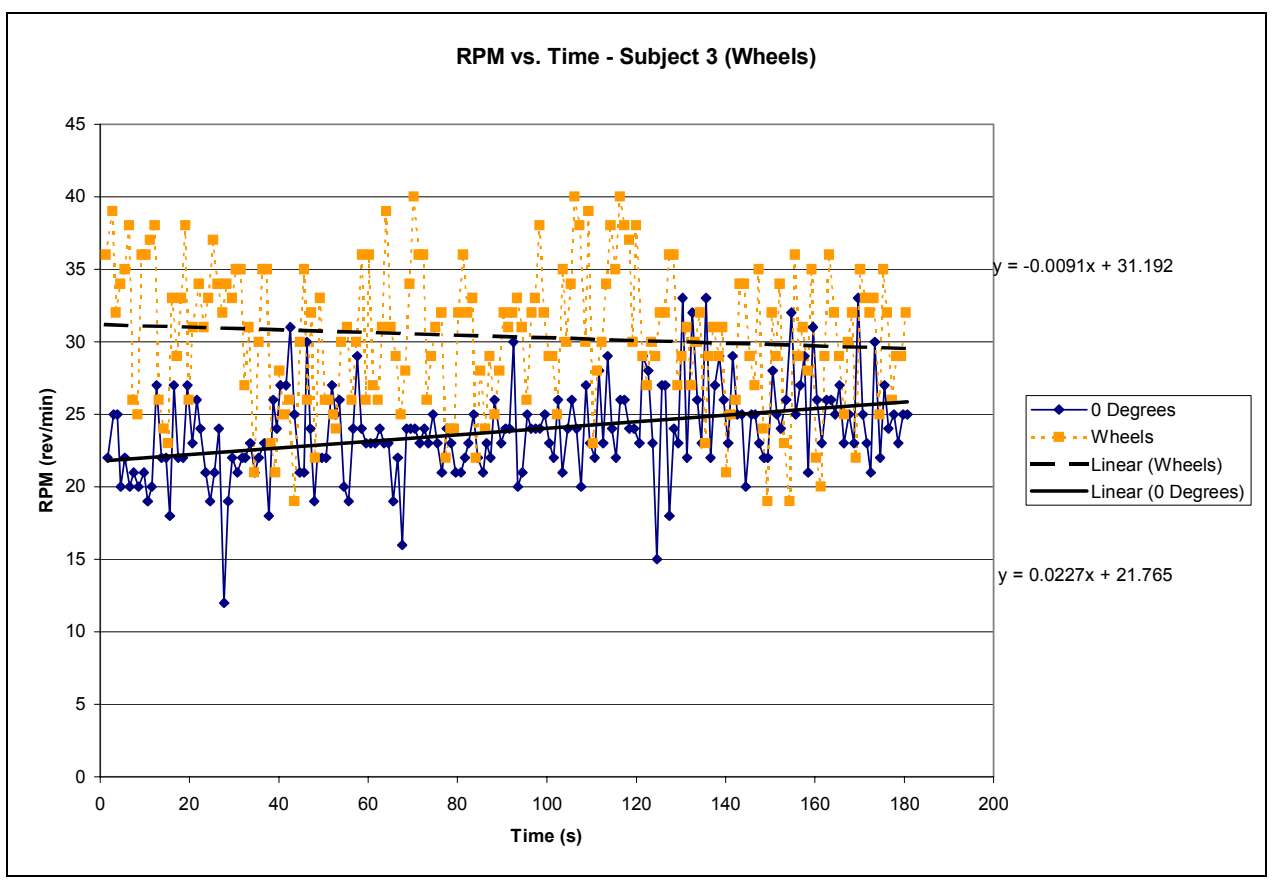

Figure 125 - RPM Results - Subject 3 - Wheels (10 in*lbs) 


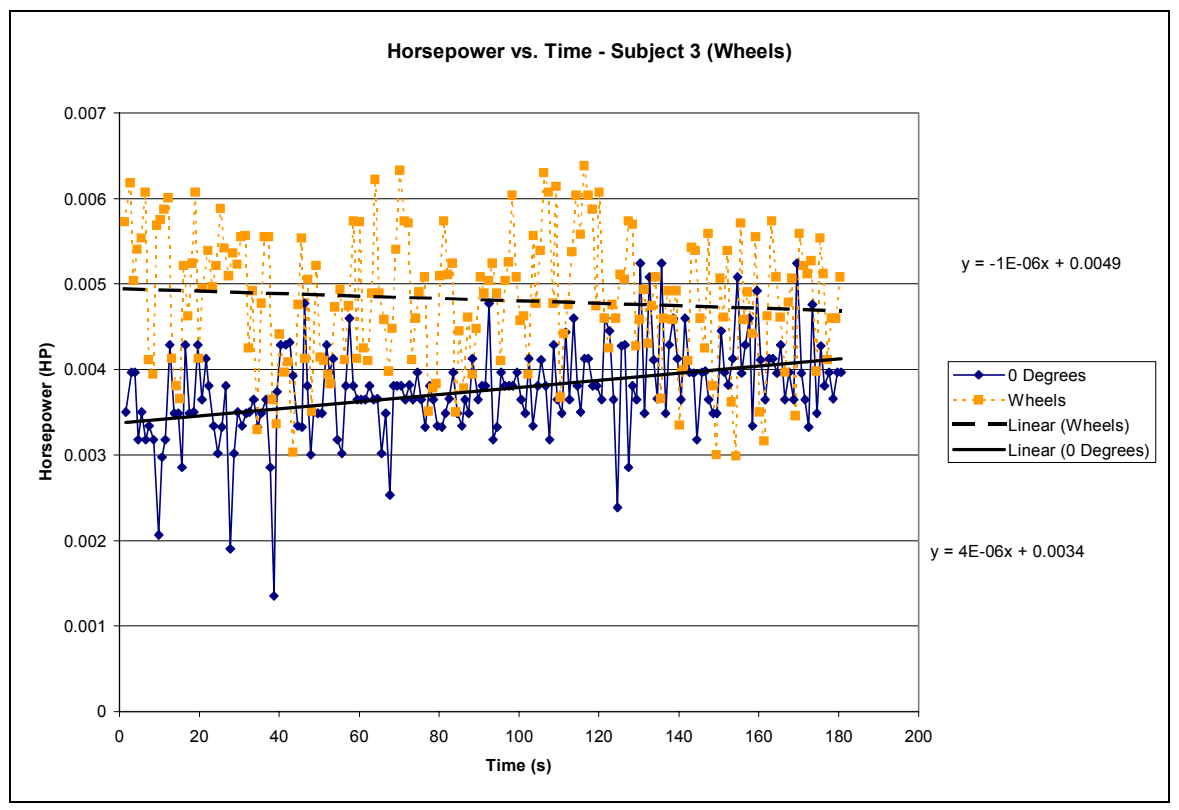

Figure 126 - Horsepower Results - Subject 3 - Wheels (10 in*lbs)

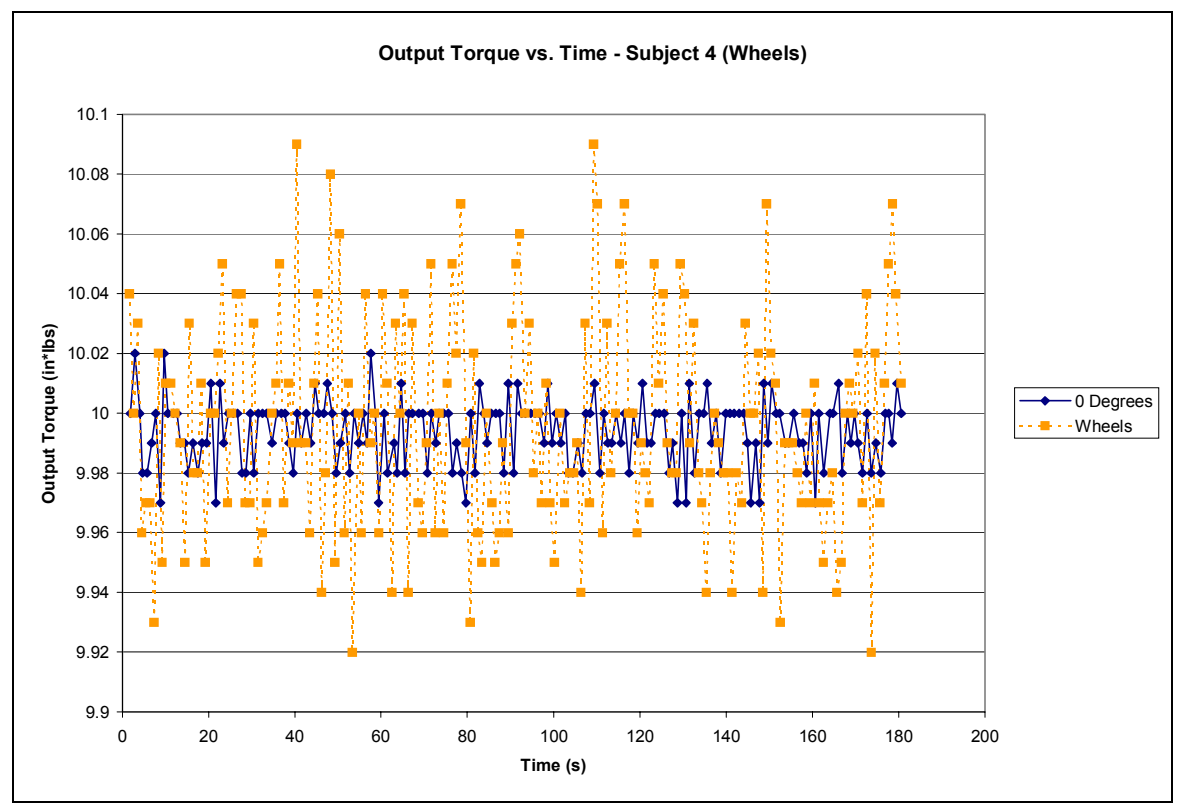

Figure 127 - Torque Results - Subject 4 - Wheels (10 in*lbs) 


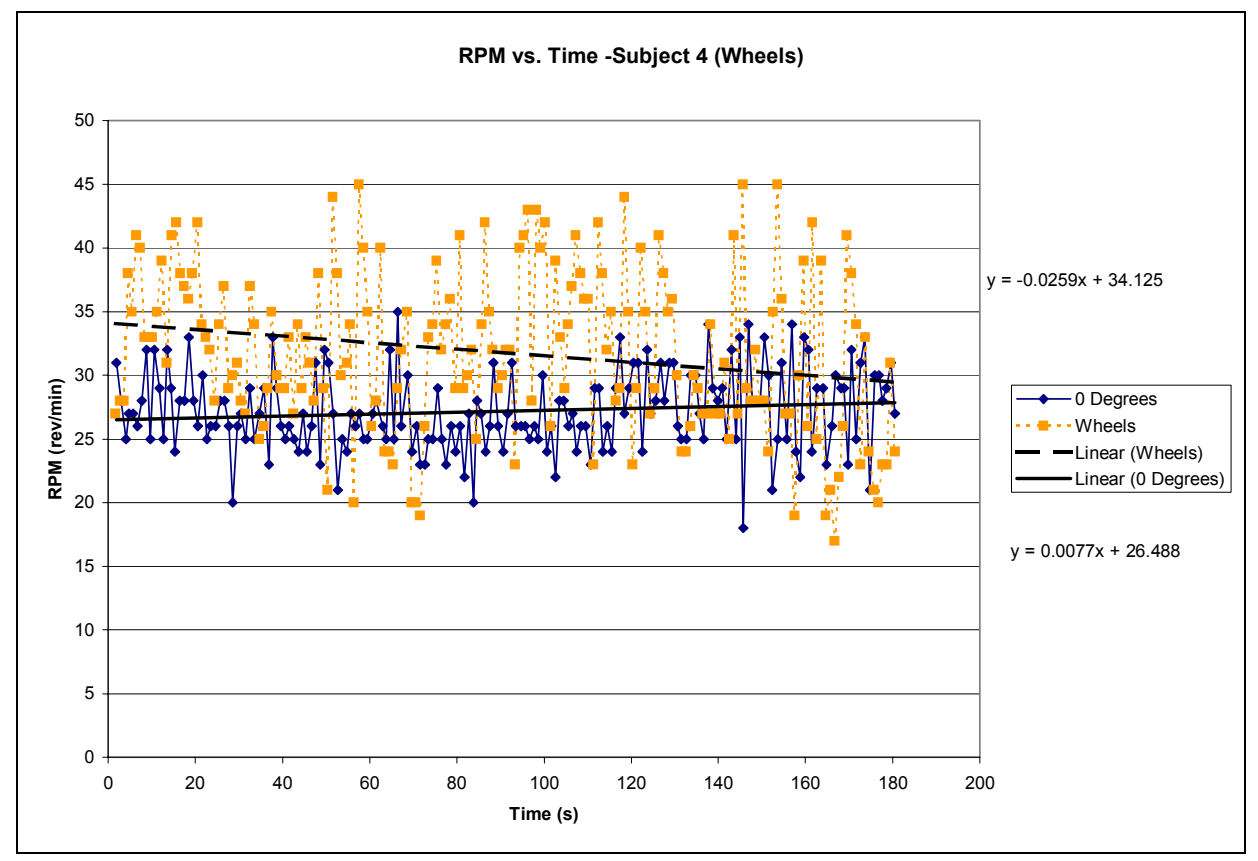

Figure 128 - RPM Results - Subject 4 - Wheels (10 in*lbs)

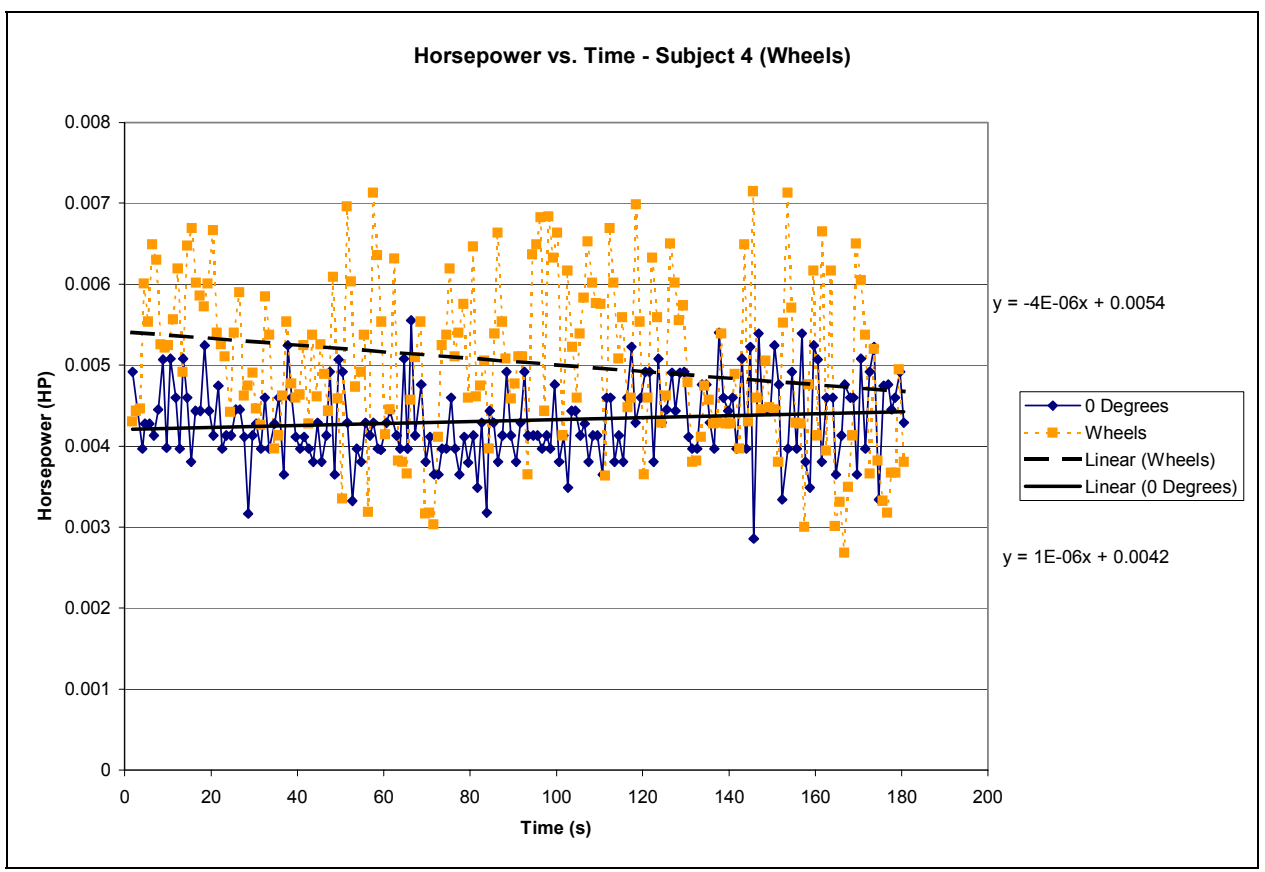

Figure 129 - Horsepower Results - Subject 4 - Wheels (10 in*lbs) 


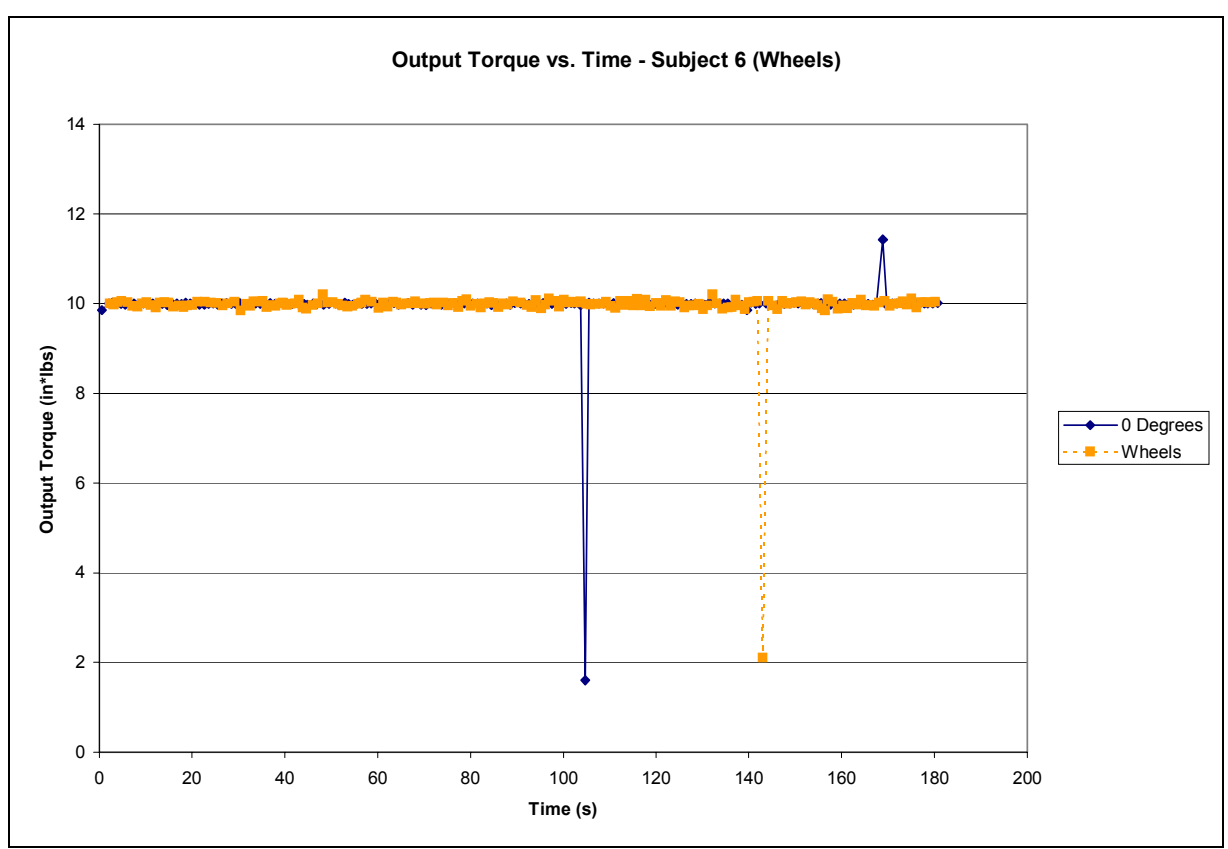

Figure 130 - Torque Results - Subject 6 - Wheels (10 in*lbs)

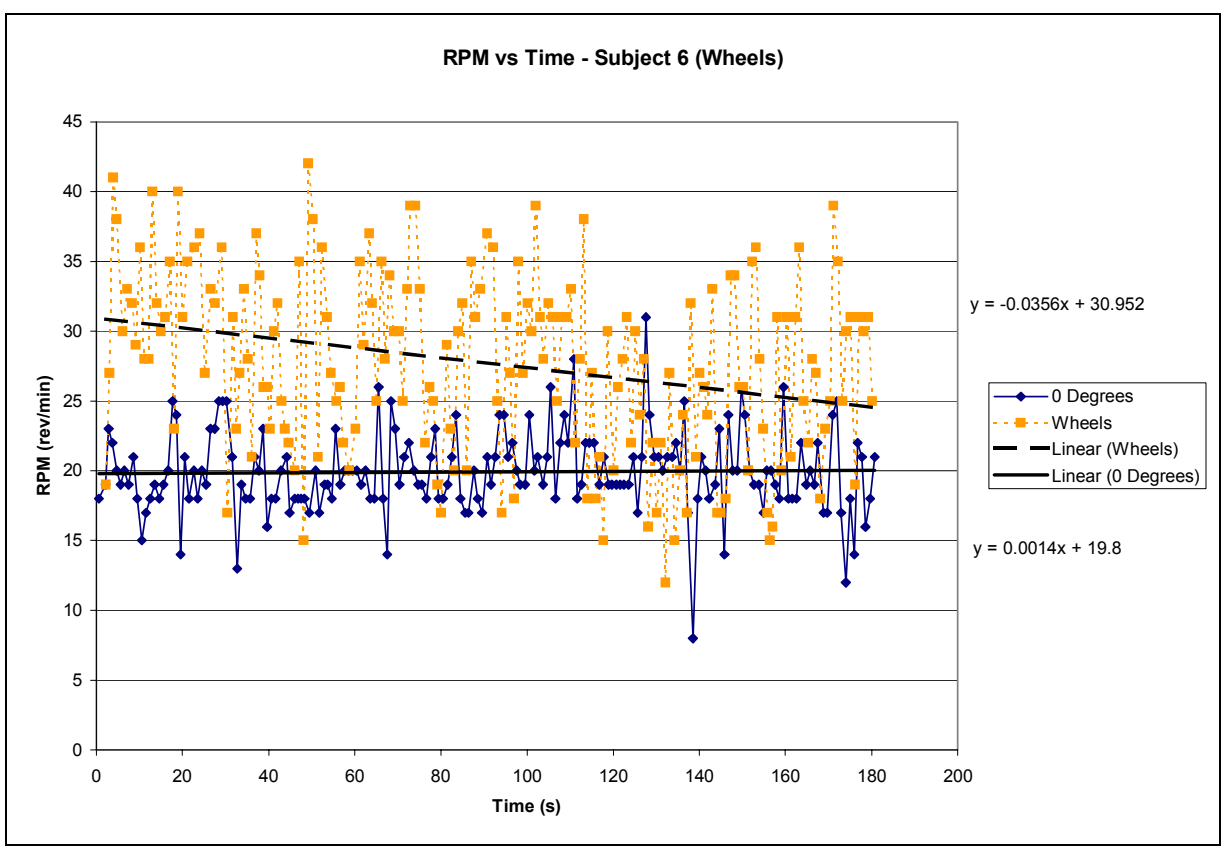

Figure 131 - RPM Results - Subject 6 - Wheels (10 in*lbs) 


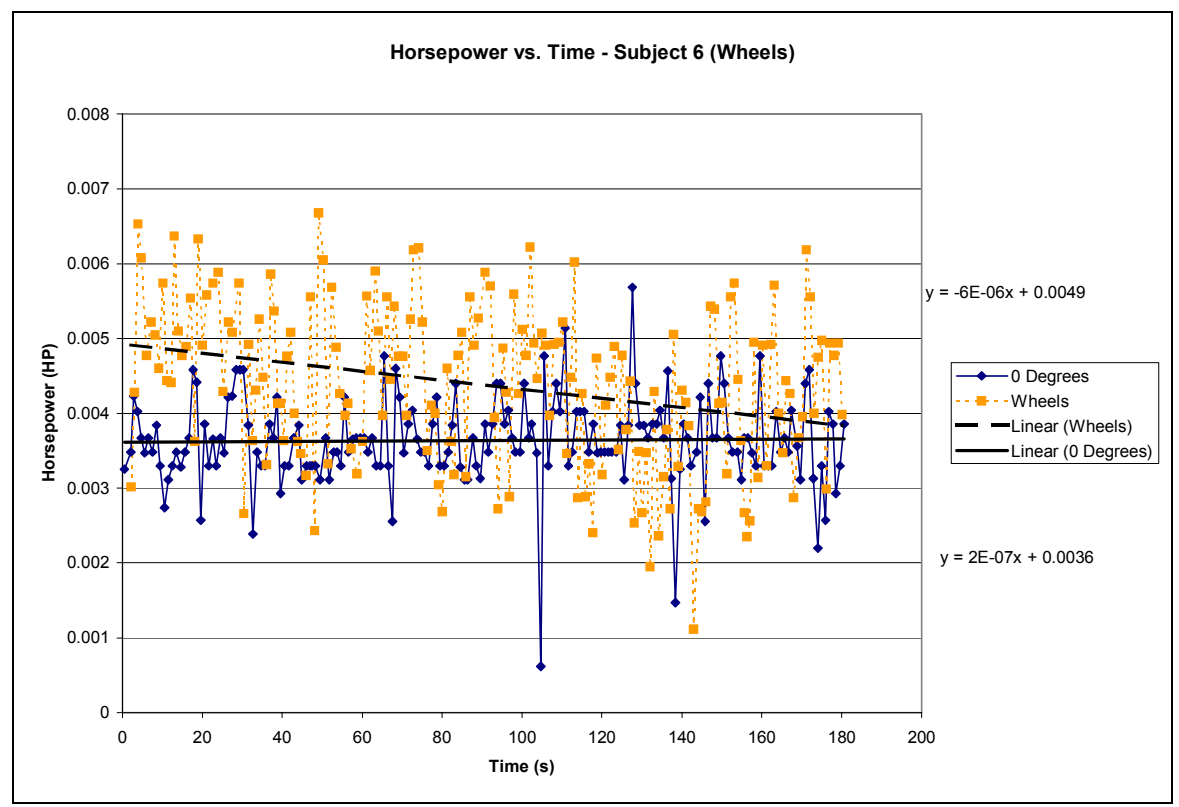

Figure 132 - Horsepower Results - Subject 6 - Wheels (10 in*lbs)

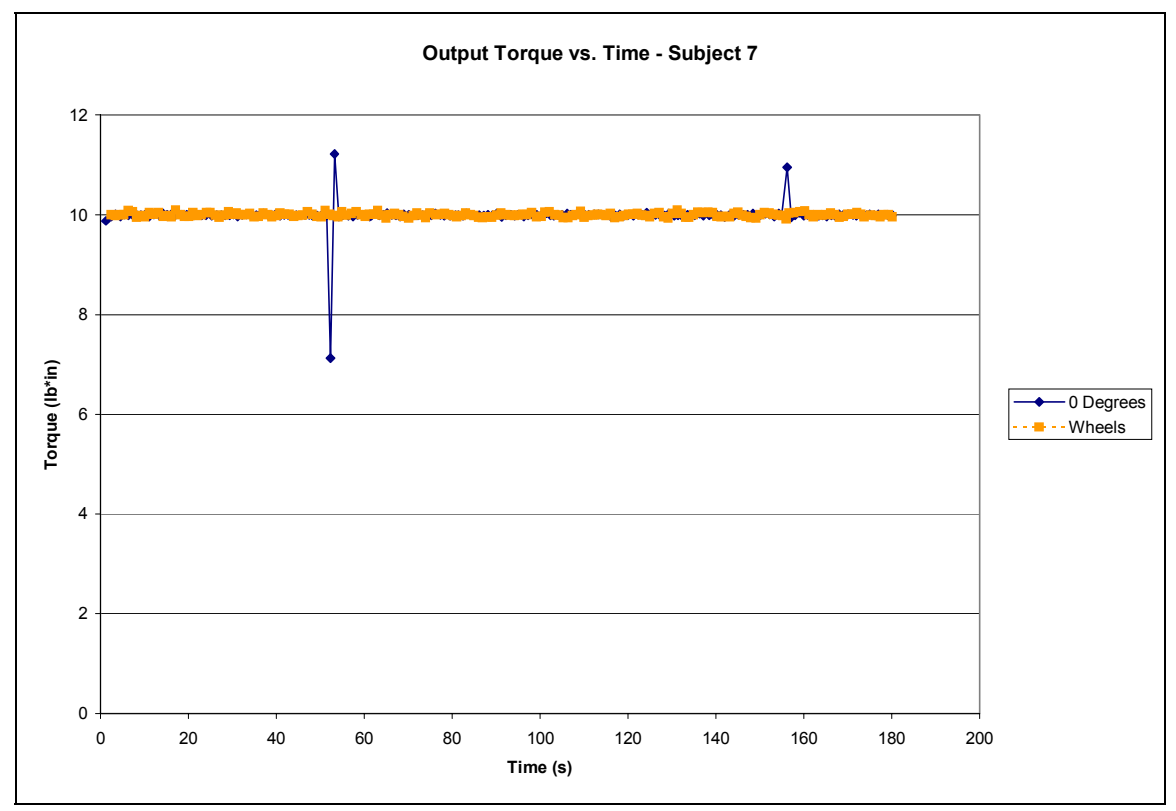

Figure 133 - Torque Results - Subject 7 - Wheels (10 in*Ibs) 


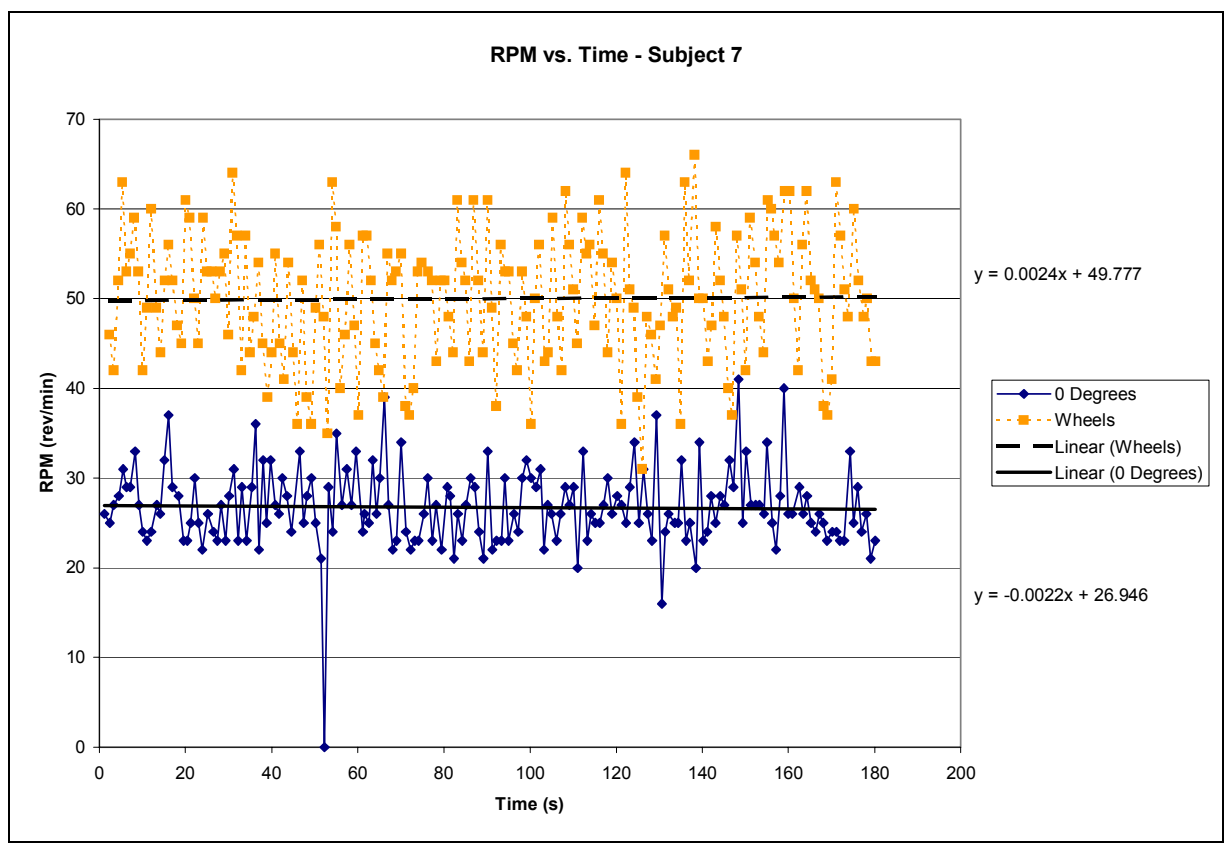

Figure 134 - RPM Results - Subject 7 - Wheels (10 in*lbs)

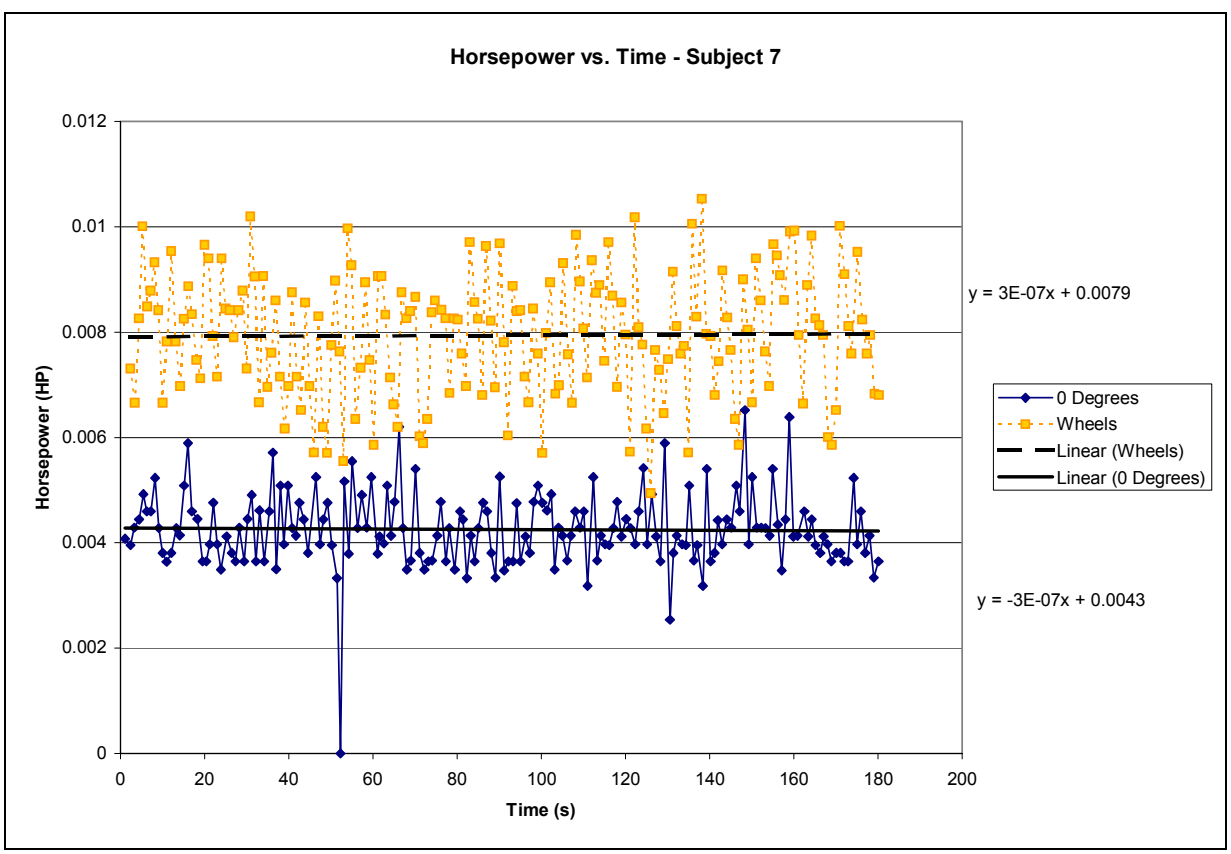

Figure 135 - Horsepower Results - Subject 7 - Wheels (10 in*lbs) 


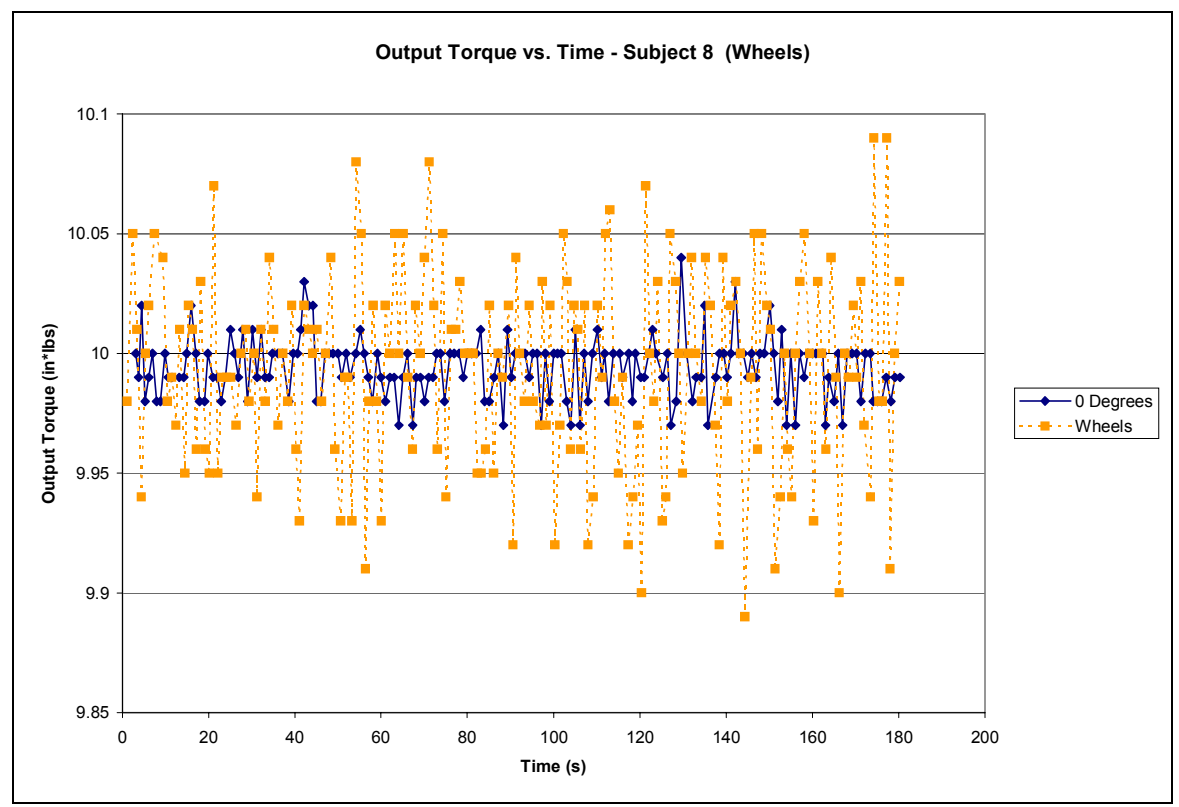

Figure 136 - Torque Results - Subject 8 - Wheels (10 in*lbs)

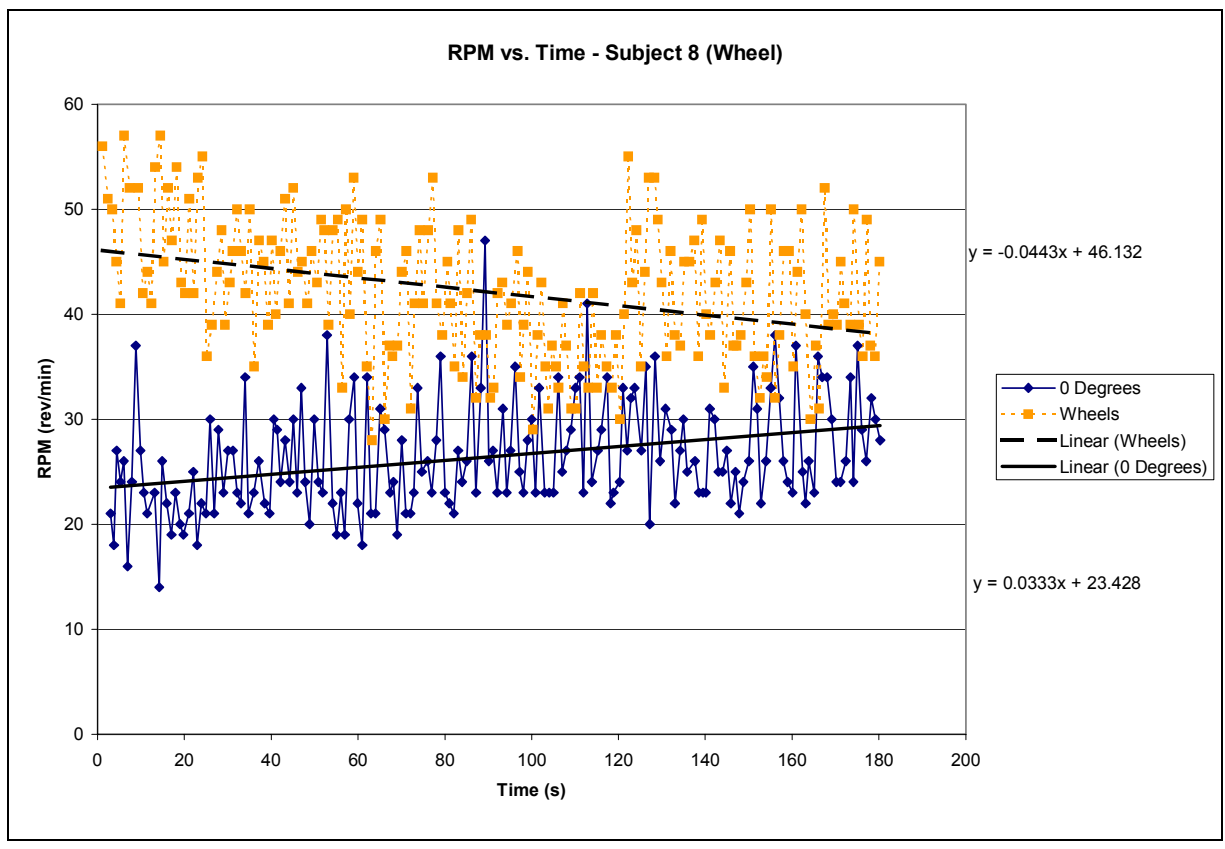

Figure 137 - RPM Results - Subject 8 - Wheels (10 in*lbs) 


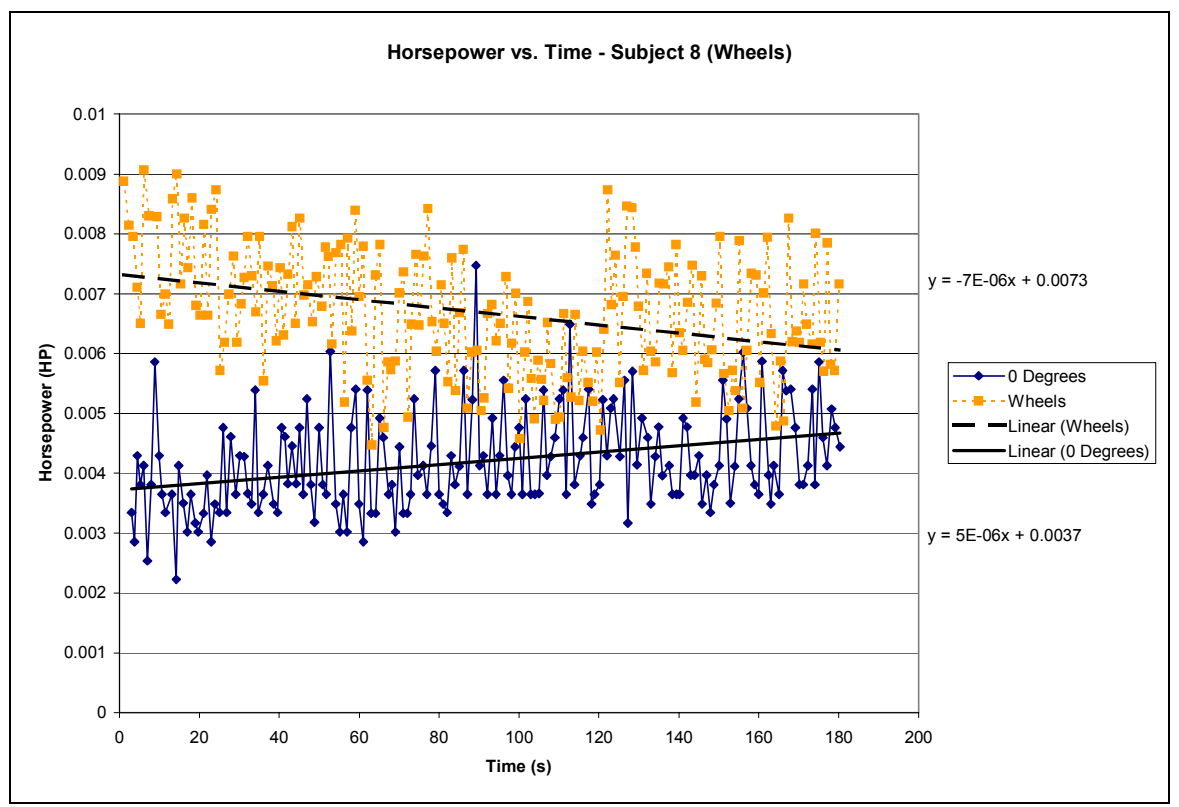

Figure 138 - Horsepower Results - Subject 8 - Wheels (10 in*lbs)

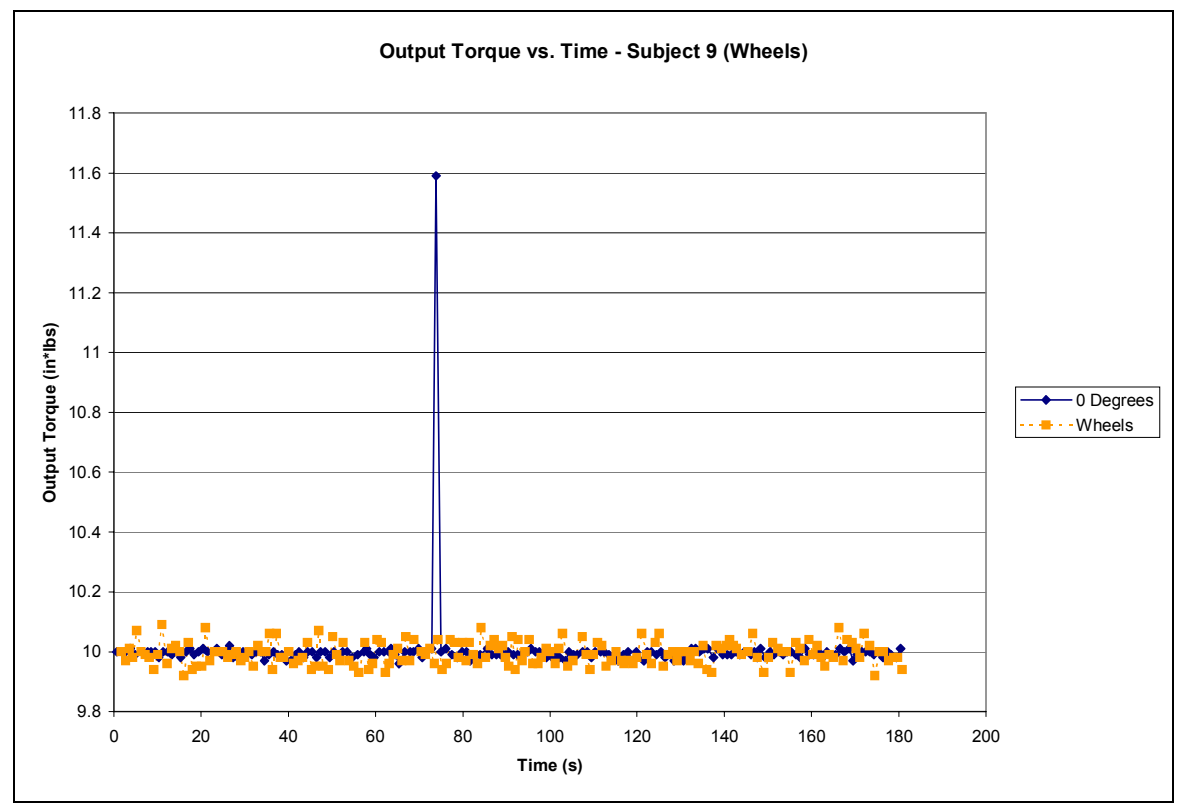

Figure 139 - Torque Results - Subject 9 - Wheels (10 in*lbs) 


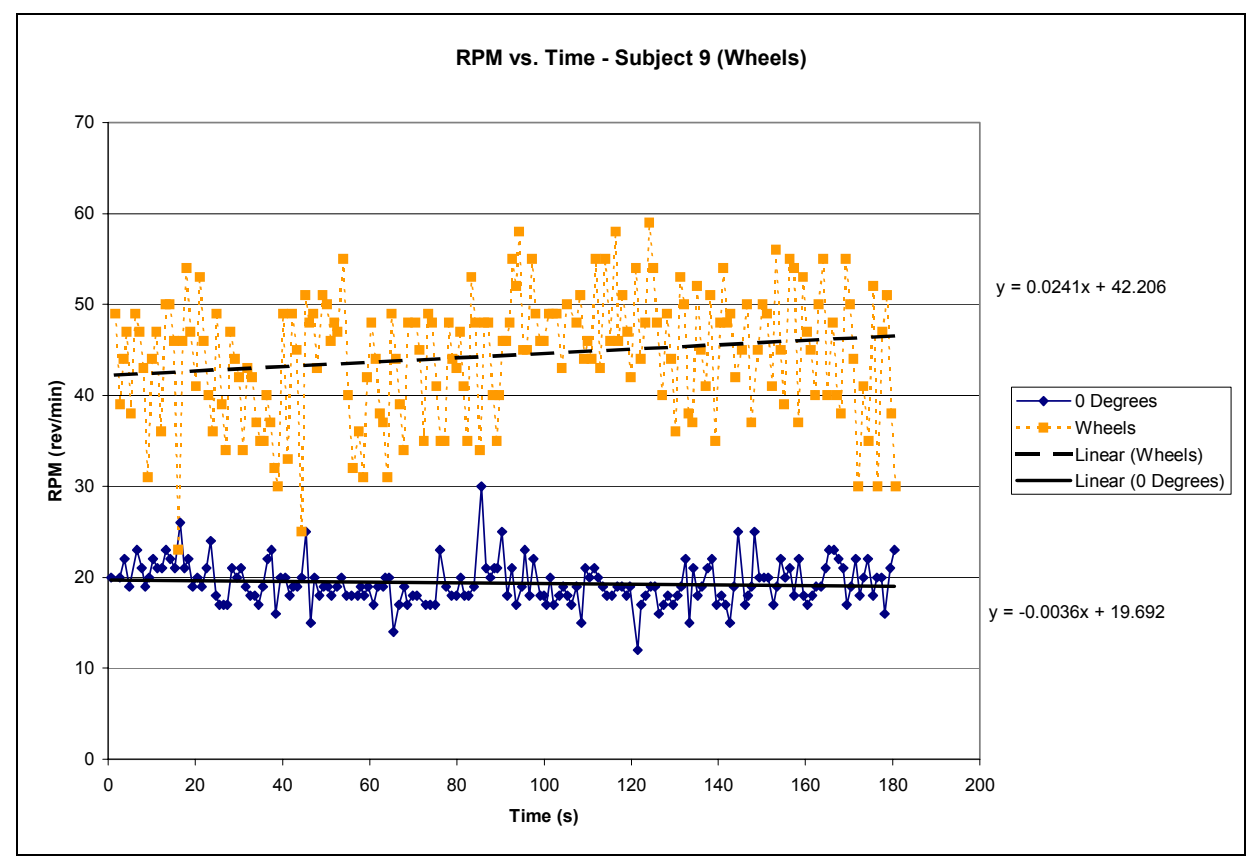

Figure 140 - RPM Results - Subject 9 - Wheels (10 in*lbs)

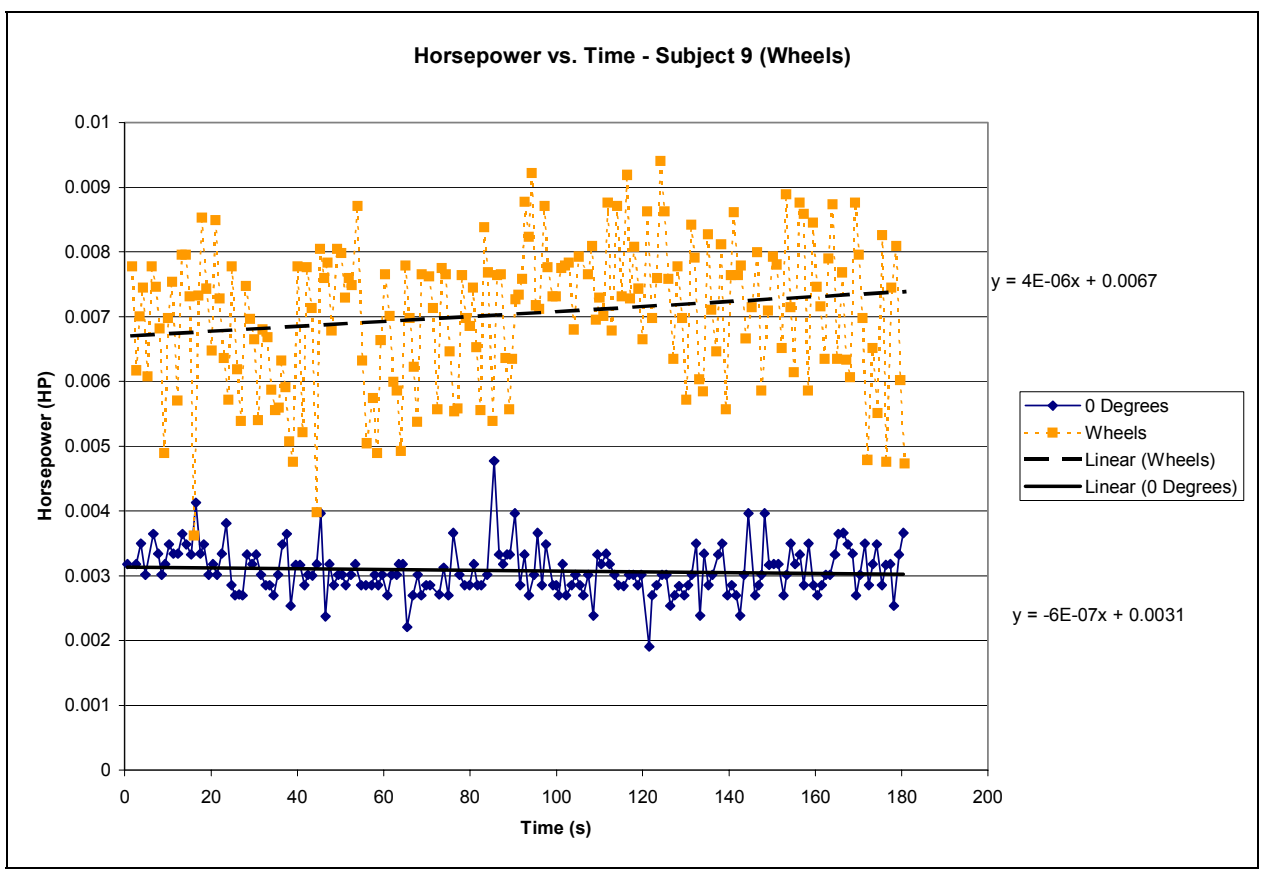

Figure 141 - Horsepower Results - Subject 9 - Wheels (10 in*lbs) 


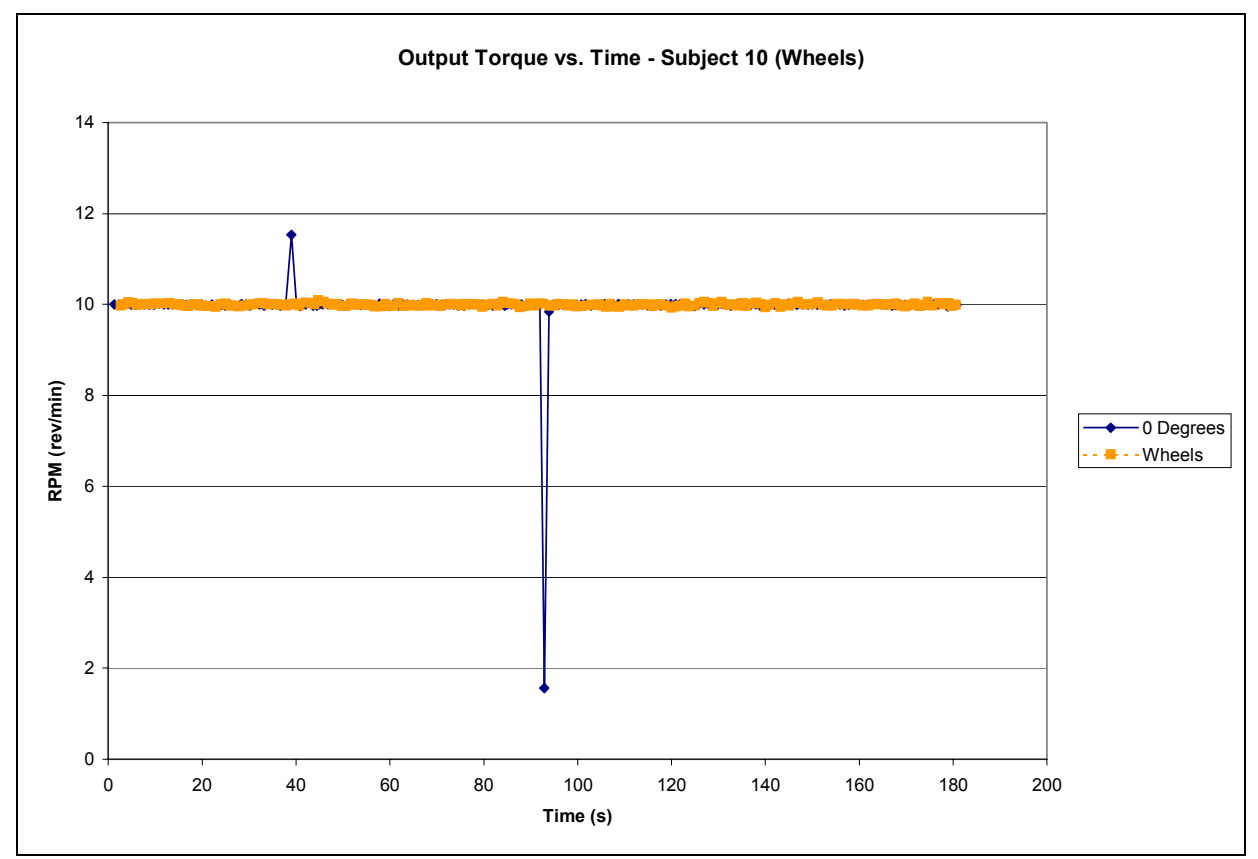

Figure 142 - Torque Results - Subject 10 - Wheels (10 in*lbs)

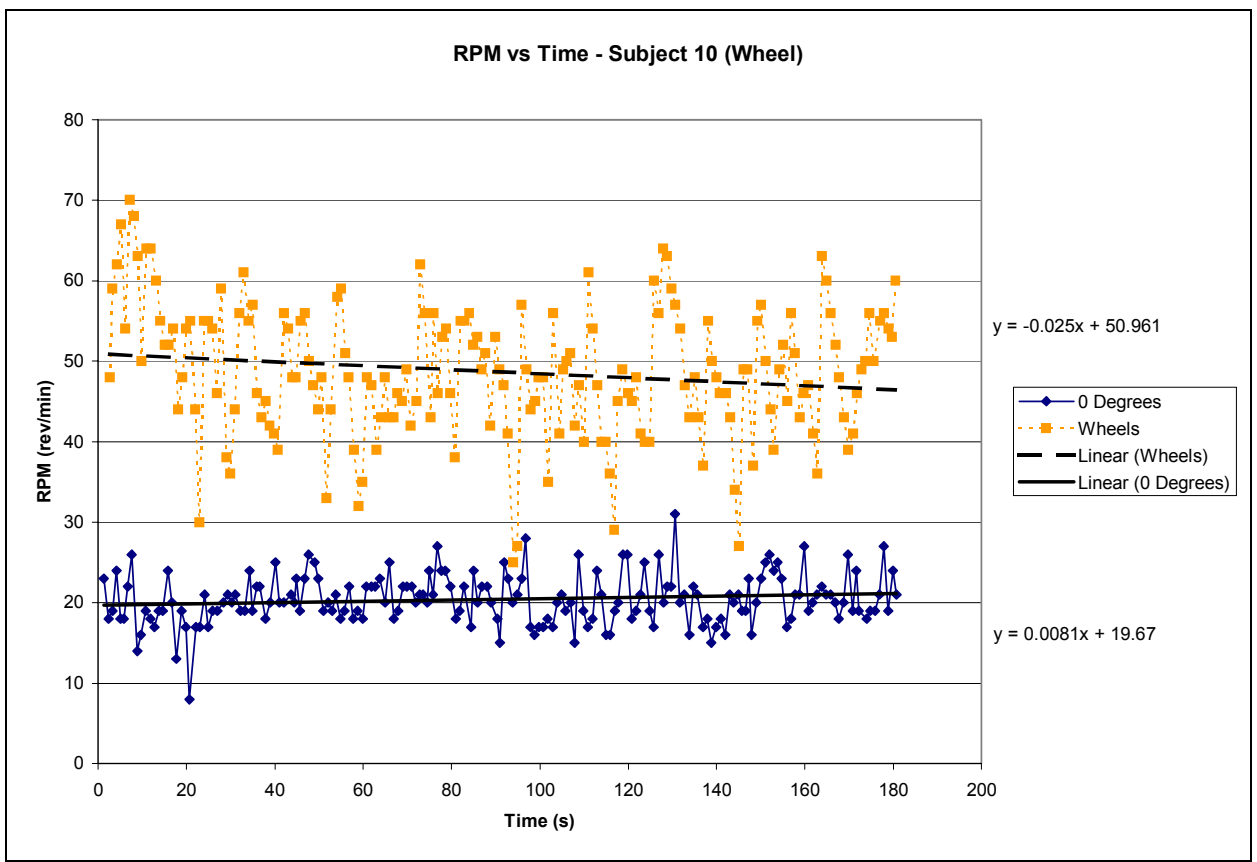

Figure 143 - RPM Results - Subject 10 - Wheels (10 in*lbs) 


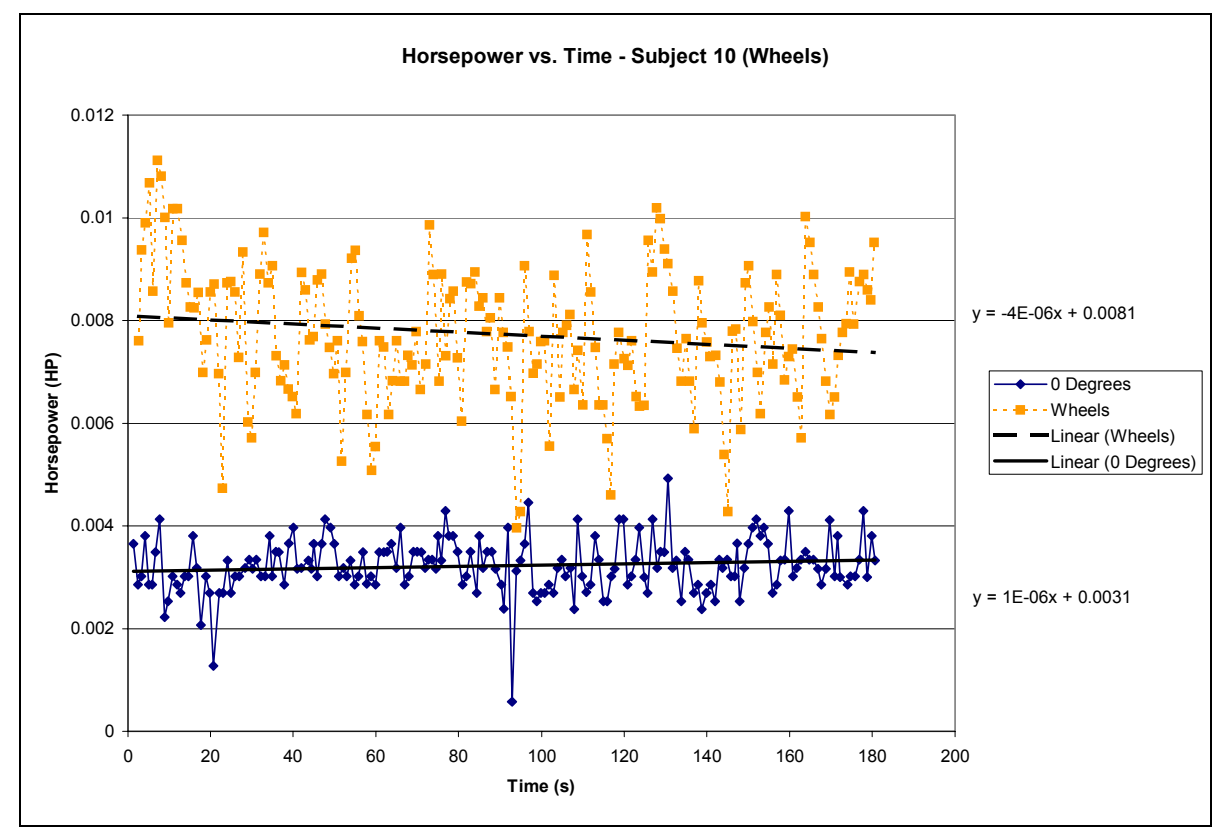

Figure 144 - Horsepower Results - Subject 10 (10 in*lbs)

149 


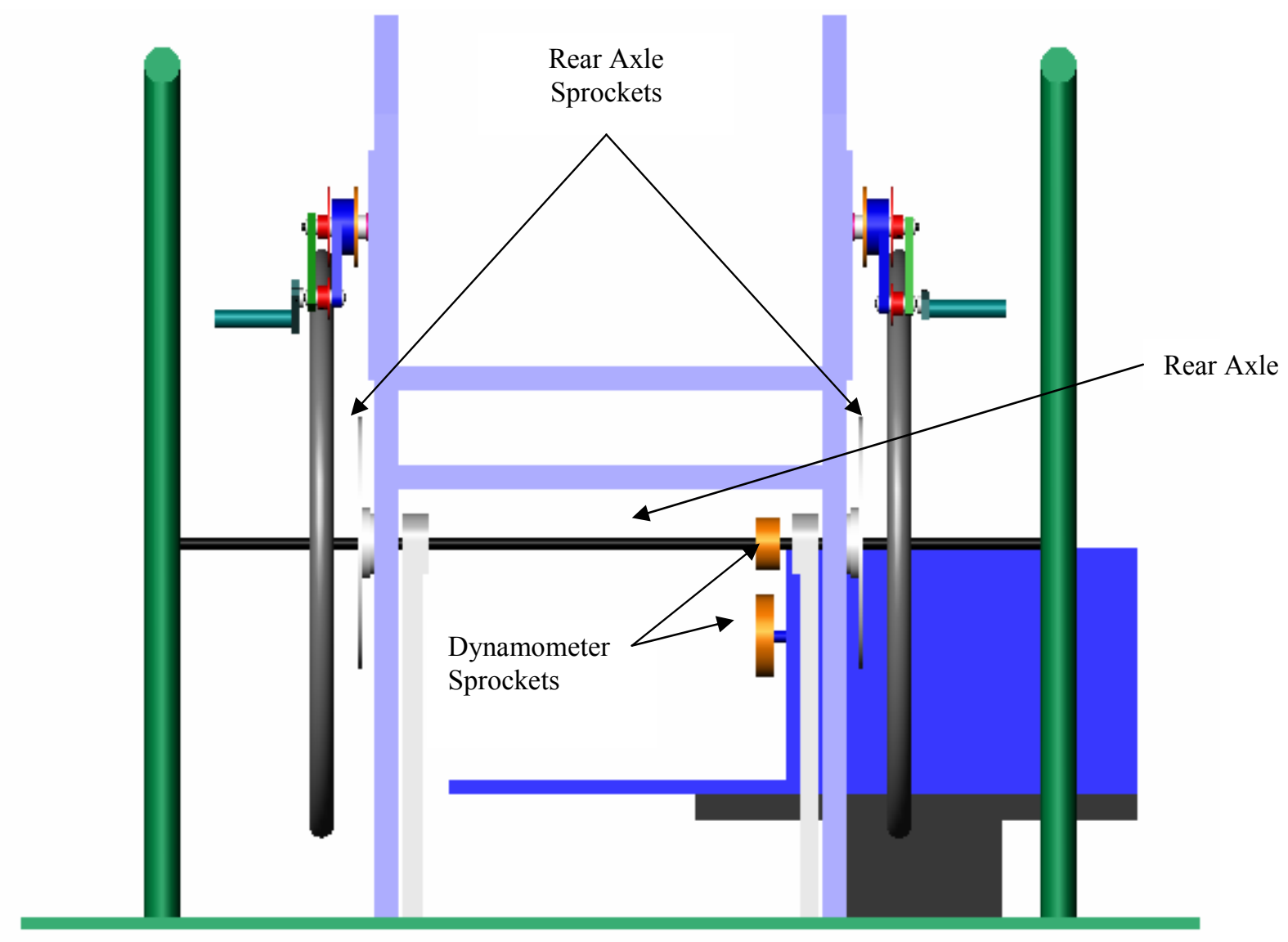

Figure 145 - Labeled Parts For Dynamometer Setup 